\title{
Economic Valuation of Biological Diversity
}

\author{
Exploring Non-market Perspectives \\ in the Vicinity of the Lore-Lindu National Park in \\ Indonesia’s Central Sulawesi Region
}

\author{
Dissertation \\ zur Erlangung des Doktorgrades \\ der Fakultät für Agrarwissenschaften \\ der Georg-August-Universität Göttingen
}

vorgelegt von

Klaus Glenk

geboren in Schwabach

Göttingen, August 2006 
D7

1. Referent: $\quad$ Prof. Dr. Rainer Marggraf (Universität Göttingen)

2. Korreferent: $\quad$ Prof. Dr. Manfred Zeller (Universität Hohenheim)

Tag der mündlichen Prüfung: 16. November 2006

Author:

Klaus Glenk

Dipl. Forstwirt (Univ.)

\section{Contact:}

Institute of Agricultural Economics

Platz der Goettinger Sieben 5

Goettingen, 37073

Tel: ++49-551-394830

Fax:++49-551-394812

Email: kglenk@gwdg.de 


\section{Abstract}

The Convention on Biological Diversity (CBD) stresses the importance of protecting and using biodiversity in a sustainable manner. In particular, the CBD Ecosystem Approach summons the contracting parties to adopt economically and socially sound conservation strategies. The Central Sulawesi rainforests in Indonesia are part of the global Wallacea biodiversity hotspot. Due to their exceptional contribution to global biological diversity, the conservation of these rainforests is an important case for an application of conservation strategies in line with the CBD Ecosystem Approach. Based on this, the overall objective of this thesis is to generate knowledge that could be used to facilitate the design of economically informed and socio-economically sensitive conservation strategies for this important ecoregion.

One of the biggest obstacles facing the development and implementation of such conservation strategies is the lack of knowledge on the economic value of non-market benefits generated by tropical forest ecosystems and the agricultural land use systems that replace them. Economic valuation of such benefits adds to the goal of using and conserving biodiversity in a more efficient manner. In particular, this study hopes to contribute to overcoming the ignorance regarding non-market benefits of tropical forest ecosystems by an assessment of marginal values of biodiversity of inhabitants living around the Lore Lindu National Park. This study focussed on preferences for changes in the provision of several different (non-market) ecosystem goods and services of relevance to the local population.

A choice experiment survey was designed to elicit preferences for rattan availability, water supply for irrigation, population size of the endemic dwarf buffalo Bubalus sp. ('Anoa') as well as different ways of cocoa cultivation along a shade gradient. The survey was administered to 301 randomly selected households in the vicinity of the Lore Lindu National Park. In addition to information regarding the choice experiment, further data was collected that was related to the choice task (e.g. difficulty and confusion), attributes (e.g. experience, present use, attitudes) as well as several socio-economic 
characteristics of respondents and households (e.g. age, education, wealth status). The choice behaviour was analysed using multinomial and nested logit models.

The results indicate that the choice experiment on the valuation of the four mostly functional biodiversity services could be conducted successfully. By using design features such as a self-explicated status-quo alternative and the use of visualisations, the design was adjusted to a complex rural so-called "developing” country setting. Applying an ecosystem service approach facilitated the valuation of functional benefits of biodiversity. The magnitude of marginal willingness-to-pay (MWTP) for an improved provision of ecosystem services ('water', 'rattan', 'anoa') is quite substantial considering the living conditions of the inhabitants of the Lore Lindu region and indicate a willingness to contribute actively to the maintenance of their natural resource base. In the fast growing sector of cocoa agroforestry systems, on the other hand, respondents indicated an unexpectedly clear preference for more intensively managed plantations with fewer shade trees. Thus, biodiversity conservation measures aiming at more sustainable ways of cocoa cultivation (measured here by a shade tree gradient) will be unlikely to be successful without creating economic incentives for the cocoa farmers. One such incentive could be a price premium for "biodiversity-friendly” cocoa production.

A second main objective was to improve the understanding of the behaviour and situation of local economic agents - mainly smallholder farmers - with respect to their demand for forest ecosystem goods and services. In this regard, the influence of socioeconomic, socio-demographic, attitudinal and choice-task related variables on the choice behaviour of respondents was analysed. Regarding different sizes of the anoa population, for example, the results show that marginal willingness-to-pay is a function of an individual's general attitude towards that animal and their knowledge on population biology reflected by an individual's statement on the perceived probability of extinction for a very small population size. The model results suggest that educational efforts can contribute to anoa conservation by altering people's attitude and their knowledge about anoa.

By analysing the differential influence of relative poverty on preferences for the four ecosystem services included in the choice experiment, the study could contribute to improving the understanding of distributional effects of changes in the provision of ecosystem services on the welfare depending on the welfare status of the local population. The results suggest that the poorest and poor households - according to their ranking on a relative poverty index - would benefit relatively more from improvements of the rattan and 
water attributes. As compared to the poor for anoa, both, the poorest and the less poor, gain relatively higher benefits, however for probably very different reasons.

Split-sample experiments can contribute to improving the validity and robustness of the results by observing the influence of small changes in the design on model estimates of choice experiments. Results from such experiments conducted in this thesis show that estimates of MWTP are not robust to a varying order of attributes on choice cards. Effects of attribute order suggested the occurrence of recency effects. The magnitude of recency effects can depend on the relative importance respondents ascribe to the attributes on the choice cards. Further split-sample experiments addressed (i) changes in the institutional background of the payment, and (ii) changes in the frequency of the payment. While MWTP estimates were found to be robust to (i), they differed significantly for (ii). The varying cash availability among households may be an important factor to explain this. 


\section{Acknowledgements}

I wouldn't want to miss any of the contributions of the persons and institutions mentioned below. Each of them supported my work in a distinct and special way. Without any of these, my work of three years, both in the Palu region of Indonesia and in Goettingen, would have resulted in a different outcome - be it on a professional or personal level. Therefore, I want to take the opportunity to express my respect and gratitude to:

DFG for funding; Dr. Jan Barkmann, Prof. Dr. Rainer Marggraf and Prof. Dr. Manfred Zeller for scientific support and supervision; the village administration and inhabitants of Bora, Kalawara, Lawua, Tompi Bugis, Watukilo, Dodolo, Bobo, Tanah Harapan, Ranteleda, Toro, Sidondo II, Maranatha, Pandere, Berdikari, Sejahtera, Wanga, Watumaeta, Wuasa, Rompo, Sintuwu, Bulili, Lawe, Lempelero, Bolapapu, and Namu; Sumarno Syamsuri, S.Pt., Muhammad Rifai Lasamana, S.P., Zulkifli Lasamana, S.H., Yonathan, SP., Muhammad Din and Harry Wibowo; Rina Yussuf and Armando; the drivers and coordination staff of STORMA; Stefan Schwarze, Nunung Nuryartono, Adhitya Wardhono, Günter Burkard, Robert Weber, Alwin Keil, Kerstin de Vries; Muhammad Yasin Paada, TNC Palu, SUCCESS Palu, Andi Tanra Tellu, Prof. Dudung Darusman, Dr. Letty Sundawati; my collegues at the Institute Claudia Cerda, Christina Rüffer, Elke Bertke; Marianela Fader and Sebastian Koch; the technical assistants of the Institute; Christine Schnorrer; Frauke Becker; Christina and Konrad Schoenborn; Susanne Menzel; Lars Woltmann and Marieke Harteveld; Doreen Gabriel; and, above all, my family. 


\section{Table of Contents}

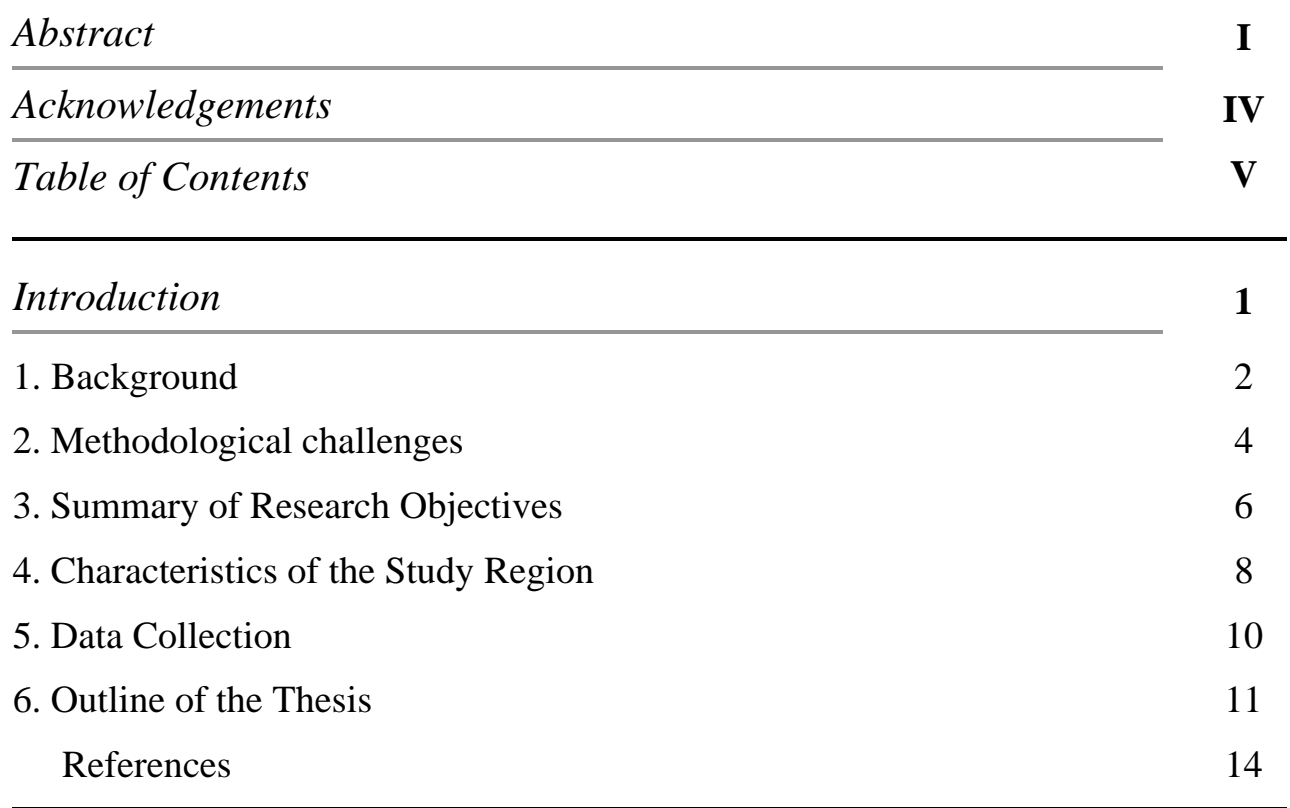

Chapter 1 Confronting unfamiliarity with ecosystem functions: The case for an ecosystem service approach to environmental valuation with stated preference methods

Barkmann, J., Dietrich, N., de Vries, K., Gerold, G., Glenk, K., Keil, A., Faust, H., Leemhuis, C. and R. Marggraf

Submitted to Ecological Economics

$\begin{array}{ll}\text { 1. Introduction } & 19\end{array}$

2. Valuing ecosystem functions - the challenges 20

3. Making sense from ecosystem functions via an ecosystem 22 service approach

3.1 The background problem $\quad 22$

3.2 The ecosystem service approach $\quad 24$

4. Case Study: Valuating a hydrological ecosystem service in 25 rural Indonesia

4.1 Description of the research area 26

4.2 Design and application of choice experiment attributes 27

4.2.1 Design of the attributes 27

4.2.2 Administration and analysis of the choice experiment 29 
4.2.3 Validity tests and influence of respondent comprehension

4.3 Results 33

4.3.1 Base model, validity tests 33

4.3.2 Willingness-to-pay calculation 36

5. Discussion 38

5.1 Unfamiliarity aspects 38

5.2 Data and modeling aspects $\quad 41$

6. Conclusion 42

Acknowledgements 43

References 44

Chapter 2 Design and Application of Choice Experiment Surveys in So-Called Developing Countries: Issues and Challenges

Glenk, $\mathbf{K}$.

Diskussionsbeitrag 0603. Institut für Agrarökonomie, Georg August Universität Göttingen, 2006

1. Introduction 50

2. A choice experiment study from Central Sulawesi, Indonesia 51

2.1 Background 51

2.2 Study area $\quad 52$

2.3 Attributes $\quad 52$

2.4 Experimental design 53

2.5 Data collection $\quad 54$

3. On the design of the survey instrument 54

3.1 Wording 54

3.2 Framing: finding the appropriate context 57

3.3 Setup of the questionnaire 59

$\begin{array}{ll}3.4 \text { Visualisations } & 60\end{array}$

3.5 Status-quo 61

4. Survey preparation and administration 62

4.1 Enumerator selection 63

4.2 Enumerator payment $\quad 64$

4.3 Enumerator training $\quad 65$

4.4 Administering the survey in the field 68

5. Concluding remarks 69

$\begin{array}{ll}\text { References } & 71\end{array}$ 
Chapter 3 Locally Perceived Values of Biological Diversity in Indonesia - a Choice Experiment Approach

Glenk, K., Barkmann, J. and R. Marggraf

$8^{\text {th }}$ Annual BIOECON Conference on Economic Analysis of Ecology and Biodiversity, Cambridge, UK, 2006

1 Introduction $\quad 75$

2 The research area: around the Lore Lindu National Park 77

3 The choice experiment method $\quad 77$

4 The choice experiment design $\quad 80$

4.1 Attribute selection 81

4.2 Framing $\quad 84$

4.3 The 'cost' attribute $\quad 85$

4.4 Experimental design and status quo $\quad 85$

$\begin{array}{ll}4.5 \text { Socio-demographic characteristics } & 87\end{array}$

4.6 Data collection $\quad 88$

5 Model results $\quad 89$

6 Welfare Analysis 93

6.1 Implicit prices 93

6.2 Scenario analysis $\quad 95$

7 Concluding remarks $\quad 97$

References 99

Chapter 4 Differential influence of relative poverty on preferences for ecosystem services: Evidence from rural Indonesia

Glenk, K., Barkmann, J., Schwarze, S., Zeller, M. and R. Marggraf Brisbane Conference on Environment and Development, 2006

1. Introduction 106

2. Methods 106

2.1 Study area 106

2.2 'Poverty' elasticity of willingness to pay (WTP) 106

2.3 The choice experiment 108

2.4 Expectations 110

2.5 Data collection 110

3. Results 110

4. Discussion 115

5. Conclusion 118

$\begin{array}{ll}\text { References } & 119\end{array}$ 
Chapter 5 Unveiling regional preferences for biological diversity in Central Sulawesi: a choice experiment approach

Glenk, K., Barkmann, J. and R. Marggraf

STORMA Discussion Paper Series No 16. Bogor, Indonesia: Universities of Göttingen and Kassel, Germany and the Institut Pertanian Bogor and Universitas Tadulako, Indonesia, 2006

1. Introduction

2. The research area

3. Valuation of functional benefits of biological diversity the ecosystem service approach

4. The choice experiment

4.1 Introduction to the method

4.2 Choice experiment - a short summary

5 . The choice experiment design

5.1 Attribute selection

5.2 Framing

5.3 Experimental design and status quo

5.4 Data collection

6. Results and discussion

6.1 Overall model results

6.2 ASC and interactions

6.3 Part worths

7. Conclusion

Chapter 6 Framing Effects of the Payment Mechanism in Choice Experiments

Glenk, K. and R. Marggraf

To be submitted to Australian Journal of Agricultural and Resource Economics

1. Introduction

2. Choice experiments and the multinomial logit model

3. Present study

3.1 Research area

3.2 Study design and sample characteristics

4. Hypotheses

5. Methods

5.1 Test statistics for parameter equality

5.2 Testing equality of implicit prices 
6.2 Implicit prices

6.3 Status quo choices 174

7. Discussion 175

7.1 'Fund/Tax' split sample 175

7.2 'Month/Year’ split sample 176

8. Conclusion 179

$\begin{array}{ll}\text { References } & 180\end{array}$

Chapter 7 A split sample experiment to test for effects of attribute order in choice experiments

\section{Glenk, $\mathbf{K}$.}

Book chapter prepared for the documentation of the workshop 'The Choice Experiment in Environmental Valuation', 21. - 22. November 2005, Leipzig, Germany. To be published by Metropolis: Marburg

1. Introduction 185

2. Response-order effects: primacy and recency effects 186

3. Effects of attribute order in choice experiments 186

4. Present study 188

5. Method 191

5.1 Test statistics for parameter equality 192

5.2 Testing equality of implicit prices 193

6. Results 193

6.1 Parameter equality 193

6.2 Implicit prices 194

6.3 Potential 'drivers' enhancing ordering effects 195

7. Discussion 199

8. Conclusion 200

References 201

Chapter $8 \quad$ Summary of Research Outcomes $\quad 204$

$\begin{array}{lll}\text { Appendix } & \text { on an enclosed CD } & 208\end{array}$

I: Survey instrument (Indonesian version): survind.pdf

II: Questionnaire (condensed English version): questing.pdf 
Introduction 


\section{Background}

The Convention on Biological Diversity (CBD) regards ecosystems as dynamic functional units of complex plant, animal and micro-organism communities and their non-living environment. The ecosystem concept is an appropriate approach to compartmentalize nature into units that can be examined by researchers of both ecological and economic disciplines. Biodiversity is defined as the diversity within and between living organisms as well as between ecosystems. Since biodiversity provides a flow of tangible and intangible benefits to humans, it can be regarded as a 'natural asset'. There are manifold links between biodiversity and ecosystems. Diversity is a structural attribute of ecosystems, and the variability among ecosystems is an element of biodiversity. Thus, changes in biodiversity and the related changes of ecosystems can affect the generation of ecosystem functions that are beneficial to humans (MEA 2005, 2006).

During past decades, biodiversity loss has reached an unprecedented rate in human history (Sinclair 2000). In this regard, the main anthropocentric interferences that are expected to become dominant are land use change, nitrogen deposistion and climate change (MEA 2006). For example, according to results from scenario studies, land use change will probably be the main factor affecting global terrestrial vegetation (Sala et al. 2000). From an economic perspective, the main reason for the 'erosion' of biodiversity is that there is an underlying disparity between the private and social costs and benefits of biodiversity use and conservation (Dixon and Sherman 1990, Pearce and Moran 1994). This disparity is partly due to market failure, which can occur when markets do not reflect the full social costs or benefits of a 'good' (Pearce and Moran 1994).

The CBD stresses the importance of protecting and using biodiversity in a sustainable manner. In particular, the CBD Ecosystem Approach summons the contracting parties to adopt economically and socially sound conservation strategies. The Central Sulawesi rainforests in Indonesia are part of the global Wallacea biodiversity hotspot (Myers et al. 2000), and are among the world's most biologically valuable ecoregions (Olson \& Dinerstein 1998). Due to their exceptional contribution to global biological diversity, the conservation of Central Sulawesi rainforests is an important case for an application of conservation strategies in line with the CBD Ecosystem Approach. Based on this, the overall objective of this thesis is to generate knowledge that could be used to facilitate the design of 
economically informed and socio-economically sensitive conservation strategies for this important ecoregion.

One of the biggest obstacles facing the development and implementation of economically sound conservation strategies is the lack of knowledge on the economic value of nonmarket benefits generated by tropical forest ecosystems and the agricultural land use systems that replace them (cf. Balmford et al. 2002, Bawa 2004). Economic valuation of biodiversity benefits, which are not reflected by markets, contributes to the goal of using and conserving biodiversity in a more efficient manner (Marggraf and Birner 1998). Biodiversity resource valuation is a key issue regarding investment decisions on land use and economic valuation of non-market benefits is one integral part of it (Pearce and Moran 1994).

In particular, this study hopes to contribute to overcoming the ignorance regarding nonmarket benefits of tropical forest ecosystems by assessing the marginal values of biodiversity of inhabitants living around the Lore Lindu National Park in Central Sulawesi. Rather than investigating different levels of biodiversity or ecosystem services using a holistic approach (cf. Christie et al 2004), this study focuses on preferences for changes in the provision of several different (non-market) ecosystem goods and services of relevance to the local population.

During the last decades, a large variety of valuation techniques have been developed towards the ends of conducting economic valuation of non-market benefits (cf. Mitchell and Carson 1989, Bennett and Blamey 2001, Bateman et al. 2002). Such techniques are commonly divided into revealed and stated preference methods. The first use actual market data and the second comprise of survey-based techniques for assessing values in hypothetical markets (Adamowicz 1998). Stated preference techniques include contingent valuation and choice modelling as the two most popular alternatives (Hanley et al. 2001). They both allow for assessment of non-market benefits. According to Colombo et al. (2005: 82), contingent valuation "... may be better suited to situations where changes in the total economic value of a non-market good are at issue or where environmental resources are hard to describe using attributes". Advantages of choice modelling include the possibility of explicitly incorporating substitute goods, and some evidence suggests that choice experiments are less susceptible to bias such as 'warm-glow' effects or starting point bias (Morrison et al. 1996). Besides these advantages, choice modelling was particularly suitable for the pur- 
pose of this study due to its potential for allowing a simultaneous elicitation of multiattribute benefits. Choice experiment data allows for the monetary quantification of two types of welfare economic estimates for these benefits namely, (i) implicit prices (marginal willingness-to-pay or part-worth utilities) ${ }^{1}$ for marginal changes in the supply of single ecosystem goods and services, and, resting on implicit prices and (ii) measures of Hicksian compensating variation for supply changes of bundles of ecosystem goods and services (scenario analysis) (Bennett and Blamey 2001).

The CBD recognizes that any conservation effort needs to take the livelihood of people that depend on the use of natural resources into account. From an economic point of view, Central Sulawesi is one of the poorest provinces in Indonesia (Suryahadi and Sumarto 2001). It follows, that local economic agents find themselves situated between globally defined conservation objectives and more locally perceived - pressing - needs for development. This scenario requires the socio-economic impacts of any conservation measure on the local population to be carefully considered. Understanding the behaviour and situation of local economic agents with respect to their demand for forest ecosystem goods and services can be further improved by analysing the influence of socio-economic, sociodemographic, attitudinal and choice-task related variables on the choice behaviour of respondents, and thus on welfare estimates of non-market benefits. In addition, such analysis can also support an assessment of model validity for the researcher, who expects the preferences for ecosystem goods and services to differ with respect to individual traits and socio-economic characteristics of respondents.

\section{Methodological challenges}

In general, the application of stated preference techniques is not without dispute when applied to functional ecosystem values, such as the provision of water, or flooding or erosion control (e.g., Nunes and Bergh 2001, Gatto and de Leo 2001). In particular, the unfamiliarity of respondents with the scientific description of the ecosystem functions has prompted much critique. Hence, it was necessary to develop a conceptual framework for the valuation of such values that addresses this critique.

\footnotetext{
${ }^{1}$ All terms are used interchangeably throughout this thesis.
} 
A successful application of the choice experiment technique requires a careful adjustment of the survey instrument to suite the local conditions of the cultural, institutional and natural environment. This can be a challenge in so-called "developing" countries, and particularly in rural areas. In such countries, applications of choice experiments are rare compared to the so-called "developed" world. Apart from logistical constraints, a general concern may be that the cognitive demand for respondents due to the choice task complexity is perceived to be relatively high, while, on average, respondents have a rather low level of literacy. $^{2}$ Therefore, an array of adjustments was required to enable respondents to express their preferences meaningfully.

Survey research has long demonstrated that small changes of the survey instrument with respect to wording (Schuman and Presser 1981, Payne 1951), context (Tversky and Kahneman 1981) or order (Krosnick and Alwin 1987) can significantly influence the outcome. In this regard, split samples can contribute to improving the validity and robustness of the results by observing the influence of small changes in the design on welfare estimates.

\footnotetext{
${ }^{2}$ For example, according to UNESCO (2000), more than 98 per cent of the world's adult illiterate population are found in the less developed regions.
} 


\section{Summary of research objectives}

The main objective of this thesis is to generate knowledge that could contribute to facilitating the design of economically informed and socio-economically sensitive conservation strategies for the tropical rain forests of Central Sulawesi, Indonesia. The study contributes to this objective by aiming to understand the behaviour and situation of local economic agents with respect to their demand for forest ecosystem goods and services.

In particular, the study adresses the following research objectives:

R1

to identify locally relevant non-market benefits of ecosystem goods and services around the Lore Lindu National Park;

to quantify locally perceived non-market values for a bundle of relevant ecosystem goods and services related to biodiversity;

R3

to identify of sources of preference heterogeneity for the observed ecosystem goods and services;

to quantify of the impact of sources for preference heterogeneity on the magnitude of welfare estimates.

Methodologically, the thesis aims at an improvement of the following issues:

M1

to improve the applicability of the choice experiment for an assessment of functional values of biodiversity;

M2

to improve the applicability and performance of choice experiments in socalled developing countries;

M3

to assess the validity of choice experiment estimates with respect to robustness to small changes in the design.

The research was integrated into the inter-disciplinary project SFB 552 'Stability of Rainforest Margins in Indonesia' (STORMA). The three principal research goals of STORMA were: 
(1) the analysis of key factors and processes that lead to destabilisation and forest degradation in the forest margin zone of Central Sulawesi,

(2) the identification and assessment of social, economic, political and ecological conditions that are imperative for stability in the forest margin zone, and

(3) the development of Rapid Appraisal Systems that may serve to evaluate the socioeconomic and ecological status of tropical forest margin regions.

Apart from contributing to the research objectives of STORMA, a collaboration with researchers of other disciplines within STORMA, such as socio-economics of rural land-use or natural sciences such as hydrology, biology or ecology, facilitated an assessment of the functional services that was based on scientific knowledge and extensive field experience. Socio-economic and ethnological research within STORMA provided data and knowledge that assisted a more comprehensive interpretation and discussion of the choice experiment results. 


\section{Characteristics of the Study Region}

The research region (Figure 1) was located in the humid tropics about 1 degree south of the equator. It comprised of 7 administrative districts in the province of Central Sulawesi. It has a population of about 130.000 , across more than 115 villages, - mainly smallholder farmers - within an area of $7.220 \mathrm{~km}^{2}$. The Lore Lindu National Park is centered within the study region and covers some $2.200 \mathrm{~km}^{2}$ of mainly mountainous rainforest. Although founded in 1982, the national park was not officially recognized until 1993, and it's permanent border was only established in 1999 (Maertens 2004). A large number of species endemic to Sulawesi, including the mammals anoa (Bubalus sp.) or babirussa (Babyrousa babirussa), for example, as well as many endemic bird species, can be found in the National Park area, which is one of the few large forest areas left on Sulawesi (Waltert et al. 2002).

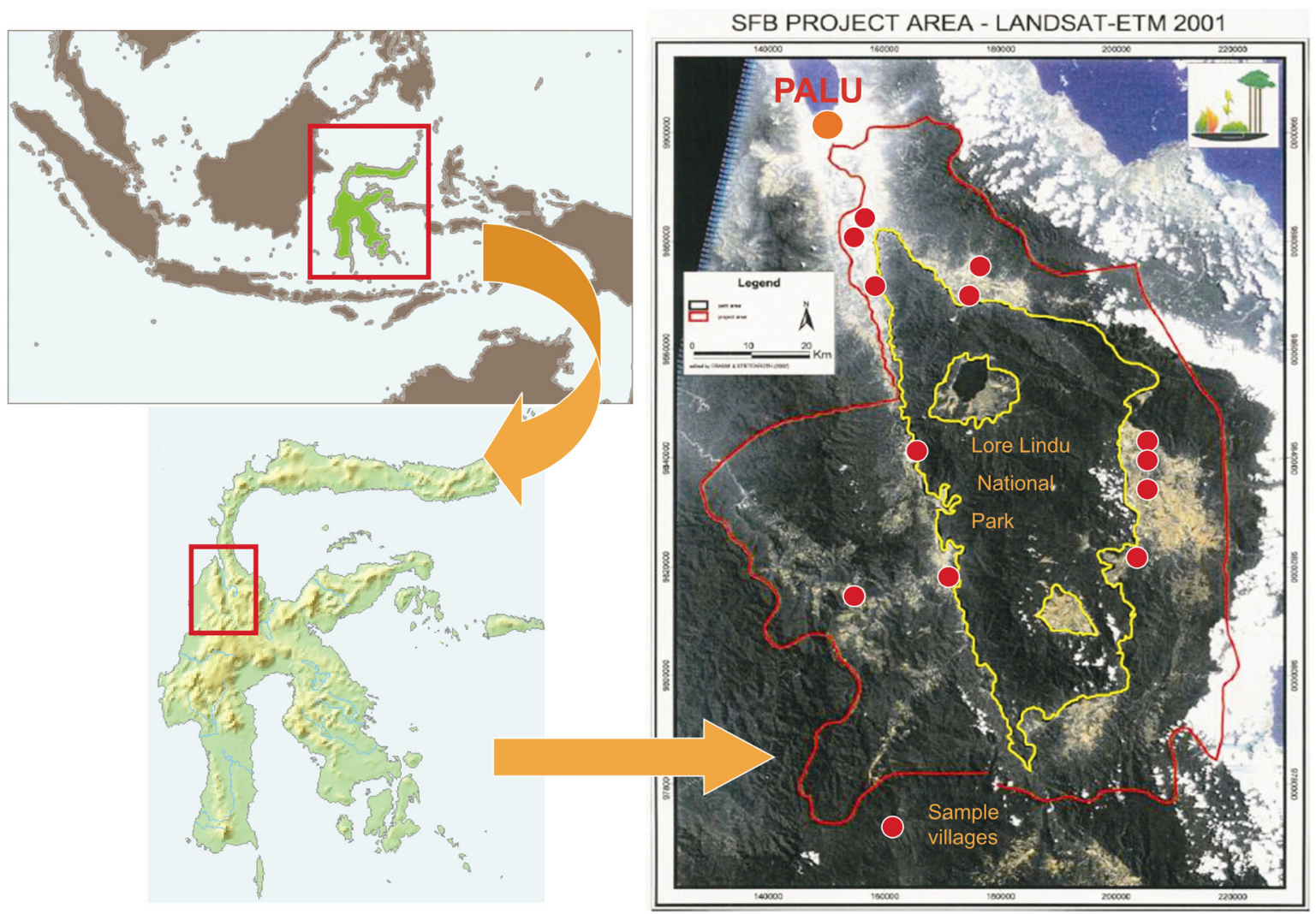

Figure 1. Overview of the research area

The demographics as well as land use are characterized by strong dynamics which were mainly driven by a population increase of $60 \%$ between 1980 - 2001 (Maertens 2004). This observation provided an interesting background with regard to a potential area of conflict between development and conservation goals. 
The geophysical conditions of the research region vary to a large extent. The altitude ranges from just above sea level up to 2500 meters and rainfall varies from 500 to 2500 mm per year (Maertens 2004). In combination with other heterogeneous physical features such as relief and soil conditions, the prerequisites for agricultural activity are quite diverse in the districts of the research region, which mainly follows a topography of distinct valleys and their bordering mountain ranges.

In general, a large variation of land use patterns can be found in the study region (Schwarze 2004). During the 'cocoa boom' in Indonesia (Akiyama and Nishio 1996), cocoa became the dominant 'cash' crop in the research region. It is often cultivated in the upland areas, while wetland rice remained the dominant 'food' crop that is mainly cultivated in the lowland, resulting in a lowland-upland dichotomy throughout the research region. Based on data from the household level, together, cocoa and wetland rice account for $57 \%$ of the net crop income (Schwarze 2004). Factors that facilitated the increased cultivation of cocoa included amongst others, the availibility of suitable land, low production cost and the entrepreneurship of smallholders (Akiyama and Nishio 1996). Thus, over the past two decades, the agricultural area in the Lore Lindu region itself has increased to a large extent (Maertens 2004). The related land use change (LUC) is closely related to the increasing production of (cash) crops (e.g. cocoa) (ibid 2004), and can be divided into conversion of (primary or secondary) forest into arable land, and conversion within land previously used for agriculture (e.g. wet rice fields to cocoa plantations, coffee to cocoa). Concerning forest products, collection of fuel wood is widespread for private consumption, while rattan is the most important marketed forest product (Schwarze 2004). Loss of forest area due to conversion into unsustainable agricultural practices as well as forest degrading activities such as rattan collection are of particular concern to (biodiversity) conservation efforts.

A broad array of factors can be identified as driving forces for LUC, ranging from market forces over changes of the natural environment (e.g. lack of water for irrigation) to social processes within local communities related to in-migration (e.g. Burkard 2002). 


\section{Data collection}

In order to maximise the benefits of data exchange with other projects in STORMA and to enable aggregation of the (perceived) values for ecosystem services by a sampled population on a regional level in congruency with the STORMA research region, the common sampling frame of STORMA was adopted (for details, see Zeller et al. 2002). The choice experiment survey was administered to 301 randomly selected households in 12 villages (see Figure 1) from December 2004 to March 2005. ${ }^{3}$ One-on-one interviews were conducted by 6 well-trained local enumerators who were all B.Sc. (UNTAD/Palu) graduates. To minimize potential interviewer effects, the enumerators were assigned to the households randomly.

In addition to the above, further data was collected that was related to the choice task (e.g. difficulty and confusion), attributes (e.g. past experience, present use, attitudes) as well as several socio-economic characteristics of respondents and households (e.g. age, education, wealth status).

\footnotetext{
${ }^{3}$ The village Bulili (former dusun Nopu/Rahmat) was included in the household survey for the purpose of data exchange and collaboration with other researchers. The sample of Bulili consisted of 25 additional households.
} 


\section{Outline of the Thesis}

The current thesis consists of seven chapters. Each of the chapters exist as stand-alone manuscripts in their own right. Together, each of the manuscripts exclusively targets some of the research objectives mentioned above in one way or other. In order to guide the reader, a graphical overview of the structure of the thesis is provided below (Figure 2). The link between change, biodiversity, ecosystem services and human well-being shown in this overview is represented in a simplified and linear way and does not account for the dynamics of the system and feedback mechanisms. Various details on that link can be found in MEA $(2005,2006)$.

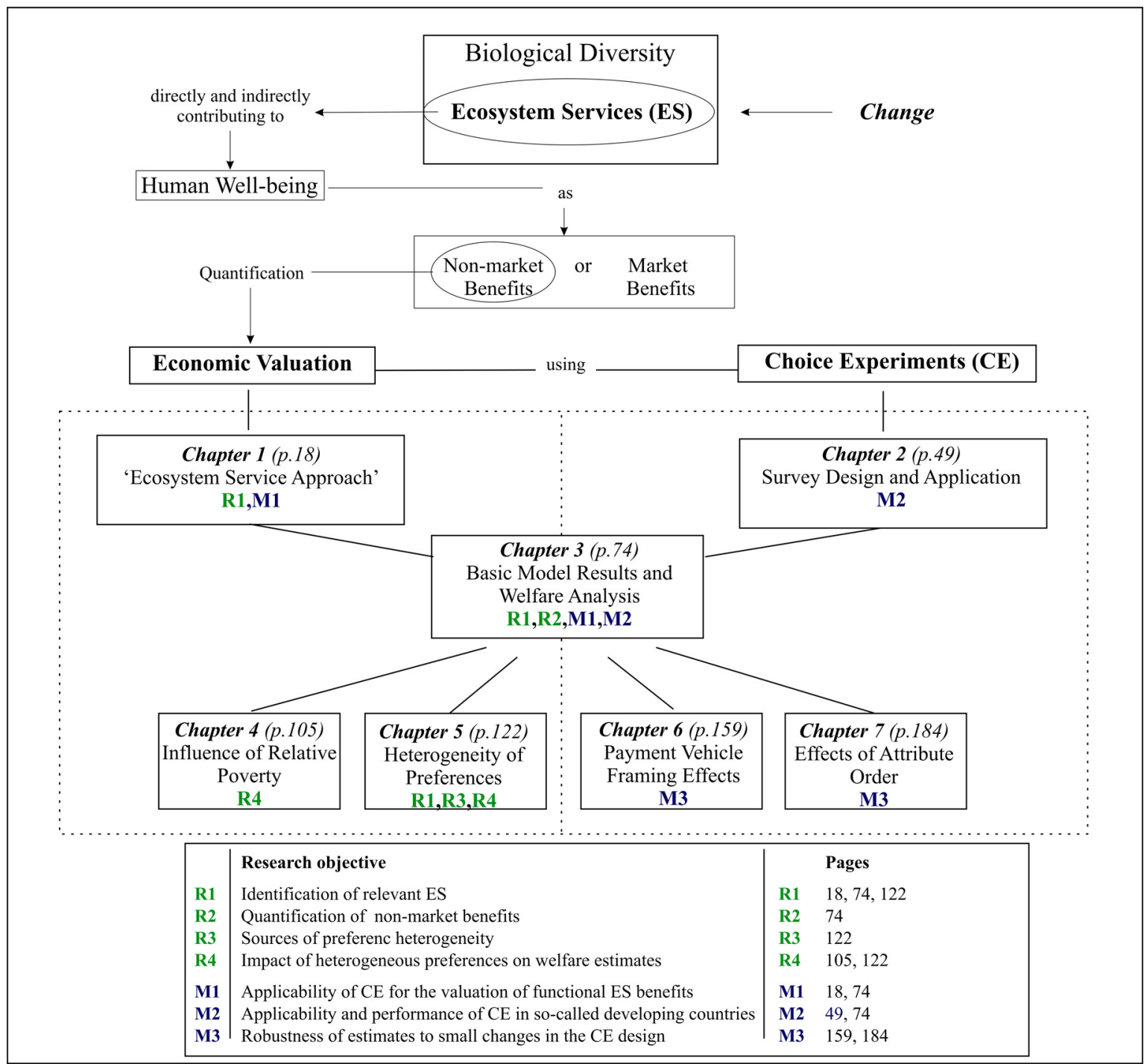

Figure 2. Outline of the thesis: Overview 
The original survey instrument and a condensed English version of the questionnaire are added as appendices (see Appendix I and II). It should be noted that the English version does not capture the whole dimension of the meaning of every comment and question. In this regard, it only serves the purpose of providing an impression of the questionnaire structure and the nature of questions to readers who have no knowledge of the Indonesian language.

Chapter 1 addresses research objective M1 mainly. Ecosystem functions are a central topic of environmental valuation research. Lay respondents are usually unfamiliar with the implications of scientific descriptions of ecosystem functioning. Thus, the applicability of stated preference methods for the valuation of ecosystem functions is a matter of debate. As part of the general discourse on the economic valuation of ecosystem functions, it was suggested to valuate ecosystem functions via the ecosystem serivces they provide. In this chapter, it is argued that the recognition of this principle is also the key for applying the stated preference methods to the valuation of ecosystem functions. Such a successful application requires a precise differentiation between the descriptive realm of ecosystem functions and the evaluative realm of ecosystem services. Based on this premise, an ecosystem serivce approach for the economic valuation of ecosystem functions is presented.

An application of the ecosystem service approach is succinctly outlined for the valuation of a hydrological ecosystem function in rural Indonesia. Identification and representation of the ecosystem services (R1) were based on extensive investigations of respondent perceptions of hydrological phenomena.

Chapter 2 highlights some of the issues that a choice experiment researcher may have to face when focussing on a so-called developing country environment. In doing so, the discussion contributes mainly to research objective M2. Once the choice experiment method for an application of the ecosystem service approach was decided upon, an array of adjustments had to be made to the design in order to ensure that respondents were able to respond meaningfully to the choice task and the additional questions that were offered. In this respect, some selected aspects of survey preparation and administration are also discussed. 
In particular, some design issues surrounding the choice experiment survey instrument that contributed to a successful application are described. These include issues of wording, framing of the hypothetical scenarios of the choice experiment, setup of questionnaires and task complexity including use of visual decision aids. Since pratical advice and suggestions are seldom found in journal articles, some practical aspects of survey preparation and administration are also presented and discussed.

Chapter 2 has the main objective of enlarging the pool of ideas and providing decision aid for choice experiment researchers facing similar challenges. The examples and suggestions contained in this section are the results of the particular research process and research environment of the study area in Central Sulawesi.

Chapter 3 can be viewed as the central part of the thesis. Aspects discussed in chapters 1 and 2 are merged for a comprehensive overview of the choice experiment study conducted in Indonesia. Chapter 3 also deals with the central welfare economic discussion pertaining to the choice experiment results.

In particular, the relevant ecosystem services included as attributes in the choice experiment are introduced (R1). A basic model is being developed and results are presented. Welfare estimates (implicit prices and compensating variation) are reported and discussed (R2). The empirical results of the choice experiment and related data are used to discuss the applicability of choice experiments for, (i): the valuation of functional values of biodiversity (M1) and, (ii): with respect to a so-called "developing" country setting (M2). The chapter concludes with an assessment of the relevance of the findings for both policy makers and valuation research.

Upon analysing the differential influence of relative poverty on preferences for the four ecosystem services included in the choice experiment, chapter 4 mainly addresses research objective R4. The chapter aims to present, (i): an improved understanding of distributional effects of changes in the provision of ecosystem services on the welfare of local households and, (ii): the generation of further insights into the link between poverty and environment. 
Chapter 5 extends several aspects that were previously discussed in chapter 3 . However, particular aspects such as the selection of attributes (R1), are reported with greater detail. While the main focus of chapter 3 is based on the welfare economic discussion, chapter 5 specifically targets the identification of sources of preference heterogeneity (R3) and observes their impact on choice behaviour and marginal willingness-to-pay regarding the four attributes (R4). While marginal willingness-to-pay is calculated selectively for socioeconomic groups distinguished by a single variable (relative poverty) in chapter 4 , chapter 5 employs interactions with a wide range of socio-demographic, socio-economic or attitudinal variables in order to obtain a more distinct view on the choice behaviour of respondents.

Both chapters 6 and 7 contribute to the methodological objective of the study in assessing the validity of choice experiment estimates with respect to their robustness to small changes in design (M3). For such an assessment, both chapters analyse differences between split samples.

The split sample experiments reported in chapter 6 were designed to test for the effects of different framing of the 'cost' attribute on parameter estimates and implicit prices. In particular, we tested for the influence on choices of, (i): changes in the institutional background of the payment, and (ii): changes in the frequency of payments. Lastly, chapter 7 investigates the effects of attribute order on choice cards on parameter estimates and implicit prices.

\section{References}

Adamowicz, W., Louviere, J. and J. Swait, 1998. Introduction to Attribute-Based Stated Choice Methods. Prepared by Advanis Inc. for the National Oceanic and Atmospheric Administration, US Departement of Commerce.

Akiyama, T. and A. Nishio, 1996. Indonesia's Cocoa Boom. Hands-off Policy Encourages Smallholder Dynamism. Policy Research Working Paper 1580. Washington, D.C.: World Bank.

Balmford, A., Bruner, A., Cooper, P., Constanza, R., Faber, S., Green, R., Jenkins, M., Jeffer- iss, P., Jessamy, V., Madden, J., Munro, K., Myers, N., Naeem, S., Paavola, J., Ray-ment, M., Rosendo, S., Roughgarden, J., Trumper, K. and R. Turner 2002. Economic reasons for conserving wild nature. Science 297: 950-53. 
Bateman, I.J., Carson, R.T., Day, B., Hanemann, M., Hanley, N., Hett, T., Jones-Lee, M., Loomes, G., Monrato, S., Ozdemiroglu, E., Pearce, D., Sugden, R. and J. Swanson, 2002. Economic Valuation with Stated Preference Techniques - A Manual. Cheltenham, UK: Edward Elgar.

Bawa, K., Kress, W., Nadkarni, N., Lele, S., Raven, P., Janzen, D., Lugo, A., Asthon, P. and T. Lovejoy 2004. Tropical Ecosystems into the $21^{\text {st }}$ Century. Science 306: 227-228.

Bennett, J. and R. Blamey (Eds), 2001. The Choice Modelling Approach to Environmental Valuation. Edward Elgar, Cheltenham, UK.

Burkard, G. 2002. Natural Resource Management in Central Sulawesi: Past Experience and Future Prospects. STORMA Discussion Paper Series No. 8, Universities of Göttingen and Kassel, Germany and the Institut Pertanian Bogor and Universitas Tadulako, Indonesia.

Christie, M., Hanley, N., Warren, J., Hyde, T., Murphy, K. and R. Wright 2004. A valuation of biodiversity in the UK using choice experiments and contingent valuation. 6th International BIOECON conference on "Economics and the Analysis of Biology and Biodiversity", Kings College Cambridge.

Colombo, S., Calatrava-Requena, J. and N. Hanley, 2005. Designing Policy for Reducing the Offfarm Effects of Soil Erosion Using Choice Experiments. Journal of Agricultural Economics, 56(1): 81-95.

Dixon, J. A. and P.B. Sherman 1990. Economics of protected areas: A New Look at the Benefits and Costs. Island Press, Washington D.C..

Gatto, M. and G. de Leo 2000. Pricing Biodiversity and Ecosystem Services: The Never Ending Story. Bioscience 50 (4): 347-355.

Hanley N, Mourato S and R. Wright 2001. Choice modelling approaches: a superior alternative for environmental valuation?. Journal of Economic Surveys 15(3): 1-25.

Krosnick, J.A. and D.F. Alwin 1987. An Evaluation of a Cognitive Theory of Response-Order Effects in Survey Measurement. The Public Opinion Quarterly 51(2): 201-219.

Maertens, M., 2004. Economic Modelling of Agricultural Land-Use Patterns in Forest Frontier Areas. Ph.D. thesis, Institute of Rural Development, University of Goettingen.

Marggraf, R. and R. Birner, 1998. The Conservation of Biological Diversity from an Economic Point of View. Theory in Biosciences, 117: 238-55.

Millennium Ecosystem Assessment 2005. Ecosystems and Human Well-being: Synthesis. Island Press, Washington, DC.

Millennium Ecosystem Assessment 2006. Ecosystems and Human Well-being: Scenarios, Volume 2. Findings of the Scenarios Working Group of the Millennium Ecosystem Assessment. Edited by: S.R. Carpenter, P.L. Pingali, E.M. Bennett and M.B. Zurek. Island Press, Washington, DC.

Mitchell, R.C. and R.T. Carson 1989. Using Surveys to Value Public Goods: The Contingent Valuation Method. Baltimore: John Hopkins University Press. 
Morrison M., Blamey, R. Bennett, J. and J. Louviere, 1996. A Comparism of Stated Preference Techniques for Estimating Environmental Values. Research Report No.1. Canberra, Australia: School of Economics and Management. The University of New South Wales.

Myers, N., Russel, A., Mittermeier, R., Mittermeier, C., da Fonseca, G. and J. Kent, 2000. Biodiversity hotspots for conservation priorities. Nature, 403:853-58.

Nunes, P. and J. v.d. Bergh, 2001. Economic valuation of biodiversity: sense or nonsense?. Ecological Economics 39: 203-22.

Olson, D.M. and E. Dinerstein, 1998. The Global 200: a representation approach to conserving the Earth's most biologically valuable ecoregions. Conservation Biology 12: 502.

Payne, S. 1951. The Art of Asking Questions. Princeton: Princeton University Press.

Pearce, D. W. and D. Moran 1994. The economic value of biodiversity. IUCN - The World Conservation Union. Earthscan, London.

Sinclair, A.R.E. 2000. The loss of biodiversity: the sixth great extinction. In G.C. Van Kooten, E.H. Bulte and A.R.E. Sinclair (Eds.): Conserving nature's diversity. Ashgate, Vermont.

Sala, O.E., Chapin III, F.S., Armesto, J.J., Berlow, E., Bloomfield, J., Dirzo, R., Huber-Sanwald, E., Huenneke, L.F., Jackson, R.B., Kinzig, A., Leemans, R., Lodge, D.M., Mooney, H.A., Oesterheld, M., LeRoy Poff, N., Sykes, M.T., Walker, B.H., Walker, M. and D.H. Wall 2000. Global biodiversity scenarios for the year 2100. Science 287: 1770-1774.

Schuman, H., and S. Presser 1981. Questions and Answers in Attitude Surveys: Experiments on Question Form, Wording, and Content. New York: Academic Press.

Schwarze, S., 2004. Determinants of Income Generating Activities of Rural Households, A Quantitative Study in the Vicinity of the Lore-Lindu National Park in Central Sulawesi/Indonesia. $\mathrm{Ph} . \mathrm{D}$. thesis, Institute of rural Development, University of Goettingen.

Suryahadi, A. and S. Sumarto, 2001. The chronic poor, the transient poor, and the vulnerable in Indonesia before and after the crisis. SMERU working paper. Jakarta: SMERU Research Institute.

Tversky, A. and D. Kahneman 1981. The framing of decisions and the psychology of choice. Science 211: 453-458.

UNESCO 2000. Education for All Year 2000 Assessment, Statistical Document. Published by UNESCO Institute for Statistics for the International Consultative Forum on Education for All, Paris.

Waltert, M., Mardiastuti, A. and M. Mühlenberg, 2004. Effects of land use on bird species richness in Sulawesi, Indonesia. Conservation Biology, 18: 1339-46. 
Zeller, M., Schwarze, S. and T. van Rheenen, 2002. Statistical Sampling Frame and Methods Used for the Selection of Villages and Households in the Scope of the Research Programme on Stability of Rainforest Margins in Indonesia (STORMA). STORMA Discussion Paper Series No. 1, Universities of Göttingen and Kassel, Germany and the Institut Pertanian Bogor and Universitas Tadulako, Indonesia. 


\section{CHAPTER 1}

Confronting unfamiliarity with ecosystem functions:

The case for an ecosystem service approach to

environmental valuation with stated preference methods 


\section{Introduction}

Ecosystem functions and the benefits humans derive from them have become a central topic of research at the interface of social and natural systems (Costanza et al. 1997, Daily 1997, Carpenter \& Turner 2000; Farber et al. 2002, Alcamo et al. 2003, Heal et al. 2005). Along with the recognition of their economic importance, there is an intensive debate on the economic valuation of ecosystem functions and the services they provide (Costanza \& Farber 2002).

In particular, there is substantial disagreement on the suitability of stated preference methods (contingent valuation, choice modeling) for the economic valuation of ecosystem functions ${ }^{1}$. The Millennium Ecosystem Assessment, for example, relies on contingent valuation as a "commonly used" valuation method for the quantification of indirect use values to which ecosystem functions belong (Alcamo et al. 2003). In contrast, de Groot et al. (2002:404; tab. 2) suggest to restrict stated preference methods to a valuation of "information services", such as ecosystem services for recreation and tourism. While the German Council of Environmental Advisors demands non-optimizing "categorical" valuation methods for "essential" ecosystem functions (WGBU 1999), stated preference practitioners regularly include ecosystem functions along with other passive use values in the set of suitable objects for stated preference studies (e.g., Carson et al. 1999).

Echoing earlier critical assessments (e.g., Diamond \& Hausman 1994), one particularly serious challenge for the applicability of stated preference methods to ecosystem functions was put forward by Nunes \& Bergh (2001). They stress that lay respondents surveyed in stated preference studies will usually lack sufficient insight into ecosystem life support functions and processes, such as photosynthesis or biogeochemical matter cycling. Without sufficient familiarity with such ecosystem functions, respondents are not able to make meaningful preference statements. Although the critique is well taken with regard to the valuation of ecosystem functions, it is less clear, however, that the critique also applies to the ecosystem services that the ecosystem functions provide. In fact, it is the main purpose of this paper to show that stated preference techniques can be

\footnotetext{
${ }^{1}$ Restricting this paper to a discussion of unfamiliarity effects should not be construed as a denial of further issues that continue to be a matter of intensive debate (e.g., Diamond and Hausman 1994, Sugden 2005).
} 
successfully applied to the valuation of ecosystem functions if they are translated into ecosystem services. In line with the most recent recommendations by Heal et al. (2005:121), this effort can be viewed as an extension of insights of the general debate on the economic valuation of ecosystem functions where it is stressed that the economic value of ecosystem functions should be judged by the value of the ecosystem service flows they provide (Freeman 1998).

In this paper, we first outline the unfamiliarity critique at stated preference methods, and sketch corresponding problems of alternative valuation approaches (Section 2). In section 3, we propose to regard the difference between ecosystem functions and ecosystem services as an epistemological difference, which results in the proposal for the ecosystem service approach. Based on these ideas, sections 4 and 5 present and discuss a case study from Central Sulawesi, Indonesia, focusing on the valuation of hydrological ecosystem functioning via a central ecosystem service it provides.

\section{Valuing ecosystem functions - the challenges}

Unfamiliarity with an environmental good can result in numerous biases that may distort valuation results. In particular, it can result in

- information bias: The less respondents are familiar with the good to be valued, the more their response will be affected by inaccurate, imprecise or even spurious information.

- methodological misspecification bias: Even if the information provided is precise and accurate, there is a risk that respondents do not understand the presented information as intended. Other things being equal, it must be expected that any distortion is the more severe the less familiar the good is.

It is undisputed that these biases have to be taken into account with high priority in the design of stated preference survey instruments (Bateman et al. 2002:76, 81, 119ff). For ecosystem functions, unfamiliarity is likely a major problem as non-expert respondents usually have very restricted knowledge of ecosystem functioning. For ecosystem functions 
that fall into the indirect use category - including regulation functions of the water cycle -, the suitability of stated preference techniques was explicitly challenged on misspecification bias grounds (Nunes \& Bergh 2001:205). Stated preference methods will fail to "value categories that the general public is not informed about nor has experience with", creating a problematic situation for the valuation of changes in these goods that are "far removed from human perceptions" (Nunes \& Bergh 2001:208, 217). Because of the complexity of the ecological interactions that give rise to ecosystem functions, the misspecification problems are unlikely to be remedied by improved design of the survey instrument, Nunes $\&$ Bergh claim. Thus, the case against the direct valuation of most ecosystem functions of the indirect use value type by stated preference techniques appears conclusive.

Revealed preference valuation methods provide an alternative valuation approach. These methods rely directly or indirectly on market data. Reliable market data are rare and/or difficult to interpret for many ecosystem functions, however. Thus, it can be expected that revealed preference methods feature their own set of restrictions and imperfections. For example, travel cost and hedonic pricing techniques can only be applied to ecosystem support functions related to tourism and housing. For most ecosystem functions, this relation is absent. For replacement cost calculations, Bockstael et al. (2000) require compliance with three seldom met conditions:

(i) the replacement system provides functions that are quantitatively and qualitatively equivalent to the original ecosystem functions,

(ii) the investigated replacement system is the least-cost-option of all potential replacement systems, and

(iii) aggregate willingness-to-pay for the replacement actually exceeds the cost for the replacement in the face of the loss of the original ecosystem functions.

A parallel line of reasoning holds for averting costs. The averting measure must be effective in all regards, the least-cost-option must be identified, and its costs may not exceed aggregate WTP. According to the review by Heal et al. (2005:191), replacement cost and avoided cost analysis are justified under restrictive conditions only. Production function approaches suffer from the fact that the opportunity costs of switching to the second-best production technology must be known. This can be difficult to achieve if 
complex substitution and adaptation processes occur, or if policy or production impacts are strongly non-linear. Combined with complex ecological models, considerable progress has been achieved here (Heal et al. 2005:113ff). However, many functional ecosystem benefits include non-marketed, public option value or insurance value components (Barkmann \& Marggraf 2004). Production functions approaches do structurally not account for these value components.

Although we cannot provide an extensive review of currently available methods for the economic valuation of ecosystem functions and/or services here, we conclude that each method comes with a specific profile of advantages and disadvantages. In practical terms, this suggests that no single approach should be dismissed prematurely as non-applicable including stated preference techniques.

\section{Making sense from ecosystem functions via an ecosystem service approach}

\subsection{The background problem}

Because of the multitude of different meanings of the function concept among different sciences, 'ecosystem function' can be interpreted in several, at times conflicting ways (de Groot et al. 2002). The most important conflict exists between a descriptive interpretation and a normative interpretation (cf. Whigham 1996). In a descriptive interpretation, ecosystem function merely relates to some ecosystem phenomenon that can be thought of as contributing to something else. Accepting the scientific fact of such a contribution does not entail any value judgment. The complication arises, however, that many phenomena to which ecosystem states, processes or structures contribute can have some - sometimes essential - importance for human wellbeing. Consequently, there exists a normative interpretation, in which an ecosystem function is regarded as an environmental value, as a source of ecosystem benefits in social and/or economic terms. Both interpretations are, as such, legitimate and ultimately a matter of terminological taste. Problems can easily arise, however, in form of a serious category error. This happens if the 
existence of a decision-relevant normative ecosystem function is inferred directly from the existence of a related ecosystem function in descriptive terms.

Where ecosystem function is explicitly defined in the recent literature, a descriptive interpretation dominates (e.g., Whigham 1996, Costanza et al. 1997, Freeman 1998, Heal et al. 2005). If a descriptive notion is favored, a decisively normative notion of ecosystem services suggests itself. In a proposal for a systematic description and valuation of the functions, goods and services of ecological systems, de Groot et al. (2002) "reconceptualise" or "translate" descriptive ecosystem functions into the normative concepts of ecosystem goods and services if and only if human needs or values are affected. Along these lines, several valuation approaches focus on ecosystem services. The Millennium Ecosystem Assessment (MA; Alcamo et al. 2003), for example, concentrates nearly exclusively on ecosystem services (also see, Toman 1996, Heal et al. 2005).

In the MA, ecosystem services are defined as

"the benefits people obtain from ecosystems. These include provisioning services such as food and water; regulating services such as regulation of floods, drought, land degradation, and disease; supporting services such as soil formation and nutrient cycling; and cultural services such as recreational, spiritual, religious and other nonmaterial benefits." (Draft Box 1, Key Definitions, MA Summary)

In line with MA terminology, we regard ecosystem services as immaterial economic goods provided by ecological systems including their elements, structures, processes, states, dynamics etc. If an ecosystem provides a material good, such as water used for irrigation, the process of provisioning the material good is an ecosystem service.

In their ecosystem and biodiversity valuation critique, Nunes \& Bergh (2001) develop a detailed classification of biodiversity values. They do not differentiate systematically, though, between functions and services. For example, "functional diversity" (Nunes \& Bergh 2001:204) encompasses "primary ecosystem processes" (photosynthesis and biogeochemical cycling) - ecosystem functions in a descriptive sense. Functional diversity also encompasses "ecosystem life support functions", e.g., the regulation of water and carbon cycles - as regularly included in lists of ecosystem services (e.g., Heal et al. 2005:80-83). If combined with the unfamiliarity critique, the lack of a 
clear differentiation may foster the impression that stated preference methods are principally unsuitable for the valuation of ecosystem functions.

\subsection{The ecosystem service approach}

Lay respondents are utterly unfamiliar with scientific descriptions of the processes, structures and states that make up ecosystem functions. Thus, it is virtually impossible to sample meaningful economic preference statements for ecosystem functions described by basic science models (Fig. 1a). As an example, we included an exceedence time graph in the following case study section that represents a central hydrological ecosystem function in a small Central Sulawesi catchment (Fig. 3). Although simple to interpret for the scientifically trained analyst, very few stated preference respondents will muster the patience to lean enough hydrology during the valuation interview to do so.

Even worse, without additional engineering and agricultural data, even experts can only make an educated guess how changes in the exceedence time graph may correlate with improved water availability for wet rice cultivation in the dry season in a heterogeneous multi-catchment project area. Mismatches between the ecosystem function output of basic science models and the requirements for economic analysis are rather common (see example by Freeman 1998:249f).

The situation improves if we employ an ecosystem service approach to environmental valuation (Fig. 1b). Precursors of the ideas presented here are provided by Carson et al. (1999), Pattanayak \& Kramer (2001), and Bennett (2002). Using the ecosystem service approach, we invest a certain measure of normativity that allows us to differentiate between ecosystem states, structures and processes that do in fact contribute to human production and consumption, and those that - to the best of our knowledge and with reference to the valuation task at hand - do not. With this differentiation in mind, engineering models can be constructed that are concerned with socially relevant ecosystem services (ecosystem services I). The unfamiliarity of respondents with model outputs decreases. For communication with lay stakeholders, however, model outputs are often still not suitable because engineering models themselves are usually expert models. An additional step is required to translate ecosystem services I into the language of the interests, concepts and perceptions of lay respondents (transdisciplinary model; ecosystem services II). This step requires substantial qualitative social science research into the 
subjective, pre-theoretic patterns of perception and valuation of the natural phenomena at stake (Barkmann et al. 2005a).

\begin{tabular}{|c|c|c|c|}
\hline $\begin{array}{l}\text { basic science models } \\
\text { ecosystem functions } \\
\text { (process, structure...) }\end{array}$ & $\begin{array}{l}\text { engineering models } \\
\text { ecosystem services I }\end{array}$ & $\begin{array}{l}\text { transdisciplinary } \\
\text { models } \\
\text { ecosystem services II }\end{array}$ & $\begin{array}{l}\text { lay person concepts } \\
\text { life-world interests }\end{array}$ \\
\hline
\end{tabular}

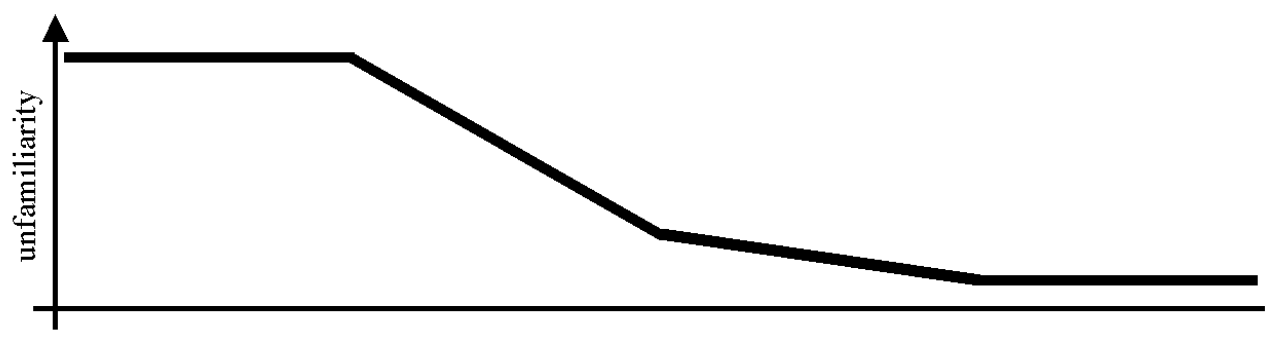

a) basic science models ecosystem functions (process, structure...)

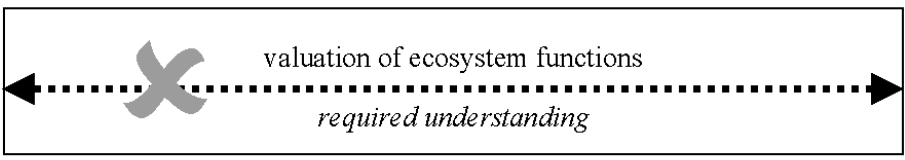

b)

\begin{tabular}{|c|c|c|}
\hline $\begin{array}{l}\text { basic science models } \\
\text { ecosystem functions } \\
\text { (process, structure...) }\end{array}$ & $\begin{array}{l}\text { engineering models } \\
\text { ecosystem services I }\end{array}$ & $\begin{array}{l}\text { ecosystem } \\
\text { services approach } \\
\text { ecosystem services II }\end{array}$ \\
\hline
\end{tabular}

valuation of ecosystem services II required understanding

Fig. 1. Valuation of ecosystem functions versus valuation of ecosystem services: advantages and disadvantages in the face of unfamiliarity of lay respondents with detailed scientific knowledge; (a) stated preference valuation of ecosystem functions; (b) stated preference valuation of ecosystem services II.

\section{Case study: Valuating a hydrological ecosystem service in rural Indonesia}

Aware of the criticism expressed at the application of stated preference methods to hydrological ecosystem functions, a valuation study was designed that aimed at minimizing information and misspecification biases by a careful differentiation between ecosystem structures and processes, and the ecosystem services they generate (Barkmann \& Marggraf 2003:248). Although the presentation below focuses on hydrologic aspects, the case study itself deals with four ecosystem services of which only one is related to ecosystem hydrology. Thus, our preference estimations do not capture the full range of services that depend on local hydrologic ecosystem functioning. Instead the case study (i) 
illustrates how the ecosystem service approach can be implemented, and (ii) tests its applicability with a focus on an ecosystem function for which the applicability of stated preferenece methods has explicitly been challenged.

\subsection{Description of the research area}

The economic valuation exercise took place in the area of the Lore Lindu National Park in Central Sulawesi, Indonesia. The project area of about 7,220 $\mathrm{km}^{2}$ is inhabited by $\sim 137,000$ people, mostly agricultural smallholders (data from 2001; Maertens at el. 2004). The area is part of the globally important Wallacea biodiversity hotspot.

In one of the research villages, Nopu, Keil et al. (2003) investigated the effects of forest conversion on water availability and local water use. For approximately ten years, smallholders have cultivated cacao in the floodplains of the catchment, where the village is located. Between 650 and $950 \mathrm{~m}$ above sea level, the tropical forest is rapidly being replaced by patches of slash-and-burn agriculture, pasture, secondary forest, and cacao agroforestry. To varying degrees, these processes characterise the entire project area aound Lore Lindu National Park.

Since September 2001 the Nopu catchment is instrumented with water level recorders, hydrologic parameter sensors, rain gauges, and meteorological stations. As an example of scientific key findings on hydrologic ecosystem functions, we present data from 2002 that were already available when the economic valuation study started in July 2003. The river discharge distribution shows a seasonal pattern with a peak in June and a low in November reflecting a spring/early summer peak in precipitation (Fig. 2). Between months with a peak in precipitation (maximum daily runoff) and months with a peak in minimum discharge, there is a time lag of about two months.

One of the most appropriate scientific descriptions of the hydraulic ecosystem functions with relevance to water supply are exceedence time graphs (Fig. 3). Exceedence time graphs indicate the number of days of a year in which river discharge exceeds the values indicated by the ordinate of the graph. Daily discharge values of Nopu river below $0.05 \mathrm{~m}^{3}$ indicate low water availability for about $2 / 3$ of the year. 


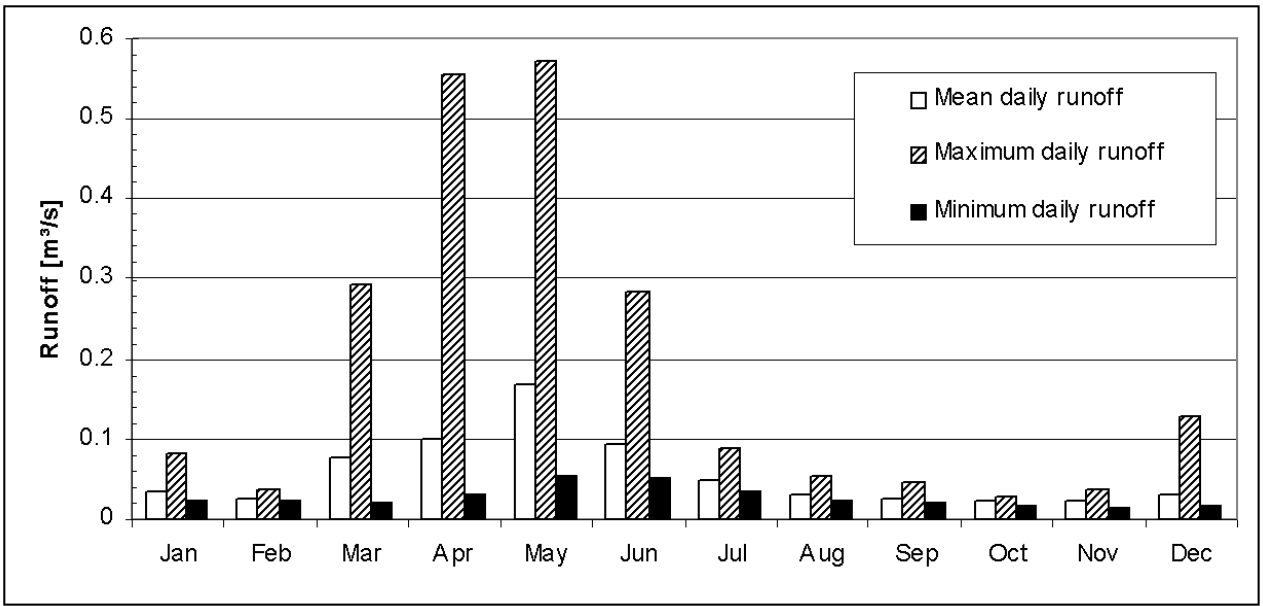

Fig. 2. Monthly minimum, maximum and mean daily runoff of Nopu catchment, Central Sulawesi, in 2002 (Keil et al. 2003).

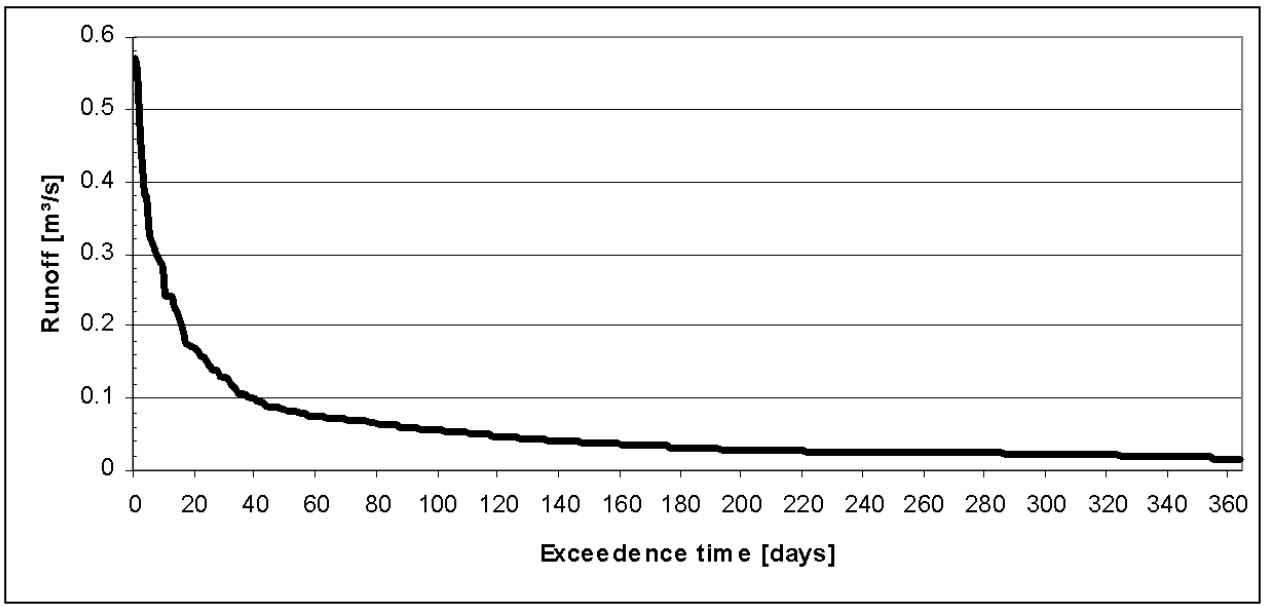

Fig. 3. Exceedence time graph 2002, Nopu catchment, Central Sulawesi (Keil et al. 2003).

\subsection{Design and application of choice experiment attributes}

\subsubsection{Design of the attributes}

Blamey et al. (1997) differentiate between demand-relevance and policy-relevance of goods included in stated preference studies. Demand-driven goods are expected to show up spontaneously in focus groups or semi-structured interviews because respondents perceive the natural resource management issue as pressing. If the issue is not mentioned spontaneously, there is a higher risk that respondents are not familiar with the issue. Consequently, information and misspecification biases are a more serious threat to validity than for demand-driven attributes. 
Information gathered from 120 households in 12 villages of the project region did already suggest in 2002 that there is a high awareness of drought and flooding related problems (Birner \& Mappatoba 2002). Keil et al. (2003) specifically addressed perceived water availability in a one-day Participatory Rural Appraisal (PRA) held in Nopu in May 2002. Participants were asked to assess monthly rainfall and local water availability for a 'normal' year (Fig. 4). The subjective assessment of water availability follows perceived rainfall patterns with a delay of up to two months. Although the seasonal distribution of precipitation and river discharge in 2002 differed from that of a 'normal' year, the gap between peaks in precipitation and minimum river discharge is mirrored in the perceptions of PRA participants. Additional focus group and semi-structured in-depth interviews were conducted in several villages of the study region in 2003. Problems with water regulation and water shortage figured prominently as resource management issues in a forest-related context, i.e. at an ecosystem level (Fig. 5).

Based on these results, an attribute on water availability during the dry season appeared to be a suitable - albeit partial - translation of the scientific description of hydrological processes into a demand-relevant ecosystem service. In particular, we operationalised water availability during the dry season via different combinations of months with "enough", "hardly enough", and "not enough" water. As most water in the project area is used for irrigation of wet rice, the attribute on water availability was linked to wet rice cultivation. By focusing on this aspect, we deliberately ignore a range of other hydrologic ecosystem services also deserving close investigation, namely the supply of potable water and flooding related services.

In addition to the water availability attribute, we selected the population size of an endemic local species, the dwarf buffalo Bubalus depressicornis/B. quarlesi ('anoa'), the amount of shade in cacao plantations, and the availability of rattan as additional attributes. The attributes were defined and operationalised in a similar manner as water availability. To alleviate the cognitive burden of the choice task, we used visualizations for the attributes and attribute levels crafted by a local artist. The choice task was framed as a selection between different versions of a village development program to which a financial contribution was required if implemented. 


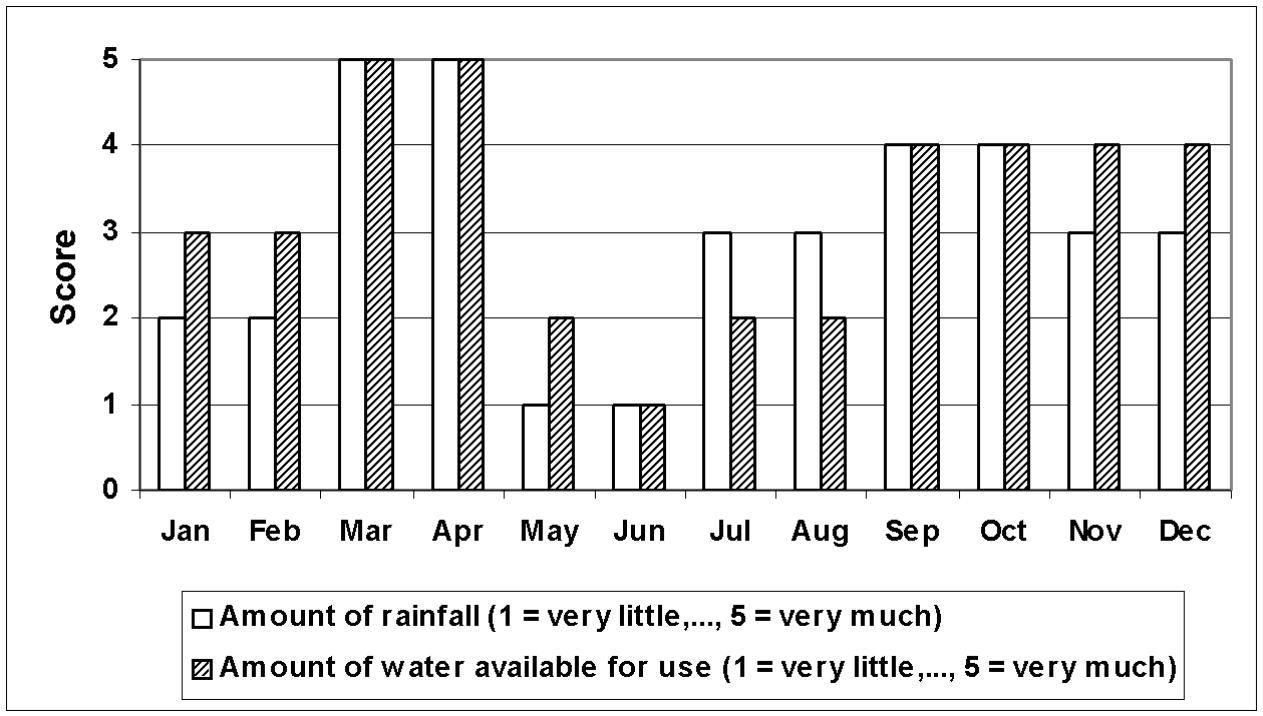

Fig. 4. Average rainfall distribution and water availability in Nopu, Central Sulawesi, for a 'normal' year (PRA reaults, modified from Keil et al. 2003)

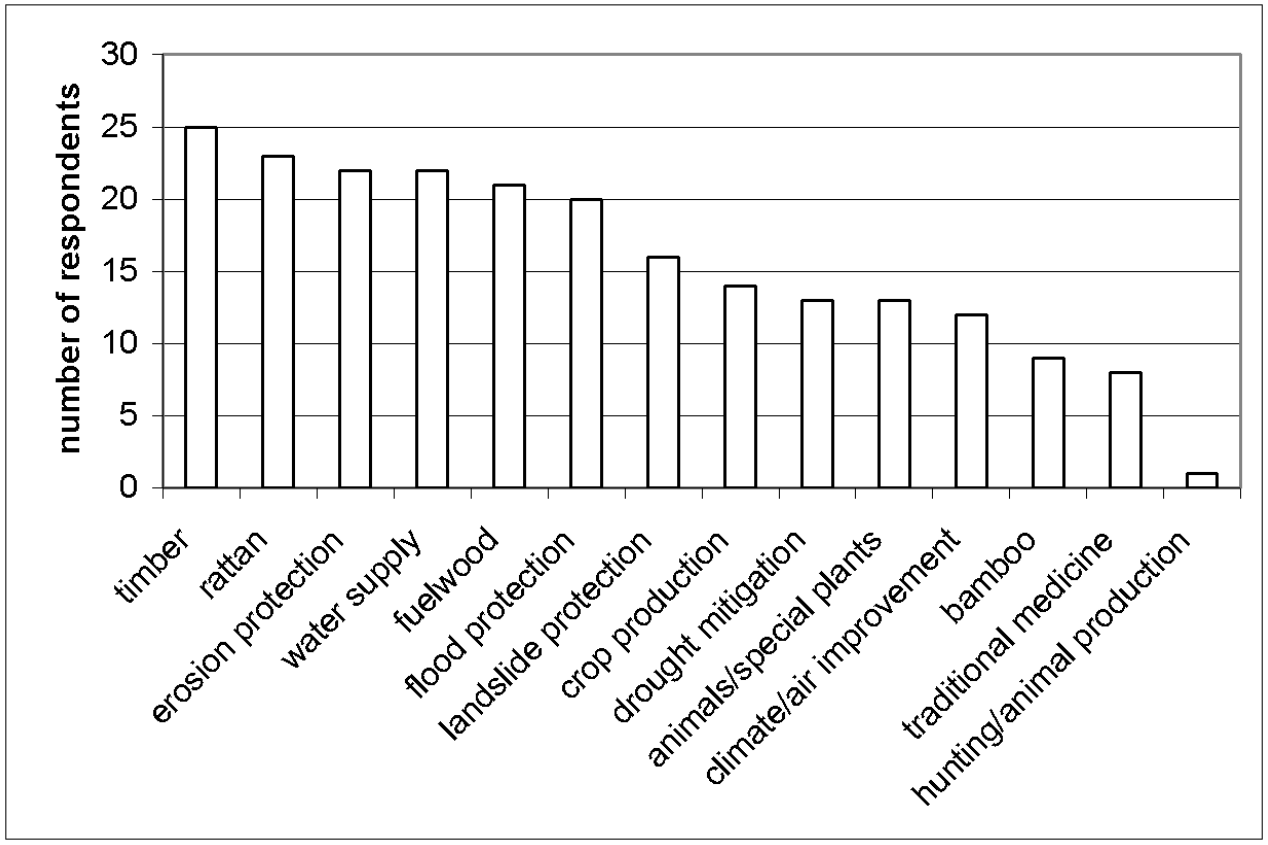

Fig. 5. Perceived forest benefits: results of 26 pre-study interviews conducted in several villages of the Lore Lindu area in 2003 (original data).

\subsubsection{Administration and analysis of the choice experiment}

The choice experiment (CE) instrument was pre-tested and piloted in $2004(n=96)$. The main survey was conducted from December 2004 to March 2005 as a random face-toface survey in 12 of the about 120 villages in the project area $(n=301)$. The interviews were conducted by six well-trained local enumerators. Thirteen respondents consistently chose 
the status quo without quoting lack of money or low attractiveness of the offered alternatives as reasons. Such respondents were classified as not responding to the CE task and omitted from parameter estimation (Adamowicz et al. 1998:68). Quantitative analysis is performed on a subset of 249 households for which an extensive set of sociodemographic variables is available (for descriptive statistics, see Tab. 1.).

Tab. 1. Selection of variables for the socio-economic and attitudinal description of the sample of Central Sulawesi respondents/respondent households

\begin{tabular}{|c|c|c|c|c|c|}
\hline Variable & Type & Coding & Scale construction & Mean & $\begin{array}{l}\text { Std. } \\
\text { Dev. }\end{array}$ \\
\hline Respondent Age & SD & & n.a. & 45.8 & 14.0 \\
\hline Respondent Education [years] ${ }^{\S}$ & $\mathrm{SD}$ & & n.a. & 7.6 & 3.2 \\
\hline Relative Poverty & $\mathrm{SD}$ & \multicolumn{2}{|c|}{ see Zeller et al. 2003} & 0.02 & 0.81 \\
\hline Rattan Collector $\$$ & SD & $0 ; 1$ & n.a. & 0.12 & 0.33 \\
\hline Wet Rice Involvement ${ }^{\$}$ & SD & $0 ; 1$ & n.a. & 0.60 & 0.49 \\
\hline Cacao Farmer $\$$ & SD & $0 ; 1$ & n.a. & 0.76 & 0.43 \\
\hline $\begin{array}{l}\text { Perception of \% shading in local } \\
\text { cacao plots }\end{array}$ & SSQ & $\begin{array}{r}\text { responde } \\
\text { shadi } \\
(5 \%\end{array}$ & $\begin{array}{l}\text { ts choose from cacao } \\
\text { g attribute levels } \\
5 \% ; 65 \% ; 95 \% \text { ) }\end{array}$ & 42.8 & 18.2 \\
\hline Rattan Value & PMT & $1 ; \ldots ; 4$ & mean of two items & 1.55 & 1.05 \\
\hline Probability Rattan Loss & PMT & $1 ; \ldots ; 4$ & mean of two items & 2.26 & 0.97 \\
\hline Water Value & PMT & $1 ; \ldots ; 4$ & one item & 3.10 & 1.34 \\
\hline Severity of Forest Loss & PMT & $1 ; \ldots ; 4$ & one item & 3.25 & 0.98 \\
\hline Cacao Shade Value & PMT & $1 ; \ldots ; 4$ & one item & 1.51 & 0.96 \\
\hline Probability Cacao Problems & PMT & $1 ; \ldots ; 4$ & one item & 3.00 & 1.06 \\
\hline Severity Anoa Extinction & PMT & $1 ; \ldots ; 4$ & one item & 1.29 & 0.59 \\
\hline Government Response Efficacy & PMT & $1 ; \ldots ; 5$ & mean of two items & 4.08 & 0.47 \\
\hline Respondent Comprehension Rating & RCR & $1 ; \ldots ; 5$ & n.a. & 3.12 & 0.85 \\
\hline
\end{tabular}

SD: socio-demographic variable; SSQ: self-explicated status quo; PMT: Protection Motivation Theory

(Rogers \& Prentice-Dunn 1997); RCR: rating of respondent comprehension performed by enumerators immediately after the choice experiment; ${ }^{\S}$ of the mean of 7.6 years, 6 years are primary school; ${ }^{\$}$ mean indicates share of households involved in respective activities; $n=249$.

For all attributes, linear utility functions were assumed. For cacao shading, an additional quadratic term was included in order to allow for a shading optimum at intermediate shade levels. Preliminary analyses indicated the risk of violations of the independence from irrelevant alternatives (IIA) condition necessary for the application of multi-nomial logit analysis. Because Nested Logit (NL) analysis does not rely on the IIA assumption, an 
eligible NL tree structure was identified, and the corresponding models estimated with NLOGIT 3.0. The inclusive value was set to 1.0 for the degenerated branch, and the model initiated with starting values obtained from a non-nested NL model (Hensher et al. 2005:530ff). All scale parameters were normalized at the lowest level (RU1). Willingnessto-pay calculations are based on extrapolations from mean marginal WTP values. Individual self-explicated status-quo levels were accounted for when necessitated by nonlinear utility terms. For the aggregation of WTP across the households of the project region, we regarded 13 non-responding participants as filing protest statements indicating zero WTP.

\subsubsection{Validity tests and influence of respondent comprehension}

Four NL models are calculated that show basic results (Tab. 2, model a), and allow for the evaluation of a number of validity issues (Tab. 2, models b-d). The validity tests address three potential challenges to the results of the case study.

First, it could be claimed that we do not measure the value of functional indirect use benefits at the ecosystem level, but the value of direct use benefits at the level of the individual farm household that, e.g., directly uses irrigation water. Although the actual irrigation water needs to be "produced" from the water available at the ecosystem level by the construction and maintenance of irrigation systems and, thus, cannot be used directly for irrigation -, we decided to conduct a simple test if preferences are exclusively linked to the economic activities of the individual households (model b). We do so by including an interaction term with a dummy variable indicating if a household is involved in wet rice farming, extracts rattan, or owns a cacao plot.

The second challenge refers to the general validity of CE results in face of the hypothetical character of stated preference methods. In model (c), we use attitudinal items that operationalise risk and coping appraisal variables from Protection Motivation Theory (PMT, Rogers \& Prentice-Dunn 1997). PMT is a social-psychological action theory that has been used successfully for the explanation of economic preferences calculated from stated preference data (Menzel 2003, Barkmann et al. 2005b). An additional set of PMT items was sampled on forest-related attitudes. Six items were sampled that refer to respondent attitudes towards the government's ability to use taxpayer money successfully and responsibly for village development. For quantitative analysis, we use a two-item 
subscale singled out by factor analysis that focuses on attitudes beyond village government (for details, see Tab. 1).

A standard procedure to test for validity in stated preference studies relies on the expected positive influence of income on WTP. Under the semi-subsistence conditions prevalent in the project area, we tested for more broadly defined wealth effects on preferences using a relative poverty index (Glenk et al. subm., Zeller et al. 2003).

The third challenge refers to respondent unfamiliarity with the ecosystem services sampled. Unfamiliarity may result in poor comprehension of the subject matter of the choice experiment. Enumerators rated respondent comprehension directly after the choice experiment on a scale from 1 (= insufficient understanding) to 5 (= very good understanding). The average comprehension rating was 3.12 with only four respondents in the 'insufficient' category (Tab. 1). With this indicator of respondent comprehension, we test three hypotheses:

1. Respondent comprehension influences preferences for ecosystem services. Influences are tested by constructing interaction terms between attributes and comprehension rating.

2. Inclusion of the interaction terms does not result in materially differing preference estimates.

Both hypotheses are tested in model (d), into which the interaction terms are introduced in addition to the interaction terms from model (c).

3. Lower comprehension as a result of unfamiliarity results in a less thorough cognitive integration of the information given in the choice sets. We test this hypothesis

a. by observing the sign of a dummy variable representing the non-status quo alternatives ('ASC'). If respondents feel ill-informed with regard to the costly alternatives to the status quo, one would expect a negative sign of the ASC (Kontoleon \& Yabe 2004); 
b. by constructing an interaction term between the respondent comprehension rating and the ASC. If hypothesis 3 is true, the interaction term should become a significant predictor of choice, and its sign should be opposite to the sign of the ASC.

The ASC dummy and the interaction term with the ASC dummy are included in all four models.

\subsection{Results}

\subsubsection{Base model, validity tests}

All NL models are highly significant ( $\mathrm{P} \leq 0.0001$; Tab. 2). The base model (a) displays the expected signs for the attribute terms: disutility for longer distance to the next rattan site, disutility of decline in water availability, positive utility for bigger anoa populations, disutility of higher costs. For shading in cacao plots, we find positive utility for more shade along with a negative sign of the quadratic term indicating an unimodal response to shade. The attribute on preferences for the hydrological ecosystem service availability of irrigation water in the dry season is highly significant $(\mathrm{P}<0.0001)$.

Model (b) reveals that for rattan, water and cacao shade, the direct utilization terms become highly significant; the non-interacted attributes indicating non-production preferences are also highly significant. Taking the fraction of households into account that are involved in rattan extraction and wet rice farming (Tab. 1), a comparison of the rattanand water-related coefficients suggests that about $71 \%$ of the preferences for improved rattan availability are attributable to non-production benefits of the individual household; for improved availability of irrigation water, about $57 \%$ are attributable to non-production benefits. 
Tab. 2. Valuation of functional ecosystem services in Central Sulawesi (Indonesia)

\begin{tabular}{|c|c|c|c|c|}
\hline Variable & (a) Base Model & $\begin{array}{l}\text { (b) Direct } \\
\text { Utilisation }\end{array}$ & $\begin{array}{r}\text { (c) PMT } \\
\text { and Relative } \\
\text { Poverty }\end{array}$ & $\begin{array}{r}\text { (d) PMT and } \\
\text { Respondent } \\
\text { Comprehen- } \\
\text { sion } \\
\end{array}$ \\
\hline Rattan availability & $-0.0457 * * *$ & $-0.0334 * * *$ & $-0.0707 * *$ & -0.0267 \\
\hline $\begin{array}{l}\text { Water for irrigation in } \\
\text { the dry season }\end{array}$ & $-0.9771 * \star *$ & $-0.5742 * * *$ & -0.0102 & 0.4222 \\
\hline Cacao Shade (linear) & $0.0173 *$ & $0.0288 * * *$ & $0.0447 * * *$ & $0.0458 * \star \star$ \\
\hline Cacao Shade (quad.) & $-0.0003 * \star \star$ & $-0.0003 * \star \star$ & $-0.0003 * \star \star$ & $-0.0003 * * *$ \\
\hline Anoa Population Size & $0.0013 * * *$ & $0.0014 * * *$ & -0.0007 & 0.0001 \\
\hline Cost & $-0.0247 * \star \star$ & $-0.0256 * \star \star$ & 0.0174 & -0.0029 \\
\hline Cost*Resp. Efficacy & & & $-0.0107 * \star$ & $-0.0107 * \star$ \\
\hline ASC (non-status quo) & $1.4081 * \star \star$ & $1.4106 * \star \star$ & $1.5461 * \star \star$ & $2.1543 * \star \star$ \\
\hline $\mathrm{ASC} \mathrm{RCR}^{*}$ & $-0.2735 * \star$ & $-0.3021 * \star \star$ & $-0.3261 * \star \star$ & $-0.5322 * \star$ \\
\hline Rattan*Rat. Collector & & $-0.1101 * \star *$ & & \\
\hline Water*Involvement & & $-0.7305 * \star \star$ & & \\
\hline Cacao*Cacao Farmer & & $-0.0130 * \star$ & & \\
\hline Rattan*Rattan Value & & & $-0.0286 * \star$ & $-0.0281 * \star$ \\
\hline Rattan*Probability & & & $0.0284 * \star \star$ & $0.0279 * *$ \\
\hline Water*Water Value & & & $-0.2181 * \star \star$ & $-0.2077 * \star \star$ \\
\hline Water*Severity/Forest & & & $-0.1033 \star$ & $-0.0925 \mathrm{~T}$ \\
\hline Cacao*Value & & & $-0.0043 *$ & $-0.0041 *$ \\
\hline Cacao*Probability & & & $-0.0061 * * *$ & $-0.0060 * *$ \\
\hline Cacao*Relat. Poverty & & & $-0.0042 \mathrm{~T}$ & -0.0039 \\
\hline Anoa*Severity & & & $0.0017 * \star$ & $0.0016 * *$ \\
\hline Rattan* RCR & & & & -0.0146 \\
\hline Water*RCR & & & & $-0.1658 *$ \\
\hline Cacao*RCR & & & & -0.0006 \\
\hline Anoa*RCR & & & & -0.0002 \\
\hline Cost*RCR & & & & 0.0048 \\
\hline Log-likelihood & -728.2 & -690.0 & -680.6 & -678.1 \\
\hline $\mathrm{P}\left(\mathrm{Chi}^{2}\right) ; \mathrm{DF}$ & $<0.0001 ; 9$ & $<0.0001 ; 12$ & $<0.0001 ; 18$ & $<0.0001 ; 23$ \\
\hline Inclusive value (IV) & 0.8576 & 0.8695 & $0.8563 *$ & $0.7789 *$ \\
\hline Adj. $\rho^{2}\left(\text { Pseudo- } R^{2}\right)^{\S}$ & 0.273 & 0.3117 & 0.319 & 0.3198 \\
\hline
\end{tabular}

***: significant at $\mathrm{p} \leq 0.001 ; * *$ : significant at $\mathrm{p} \leq 0.01 ; *$ : significant at $\mathrm{p} \leq 0.05$; $\mathrm{T}$ : tendency at $\mathrm{p} \leq 0.1 ;$ cost coefficients for $1,000 \mathrm{IDR} / \mathrm{yr} ;{ }^{\&} \mathrm{IV}$ of non-degenerated branch; degenerated branch set to $1.0 ;{ }^{\S}$ Pseudo-R ${ }^{2}$ values in reference to a constants only model - values between 0.3 and 0.4 correspond to $\mathrm{R}^{2}$ values of 0.6 to

0.8 value in ordinary least squares regression (Hensher et al. 2005:338); ${ }^{\#}$ all IV statistics are highly significantly different from 0 , asterisks denotes difference from 1; RCR: respondent comprehension rating;

DF: degrees of freedom; Nested Logit models based on 249 respondents with 4 choices each: $n=996$ observations.

Comparing model (c) with the base model (a), inclusion of significant interaction terms with PMT variables and with relative poverty improves adjusted Pseudo- $\mathrm{R}^{2}$ by more than four percentage points to a very reasonable value of $31.9 \%$. Log Likelihood ratio-tests 
show that model specification (c) improves model fit compared to models (a) and (b) $(\mathrm{P}<0.0001 ; \mathrm{P}=0.027)$. Significant interaction terms are found for all attributes. Two interactions with the water attribute are significant, water value $(\mathrm{P}<0.0001)$ and severity of forest loss $(\mathrm{P}=0.037)$. The more respondents agree on average with the statement that they "very much need water for irrigation in the dry season" (water value) the higher is the disutility of more months with low water availability. Likewise, a more concerned attitude towards loss of "trees on the hillsides" correlates with higher preferences for water availability. Both interaction terms explain variation in choice behavior as expected. In fact, they explain the variation so well that the non-interacted water attribute becomes statistically and materially insignificant. The cost attribute displays the same pattern with a highly significant influence of the perceived response efficacy of government $(\mathrm{P}=0.0039)$.

Under model specifications (c) and (d), none of the theoretically expected linear influences of relative poverty on preferences could be detected at standard significance levels. Only the interaction with the cacao attribute displays a tendency $(\mathrm{P}=0.075)$ in model (c); only the interactions with cacao are retained in the final models.

Tab. 3. Impact of the inclusion of the respondent comprehension rating on disutility for one additional month with water scarcity for an "average" household.

\begin{tabular}{|c|c|c|c|c|c|}
\hline \multirow{2}{*}{ Variable } & \multicolumn{2}{|c|}{ model coefficients } & \multirow{2}{*}{$\begin{array}{c}\text { mean of } \\
\text { interacted } \\
\text { variable }\end{array}$} & \multicolumn{2}{|c|}{ interacted coefficients } \\
\hline & model (c) & model (d) & & model (c) & model (d) \\
\hline $\begin{array}{l}\text { Water for irrigation in the } \\
\text { dry season }\end{array}$ & -0.0102 & 0.4222 & & -0.0102 & 0.4222 \\
\hline Water*Water Value & -0.2181 & -0.2077 & 3.10 & -0.6770 & -0.6449 \\
\hline Water*Severity/Forest & -0.1033 & -0.0925 & 3.25 & -0.3360 & -0.3008 \\
\hline Water*RCR & & -0.1658 & 3.12 & & -0.5167 \\
\hline Sum Water & & & & -1.0232 & -1.0403 \\
\hline Cost $^{\$}$ & 0.0174 & -0.0029 & & 0.0174 & 0.0029 \\
\hline Cost*Response Efficacy & -0.0107 & -0.0107 & 4.08 & -0.0436 & -0.0438 \\
\hline Cost*RCR & & 0.0048 & 3.12 & & 0.0149 \\
\hline Sum Cost & & & & -0.0262 & -0.0261 \\
\hline Marginal WTP $^{\S}[\mathrm{IDR} / \mathrm{yr}]$ & & & & $-38,979$ & $-39,927$ \\
\hline
\end{tabular}

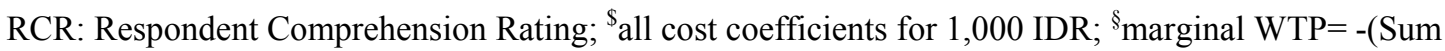
Water/Sum Cost)*1,000.

Model (d) addresses respondent comprehension. Only the interaction of the comprehension rating and the water attribute influences choices $(\mathrm{P}=0.019)$. Model $(\mathrm{d})$ predicts that a better comprehension rating results in higher disutility of water scarcity, i.e., better understanding 
respondents have stronger preferences for the ecosystem service water availability than respondents with a lower comprehension rating. The next best interaction term is the interaction term with rattan $(\mathrm{P}=0.194)$. Table 3 details that the inclusion of the respondent comprehension rating results in virtually identical coefficients of models (c) and (d) when summed up across all relevant terms (see hypothesis 2). Accordingly, the two marginal willingness-to-pay estimations for one month of reduced water scarcity around 39,00040,000 IDR/yr hardly differ.

If we stipulate contra-factually that respondents had a mean comprehension rating of 4 instead of just above 3, model (d) predicts that the sum of the water coefficients would increase by $14.1 \%(-0.146)$. In this calculation, we keep the coefficient of the interaction cost attribute* comprehension rating constant because it is clearly not significant $(\mathrm{P}=0.215)$.

In addition to the analysis of respondent comprehension at the level of individual attributes, we tested if potential unfamiliarity effects influenced choice between the status quo option and the village development program - i.e., non-status quo - alternatives. As hypothesized, the interaction term of the ASC-dummy representing the non-status quo alternatives consistently influenced choices (Tab. 2, models a-d). The significance and positive sign of the ASC itself indicate that respondents favor the proposed village development program beyond the actual ecosystem service change presented in the scenarios. This effect is partially counterbalanced by the interaction term between ASC and respondent comprehension rating because its sign is opposite to the sign of the ASC coefficient. For respondents with average comprehension, the effect is reduced by nearly one half. Thus, hypothesis 3 that claims that lower comprehension results in worse cognitive integration of the information actually offered in the choice experiment could not be rejected. The sign of the ASC is not consistent, however, with high levels of subjective uncertainty caused by unfamiliarity (test $3 a$ ). In this case, the uncertainty should have lead to a rejection of the offered choices in favor of the status quo beyond the information given. This would have been expressed by a negative sign of the ASC.

\subsubsection{Willingness-to-pay calculation}

For an estimation of marginal WTP values, we return to model (c), which fits the data no worse than model (d) but which contains only one insignificant interaction term (cacao*relative poverty; Log Likelihood ratio-test of model fit improvement: $\mathrm{P}=0.834$ ). 
Marginal mean values range from about $400 \mathrm{IDR} / \mathrm{household} / \mathrm{yr}$ for cacao shading to about 39,000 IDR for improved water availability (Tab. 4).

Tab. 4. Marginal WTP and exemplary scenario calculation based on model (c) statistics.

\begin{tabular}{ccccc}
\hline \hline & Rattan & Water & Cacao & Anoa \\
\hline Marginal Unit & $\begin{array}{c}\text { harvesting } \\
\text { location1 km } \\
\text { closer }\end{array}$ & $\begin{array}{c}1 \text { month less } \\
\text { with water } \\
\text { scarcity }\end{array}$ & $\begin{array}{c}1 \% \text { less } \\
\text { shading in } \\
\text { plantations of } \\
\text { village }\end{array}$ & $\begin{array}{c}1 \text { individual } \\
\text { more }\end{array}$ \\
$\begin{array}{c}\text { Marginal mean } \\
\text { WTP/household [IDR/yr] }\end{array}$ & 1,936 & 38,979 & $408^{\$}$ & 49 \\
\hline $\begin{array}{c}\text { Scenario Change } \\
\text { Mean scenario }\end{array}$ & $-10 \mathrm{~km}$ & -1 month & $-20 \%{ }^{\S}$ & +150 \\
$\begin{array}{c}\text { WTP/household } \\
\text { Aggregated scenario }\end{array}$ & 19,362 & 38,979 & $4,438^{\#}$ & 7,386 \\
$\begin{array}{c}\text { WTP(scenario)/project } \\
\text { area [Mio. IDR/yr] }\end{array}$ & 431.8 & 869.2 & 98.8 & 164.7 \\
\hline \hline
\end{tabular}

${ }^{\$}$ accounting for self-explicated status quo (see Tab. 1 ); ${ }^{\$}$ for respondents perceiving $5 \%$ shading, scenario change $=-5 \%$; " because of non-linear preferences for cacao shading, mean scenario $\mathrm{WTP} \neq$ marginal mean WTP*scenario change; aggregation based on $23,307 *(301-13) / 301=22,300$ households in the project region that did not file protest responses; $1 € \sim 11,500$ IDR (winter/spring 2005).

Additionally, table 4 presents an exemplary scenario calculation. The scenario assumes that the next commercially exploitable rattan sites are $10 \mathrm{~km}$ closer to the villages, water shortage is reduced by one month, cacao shading is reduced by $20 \%$, and anoa numbers increase by 150 . With respect to scenario WTP values, the improvement of hydrological ecosystem services is the most valued change. A methodologically more intricate WTP and scenario analysis with three differing scenarios is provided by Glenk et al. (subm.). Extrapolating household WTP/year to the entire project region of approximately 23,300 households based on the above scenario results in an aggregated annual WTP of about 870 Mio. IDR $(\sim 76,000 €)$ for improved availability of irrigation water, and about 1,560 Mio. IDR $(\sim 136,000 €)$ for an implementation of all improvements. 


\section{Discussion}

\subsection{Unfamiliarity aspects}

The case study documents that unfamiliarity of lay respondents with the scientific details of ecosystem functioning is no principal objection against the application of stated preference techniques for a monetary quantification of 'functional' indirect use values. In particular, we showed that unfamiliarity with technical descriptions of a hydrological ecosystem function represented by the discharge characteristics of a small catchment does not prevent a meaningful economic valuation a closely related ecosystem service.

Apart from statistical evidence such as the high significance of all calculated NL models and the water availability-related attributes, we base this optimistic view on several observations. At the most fundamental level, water availability is clearly a demand-driven environmental valuation issue of high economic and social relevance in the project region. This is an important factor that helps avoiding information and misspecification biases. The relevance and realism of the entire valuation exercise is mirrored by the fact that only 13 protest responses were filed by 301 initial respondents.

We investigated if the ecosystem services at hand could be explained completely by motivations for direct resource use at the household level. If so, the need to apply stated preference techniques could be questioned. In particular, for the availability of irrigation water, a substantial share of benefits $(57 \%)$ could not be attributed directly to wet rice production activities at the household level. Thus, the measured preferences include nonuse and/or indirect use values not captured by standard production economic analysis.

Two variables from Protection Motivation Theory interacted with the water attribute, water value and severity of forest loss, explain variations in choice behavior so well that the water attribute itself became insignificant. Thus, preferences stated in response to the chosen representation of water availability correlate well with underlying values and risk perceptions of the respondents derived from social-psychological theory.

Preferences for the availability of water and rattan, and for a larger anoa population did not increase linearly with relative poverty. In more detailed analyses to be published elsewhere (Glenk et al. subm., Barkmann et al. 2005c), preferences for shading in cacao 
had displayed a (negative) linear correlation with relative poverty. This tendency is also visible here in model (c). As there are indications for a systematically non-linear relationship between relative poverty and preferences for these ecosystem services ('middle class goods'), the results of this validity analysis are inconclusive.

To test for unfamiliarity effects, the comprehension of respondents was rated directly after the CE by local, well-trained enumerators. Only four respondents were rated to have insufficient comprehension. The average comprehension rating was 3.12 with about $80 \%$ of respondents in the average to very high comprehension range. Although the comprehension rating influenced the probability with which the village development alternatives were chosen over the "do nothing"-status quo option, the sign of the non-status quo dummy does not give any indication of comprehension problems. With unfamiliarity issues looming, one would have expected a status quo bias (negative sign of the non-status quo ASC) as respondents choose the save haven of the current situation instead of paying for a change in a good troubled by unfamiliarity. Instead, respondents favored the nonstatus quo alternatives strongly (for a more detailed discussion, see Glenk et al., in prep.).

When interacted with the water attribute, the comprehension rating significantly influenced choices. Potential unfamiliarity effects were stronger for the hydrological ecosystem service than for other ecosystem services, such as availability of rattan or shading in cacao plantations. While the inclusion of the comprehension rating had hardly any effect on WTP estimates, improved familiarity may result in different - in our case higher - WTP estimates. If we attribute comprehension deficits completely to persisting unfamiliarity - which is certainly an exaggeration -, the comprehension rating indicates that unfamiliarity may continue to be a problem for about $20 \%$ of respondents. NL model (d) predicts that respondents with a comprehension rating of 4 are expected to value improved water availability by about $14 \%$ more than respondents with an average rating. While percieved response efficacy of government activities strongly impacts monetary preferences via an influence on the cost attribute, no evidence was found that unfamiliarity exerts a similar influence.

The comprehension analysis suggests that our implementation of the ecosystem service approach solved the comprehension problems sufficiently when applied to a respondent sample with an average of 7.6 \pm 3.2 years of formal education (Tab. 1). For remaining comprehension problems caused by unfamiliarity, the inclusion of a 
comprehension rating variable allows for an assessment of the maximum unfamiliarity impact - and a correction of WTP estimates if desired.

The calculated WTP values per household of a few Euro/year appear low. However, WTP for improving water availability by one month equals about $1 \%$ of mean cash income of households in the project area. WTP for the implementation of all scenario improvements covers the basic needs of one household member for about half a month (cf. van Rheenen et al. 2004). To our knowedge, the only stated preference study on the valuation of a similar ecosystem service in Indonesia was conducted by Pattanayak \& Kramer (2001). They conducted a contingent valuation study on improved drought mitigation services by watershed protection around Ruteng Park (Flores Island). They report a comparable WTP of 2-3 \$ per household/year.

Also the WTP value aggregated across the about 23,300 households of 76,000 €/yr for one month of improved water availability appears low. For the conservation of Leuser National Park on Sumatra, Beukering et al. (2003) calculated annual net benefits for averted losses in water supply alone equivalent to $98 \mathrm{Mio}$. US\$/year. Even considering the fact that Leuser National Park is about three times the size of the Lore Lindu project area and taking vastly differing scenario assumptions into account, differences of about two orders of magnitude remain. These differences are most likely caused by

(i) the restriction of our study to water availability for irrigation (versus drinking water and industrial uses),

(ii) a different stakeholder definition (inhabitants of the project area versus inclusion of local and national governments), and

(iii) the implications of severe budget constraints operating at the household level versus unconstrained cost calculations in Beukering et al. (2003; see also discussion in section 2).

Higher WTP may have been obtained if the proposed village development program had included micro-credit and agricultural extension schemes. Such a valuation frame may have alleviated existing budget and know-how constraints. Also, the levels of the cost attributes did not exhaust the maximum WTP of the few 'rich' respondents. As an 
estimation of current local WTP for an important but narrowly defined ecosystem service in the face of severe poverty $-63 \%$ of project area inhabitants are reported not to be able to meet basic needs (van Rheenen et al. 2004), the seemingly low values reported here appear realistic.

In sum, the applicability of the CE instrument, the statistical significance of preferences for water availability, and most validity tests support the conclusion that the ecosystem service availability of irrigation water in the dry season was successfully valued. While most respondents sufficiently understood the ecosystem services to be valued, precautionary measures may be advisable to quantify the maximum impact of remaining unfamiliarity/comprehension problems.

\subsection{Data and modeling aspects}

Compared to the direct valuation of ecosystem functions, an ecosystem service approach places seemingly high demands on models and data needed to actually use WTP estimates to generate policy advice. Why demands may be hard to meet, can be explained from the modeling perspective introduced in section 3.2 (Fig. 1). Because the ecosystem services approach does not confront respondents with technical descriptions of changes of ecosystem processes, structures and states ('ecosystem functions'), changes in these phenomena are not directly valuated. Therefore, the basic science models that represent these phenomena cannot be used directly to relate the valuated changes to changes in ecosystem functioning.

One example is the land use change in the Nopu catchment in Central Sulawesi. Detailed hydrological data exist how land use change affects variables of the hydrological cycle in this catchment (Kleinhans 2004). While the underlying basic science model gives a precise description of hydrological ecosystem functioning, it cannot translate the land use changes into changes in the months with enough, barely enough and not enough water for irrigation purposes. This is no problem for Nopu where wet rice fields have been converted to cacao plots. It is a problem for the project area at large, however, where wet rice is a highly important subsistence crop. Still, village-specific engineering models that are capable of the necessary translations have not been completed, yet.

This is a typical situation for early phases of planning processes. Here, economic 
valuation is not used for the appraisal of detailed project proposals. Instead, it is used for the identification and quantification of local preferences in order to improve the design of project or policy options. For informing early planning phases, choice experiments are particularly well-suited because (i) they do not have to assume linear preferences across the potential range of attribute level changes, and (ii) they generate trade-off information not only between a bundle of changes in environmental goods and income but also among the components of the bundle. These characteristics facilitate the meaningful application of stated preference results for the economic valuation of the final set of project or policy options.

\section{Conclusion}

Descriptive and normative interpretations of the ecosystem function and the ecosystem service concepts should be carefully distinguished. On this basis, the Central Sulawesi case study presents evidence for the applicability of an ecosystem service approach to the environmental valuation of potentially unfamiliar ecosystem functions. Three recommendations emerge from the case study to confront unfamiliarity in stated preference valuation:

(i) After extensive qualitative pre-studies, select demand-relevant ecosystem services for the description of the ecosystem function(s) to be valued,

(ii) use utmost care in the design and representation of the chosen set of ecosystem services, and

(iii) include variables that assess the potential impact of remaining unfamiliarity/comprehension problems.

To ensure the eventual policy relevance of valuation results, enough applied science and engineering expertise has to be available to translate changes in ecosystem functioning into meaningful ecosystem service descriptions, and to relate these changes to realistic policy or project interventions. Such translations remain a challenge for the entire discipline that only few studies - including revealed preference studies - have met (Heal et al. 2005:154). 
We conclude that the proposed ecosystem service approach can reduce the degree of unfamiliarity to a point where it does not pose a principal obstacle to the application of stated preference techniques. Because the number of ecosystem services that can be included in a survey study is limited, it will often only by possible to establish lower bounds of the total economic value of an ecosystem function. Still, it would constitute an unwarranted limitation of the diverse set of economic valuation techniques to exclude stated preference methods from the valuation of ecosystem functions on unfamiliarity grounds.

\section{Acknowledgements}

We thank Deutsche Forschungsgemeinschaft (DFG SFB 552) and BMBF (DEKLIM C) for financial support. Most appreciated advise and assistance was received from M. Bos, G. Burkard, D. Darusman, M. Fremerey, W. Lorenz, S. Schwarze, L. Sudawati, A.T. Tellu, M. Zeller and our Sulawesi enumerator team. 


\section{References}

Adamowicz, W., Boxall, P., Williams, M., and Louviere, R., 1998. Stated preferences approaches to measuring passive use values: Choice experiments and contingent valuation. American Journal of Agricultural Economics, 80: 64-75.

Alcamo, J., and 49 others, 2003. Millennium Ecosystem Assessment - Ecosystems and Human Well-Being: A Framework for Assessment. Island Press, Washington, 245 pp.

Barkmann, J. and Marggraf, R., 2003. Project A5 - Biological diversity of the rainforest margin as an economic good. In: Stability of Rainforest Margins, Fortsetzungsantrag 2003-2006, Georg-August-Universität Göttingen, Februar 2003, pp. 229-263.

Barkmann, J. and Marggraf, R., 2004. Ökologische Schäden durch Vernachlässigung des Vorsorgeprinzips im nachhaltigen Landschaftsmanagement - eine umweltökonomische Perspektive. In: T. Potthast (Editor), Ökologische Schäden. Peter Lang, Frankfurt/M., pp. 57-76.

Barkmann, J., Cerda, C. and Marggraf, R., 2005a. Interdisziplinäre Analyse von Naturbildern: Notwendige Voraussetzung für die ökonomische Bewertung der natürlichen Umwelt. Umweltpsychologie, 9:10-29.

Barkmann, J., Cerda, C., and Marggraf, R., 2005b. Trading-off ecological insurance in an uncertain world: Economic preferences for species-diversity ensuring fundamental ecosystem functioning. Paper presented at DIVERSITAS $1^{\text {st }}$ Open Science Conference, 9-12 November 2005, Oaxaca, Mexico.

Barkmann, J., Glenk, K., Schwarze, S., Zeller, M. and Marggraf, R., 2005c. Differential influence of relative poverty on environmental preferences - Evidence from rural Indonesia. Paper presented at $75^{\text {th }}$ Southern Economics Association Meeting, 18-20 November 2005, Washington, DC.

Bateman, I.J., Carson, R.T. Day, D., Hanemann, M., Hanley, N., Hett, T., Lones-Lee, M., Loomes, G., Mourato, S., Özdemiroglu, E., Pearce, D.W., Sugden, R. and Swanson, J., 2002. Economic Valuation with Stated Preference Techniques - A Manual. Edward Elgar, Cheltenham, UK, 458 pp. 
Bennett, J., 2002. Non-Market Valuation Scoping Study - A report prepared for the Murray Darling Basin Commission, The Living Murray Project, September 2002. [http://www.thelivingmurray.mdbc.gov.au/_data/page/259/Nonmarket_valuation_scoping_report1.pdf]

Birner, R. and Mappatoba, M., 2002. Community-Based Agreements on Conservation in Central Sulawesi - A Coase Solution to Externalities or a Case of Empowered Deliberative Democracy? STORMA Discussion Paper Series, No. 3, Göttingen and Bogor.

Blamey, R., Rolfe, J., Bennett, J. and Morrison, M., 1997. Environmental Choice Modeling: Issues and Qualitative Insights. Research Report No. 4. Canberra, Australia: School of Economics and Management, The University of New South Wales.

Bockstael, N.E., Freeman, A.M., Kopp, R.J., Portney, P.R., and Smith, V.K., 2000. On measuring economic values for nature. Environmental Science and Technology, 34:1384-1389.

Carpenter S. R. and Turner M., 2000. Opening the Black Boxes: Ecosystem Science and Economic Valuation. Ecosystems, 3:1-3.

Carson, R.T., Flores, N.E., and Mitchell, R.C., 1999. The Theory and Measurement of Passive Use Value. In: I.J. Bateman and K.G. Willis (Editors), Valuing Environmental Preferences. Oxford University Press, Oxford, pp. 95-130

Costanza, R., d'Arge, R., de Groot, R.S., Farber, S., Grasso, M., Hannon B., Naem S., Limburg K., Paruelo J., O’Neill R.V., Raskin, R., Sutton, P., and van den Belt, M., 1997. The value of the world's ecosystem services and natural capital. Nature, 387:253-260.

Costanza, R., and Farber, S., 2002. Introduction to the special issue on the dynamics and value of ecosystem services: integrating economic and ecological perspectives. Ecological Economics, 41:367-373.

Daily, G. (Editor), 1997. Nature's services: societal dependence on natural ecosystems. Island Press, Washington, DC, 392 pp.

de Groot, R.S., Wilson, M.A. and Boumans, R.M.J., 2002. A typology for the classification, description and valuation of ecosystem functions, goods and services. Ecological Economics, 41:393-408. 
Diamond, P.A., and Hausman, J.A., 1994. Contingent Valuation: Is Some Number Better than No Number? Journal of Economic Perspectives, 8:45-64.

Farber, S.C., Costanza, R. and Wilson, M.A., 2002. Economic and ecological concepts for valuing ecosystem services. Ecological Economics, 41:375-392.

Freeman III, A.M., 1998. On Valuing the Services and Functions of Ecosystems. In: A.M. Freeman III (Editor), The economic approach to environmental policy: the selected essays of A. Myrick Freeman III, Edward Elgar, Cheltenham (UK).

Glenk, K., Barkmann, J., and Marggraf, R., in prep. Locally perceived values for biodiversity in rural Inodesia - a choice experiment approach.

Glenk, K., Barkmann, J., Schwarze, S., Zeller, M., and Marggraf, R., subm. Diferential influence of relative poverty on preferences for ecosystem services: Evidence from rural Indonesia. Paper submitted to International Association of Agricultural Economics (IAAE) 2006 Conference, Brisbane.

Heal, G.M., Barbier, E.B., Boyle, K.J., Covich, A.P., Gloss, S.P., Hershner, C.H., Hoehn, J.P., Pringle, C.M., Polasky, S., Segerson, K. and Shrader-Frechette, K., [Committee on Assessing and Valuing the Services of Aquatic and Related Terrestrial Ecosystems] 2005. Valuing Ecosystem Services: Toward Better Environmental Decision-making. National Academies Press, 277 pp.

Hensher, D.A., Rose, J.M. and Greene, W.H., 2005. Applied choice analysis: a primer. Cambridge University Press, New York, 717 pp.

Keil, A., Kleinhans, A., Schwarze, S., Birner, R., Gerold, G. and Lipu, S. 2003. Forest conversion, water availability and water use in Central Sulawesi, Indonesia. Die Erde, 134:411-427.

Kleinhans, A., 2004. Einfluß von Landnutzung und pedohydrologischer Gebietsvarianz auf den Wasser- und Nährstoffumsatz in einem tropischen Einzugsgebiet (Zentralsulawesi). Dissertation, Georg-August-Universität Göttingen.

Kontoleon, A. and Yabe, M., 2004. Assessing the Impacts of Alternative 'Opt-out' Formats in Choice Experiment Studies. Journal of Agricultural Policy Research 5: 132. 
Maertens, M., Zeller, M. and Birner, R., 2004. Does Technical Progress in Agriculture have a Forest Saving or a Forest Clearing Effect? Theory and Evidence from Central Sulawesi. In: G. Gerold, M. Fremerey and E. Guhardja (Editors), Land Use, Nature Conservation and the Stability of Rainforest Margins in Southeast Asia. Springer, Berlin, pp. 179-197.

Menzel, S., 2003. Der Beitrag der Protection Motivation Theory für die Zahlungsbereitschaftsäußerungen zur Erhaltung biologischer Vielfalt. Umweltpsychologie, 7:92-112.

Nunes, P.A.L.D and v.d. Bergh, J.C.J.M., 2001. Economic valuation of biodiversity: sense or nonsense? Ecological Economics, 39:203-222.

Pattanayak, S. and Kramer, R.A., 2001. Pricing Ecological Services: Willingness to pay for drought mitigation from watershed protection in eastern Indonesia. Water Resources Research, 37:771-778.

Rogers, R.W, and Prentice-Dunn, S., 1997. Protection motivation theory. In: D.S. Gochman (Editor): Handbook of Health Behavior Research. Plenum, New York, pp.113-132.

Sugden, R., 2005. Anomalies and Stated Preference Techniques: A Framework for a Discussion of Coping Strategies. Environmental and Resource Economics, 32:1-12.

Toman, M.A., 1996. Ecosystem Valuation: An Overview of Issues and Uncertainties. In: R.D. Simpson and N.L. Christensen Jr. (Editors): Ecosystem Function \& Human Activities. Chapman \& Hall, New York, pp. 26-44.

van Beukering, P.J.H., Cesar, H.S.J. and Janssen, M.A., 2003. Economic valuation of the Leuser National Park on Sumatra, Indonesia. Ecological Economics, 44:43-62

van Rheenen, T., Elbel, C., Schwarze, S., Nuryartono, N., Zeller, M., and Sanim, B., 2004. Encroachments on Primary Forest: Are They Really Driven by Despair? In: G. Gerold, M. Fremerey and E. Guhardja (Editors), Land Use, Nature Conservation and the Stability of Rainforest Margins in Southeast Asia. Springer, Berlin, pp. 199-213.

WBGU [Wissenschaftlicher Beirat der Bundesregierung Globale Umweltveränderungen] 1999. Welt im Wandel - Umwelt und Ethik, Metropolis, Marburg, 149 pp. 
Whigham, D.F., 1996. Ecosystem Functions and Ecosystem Values. In: R.D. Simpson and N.L. Christensen Jr. (eds): Ecosystem Function \& Human Activities. Chapman \& Hall, New York, pp. 225-239.

Zeller, M., Wollni, M. and Shaban, A., 2003. Evaluating the poverty outreach of development programs? Empirical Evidence from Indonesia and Mexico. Quarterly Journal of International Agriculture, 42:371-383. 


\section{CHAPTER 2}

Design and Application of Choice Experiment Surveys in So-Called Developing Countries:

Issues and Challenges 


\section{Introduction}

Within approximately the last ten years, choice experiments (CE) have become a very popular technique for non-market environmental valuation. The choice experiment technique allows for simultaneous elicitation of multi-attribute benefits (use and non-use, e.g. in a policy scenario). Further advantages include the possibility to explicitly incorporate substitute goods and also that some evidence shows that the CE is less susceptible to bias than the contingent valuation method (CVM; Hanley et al. 2001, Morrison et al. 1996). CVM might be preferred over CE; if a scenario is difficult to be split into components; if the researcher wants to evaluate change of the total economic value of some none-market good (Colombo et al. 2005). Thus, the choice of the most suitably stated preference technique method also depends on the research objectives.

Applications of CE in so-called developing countries, however, are still relatively rare compared to CVM. Apart from logistical reasons, a general concern may have been that the cognitive demand for respondents due to the choice task complexity is perceived to be relatively high, while, on average, respondents have a rather low level of literacy. In this article, I will present a survey on the valuation of ecosystem services adjusted for and conducted in a rural part of Central Sulawesi/Indonesia. Based on this example, I will highlight some issues a CE researcher may have to face with a focus on a so-called developing country environment.

In his paper on the performance of CVM studies in so-called developing countries, Whittington (2002) finds that CVM studies in so-called developing countries are often of poor quality. He ascribes this finding to three major reasons, which may also apply for the choice experiment:

- Poor adjustment of scenarios to the research objective and the research environment;

- poor administration and execution;

- absence of split-sample tests for the robustness of results when small changes in the design are applied. 
This paper addresses the first two issues in order to enlarge the pool of ideas and to provide decision aid for CE researchers facing similar challenges. The reader should keep in mind that my examples and suggestions are the results of the particular research process and environment I faced in Central Sulawesi. The reader himself may decide which aspects are applicable in a more general context. ${ }^{1}$

The structure of this paper is as follows: the research area and the study is briefly introduced in the following section; in section 3, some design issues of the CE survey instrument that contributed to a successful application (including, e.g., wording, framing of the hypothetical scenarios of the choice experiment, questionaire setup and task complexity leading to the use of visual decision aids) are described; since pratical advice and suggestions are seldom found in journal articles, some practical aspects of survey preparation and administration are discussed in section 4; the paper ends with some concluding remarks.

\section{A choice experiment study from Central Sulawesi, Indonesia}

\subsection{Background}

An important issue for the biodiversity debate is the loss of species, for which land-use change is an important driving force (e.g. Pearce and Moran 1994). Land-use change alters ecosystems and thus influences the provision of ecosystem goods and services. The Central Sulawesi rainforests are part of the global Wallacea biodiversity hotspot (Myers et al. 2000), and Sulawesi's moist forests were found to be among the world's most biologically valuable eco-regions (Olson and Dinerstein 1998). The Lore Lindu National Park in Central Sulawesi is one of a few large forest areas left on the island of Sulawesi (Waltert et al. 2004). Therefore, ensuring its integrity is an important contribution to global biodiversity conservation efforts as demanded by the Convention on Biological Diversity. The CBD recognizes that any conservation effort needs to consider the livelihood of people that depend on the use of natural resources. Consequently, it is acknowledged that economic and social development targeting poverty eradication are priority issues in developing countries. Central Sulawesi is one of the poorest provinces in Indonesia (Suryahadi and Su-

\footnotetext{
${ }^{1}$ The use of the male-appointed "he, himself, his etc." is not used as a political omission of women, but rather that it also includes the female perspective. However, to ensure the flow of writing, both genders fall under these terms for the purpose of this paper.
} 
marto 2001). Thus, residents are situated between (global) conservation objectives and (local) development goals. By eliciting preferences for biodiversity held by inhabitants around the Lore Lindu National Park in Central Sulawesi, this study aims at (i) improving the knowledge base of decision-makers for the development of economically informed conservation strategies, and at (ii) providing information regarding the economic behaviour of agents - mainly smallholder farmers (Schwarze 2004).

\subsection{Study area}

The research region is located within the humid tropics about 1 degree south of the equator. It comprises of 7 administrative districts in the Indonesian province of Central Sulawesi. It holds a population of about 130.000 on $7.220 \mathrm{~km}^{2}$ in more than 115 villages. Centred within the study region, the Lore Lindu National Park covers some $2.200 \mathrm{~km}^{2}$ of predominantly mountainous rainforest. A large number of species endemic to Sulawesi, including, for example the mammal anoa (Bupalus sp.), can be found in the National Park area.

The geophysical conditions of the research region vary largely. The altitude ranges from just above sea level to up to 2500 meters, and rainfall varies from 500 to $2500 \mathrm{~mm}$ per year (Maertens 2004). In conjunction with other heterogeneous physical features, such as relief and soil conditions, the prerequisites for agricultural activity are diverse amongst the 7 districts. Driven by migration processes (e.g., Weber 2005), ethnical diversity is high between, and often also within, villages and districts.

\subsection{Attributes}

In a choice experiment, respondents choose between alternatives or 'goods' that alternative with the highest (expected) utility. In the environmental context, the choice offered most commonly consists of a number of "proposed changes" and a "status quo option"; in this case between different management alternatives for the Lore Lindu area and the present situation.

These goods are characterized by a number of attributes. Selection of attributes and attribute levels were guided by an ecosystem service approach (Barkmann et al. subm), and 
facilitated by information gathered in individual and peer-group interviews in various villages of the Lore Lindu area. Additional information and data were obtained from scientists working in the region as well as from literature (e.g. Belsky and Siebert 2003; Keil 2004; Siebert 2002). Four attributes with four levels each were used (table 1): water for irrigation of wetland rice; rattan stock in the forest; ways of cocoa cultivation; population size of anoa. Changes in these attributes were framed as a government development program.

An additional 'cost' attribute was double split-sampled as: (i) a rise in "house and land" tax versus a donation to a village fund affecting every household of the research region; (ii) a monthly versus a yearly payment scheme. A more detailed description of the attributes and underlying assumptions is given in Glenk et al. (2006a,b). To simplify the exposition, attributes are denoted as 'rattan', 'water'. 'cocoa', 'anoa' and 'cost'.

Table 1. Attributes and levels

\begin{tabular}{|c|c|c|c|}
\hline Label & Attribute & Levels & $\begin{array}{l}\text { Ecosystem ser- } \\
\text { vice category }\end{array}$ \\
\hline Rattan & $\begin{array}{l}\text { Availability of rattan (Calamus spp.) } \\
\text { as expressed in distance from village }\end{array}$ & $\begin{array}{c}{[\mathrm{km}]} \\
5,10,15,20\end{array}$ & $\begin{array}{l}\text { provisioning } \\
\text { service }\end{array}$ \\
\hline Water & $\begin{array}{l}\text { availability of irrigation water for wet } \\
\text { rice cultivation as expressed in num- } \\
\text { ber of months with water scarcity }\end{array}$ & $\begin{array}{c}{[\text { No of months }]} \\
0,1,2,3\end{array}$ & $\begin{array}{l}\text { regulating ser- } \\
\text { vice }\end{array}$ \\
\hline Cocoa & $\begin{array}{l}\text { preponderance of cocoa plantations } \\
\text { differing along a shade tree gradient }\end{array}$ & $\begin{array}{c}{[\% \text { under shade }]} \\
5,35,65,95\end{array}$ & $\begin{array}{l}\text { regulating ser- } \\
\text { vices }\end{array}$ \\
\hline Anoa & $\begin{array}{l}\text { Populations of different sizes of the } \\
\text { endemic dwarf buffalo anoa (Bubalus } \\
\text { sp.) }\end{array}$ & $\begin{array}{c}{[\text { No of animals }]} \\
10,180,350^{\S}, 520\end{array}$ & $\begin{array}{l}\text { cultural/ } \\
\text { provisioning } \\
\text { service }\end{array}$ \\
\hline $\begin{array}{l}\text { 'Cost' } \\
\text { attribute }\end{array}$ & $\begin{array}{l}\text { Extra taxes or donation to village } \\
\text { fund }\end{array}$ & $\begin{array}{c}{\left[\begin{array}{lll}1 & 000 & I D R\end{array} \text { year }\right]} \\
0,18,36,54,72\end{array}$ & - \\
\hline
\end{tabular}

$\S$ present state; 1 US $\$ \sim 8500$ IDR at the time of the survey

\subsection{Experimental Design}

For the main-effects experimental design, an orthogonal fraction of 16 out of the $4^{5}$ possible combinations of attribute levels was selected (Louviere et al. 2001), and combined into choice scenarios that consisted of two (generic) alternatives; A and B, and a status-quo 
option presented on choice cards. The choice sets were blocked into 4 versions so that each respondent faced 4 choices.

\subsection{Data collection}

A stratified village sampling frame was adopted. The strata for the sample were ethnicity composition, vicinity to the Lore Lindu National Park and population density of a village. Households were then randomly selected within each village. Details of the sampling are described in Zeller et al. (2002). The choice experiment survey was administered to 301 households in 12 villages of the research region (December 2004 - March 2005). Face-toface interviews were conducted by 6 well-trained local enumerators. To minimize potential interviewer effects, enumerators were randomly assigned to the households.

\section{On the design of the survey instrument}

Among an array of different design issues apart from the experimental design, a few are exemplarily highlighted below. The objective of this selection of topics and examples is to show that there is a large variety of issues that are worth being considered by a researcher in order to customize the questionnaire with respect to the local conditions of the research region. It is explicitly not the aim to provide the reader with a comprehensive guide on how to design a CE questionnaire.

\subsection{Wording}

The influence of wording is widely documented in literature (e.g., Schuman/Presser 1981, Payne 1951). In strange research environments the researcher has to be especially aware of the impact of wording.

The researcher may often develop a first version of the questionnaire in his/her first language (or English), and then translate it into the interview language. Re-translation of the questionnaire by a different translator helps to detect problems in the wording of questions. Further problematic terms and verbalizations may emerge during enumerator training and pre-testing. 
In the Indonesian study, the first language of the respondents was often not Indonesian as the official language (Bahasa Indonesia), but their local language. The sample comprised of respondents from various ethnicities. Every ethnicity, in turn, has its own local language. Furthermore, there are differences in the urban and rural use of Bahasa Indonesia. Additionally, English is merely a secondary language for both the author of this article and his Indonesian assistant. Understandably, special attention had to be paid to the wording during several pre-tests to avoid misunderstandings.

It is my experience that the use of simple language is obligatory (also see chapter 4.3). In order to ensure that respondents would understand the question, a mere word-toword translation is often not sufficient. The wording of the questions has to be adjusted to the customary way of orally presenting questions in the country. In Indonesia, for example, it is often not custom to ask for the key issue immediately. The information contained in a question comprising, for example, of 15 words in English, may have to be subdivided into several sentences and a threefold amount of words. The question text may also include peramblulations that simply prepare the respondent for the actual question itself.

Using simple wording also means avoiding technical and scientific terms wherever possible. Apart from the fact they may complicate matters for the respondents, the comprehension of such terms may not always comply with the scientific definition. When asked about benefits of the forest in pre-tests, most respondents mentioned 'erosion' ('erosi') to be a consequence of deforestation. I was at first surprised about their relatively deep understanding about the ecological impact of deforestation. Many respondents said to have obtained this information from educational meetings held by NGOs or governmental institutions such as the Forestry Department. However, most respondents didn't have a clear association what 'erosi' would actually mean, and provided a more or less vague personal explanation, if any at all. The range of explanations given varied from landslides, events of flooding, rice fields being swept away, to the loss of soil. Certainly, all these are erosive events. The high variation on the perception of 'erosi', however, suggests that this scientific term had to be used with caution in the questionnaire - despite the fact that it seemed to be a familiar term at first glance. As a consequence, it did not make much sense to include an attribute like 'level of erosi' for example, in the choice experiment, or to obtain information regarding their perceived severity of 'erosi'. 
Wording is not only about the 'exact' meaning of the words used, but also about the context in which terms are applied. For example, several questions were included about the incomes of respondents in the socio-demographic part of the questionnaire. The term 'pendapatan', which is the dictionary translation of 'income', was used. Despite the fact that respondents understood this word, enumerators frequently reported that they had to provide respondents with lengthy explanations about the intention of these questions. Even then, some respondents were not able to give meaningful answers. It turned out that the entire concept of income was often perceived differently compared to a 'western' understanding prevalent in most of the so-called developed world. Many respondents, and particularly those who were farmers, defined their income by the degree of being able to fulfil their needs ('kebutuhan'). They often didn't know the net profit of their harvests, and could not report on their (cash) income. Additionally, the cash flow was highly fluctuating over time. Thus, asking directly for their 'pendapatan' didn't make sense. To counter this, a question was included that accounted for the different understanding was included. Respondents were asked about their (perceived) discretionary income based on the perceived degree of fulfilment of primary and secondary needs. ${ }^{2}$

Another example of cultural differences in the use of language was the term 'environment' ('lingkungan'). In the first English version of the questionnaire, the term 'environment' showed up several times in the context of, for example, environmental protection. Based on personal experience, the meaning of 'environmental protection' is currently commonly excluding the explicit human environment in Germany. Rather, it is understood as a description for the protection of the natural environment from negative human impact. It is nowadays usually associated with the maintenance of the natural physical and biological surroundings. In the Indonesian research region, however, the term has not (yet) evolved in that manner. The meaning is closer to the 'original' one, which still comprises the human environment. Thus, 'improving environmental conditions' can also mean to improve the cleanliness, infrastructure or even the administration of a village or region. The Indonesian term for 'nature' ('alam'), in turn, was found to be tendentiously associated with the physical components of nature rather than the living ones. Finally, the use of the term 'alam dan lingkungan hidup' ('nature and living environment') was decided upon in order to make sure that the respondents understood the questions as intended.

\footnotetext{
${ }^{2}$ However, the respondents easily understood what was meant by the term 'sources of income' ('sumber pendapatan').
} 


\subsection{Framing: finding the appropriate context}

"The questionnaire must strive to establish the frame in respondents' minds which is appropriate to the circumstances of the [...] decision being made" (Bennett 1999, p.9). It is a central aspect of the frame to describe the context in which the hypothetical scenarios are presented to the respondent. Without an appropriate context, there is little incentive for respondents to take the choice task seriously. The context should be credible. It should raise interest among the respondents for the key issue described or even create suspense towards the scenarios offered. If the context is misleading or not credible, there is little incentive for respondents to take the choice task seriously. Hence, it is suggested to link the frame to some real-world process.

There may be a large amount of literature or other kinds of information - whether scientific, political or simply prosaic - available on the environmental, cultural and political background of the research region. The researcher possibly even based the initial idea for the research on information from these sources. In so-called developing countries - and even more so in rural areas - the researcher is in most cases an outsider. Naturally, the researcher is tempted to base the frame on the information available, e.g. on development programs proposed or resource management, in order to enhance the credibility of hypothetical scenarios within the CE.

However, the researcher cannot always be sure that this will prove to be a successful strategy. In reality (i.e. in the research region itself) the researcher may actually be confronted with a different, more complex situation. One major reason for that is that - even if all the information is true - literature and particularly scientific literature seldom contains or describes emotions and prejudices that are involved in almost every public discourse.

Therefore, one has to carefully investigate, how people react at the time when they are confronted with the description of a potential CE context. Besides learning a lot about the local circumstances, it will also provide the researcher with insights regarding cultural specifics of the decision-making process. The researcher cannot expect that the locals will differentiate between scientific and political interests or objectives. Rather, they might look for hints that allow them to find out whether the research (and the interviewer) tends to be pro-environment, for example, and perceive the survey instrument as biased. The institu- 
tional background, which may be included in the frame, can serve as an indication. ${ }^{3}$ Green and Tunstall (1992, p. 235) note that “... public confidence in the institutional arrangements for environmental management and service provision may affect response [...] and [that] this effect may be particularly significant where the service provider or environmental manager is the sponsor of the research". Unless not desired explicitly, the CE researcher usually wants the respondents to base their choices only on the trade-offs between the particular attributes and cost. Consequently, the researcher tries to minimize the influence of unobserved attributes associated with, e.g., strategic behaviour resulting from a positive or negative opinion about institutions involved in a development programme, or from task compliance.

The primarily focus of the Indonesian study was to learn more about locals' preferences for ecosystem services. The attributes were framed as the outcome of a governmental development program on a village scale. In order to accentuate neutrality, respondents were repeatedly reminded that this research was not part of any NGO or governmental activity, and that there were no pre-defined interests regarding the future of the National Park and its surroundings. Multi-level development programs that address many different aspects are not unfamiliar to the locals. One example is the CSIADP (Central Sulawesi Integrated Area and Development Program, ANZDEC 1997).

The first intention, however, was to closely link such a program to an actual policy process taking place in the Lore Lindu region in order to enhance credibility. One of the processes that seemed to be particularly well-suited in the first place was a proposed 'zoning' of the National Park area in combination with a buffer-zone management of adjacent areas. Institutions involved in the planning stage included the Forestry Department, the National Park Administration and several local and international NGOs.

After presenting the plans to respondents, they tended to exhaustively and emotionally discuss issues of such property rights, the management of the National Park area, or about the role of the institutions involved. In most cases, the respondents did not focus on the impact of attribute changes on their individual welfare any more. It was not questionable whether people took the informational context seriously. Instead, it appeared to be a serious problem that respondents took it too seriously! This complies with the findings of

\footnotetext{
${ }^{3}$ This aspect is linked to bias from compliance (see section 4.3)
} 
Whittington (1998, p.4) for CVM scenarios: "In developing countries CV researchers often face a situation that many of their counterparts in industrialized countries would at first glance envy: the CV scenarios used in such surveys may not be hypothetical, but all too real". The choices were strongly influenced by the degree of approval or disapproval for details such as the institutional and legal background of the implementation of such a program. Thus, choices were subject to strategic behaviour with respect to property rights and the institutions involved.

Additionally, it was unclear any more if respondents were still able to grasp the hypothetical nature of the context. As a consequence, expectations arose from presenting the research in such a context. As it was by no means possible to be sure that the proposed improvements regarding attribute changes would be delivered in the future, the initial plans to link the frame to this real-world process were also abandoned for ethical reasons.

\subsection{Setup of the questionnaire}

Particularly in so-called developing countries, the array of different problems and pressing issues to improve the living conditions of the population is often large. Hence, the questionnaire should be designed in such a way, which facilitates that respondents can understand why the researcher is focussing only on a limited range of issues. One guiding principle that helps to achieve this is to move from the general to the particular. By recognizing other important issues, the researcher shows an understanding for the life of respondents. Additionally, the researcher can use this information to find out how demanding the $\mathrm{CE}$ issues are when compared to others.

Therefore, respondents were sensitized to potential changes in the future by allowing them to recall past changes in the fields of agriculture, infrastructure and living conditions at the beginning of the questionnaire. Thereafter, they were invited to choose out of six competing development issues ranging from health care and education to environmental conditions those three ones, which they thought should have priority for spending public money. ${ }^{4}$ Besides contributing to establish "a frame of reference for respondents",

\footnotetext{
${ }^{4}$ Averaged over the whole research region, the issues are, with decreasing frequency of being chosen: improving agricultural productivity, improving health care, improving education, access to clean water, improvements in road and electricity infrastructure, and finally protecting nature and the environment. The attributes of the choice experiment only touch on the first and last aspect.
} 
this question also served as a 'warm-up' exercise for the choice task (Bennett and Adamowicz 2001, p.52). Respondents were further sensitized to changes that had occurred in the past and the desired direction of changes for the future by several questions addressing these issues prior to the choice experiment. Finally, they were offered a dominant choice set, which served as a further preparative 'warm-up' exercise. Additionally, it provided useful information about whether respondents sufficiently understood the choice task (cf. Glenk et al. 2006b).

\subsection{Visualisations}

In so-called developing countries, the level of literacy is often quite low in comparison with countries of the so-called developed world. Jae and Delvecchio (2004) found that the presence of a visual decision aid can improve choice by reducing task complexity and facilitating the mediation of information for low-literacy consumers. Hence, the researcher might think of using visualisations to facilitate the understanding of respondents.

In general, visualisations can be a useful tool. However, the researcher should bear in mind that visual information can be in fact more influential than written or oral information, and at the same time, less exact. Therefore, the researcher should ensure that visual information serves as a decision aid and not as a substitute for textual information. It is important to thoroughly investigate what people associate with the pictures presented. This could be achieved by asking people about their associations without providing them with all the other information contained in the questionnaire. The use of photographs may not always prove to be the best option as the attention of respondents can be drawn away from the key information.

In the Indonesian example, the information was first presented orally only. The provision of the information regarding the attributes caused some fatigue and confusion among the respondents, indicating a high cognitive demand. The education of $53 \%$ of the respondents did not transcend elementary school, indicating a rather low level of literacy. Thus, pictures containing the main information were painted in discussion with the local farmers in order to meet their perception. Paintings were preferred to photographs as peo-

ple's interest in the latter mainly consisted of the specific location shown on the picture, and in what differed from the conditions in their village. The paintings allowed for a more 
generalized visualization of the issues (attributes) in which village-specific details become less important. The pictures were collected in a picture book ${ }^{5}$. The pictures and their respective informational background were simultaneously presented to the respondent during the explanation of the attributes. Each attribute was provided a symbol at the beginning of the respective attribute. These symbols also showed up on the choice cards, where they served as an orientation aid.

\subsection{Status-quo}

Alternatives of choice sets, or options, describe changes. Inclusion of a status quo alternative allows for the estimation of economic welfare measures (e.g. Louviere et al. 2001). The status quo ('do-nothing') option is the reference from which the scenarios offered by the researcher to the respondents diverge. "Selection of a base may have an important influence on CM results by affecting the utility of the base option relative to others, and by influencing the framing of outcomes, for example, as gains or losses" (Blamey et al. 1997:14).

There are several alternative ways to include a status quo option. In general, a status-quo alternative may describe the present situation or some predicted future change. Furthermore, the status quo alternative may be defined by the researcher or the respondents. Definition of the status quo by the researcher may often be difficult if the scientific data base on which the definition rests is not very well developed. Furthermore, it may not be conclusive to use a common average status quo option if the present situation varies to a large degree in a research region. On the other hand, a respondent-based definition of the status quo poses the risk of divergence between respondent's perceptions and actual (objective) measures (see Adamowicz et al. 1997).

In the Indonesian study, the status quo was primarily described as the present situation, because future attribute level changes could not easily be predicted and could differ in every village. The respondents were asked directly for the perceived levels of all attributes being most similar to their present situation with the exceptions of 'anoa' and 'cost'. By this means, respondents created their 'individual' status-quo or “...'self-explicated' alter-

\footnotetext{
${ }^{5}$ The Indonesian version of the picture book, the text book and the questionnaire can be found at http://www.storma.de/DPS/pdf/SDP16a.pdf.
} 
native" (Blamey et al. 2001:137). This was done for the following reasons: (i) It addresses local heterogeneity of environmental and socio-demographic conditions better than a 'constant base reference'. Involving respondents in the preparation of the choice experiment and customising the status quo for the individual could suspend some 'disbelief' about the hypothetical nature of the choice task, and the survey, by accounting for this heterogeneity. As an implication relevant for welfare measures, choices were thus consistently framed as gains or losses for each individual. (ii) Prior to the choice task, the respondents had to engage themselves intensively with the present situation regarding the attributes. As a result, it is likely that respondents were more confident about their choices as they became more familiar with the attributes.

\section{Survey preparation and administration}

Details about survey preparation and administration are seldom found in journal articles. However, it is the step in conducting a choice experiment that requires the most attention. In addition, it determines the accuracy of the data obtained to a large degree. It is often difficult - and sometimes impossible - to conduct surveys other than using in-person interviews in so-called developing countries, hence, much depends on the work of enumerators. Researchers - particularly but not exclusively foreign ones - are most often outsiders, who only spend a limited time in the cultural environment of their research region. It is therefore important above all to understand that the enumerators are a direct 'bridge' to the local population, their culture, language and way of life.

The researcher should perceive this as a valuable asset. Metaphorically speaking, the researcher should use and develop this bridge as often as possible, and also encourage the enumerators to intensively provide him with information that he could not possibly know as an outsider. The researcher will only be able to judge whether his data realistically reflects what he intended to find out if this bridge is firmly established. There is a more fundamental understanding needed about a culture in order to be able to develop models and to interpret the results in a truly meaningful way. As an aside, there is more for the foreign researcher to take home than merely data: a deep experience, and maybe even friendship. From the perspective of enumerators, there is also more to obtain than merely money. 
The following sub-sections comprise a number of issues related to enumerators. Despite the fact that reader may perceive many aspects as being taken for granted, my personal experience suggests that this is not always given.

\subsection{Enumerator selection}

In agreeing with Whittington's (2002) suggestions on what makes a good enumerator, he should enjoy people and communications and be at ease in the (local) community. Whittington states this as some of the main criteria for enumerator selection. Flexible time schedules are important if the enumerator is supposed to stay in the field for a longer period of time. I also agree with Whittington (2002) that extroverted people need not necessarily be the best choice. Additional to what is mentioned in this article, I found that, with regards to choice experiments or other challenging techniques, an enumerator's willingness to learn should be a key factor. Choice experiments - similar to CVM - require the enumerator to patiently provide a large amount of information to the respondent, to understand the principle of split samples and willingness to pay. Hence, the importance of present skills and experience should not be exaggerated. Sometimes experience can be counterproductive, if it prevents an enumerator to learn and accept new things.

Neutrality is another very important issue. Hence, in job interviews one should test whether a person is already too pre-occupied concerning the issues at stake in the CE scenario to be objective in the survey. Particularly, the researcher should be careful if applicants are seriously engaged with NGOs or governmental institutions. Unless it is the objective of the research to assess people's perception, attitudes and choices on issues specifically proposed by these agencies, the researcher would always hope that the enumerator treat the respondents' opinions in a neutral and respectful manner.

Finally, the enumerators have to work and often live closely together for a longer period of time. Hence, selection should also be based on how certain characters fit with each other (i.e. human dynamics). Therefore, over-individualistic and extremely selfconfident candidates might not always be a good choice - even if they have excellent interviewing skills. The benefit of constructive work and mutual help within a team will only emerge if the members of a team work and interact well in the field. 
Depending on the customary system in a country, the researcher also may consider setting up an hierarchical structure within the team, mixing juniors and seniors, and creating sub-teams that work together more closely. Senior supervisors may be delegated the responsibility to accompany, control and discuss the work of junior enumerators. They should be particularly reliable and integrative. The researcher may employ excess enumerators with a form of apprenticeship contract and decide on his/her final team after training and pre-tests. In my personal experience, however, it is better to decide quickly upon a team, as tensions and complications may arise with time; a fact that may also discourage the candidates of choice.

\subsection{Enumerator payment}

It is a huge advantage to researchers that enumerators can often be employed at relatively low cost in so-called developing countries. This does not mean, of course, that enumerators should not be reasonably paid according to the standards of the country. Rather than paying per interview, enumerators should be employed on a basic salary. They too need planning reliability for themselves and their families. In many cases, it is not particularly desirable if enumerators compete amongst each other regarding the number of interviews they can conduct per day.

Enumerators should not disturb the daily life and work of respondents particularly in rural areas, thereby leaving only a limited period of time for interviews, e.g. after dinner. The respondent should feel at ease. Therefore, quickly conducting an interview during breaks from work, for example, should be avoided. This also means that the number of interviews one enumerator can conduct per day can be seriously limited. For example, farmers may only have time in the early morning and after dinner. The researcher should investigate this in advance, and set the number of interviews he expects an enumerator to conduct per day to be conservatively low. ${ }^{6}$

For every new village, it will be necessary to consider some sort of 'adjustment' time, both for the team and for the villagers. Enumerators have to relocate to a new place. Village officials need to be informed and appointments have to be made. In informal talk,

\footnotetext{
${ }^{6}$ In the Indonesian study, pre-tests showed that the average length of an interview was $2 \frac{1}{2}$ hours. Often, enumerators had to split the interview in two parts, as they felt that the attention of respondents decreased. I therefore expected enumerators to make one interview per day.
} 
the researcher can collect valuable information about the village and its people, therefore avoiding misunderstandings while collecting sometimes important informal information for the research itself. Based on my own experience, this process requires at least two days. Additionally, it is necessary to sufficiently consider recreation periods for enumerators and to account for unexpected events such as for example marriages or blocked roads due to landslides. After incorporating all these aspects, the researcher may calculate the approximate time needed for the whole survey.

It can prove to be useful to employ the enumerators for slightly longer than for the expected time needed to conduct the training, pre-tests and the survey itself. One may wish to obtain more detailed information on certain aspects, or simply to clarify and discuss the data with the enumerators after the data set is complete. Bonus incentives such as, e.g., a lump-sum payment for successful work, references and work certificates, are useful tools to keep the morale high until the end of the survey and should be included in a working contract, stating exactly the terms of employment specifically.

The descriptions of duties and rights in working contracts should be sufficiently detailed and should also specify when an enumerator can be dismissed. If the duties are set to be very strict at the beginning, the researcher will avoid lengthy discussions about details such as field allowances at a time when the enumerators should be concentrating solely on conducting interviews. Paying in advance is a sign of trust. The researcher must keep in mind that enumerators often have to work under difficult conditions, particularly if they work in a rural environment. Hence, the enumerators should be well-equipped, providing rain protection, a medical kit, torches, clipboards and extra pens, for example.

\subsection{Enumerator training}

"Training [...] enumerators is not a trivial task" (Whittington 2002, p.325). In particular, the researcher has to ensure that the enumerators completely understand the following:

- that an important principle of research is neutrality;

- the purpose of the CE survey;

- the difference between hypotheses and opinion;

- the CE context (frame) and the hypothetical nature of the scenarios; 
- the concept of willingness-to-pay or willingness-to-accept.

If the enumerators do not understand these points, they will not be able to function as a bridge to the respondents. Hence, the researcher will not be able to be sure that the data complies with what he intended. Neutrality means that the researcher and the enumerators should be basically ignorant about the outcome of the survey. Whatever the answer or the choice of the respondent is, it has to be accepted. Hence, the opinion of the researcher or the enumerators must not enter the interview.

However, the researcher often investigates real-world problems and aspires or tries to provide data that can meaningfully support decision-makers in finding efficient and economically sound solutions. The researcher may have prior expectations, which are used to create hypotheses. These need not comply with their personal opinion about what should occur. To provide one example of this: one may have expectations about the outcome of an election (or the Football World Cup) but need not necessarily support the candidate (the team) that is predicted to win. The result of the election (the World Cup), in turn, need not comply with neither the personal opinion of who would be the best candidate (team), nor the prior expectations of who would win.

In a CE study, the respondent is being confronted with alternative scenarios to a certain issue (cf. section 2). It is important to explain the purpose of the frame, the meaning of repeated choice tasks, as well as the importance of reminding respondents emphatically of their budgetry constraints. Usually, there is a lot of new information involved for the enumerators to comprehend. Hence, it is worth spending enough time training on this issue.

It is decisive for the outcome of your CE to ensure that the enumerators understand the importance of delivering exactly the same information to each respondent. Therefore, the researcher should provide them with text versions of all the information they need, including explanations of the choice task. The compressed information about the context, the attributes and the choice task, which can often be found in CE questionnaires, might not be sufficient in a so-called developing country, as people are often not used to language being condensed. 
The work of enumerators and the understanding of respondents is jointly facilitated if the text is broken down into many small and easily understood sentences using very simple language. If the respondent the feeling that he is being told a story, he will (i) listen more closely and (ii) gain confidence in his own decision making capabilities. It is best if the respondent feels himself an interactive part of that story! I point this out as researchers sometimes tend to use condensed language as they use it as communication amongst each other and it is an exact way of expression. However, simple language need not be vague. Actually, the opposite can be true: both enumerators and respondents would be more likely to exactly understand the meaning.

The researcher should not underestimate the effect of respondents perceiving research as something they can generally not understand. Using simple language also helps to mitigate "... undesirable disparities in status between the interviewer and the respondent. It is not good for the respondent to feel that the interviewer is 'smarter' than he/she is, or to get the impression that the interviewer is judging him or her. One does not want respondents trying to impress the interviewers" (Whittington 2002, p.346). In an extreme case, the respondent might perceive the interview as an 'exam' - worrying that he might fail the 'test'. He also might have the feeling that the enumerator has superior knowledge. If he is now able to guess the 'right' answers, he can break free from constraints he has put upon herself (not to disappoint the enumerator, not to fail the 'test') and from perceived pressure from 'outside' (be it the enumerator, the researcher or the community). The respondent may have the "... desire to fulfil the norm of helpfulness (by cooperating in the interview), and also from their desire to maximize their utility (by not appearing stupid in front of the interviewer)" (Mitchell and Carson 1989, p.234). As a consequence, the results might be biased from compliance and social desirability.

A pre-test should be the final highlight of the training. Enumerators with a lack of field experience should first accompany more experienced enumerators or go two by two. The researcher might want to join a number of interviews; and may talk to respondents after the interview to get a better impression of the field performance of the survey instrument. Depending on the performance, repeated pre-tests after revisions can be necessary.

The time of enumerator training is a chance for the researcher to revise the text (as well as the questionnaire in general) together with the enumerators, further enhancing their 
understanding of the whole interview. The researcher can benefit from encouraging the enumerators to be critical about the questionnaire. They usually know more about the culture than the researcher, and they are in contact with the respondents. Apart from improving the quality of the questionnaire, they are more likely to develop a sense of responsibility for their work and the whole project if their considerations are taken seriously.

For further details about interviewer training I refer the reader to Whittington (2002). Apart from the aspects mentioned above, the enumerator training can serve the researcher to learn more about the character of the enumerators. Building a team starts here. Making the enumerators feel at ease by providing lunch or coffee for breaks, for example, will help to establish a good relationship!

\subsection{Administering the survey in the field}

Where possible, enumerators should be assigned to respondents before the survey starts or before the group enters a village. Enumerators have to first meet their respondents and clarify whether respondents agree on doing an interview after a short explanation of the research project, as well as a statement about the anonymity of their data, and the duration of the interview (see also Whittington 2004). If the respondent agrees, an appointment should be made that is convenient in his schedule.

Frequent and regular debriefings with enumerators are a must. Data entry immediately after receiving the questionnaires can also be helpful. Firstly, it motivates the enumerators to be more accurate as missing data or logical discrepancies can be detected early. If the sample comprises a larger region, the enumerators can clarify open issues when they are still close to the respondent. The researcher will become more familiar with his data set, therefore facilitating analysis and interpretation.

The motivation of enumerators can be maintained by, e.g., spending informal time together with them, praising them for good work and progress, considering their private matters such as family festivities or their birthdays, and by giving them the prospect of a farewell party after the survey. It also assists in motivation if the researcher occasionally provides enumerators working in rural areas with goods from the city that are not available 
or difficult to obtain in villages during long field stays such as newspapers or special kinds of food.

\title{
5. Concluding remarks
}

The reader should not misunderstand the collection of design issues discussed and suggestions on survey administration as a 'general' guide on how to conduct choice experiments in so-called developing countries. ${ }^{7}$ Quite to the contrary, it is one objective of this paper to support arguments against the application of 'streamlined' surveys and 'ad hoc' research not only in so-called developing countries - in favour of a careful adjustment of the survey instrument and its administration in the field.

More and more sophisticated software packages and statistical techniques are convenient tools for good survey research, but never a prerequisite. One prerequisite is, in my opinion, experience resulting from intensive observation of the research environment and its subjects, which may need more time than often available under the pressure of the sponsor. The more complex the research environment, the more important it is for the researcher to be sensible for specific traits of the region or culture, and to be aware of the responsibility arising from the research process. Accurate and intensive observation does not only have the potential to improve data quality by being able to optimize the survey instrument, but it also facilitates the interpretation and validity judgement of the results. The following two quotations underline these aspects.

\begin{abstract}
"Mathematical tests of significance, confidence intervals etc. are highly useful concepts $[\ldots]$ All these concepts are, however, of relative merit only. They have a clearly defined meaning only within the narrow confines of the model in question $[\ldots]$ As we dig into the foundation of any economic $[\ldots]$ model we will always find a line of demarcation which we cannot transgress unless we introduce another test of Significance (this time written with a capital S), a test of the applicability of the model itself [...] Something of relevance for this question can, of course, be deduced from mathematical tests properly interpreted, but no such
\end{abstract}

\footnotetext{
${ }^{7}$ Many important aspects of conducting survey research in so-called developing countries are not mentioned in this paper. Hence, I recommend Whittington (2002) on stated preference research, and Casely and Lury (1987) on data collection in general for further reading.
} 
test can ever do anything more than just push the final question one step further back. The final, the highest level of test can never be formulated in mathematical terms" (Frisch 1951, p. 9-10).

“... all too often statistical measures are used as the dominant criteria for acceptance or rejection of a particular model. Analyst judgement about overall model validity should have the ultimate decision power during model development, as a function of the analyst's experience" (Louviere et al. 2001, p. 52).

Being able to employ a rather large number of enumerators at low cost, compared to wages in the so-called industrialised world, is a big advantage for conducting surveys in so-called developing countries. It would not only be bad practice with respect to the validity and accuracy of the data, but it would also be an inefficient use of resources if this leads to the perception of enumerators as - using an admittedly exaggerated expression - 'data collection machines'.

The researcher can only benefit from putting much effort into the selection and training of the enumerators, and from building a fair and good relationship during the survey period. As an important aside, this should not be considered to be a marginal issue (or one only for the ends of the researchers themselves), if efforts of 'capacity building' in socalled developing countries are really taken seriously. 


\section{References}

Adamowicz, W., Swait, J., Boxall, P., Louviere, J. and M. Williams 1997. Perceptions versus Objective Measures of Environmental Quality in Combined Revealed and Stated Preference Models of Environmental Valuation. Journal of Environmental Economics and Management 32: $65-84$.

ANZDEC 1997. Central Sulawesi Integrated Area Development and Conservation Project. TA NO 2518 - INO. Draft Final Report - Annex (Working Papers). Indonesia.

Barkmann, J., Dietrich, N., de Vries, K., Gerold, G., Glenk, K., Keil, A., Faust, H., Leemhuis, C. and R. Marggraf submitted. Confronting unfamiliarity with ecosystem functions: The case for an ecosystem service approach to environmental valuation with stated preference methods. Submitted to Ecological Economics.

Bennett, J. 1999. Some Fundamentals of Environmental Choice Modelling. Research Report No.11. Canberra, Australia: School of Economics and Management, The University of New South Wales.

Bennett, J. and W. Adamowicz 2001. Some Fundamentals of Environmental Choice Modelling. In J. Bennett and R. Blamey (eds): The Choice Modelling Approach to Environmental Valuation. Cheltenham, UK: Edward Elgar.

Belsky, J. and F. Siebert 2003. Cultivating Cocoa: Implications of sun-grown cocoa on local food security and environmental sustainability. Agriculture and Human Values 20: 277-285.

Blamey, R., Rolfe, J., Bennett, J. and M. Morrison 1997. Environmental Choice Modelling: Issues and Qualitative Insights. Research Report No. 4. Canberra, Australia: School of Economics and Management, The University of New South Wales.

Blamey, R., Louviere, J. and J. Bennett 2001. Choice Set Design. In J. Bennett and R. Blamey (eds.): The Choice Modelling Approach to Environmental Valuation. Cheltenham, UK: Edward Elgar.

Casely, D.J. and D.A. Lury 1981. Data Collection in Developing Countries. Clarendon Press: Oxford.

Colombo, S., Calatrava-Requena, J. and N. Hanley 2005. Designing Policy for Reducing the Offfarm Effects of Soil Erosion Using Choice Experiments. Journal of Agricultural Economics, 56(1): 81-95.

Frisch, R. 1951. Some personal reminiscences of a great man. In Harris, S.E. (ed.): Schumpeter, Social Scientist. Cambridge, Mass: MIT Press.

Glenk, K., Barkmann, J. and R. Marggraf 2006a. Unveiling regional preferences for biological diversity in Central Sulawesi: a choice experiment approach. STORMA Discussion Paper 
Series No 16. Bogor, Indonesia: Universities of Göttingen and Kassel, Germany and the Institut Pertanian Bogor and Universitas Tadulako, Indonesia.

Glenk, K., Barkmann, J. and R. Marggraf 2006b. Locally Perceived Values of Biological Diversity in Indonesia - a Choice Experiment Approach. Paper presented at the $8^{\text {th }}$ Annual BIOECON Conference on Economic Analysis of Ecology and Biodiversity, Cambridge, UK.

Green, C. and S. Tunstall 1992. The Recreational and Amenity Value of River corridors. In P. Boon, P. Calow and G. Petts (eds.): River Conservation and Management. Chichester: John Wiley.

Hanley N., Mourato, S. and R. Wright 2001. Choice modelling approaches: a superior alternative for environmental valuation? Journal of Economic Surveys 15(3): 1-25.

Jae, H. and D. del Vecchio 2004. Decision Making by Low-Literacy Consumers in the Presence of Point-of-Purchase Information. The Journal of Consumer Affairs, 38(2): 342-54.

Keil, A. 2004. The socio-economic impact of ENSO-related drought on farm households in Central Sulawesi, Indonesia. Ph.D. thesis, Institute of Rural Development, University of Goettingen.

Louviere, J., Hensher, D. and J. Swait 2001. Stated Choice Methods - Analysis and Application. Cambridge, UK: Cambridge University Press.

Maertens, M. 2004. Economic Modelling of Agricultural Land-Use Patterns in Forest Frontier Areas. Ph.D. thesis, Institute of Rural Development, University of Goettingen.

Mitchell, R.C. and R.T. Carson 1989. Using Surveys to Value Public Goods: The Contingent Valuation Method. Baltimore: John Hopkins University Press.

Morrison M., Blamey, R. Bennett, J. and J. Louviere 1996. A Comparism of Stated Preference Techniques for Estimating Environmental Values. Research Report No.1. Canberra, Australia: School of Economics and Management. The University of New South Wales.

Myers, N., Russel, A., Mittermeier, R., Mittermeier, C., da Fonseca, G. and J. Kent 2000. Biodiversity hotspots for conservation priorities. Nature 403:853-58.

Olson, D.M. and E. Dinerstein 1998. The Global 200: a representation approach to conserving the Earth's most biologically valuable ecoregions. Conservation Biology 12: 502.

Payne, S. 1951. The Art of Asking Questions. Princeton: Princeton University Press.

Pearce, D.W. and D. Moran 1994. The economic Value of Biodiversity. IUCN - The World Conservation Union. London: Earthscan Publications.

Schuman, H., and S. Presser 1981. Questions and Answers in Attitude Surveys: Experiments on Question Form, Wording, and Content. New York: Academic Press.

Schwarze, S. 2004. Determinants of Income Generating Activities of Rural Households, A Quantitative Study in the Vicinity of the Lore-Lindu National Park in Central Sulawesi/Indonesia. Ph.D. thesis, Institute of rural Development, University of Goettingen. 
Siebert, F.S. 2002. From shade to sun-grown perennial crops in Sulawesi, Indonesia: implications for biodiversity conservation and soil fertility. Biodiversity and Conservation 11: 1889-1902.

Suryahadi, A. and S. Sumarto 2001. The chronic poor, the transient poor, and the vulnerable in Indonesia before and after the crisis. SMERU working paper. Jakarta: SMERU Research Institute.

Waltert, M., Mardiastuti, A. and M. Mühlenberg 2004. Effects of land use on bird species richness in Sulawesi, Indonesia. Conservation Biology 18: 1339-46.

Weber, R. 2005. Kulturlandschaftswandel während des 20. Jh. in Zentralsulawesi - eine historischgeographische Analyse der Lore-Lindu-Bergregenwaldregion. Ph.D. thesis, Institute of Geography, University of Goettingen.

Whittington, D. 1998. Administering contingent valuation surveys in developing countries. World Development 26(1): 21-30.

Whittington, D. 2002. Improving the performance of contingent valuation studies in develop-ing countries. Environmental and resource economics 22 (1-2): 323-367.

Whittington, D. 2004. Ethical Issues with Contingent Valuation Surveys in Developing Coun-tries: A Note on Informed Consent and other Concerns. Environmental and Resources Economics 28 (4): 507-515.

Zeller, M., Schwarze, S. and T. van Rheenen, 2002. Statistical Sampling Frame and Methods Used for the Selection of Villages and Households in the Scope of the Research Programme on Stability of Rainforest Margins in Indonesia (STORMA). STORMA Discussion Paper Series No. 1, Universities of Göttingen and Kassel, Germany and the Institut Pertanian Bogor and Universitas Tadulako, Indonesia. 


\section{CHAPTER 3}

Locally Perceived Values of Biological Diversity in Indonesia: a Choice Experiment Approach 


\section{Introduction}

The Convention on Biological Diversity (CBD) stresses the importance to protect and to use biodiversity in a sustainable manner. In particular, the CBD Ecosystem Approach summons the contracting parties to adopt economically and socially sound conservation strategies. The Central Sulawesi, Indonesia, rainforests are part of the global Wallacea biodiversity hotspot (Myers et al. 2000), and Sulawesi's moist forests are among the world's most biologically valuable ecoregions (Olson and Dinerstein 1998). Because of their exceptional contribution to global biological diversity, the conservation of Central Sulawesi rainforests is an important case for an application of conservation strategies in line with the CBD Ecosystem Approach. Economically, Central Sulawesi is one of the poorest provinces in Indonesia (Suryahadi and Sumarto 2001). Local economic agents find themselves situated between globally defined conservation objectives and more locally perceived often pressing - needs for development. This fact requires that the socio-economic impacts of any conservation measure on the local population be considered carefully. Thus, it is the overall objective of this study to generate knowledge that facilitates the design of economically informed and socio-economically sensitive conservation strategies for this ecoregion.

One of the most severe obstacles to the design and implementation of economically sound conservation strategies is the lack of knowledge on the economic value of nonmarket benefits generated by tropical forest ecosystems and the agricultural land use systems that replace them (cf. Balmford et al. 2002, Bawa 2004). This study contributes to filling this gap by making use of a choice experiment (CE) for an estimation of locally perceived values of biodiversity of inhabitants living around the Lore Lindu National Park in Central Sulawesi. Local residents are mainly smallholder farmers (Schwarze 2004). Rather than investigating different levels of biodiversity or ecosystem services holistically, we collected data on the trade-offs made by individual respondents between a number of different ecosystem goods and services.

Developed in transport and marketing research, the CE became increasingly popular in environmental valuation of non-market goods in the recent years (Adamowicz et al. 1994, Bennet and Blamey 2001). Choice modelling is a stated preference (SP) technique that allows for simultaneous elicitations of multi-attribute benefits of both use and non-use 
value of policy scenarios (Bateman et al. 2002, Adamowicz et al. 1994). The application of SP techniques in general is not without dispute when applied to functional ecosystem values, such as the provisioning of water, or flooding or erosion control (e.g., Nunes and Bergh 2001, Gatto and de Leo 2001). In particular, the unfamiliarity of respondents with the scientific description of the ecosystem functions has prompted much critique. Nonexpert respondents usually lack sufficient insight into the scientific background of ecosystem functions in order to make meaningful preference statements. Because of the complexity of the ecological subject matter, it is usually not possible to improve the situation sufficiently by including more detailed ecological explanations in the valuation interviews. In line with literature suggestions to focus valuation efforts on the actual benefit stream generated by ecosystem functions (Freeman III 1998, Carson et al. 1999), we developed and applied an explicit ecosystem services approach in this study. This approach reduces unfamiliarity problems effectively (for details, see Barkmann et al., subm.).

Despite widespread applications of the CE in so-called industrialized countries, applications with respondents from so-called developing countries are still comparably rare, particularly in rural areas. For metropolitan areas they are often applied to transport and sanitation issues (e.g. Abou-Ali and Carlsson 2004, Pham and Tran 2005). Seenprachawong (2003) in Thailand and Othman et al. (2004) in Malaysia both applied a CE to obtain non-use values of coastal respectively mangrove wetland ecosystems. To our knowledge, this is the first study using a CE for the valuation of non-market benefits of specific ecosystem goods and services obtained by a tropical rain forest.

After describing some features of the research region (section 2), a brief introduction into the choice experiment method (section 3 ) is followed by design issues (section 4 ) - concerning the attributes, the framing and the experimental design used in this study. Thereafter, model results are shown (section 5) and discussed. Finally, we conduct a welfare analysis including implicit prices and an exemplarily scenario analysis (section 6). The paper ends with some concluding remarks (section 7). 


\section{The research area: around the Lore Lindu National Park}

The research region is located in the humid tropics about 1 degree south of the equator. It comprises four main areas divided into seven administrative districts in the province of Central Sulawesi, Indonesia. In more than 115 villages, the project area holds a population of about 130,000 on $7,220 \mathrm{~km}^{2}$. Lore Lindu National Park is centred within the study region and covers some $2,200 \mathrm{~km}^{2}$, which is one of the few large forest areas left on Sulawesi. A large number of species endemic to Sulawesi, including, e.g., the mammals anoa (Bubalus sp.), babirussa (Babyrousa babirussa), and many endemic bird species can be found in the National Park area (Waltert et al. 2004).

The geophysical conditions of the research region vary to a large extend. Accordingly, a large variation of land use patterns can be found (Schwarze 2004). In the course of the 'cocoa boom' in Indonesia (Akiyama and Nishio 1996), cocoa became the dominant cash crop in the research region. Based household data surveys, cocoa and wetland rice together account for $57 \%$ of the net crop income (Schwarze 2004). Concerning forest products, collection of fuel wood is widespread for private consumption, while rattan is the most important marketed forest product (Schwarze 2004).

\section{The choice experiment method}

In a CE, consumers state their preference by (repeated) choice among different alternatives or goods following an experimental plan. Having foundations in Lancastarian consumer theory (Lancaster 1966, 1991), the goods are being transformed into objective characteristics (attributes) from which the consumer is assumed to derive utility. In environmental choice modelling, the alternatives are often described as different development or policy options (Bennett and Adamowicz 2001). Another main pillar of choice modelling is random utility theory (RUT) (e.g Thurstone 1927, McFadden 1973, Manski 1977) ${ }^{1}$. Utility is partitioned into a deterministic, systematic component or 'representative utility' and a random part of utility "reflecting [the] unobserved individual idiosyncrasies of taste" (Louviere et al. 2001:38):

\footnotetext{
${ }^{1}$ Further theoretical input was obtained from research of informational processing in judgement and decision-making in psychology (e.g. Luce 1959, Slovic and Liechtenstein 1971).
} 


$$
\mathrm{U}_{\mathrm{ij}}=\mathrm{V}_{\mathrm{ij}}\left(\mathrm{X}_{\mathrm{ij}}, \mathrm{S}_{\mathrm{i}}\right)+\varepsilon_{\mathrm{ij}} \forall \mathrm{j} \in \mathrm{C}_{\mathrm{i}}
$$

where $U_{i j}$ is the utility an individual $i$ is assumed to obtain from of alternative $j$ in choice set $\mathrm{C}_{\mathrm{i}} \cdot \mathrm{V}_{\mathrm{ij}}$ is the deterministic part that is held to be a function of the attributes of alternatives $X_{i j}$, which is a vector of attributes as perceived by individual $i$ for alternative $j$ and characteristics of the individual $\mathrm{S}_{\mathrm{i}} . \varepsilon_{\mathrm{ij}}$ is the random term. As the analyst is unable to measure $\varepsilon_{\mathrm{ij}}, \mathrm{s} /$ he cannot determine exactly why an individual chooses an alternative $\mathrm{j}$ out of a set of competing options $\mathrm{C}_{\mathrm{i}} \forall \mathrm{j}, \mathrm{k} \in \mathrm{C}_{\mathrm{i}}$ and $\mathrm{i}=1$,... I. However, the systematic component $\mathrm{V}_{\mathrm{ij}}$ still allows him to make probabilistic statements about the choice. This leads to equation (2) and is called a Random Utility Model (RUM). Assuming utility maximization, the probability that alternative $\mathrm{j}$ is chosen by individual $\mathrm{i}$ over any alternative $\mathrm{k}$ out of choice set $\mathrm{C}_{\mathrm{i}}$ can be expressed as:

$$
\begin{aligned}
\mathrm{P}\left(\mathrm{j} \mid \mathrm{C}_{\mathrm{i}}\right)=\mathrm{P}\left(\mathrm{U}_{\mathrm{ij}}>\mathrm{U}_{\mathrm{ik}}\right) & =\mathrm{P}\left[\left(\mathrm{V}_{\mathrm{ij}}+\varepsilon_{\mathrm{ijj}}\right)>\left(\mathrm{V}_{\mathrm{ik}}+\varepsilon_{\mathrm{ik}}\right)\right] \forall \mathrm{j}, \mathrm{k} \in \mathrm{C}_{\mathrm{i}} \text { and } \mathrm{j} \neq \mathrm{k} \neq 0 \\
& =\mathrm{P}\left[\left(\mathrm{V}_{\mathrm{ij}}-\mathrm{V}_{\mathrm{ik}}\right)>\left(\varepsilon_{\mathrm{ij}}-\varepsilon_{\mathrm{ik}}\right)\right] \forall \mathrm{j}, \mathrm{k} \in \mathrm{C}_{\mathrm{i}} \text { and } \mathrm{j} \neq \mathrm{k} \neq 0
\end{aligned}
$$

In order to be able to estimate the probabilities of equation $(2 \mathrm{a} / \mathrm{b})$, assumptions have to be made about the nature of the random error term. The majority of discrete choice models assumes that the random term is independently and identically distributed (IID), and related to the choice probability with a Type I extreme-value (Gumbel, Weibull, doubleexponential) distribution (with zero mean and a variance of $\mu^{2}$ ). As a consequence of the IID assumption, the alternatives have to be independent from irrelevant alternatives (IIA). I.e., the ratio of probabilities of choosing alternative $j$ over $k$ out of a choice set $C_{i}$ remains unaffected of the presence or absence of any other alternative. All assumptions are given now for the conditional or multinomial logit model (MNL, McFadden 1973):

$$
P\left(j \mid C_{i}\right)=\frac{\exp ^{\mu V_{j i}}}{\sum_{k \in C_{i}} \exp ^{\mu V_{k i}}}
$$

where $\mu$ is the scale parameter usually set to 1 (constant error variances) and inversely proportional to the standard deviation of the error terms (Louviere et al. 2001). $\mathrm{V}_{\mathrm{ij}}$ is assumed to be linear and additive in parameters: 


$$
V_{i j}=\alpha A S C_{j}+\sum \beta_{n} f\left(X_{n}\right)
$$

where $X_{n}$ is the attribute level of attribute $n$ of the $j^{\text {th }}$ alternative and $\beta_{n}$ is the parameter value associated with attribute $\mathrm{n} . \mathrm{ASC}_{\mathrm{j}}$ is short for alternative specific constants that equal 1 for alternative $\mathrm{j}$ (otherwise: 0 ), and can be included for $\mathrm{j}-1$ alternatives. If the alternatives are generic (unspecific, i.e. unlabelled), the ASCs are equal. Socio-economic variables can be interacted either with the ASC and/or the attributes. "It is the role of the ASCs to take up any variation in choices that cannot be explained by either the attributes or the socioeconomic variables" (Bennett and Adamowicz 2001:60). By using a statistical estimation technique such as 'maximum likelihood estimation' (MLE) as available in statistical software packages, e.g. LIMDEP (Green 2003), estimates for the coefficients associated with the attributes can be obtained.

If the variance of unobserved components of the utility function or scale is different among (subsets of) alternatives, e.g. due to heterogeneous preferences, the IID and IIA assumptions do not hold. One test frequently applied in literature is a Hausman type test (Hausman and McFadden 1984). If IIA is found to be violated, the MNL should not be used and models such as the Nested Logit (NL) (Louviere et al. 2001) or Random Parameters Logit (RPL) (Train 1998) should be considered that relax these assumptions (Louviere et al. 2001). Accounting for preference heterogeneity by interacting socioeconomic and/or attitudinal attributes may help to mitigate IIA violations (Train 1986).

As the parameters $\beta_{\mathrm{n}}$ in $\mathrm{V}_{\mathrm{j}}$ are confounded with the scale parameter $\mu$ and thus are not separable, they cannot be interpreted in absolute terms. The estimated probabilities using equation (3) can, consequently, merely serve as an indication for the relative utility an individual obtains from choosing a particular alternative from a choice set. However, the scale parameters are cancelled out if marginal rates of substitution between any pair of attributes a and $b$ are estimated. If one of the attributes (characteristics) reflects 'cost', the trade-offs are called implicit prices. For any attribute n, they can be calculated by:

$$
\operatorname{Implicit} \operatorname{price}(n)=-\left(\frac{\mu \beta_{n}}{\mu \beta_{\cos t}}\right)=-\left(\frac{\beta_{n}}{\beta_{\cos t}}\right)
$$


where $\beta_{\mathrm{n}}$ is the coefficient of attribute $\mathrm{n}$, and $\beta_{\text {cost }}$ is the coefficient of the 'cost' attribute. The implicit prices reflect the marginal willingness to pay (MWTP) for a marginal change in a single attribute on a ceteris paribus basis (Bennett and Adamowicz 2001).

If a base option is included, values of Hicksian compensating variation for a change in the state of the world from $Z_{0}$ to $Z_{1}$ can be estimated as:

$$
C V\left(Z_{0} \rightarrow Z_{1}\right)=-\frac{1}{\beta_{\cos t}}\left(V_{0}-V_{1}\right)
$$

In equation (6), $\mathrm{V}_{0}$ is the deterministic part of utility for an unchanged 'State of the World' $\mathrm{Z}_{0}$, while $\mathrm{V}_{1}$ describes changed conditions in $\mathrm{Z}_{1}$, both for multiple attributes. $\mathrm{V}_{0}$ and $\mathrm{V}_{1}$ can be calculated using equation 4 and the parameters of the MNL model, thus canceling out the scale parameter.

\section{The choice experiment design}

“... the characteristics model of consumer behaviour is designed to simplify reality. Fitting it into any given situation ultimately involves some art as well as some science” (Lancaster 1991: 67).

The design of choice experiments includes decisions about the nature of the stimuli of choice. These decisions are concerned with (i) the attributes of an alternative and their levels, (ii) the nature of the 'cost' attribute, (iii) the situation in which the alternatives are presented to the respondent ('framing'), (iv) the definition of a potential base (reference) option and (iv) the experimental plan that allows for statistical estimation of the attributes' coefficients. Besides the well-known issues as outlined in e.g. Bennett and Blamey (2001) or Bateman et al. (2002), we had to overcome several challenges and difficulties concerning (i) to (iv) arising from a complex setting of the study in a rural area of a so-called developing country. Therefore, despite lacking space for a description of all details concerning the design, several issues are reported more exhaustively. 


\subsection{Attribute selection}

Out of the universe of potential "characteristics" of biological diversity and ecosystem services from which people around the Lore Lindu National Park derive utility, which are to be selected? As a way to guide the decisions, a (multidimensional) space can be created, which is demarcated by (i) the objectives of the analyst and the research question, (ii) constraints imposed by the respondents (relevance, cognitive burden/ task complexity), (iii) the social context (e.g. problems concerning strategic behaviour) as well as (iv) specific features of the 'natural' environment of the research area.

The selection of relevant attributes and levels was based on information gathered in semi-structured individual and 'peer-group' interviews in various villages of the research region. Following Blamey et al. (1997), we screened all attributes suggested from a demand perspective. Furthermore, information and data obtained by experts as well as from literature (e.g. Belsky and Siebert 2003, Siebert 2002, Keil 2004) were incorporated for further adjustment. The attributes chosen and the respective levels are listed in Table 1 and are described in detail below.

In pre-tests, we used 5 attributes including 'cost' in two choice scenarios and a status quo alternative. First presented orally only, the bulk of information on attributes caused some fatigue and confusion among a number of respondents.. The education of 53 $\%$ of the respondents did not transcend elementary school, indicating a rather low level of literacy. Jae and Delvecchio (2004) found that the presence of a visual decision aid can improve choice by reducing task complexity and by facilitating the mediation of information to low-literacy consumers. Paintings containing the main information were developed in cooperation with local farmers in order to meet their perception. ${ }^{2}$ The pictures and their respective informational background were simultaneously presented to the respondent during the explanation of the attributes. This way of presenting the context and attributespecific information proved to be very successful in increasing the understanding of the choice task as well as raising interest and attention. Visualizations were also included in

\footnotetext{
${ }^{2}$ Painting was preferred to the use of photographs as people's interest in the latter very often consisted of the specific location shown on the picture, and in deviations from the conditions in their village. Contrarily, the visualization was also aimed at a generalization of the issues (attributes) in order to make sure that village-specific details (all of which could not possibly be addressed) became less important, while the key information was pointed out.
} 
the choice cards ${ }^{3}$. Overall, by using this tool, pre-tests suggested that respondents were able to cope with 5 attributes. For final refinement of the questionnaire, a pilot study was conducted $(\mathrm{n}=96)$.

Rattan (Calamus spp.) is the most important marketed forest product in the region. It serves as a secondary income source for locals, particularly for poorer residents (Maertens 2004, Schwarze 2004). If harvests fail, e.g. caused by droughts or flooding, rattan serves as an important income alternative (Vedeld et al. 2004) - probably also for less poor residents. Thus rattan availability has an 'option' or insurance value component for respondents who are usually not involved in rattan extraction. Previous research in the region (STORMA 2003) showed that the encounter distance from the forest edge to harvesting locations increased from $4.4 \mathrm{~km}$ on average in 1990 to $14.5 \mathrm{~km}$ in 2001, indicating an overuse of rattan resources. While market demand is likely to remain strong (Vantomme 2003), the decline of commercially valuable large-diameter and long canes in the Lore Lindu region is likely to continue (Siebert 2001, Siebert 2004). Siebert (2004: 429) reports that "The declining availability of rattan cane was evident to collectors, who responded by [...] collecting in more distant areas, and shifting collection to less valuable rattan species." In practical terms, increased encounter distances mean that human disturbance extends deeper into the primary forest as the biggest share of rattan in the research region is collected in Lore Lindu National Park. The rattan attribute was operationalized by the encounter distance to the nearest extracting location. We expect a negative sign indicating a utility gain for decreasing distance.

Sufficient water for irrigation is essential for the production of wetland rice, the region's main food crop. There is anecdotic evidence prompting many locals to belief that deforestation on the hillsides leads to water shortages in the valleys in the dry months of the year. Particularly this appears to be the case when the water originates from small watersheds in combination with simple irrigation techniques (own data ${ }^{4}$, Burkard 2002). Keil (2004) showed that perceptions of the seasonal changes of precipitation and water availability fit quite well with measured data. Thus, an ecosystem level attribute on the provision of irrigation water was created. Although negative impacts of land conversion at the hillsides on water availability were mentioned to respondents, the levels of the water avail-

\footnotetext{
${ }^{3}$ cf. www.storma.de/DPS/pdf/SDP16b.pdf

${ }^{4}$ E.g. in the village of Sintuwu, one of the streams providing water for irrigation dried up, in another the water declined to such an extend that irrigation is hardly possible any more.
} 
ability attribute make no reference to forest cover. Instead, they were simply described as months with water shortage for irrigation purposes in an average year. We expect a negative sign of the water attribute coefficient related to a utility gain associated with improved availability of water for irrigation. More details on the design of this specific attribute in accordance with the ecosystem services approach to environmental valuation with stated preference methods can be found in Barkmann et al. (subm.)

Table 1. Attributes and levels

\begin{tabular}{|c|c|c|c|c|}
\hline & Attribute & Levels & $\begin{array}{l}\text { Ecosystem } \\
\text { service cate- } \\
\text { gory }\end{array}$ & $\begin{array}{l}\text { Value type } \\
\text { (TEV) }\end{array}$ \\
\hline Rattan & $\begin{array}{l}\text { availability of rattan (Cala- } \\
\text { mus spp.) as expressed in } \\
\text { distance from village }\end{array}$ & $\begin{array}{c}{[\mathrm{km}]} \\
5,10,15,20\end{array}$ & $\begin{array}{l}\text { provisioning } \\
\text { service }\end{array}$ & $\begin{array}{l}\text { Direct use/ } \\
\text { Option value }\end{array}$ \\
\hline Water & $\begin{array}{l}\text { availability of irrigation wa- } \\
\text { ter for wet rice cultivation } \\
\text { as expressed in number of } \\
\text { months with water scarcity }\end{array}$ & $\begin{array}{c}{[\text { No of months }]} \\
0,1,2,3\end{array}$ & $\begin{array}{l}\text { regulating ser- } \\
\text { vice }\end{array}$ & $\begin{array}{l}\text { Indirect use } \\
\text { value }\end{array}$ \\
\hline Cocoa & $\begin{array}{l}\text { preponderance of cocoa } \\
\text { plantations differing along a } \\
\text { shade tree gradient }\end{array}$ & $\begin{array}{c}{[\% \text { under shade }]} \\
5,35,65,95\end{array}$ & $\begin{array}{l}\text { regulating ser- } \\
\text { vices }\end{array}$ & $\begin{array}{l}\text { Indirect use / } \\
\text { Option value }\end{array}$ \\
\hline Anoa & $\begin{array}{l}\text { populations of different } \\
\text { sizes of the endemic dwarf } \\
\text { buffalo anoa (Bubalus de- } \\
\text { pressicornis/quarlesi) }\end{array}$ & $\begin{array}{c}{[\text { No of animals }]} \\
10,180,350^{\S}, 520\end{array}$ & $\begin{array}{l}\text { cultural/ } \\
\text { provisioning } \\
\text { service }\end{array}$ & $\begin{array}{c}\text { Existence/ } \\
\text { direct use value }\end{array}$ \\
\hline $\begin{array}{l}\text { 'Cost' } \\
\text { attribute }\end{array}$ & $\begin{array}{l}\text { extra taxes or donation to } \\
\text { village fund }\end{array}$ & $\begin{array}{c}{[1,000 \text { IDR per year }]} \\
0,18,36,54,72\end{array}$ & - & - \\
\hline
\end{tabular}

${ }^{\S}$ present state; 1 US $\$ \sim 8,500$ IDR at the time of the survey

Cocoa (Theobroma sp.) is the dominant cash crop. Increasingly, the production is intensified, resulting in monocultures with no or merely low levels of planted shade trees (e.g. Gliricidia sepium). Despite higher mean yields, intensification to sun-grown cocoa leads to higher agronomic and socioeconomic risks, e.g. soil degradation and negative impacts on local food security (Belsky and Siebert 2003). Shade-grown cocoa farming can provide habitat for a wide range of native species, thus contributing to biodiversity conservation, while soil productivity may be retained (Siebert 2002). Thus, this attribute reflects tradeoffs between (short-term) economic goals and (long-term) biodiversity conservation objectives by mapping a shade tree gradient (5-35-65-95 \% under shade) for preponderance of cocoa plantations ranging from full-sun grown cocoa on one side, and cocoa cultivated beneath primary or secondary forest vegetation on the other side. Due to an observed ten- 
dency for intensification, we expected a negative sign for the cocoa coefficient although advantages such as improved pest control were pointed out to respondents.

The Sulawesi region is an important centre for species endemism, and the Lore Lindu National Park harbours many of Sulawesi's endemic mammals and birds (Waltert et al. 2004, Whitten et al. 1987). However, large forest clearings inside the National Park show that the forest frontier in the research region is by no means secured (Weber 2005). To find out how conservation objectives are supported by the local population around the National Park, different population sizes of the endemic dwarf-buffalo anoa (Bupalus depressicornis, B. quarlesi) were included as an attribute in the choice experiment. Population sizes in the research region are in decline (STORMA 2003, Burton et al. 2005). Burton et al. (2005) identified the Lore Lindu National Park as one of the areas on which to focus conservation efforts of this animal. Individual interviews showed that anoa was the most widely known forest species. As a result of discussions with locals and experts ${ }^{5}$, the present state was estimated as 350 individuals living in the forests of the Lore Lindu region. Differing population levels of anoa represent different TEV value categories. One is 'existence' value, e.g. the "... concern to protect [...] although he or she has never seen one and is never likely to ..." (Pearce and Moran 1994:12). Direct use value (e.g. hunting), bequest value (see Burton et al. 2005), or even fear of being injured by the animal may also influence choices. With the exception of fear, all other considerations point to the hypothesis that anoa is perceived as an asset leading to a positive sign for the anoa attribute coefficient.

\subsection{Framing}

"The questionnaire must strive to establish the frame in respondents' minds which is appropriate to the circumstances of the [...] decision being made" (Bennett and Adamowicz 2001: 51). This step is called 'framing'. An appropriate context must be developed, in which the hypothetical scenarios are presented to the respondent. If the context is misleading or not credible, there is little incentive for respondents to take the choice task seriously.

In the study, the 5 attributes were defined as results of alternative government development programs on a village scale. Multi-level development programs that address

\footnotetext{
${ }^{5}$ The authors would like to thank TNC Palu and Muhammad Yasin Paada from UNTAD.
} 
many different aspects are not unfamiliar to the locals. One example is the 'Central Sulawesi Integrated Area and Development Program' (ANZDEC 1997). Before making their choices, respondents were reminded emphatically of their budget constraints in order to reduce bias resulting from strategic behaviour or interviewer compliance.

\subsection{The 'cost' attribute}

The 'cost' attribute was double split-sampled. One half of respondents were confronted with a rise in "house- and land" tax (Pajak Bumi Bangunan $(P B B)$ ), the other half with a donation to a village funds (Iuran dana pembangunan desa) affecting every household of the research region. Both payment vehicles are familiar and widely accepted within the region. The second split sample involved monthly versus yearly payments.

Exploratory studies have shown that all people are familiar with monetary issues even in remote areas, though some were hardly able to pay some of the higher amounts offered. Therefore, following Whittington (1998), the use and interpretation of stated preference values will be bounded by respondents' ability to pay and by their willingness to pay. As the wealth status of the inhabitants differed to a large extend, it proved to be a challenging task to derive an appropriate price range for the cost attribute. While a few households live in concrete houses, have access to satellite television and sometimes even own a car, others share a wooden hut without electricity. According to Whittington (1998), the highest price should be rejected by $90 \%-95 \%$ of the respondents in closed-ended CVM studies. The levels were derived following this rule of thumb by using different 'prices' in pre-tests based on initial information obtained by a payment-ladder approach (cf. Bateman et al. 2002). Offering the highest price to the poor could embarrass them, and could make "the interviewers look insensitive and/or uninformed" (Whittington 1998: 8). Hence, the range of 'price' levels was cut at the high end, accepting an underestimation of WTP by ignoring the higher WTP of a low percentage of rather well-situated people. WTP values are calculated on a one years' basis.

\subsection{Experimental design and status quo}

Out of the $4^{5}$ possible combinations of attribute levels, an orthogonal fraction of 16 was selected by means of experimental design techniques (Louviere et al. 2001) using SPSS. 
These were combined into choice scenarios that consisted of two (generic) alternatives A and B and a status-quo option presented on choice cards. A typical choice set is shown in appendix 1 . The sets of the main-effects experimental design were blocked into 4 versions, so that each respondent faced 4 choices. All attributes entered the analysis as continuous attributes using actual values as in table 1 .

Inclusion of a status quo option allows for the estimation of economic welfare measures (e.g. Louviere et al. 2001). The status quo ('do-nothing') option is the reference from which the scenarios offered by the researcher to the respondents diverge. "Selection of a base may have an important influence on CM results by affecting the utility of the base option relative to others, and by influencing the framing of outcomes, for example, as gains or losses" (Blamey et al. 1997:14). The status quo was described as the present situation, because future attribute level changes could not easily be predicted and may differ in discrete villages. The respondents were directly asked for the perceived levels of all attributes being most similar to the present situation with an exception for 'anoa' and 'cost'. By this means, respondents created their 'individual' status-quo or "'self-explicated' alternative" (Blamey et al. 2001:137). We did so for the following reasons: (i) It addresses local heterogeneity of environmental and socio-demographic conditions better than a 'constant base reference'. Involving respondents in the preparation for the choice experiment and customising the status quo for the individual could suspend some 'disbelief' about the hypothetical nature of the choice task and the survey by accounting for this heterogeneity. As an implication for welfare measures, choices were thus consistently framed as gains or losses for each individual. (ii) Prior to the choice task, the respondents had to intensively engage themselves with the present situation regarding the attributes. As a result, it is likely that respondents were more confident about their choices as they became more familiar with the attributes.

Economic choices are inter alia related to people's perceptions (McFadden 2001). However, if people's perceptions diverge from actual (objective) measures, there are implications for welfare measures of impacts of objectively defined changes (Adamowicz et al. 1997). Despite there is various indication that perceived and actual status quo may not differ to a large extent such as, e.g., rather low variation within villages but rather high variation between villages or the matching of perceived scores for water availability with measured precipitation data (Keil 2004), we cannot exclude the possibility of divergence. 
Furthermore, the most similar level can happen to be over- or understated due to the coarse resolution of the attribute level range. As nothing is known about the magnitude and direction of the deviation we assume that errors of over- or underestimation of levels are nullified over the total sample.

A dominant choice set was included prior to the actual choice experiment to test for rationality (Johnson and Mathews 2001, Bradley 1988, Bradley and Daly 1994, Hanley et al. 2000), also serving as a 'warm-up' task. This was achieved by keeping all attribute levels equal in option A and B expect for price. The dominant option in the choice set was the status quo. ${ }^{6}$

\subsection{Socio-demographic characteristics}

Additional data collected included information about the choice task (e.g. difficulty, confusion) as well as data on several socio-demographic characteristics (SDC, e.g. age, education), inter alia. We included some socio-demographic variables as interactions with the ASC to better understand the choice pattern of respondents (table 2).

Table 2. Variables interacted with ASC

\begin{tabular}{|c|c|c|c|}
\hline Variable & Description & Mean & $\begin{array}{l}\text { Std. } \\
\text { Dev. }\end{array}$ \\
\hline KL & $\begin{array}{l}\text { Dummy variable showing whether respondent is from Lore or Ku- } \\
\text { lawi districts }\end{array}$ & 0.52 & 0.50 \\
\hline UNDS & $\begin{array}{l}5 \text { point Likert score for overall understanding of the choice task as } \\
\text { perceived by the interviewer }\end{array}$ & 3.14 & 0.85 \\
\hline PRISEC & $\begin{array}{l}\text { Indicator for perceived discretionary income: share of total household } \\
\text { income spend on primary needs (rather than secondary) }\end{array}$ & 1.96 & 0.69 \\
\hline YOUNG & Dummy variable for age of respondent $\leq 35$ years & 0.29 & 0.45 \\
\hline OLD & Dummy variable for age of respondent $\geq 55$ years & 0.27 & 0.45 \\
\hline
\end{tabular}

The dummy KL for respondents from Kulawi and Lore areas was created because forest degradation on hillsides is far less visible than in the Sigi Biromaru and Palolo areas, resulting e.g. in water shortages for irrigation as well as household purposes in the latter ar-

\footnotetext{
${ }^{6}$ As any clear objective improvement to the status quo could not be defined for the cocoa attribute, the choice set was not clearly dominant. The level included for cocoa in options A and B was $95 \%$ shade, while payment was less for option A. If people stated to have chosen option A because they preferred very high shade in cocoa, the answer was still counted as rational. Respondents choosing A or B for other reasons were given a brief repetition of the explanation of the choice task.
} 
eas. Hence, the threat imposed by environmental degradation was more obvious than in Kulawi or Lore. This could increase the likelihood that respondents include unobserved attributes of environmental change associated with a development program into their decision making in an effort to halt a general downward trend, thereby increasing the likelihood to opt for a change rather than the status quo. Therefore, we expect the dummy to have a negative coefficient indicating a higher probability of choosing the status quo if people live in Kulawi and Lore.

The influence of respondents' comprehension of the choice task (UNDS) as evaluated by the interviewers immediately after the choice experiment using a 5-point Likert scale was also interacted with the ASC. The status quo option may be used as an 'easy way out' due to task difficulties (Kontoleon and Yabe 2003). We expect that the likelihood of choosing the status quo increases for decreasing scores of understanding, thus providing indication that this strategy has been used.

We used a perceptual measure of discretionary income modified from Green and Tunstall (1992) as a proxy for disposable income (PRISEC). The negative coefficient expected would mean that respondents who feel that they are less able to spend on secondary rather than primary needs are the more likely to choose the status quo. This may be an expression of more severely budget constraints of poorer households. Dummies for different age groups (YOUNG, OLD) were included without having prior expectations.

\subsection{Data Collection}

In order to enable aggregation of the (perceived) values for ecosystem services by a sampled population on a regional level in congruency with the research region, a stratified village sampling frame was adopted. The strata for the sample were ethnicity composition, vicinity to the Lore Lindu National Park and population density of a village. Households were then randomly selected within each village. Details of the sampling are described in Zeller et al. (2002). The choice experiment survey was administered to 301 households in 12 villages of the research region (December 2004 - March 2005). Face-to-face interviews were conducted by 6 well-trained local enumerators. To minimize potential interviewer effects, enumerators were randomly assigned to the households. 


\section{Model results}

All 301 households completed the choice task, and 235 made choices which at least once included either option A or B. 66 respondents (22\%) chose the status quo in all four choices. 53 respondents did so as they perceived the present situation to be the relatively best option, which is a consequence of the 'individual' status quo, or as they could additionally not afford the payment required in some choices. The remaining 13 respondents always chose the status quo because of 'protest', payment aversion and exceeding cognitive capability. They were classified as "...essentially not responding to the CE task." (Adamowicz et al. 1998b:68) and omitted. This leaves 288 responses for further analysis.

261 respondents or $91 \%$ chose an option from the dominant choice set that was classified as rational. It is therefore assumed that respondents in general sufficiently understood the choice task. All attributes entered the models as continuous attributes 'anoa', 'water', 'cocoa' and 'rattan' using levels as in table 1. Model results are listed in table 3.

For the base model, it is assumed that each attribute reflects an individual's utility in a linear fashion. Overall, the base model was significant at the $99 \%$ level. Except for the anoa attribute, which is significant at the $5 \%$ level, all other choice set attributes are significant at the $1 \%$ level or better. A positive sign shows that more of an attribute results in a higher probability of an alternative being chosen, while a negative parameter signifies that more of an attribute has a negative effect on the odds of an alternative being chosen. 'Water' and 'Rattan' have - as expected - negative signs. The 'anoa' attribute is positive and significant, indicating that people do care for the maintenance of viable populations of this animal. For the 'cocoa' attribute, the coefficient is negative and significant, denoting a negative effect for more shade. We were interested in whether there was a threshold for preferences for intensification, reflecting a certain degree of risk aversion. Thus, we effects-coded the cocoa attribute, which then showed nonlinearity of preferences. Therefore, we included a quadratic term for cocoa in the model. The resulting utility function is more close to the effects-coded one (figure 1). 
Table 3. MNL model results

\begin{tabular}{|c|c|c|c|c|c|c|}
\hline Variable & Base model & & Model 1 & & Model 2 & \\
\hline Rattan availability & $\begin{array}{l}-0.0354 \\
(-4.619)\end{array}$ & & $\begin{array}{l}-0.0404 \\
(-5.179)\end{array}$ & **** & $\begin{array}{l}-0.0408 \\
(-5.127)\end{array}$ & **** \\
\hline Water for irrigation of paddy rice & $\begin{array}{r}-0.88 \\
(-18.734)\end{array}$ & **** & $\begin{array}{r}-0.8943 \\
(-18.772)\end{array}$ & $* * *$ & $\begin{array}{r}-0.8885 \\
(-18.277)\end{array}$ & $* * *$ \\
\hline Cocoa Shade (linear) & $\begin{array}{l}-0.0105 \\
(-6.620)\end{array}$ & **** & $\begin{array}{c}0.0126 \\
(2.067)\end{array}$ & $*$ & $\begin{array}{r}0.0126 \\
(2.047)\end{array}$ & $*$ \\
\hline Cocoa Shade ${ }^{2}$ (quadratic) & & & $\begin{array}{l}-0.0247 \\
(-3.913)\end{array}$ & $* * *$ & $\begin{array}{l}-0.0249 \\
(-3.890)\end{array}$ & $* * *$ \\
\hline Anoa Population Size & $\begin{array}{l}0.0009 \\
(2.856)\end{array}$ & $* *$ & $\begin{array}{c}0.0009 \\
(2.688)\end{array}$ & ** & $\begin{array}{r}0.0009 \\
(2.655)\end{array}$ & ** \\
\hline Cost (Tax rise/village fund donation) & $\begin{array}{l}-0.0262 \\
(-9.420)\end{array}$ & *** & $\begin{array}{l}-0.0254 \\
(-9.146)\end{array}$ & $* * *$ & $\begin{array}{l}-0.0256 \\
(-9.162)\end{array}$ & $* * *$ \\
\hline ASC (non-status quo choice) & $\begin{array}{l}0.3481 \\
(2.553)\end{array}$ & * & $\begin{array}{c}0.4892 \\
(3.486)\end{array}$ & $* * *$ & $\begin{array}{r}2.1967 \\
(5.660)\end{array}$ & $* * *$ \\
\hline $\mathrm{ASC} * \mathrm{KL}$ & & & & & $\begin{array}{l}-0.4039 \\
(-2.854)\end{array}$ & ** \\
\hline ASC*UNDS & & & & & $\begin{array}{l}-0.2842 \\
(-3.377)\end{array}$ & $* * *$ \\
\hline ASC*PRISEC & & & & & $\begin{array}{l}-0.2320 \\
(-2.240)\end{array}$ & \\
\hline ASC*YOUNG & & & & & $\begin{array}{l}-0.2851 \\
(-1.651)\end{array}$ & \\
\hline $\mathrm{ASC} * \mathrm{OLD}$ & & & & & $\begin{array}{l}-0.2731 \\
(-1.575)\end{array}$ & \\
\hline Log-likelihood & -865.0992 & & -857.342 & & -843.040 & \\
\hline Number of observations & 1152 & & 1152 & & 1152 & \\
\hline Adjusted $\rho^{2}\left(\text { Pseudo- } R^{2}\right)^{\S}$ & 0.2583 & & 0.2646 & & 0.2753 & \\
\hline
\end{tabular}

The quadratic term for cocoa is negative and significant (model 1). There is some threshold for shade-related intensification, which would not have been detected by using the basic linear model. Utility peaks at a level of shading of approximately $28 \%$. We find a significant improvement of the quadratic specification as compared to the base model (LR test: 15.51, 1 d.f.) as well as for additionally including interactions with SDC in model 2 (LR test: $28.60,5$ d.f.).

All interactions with SDCs are significant at the $5 \%$ level or better except for the dummies for age groups. The overall model fit of all models was assessed by the value of adjusted $\rho^{2}$ (Pseudo- $\mathrm{R}^{2}$ ) compared to the constants only model. Pseudo- $\mathrm{R}^{2}$ was 0.258 for the base model, and increases for model $1(0.265)$ and model $2(0.275)$. These pseudo- $\mathrm{R}^{2}$ values can be compared to values of $R^{2}$ as in OLS regression models, where values of $\rho^{2}$ of 
0.3 correspond to $\mathrm{R}^{2}$ values of about 0.6 , representing a decent model fit (Hensher et al. 2005). In the following, we use model 2 to calculate welfare estimates.

Figure 1. Effects coding, linear and combined linear and quadratic effects for shading in cocoa

\section{Utility of shading in cocoa}

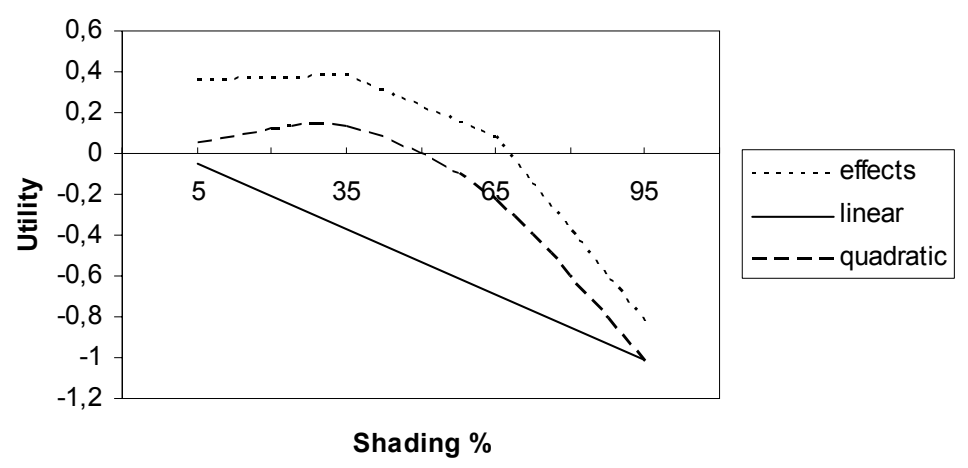

A Hausman type test (Hausman and McFadden 1984) was conducted to test for violations of the IIA assumption. The model coefficients of an unrestricted choice set are compared for significant differences with the equally specified coefficients obtained from a restricted model (where one or more choice options are omitted). In other words, it is tested whether the underlying choice behaviour remains the same when one alternative is being omitted. Hausman statistics were computed for the base model both with and without ASCs as well as for models 1 and 2 (table 4). While partial violations were found for a test without ASCs, the assumption could not be rejected for all options when ASCs were included for the test. This result can be compared with Morrison et al. (1998), where the inclusion of SDCs helped to minimise IIA violations.

Table 4. Results of the HM-tests to check for violations of the IIA assumption

\begin{tabular}{lcccc}
\hline \hline \multicolumn{4}{c}{ Alternative dropped $\left(\chi^{2}\right)^{\S}$} \\
\hline A & B & C & d.f. \\
Base (no ASC) & 7.02 & $15.54 *$ & 8.50 & 5 \\
Base (ASC) & $\leq 0^{\$}$ & 8.54 & 9.68 & 5 \\
Model 1 & $\leq 0^{\$}$ & 4.85 & 9.56 & 6 \\
Model 2 & $\leq 0^{\$}$ & 3.65 & 10.79 & 6 \\
\hline \multicolumn{1}{c}{${ }^{\S} \chi^{2}$ critical value at $\alpha=0.05: 11.07$ (5 d.f.), 12.59 (6 d.f.); }
\end{tabular}

${ }^{\$}$ If the chi square value is negative, evidence is given that the IIA assumption holds (Greene 2003);

* IIA assumption rejected at $\alpha=0.05$ Source: own calculations 
All models exhibit a positive and significant value for the ASC. This suggests that there is no particular propensity to choose the status quo option relative to the alternatives as more commonly reported in literature (e.g. Adamowicz 1998a). One exception are Mogas et al. (2002), who report a positive ASC in a study on afforestation in Catalonia. A preference for the status quo, all else equal, was often related to what is referred to as 'status-quo bias' (Samuelson and Zeckhauser 1988). One reason for status quo bias can be that the status quo is used as an 'easy way out' e.g. in case of decision difficulty and/or limited cognitive capability (Luce 1998). The positive ASC gives some evidence that this strategy was not particularly important in our study. People receive on average - everything else held constant - more utility from departing from the present situation than from keeping it. This could be due to a number of reasons like, inter alia, that respondents include unobserved attributes associated with a governmental programme, or task compliance. According to the high rate of status quo choices among all choices (53\%) it is unlikely, however, that the respondents felt 'forced' to choose among the alternatives of change as a consequence of a falsely perceived compliance with the intentions of this research.

The interactions of the ASC with SDC can shed some light on potential reasons and their heterogeneous distribution among the sample population. The negative sign of the coefficient for $\mathrm{ASC} * \mathrm{KL}$ means that the likelihood to move away from the status quo decreases if the respondent is from Kulawi or Lore areas, as we had expected. Surprisingly, respondents' understanding of the choice task as judged by the interviewers increases the likelihood of choosing the status quo relative to the alternatives. This finding further supports the assumption that respondents did not have a tendency to use the status quo as an 'easy way out' in case of difficulties associated with the choice task. Respondents that yield higher scores for understanding might make less use of unobserved attributes when making their decision.

The fewer respondents perceived they are able to spend on secondary rather than primary needs, the more likely they were to choose the status quo. This may be an expression of the limited ability to pay of poorer households. Neither young nor old age does have a significant impact on the ASC at the $95 \%$ level. 


\section{Welfare analysis}

\subsection{Implicit prices}

Using equation (5) and model 2, implicit prices (marginal WTP) were calculated for the attributes. Confidence intervals were derived using a Krinsky and Robb (1986) procedure with 1,000 random draws (table 5).

Implicit prices "can be used by policy makers to assign more resources to improving those attributes that have higher prices" (Colombo et al. 2005:89). However, care must be taken when comparing the implicit prices as the attribute units differ. MWTP to avoid 1 month of water scarcity for irrigation is about 34,800 IDR ( 4.1 US \$) per year, 100 more individuals of anoa is worth about 3,400 IDR ( 0.4 US \$) per year. MWTP for a $1 \%$ change of the cocoa attribute is slightly lower (395 IDR) if calculated without a quadratic term. This is due to the dramatic decrease in utility for very high shade levels because of the quadratic relationship. A similar effect of using a quadratic term was found by Adamowicz et al. (1998b).

Table 5. Implicit prices in IDR/year (US\$)

\begin{tabular}{|c|c|c|c|c|c|}
\hline & & Rattan & Water & $\overline{\operatorname{Cocoa}^{\S}}$ & Anoa \\
\hline Mediar & & $\begin{array}{l}-1,598 \\
(-0.19)\end{array}$ & $\begin{array}{c}-34,803 \\
(-4.1)\end{array}$ & $\begin{array}{c}-481 \\
(-0.06)\end{array}$ & $\begin{array}{c}34 \\
(0.004)\end{array}$ \\
\hline \multirow{2}{*}{$95 \%$} & Lower bound & $\begin{array}{l}-2,356 \\
(-0.28)\end{array}$ & $\begin{array}{c}-45,502 \\
(-5.35)\end{array}$ & $\begin{array}{c}-666 \\
(-0.08)\end{array}$ & $\begin{array}{c}10 \\
(0.001)\end{array}$ \\
\hline & Upper bound & $\begin{array}{c}-946 \\
(-0.11)\end{array}$ & $\begin{array}{c}-28,453 \\
(-3.36)\end{array}$ & $\begin{array}{c}-339 \\
(-0.04)\end{array}$ & $\begin{array}{c}61 \\
(0.007)\end{array}$ \\
\hline
\end{tabular}

What can be said about the absolute magnitude of the MWTP values? Are they in a reasonable range or particularly low or high? We collected some background data related to attributes, allowing a vague assessment of the plausibility of the magnitude of MWTP values, particularly for rattan and water availability. The following comparisons should not be conceived as a formal proof of external validity. Still, they are helpful in anchoring the MWTP values within a broader context.

First, the average direct tax (PBB: pajak bumi bangunan) paid by households in the research region is about 15,000 IDR per year. Thus, MWTP for one month less with water 
scarcity for irrigation equals up to $200 \%$ of the "house and land" tax people have to pay on average per year. A number of households in some villages pay irrigation fees of about 19,200 IDR per ha and year on average ${ }^{7}$. Therefore, MWTP for improved water availability expressed by the respondents can be considered to reflect a substantial amount for the inhabitants of the Lore Lindu region.

Concerning rattan, we conducted a linear regression of the time needed to reach the rattan harvesting locations $(\mathrm{h})$ on the distance $(\mathrm{km})$ (figure 2).

Figure 2. Regression of time on distance for rattan collection

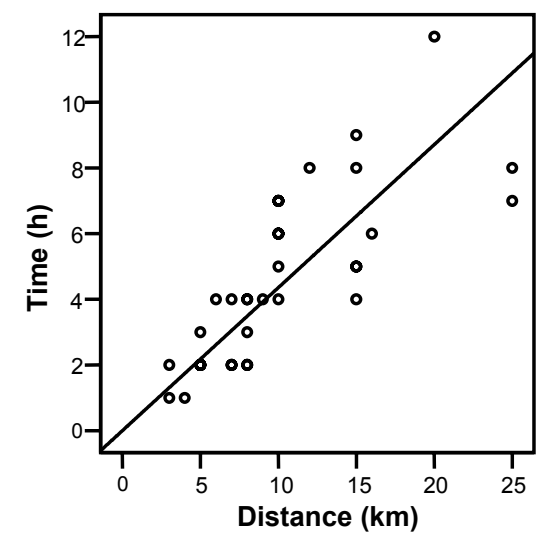

Time $=0.4358 \times$ Distance $\left(\mathrm{R}^{2}: 0.896\right)$;

calculated without constant in order to make sure that $0 \mathrm{~km}$ is associated with $0 \mathrm{~h}$ Source: own calculations

One $\mathrm{km}$ less is associated with a time saving of about 0.4 hours $(\mathrm{n}=37$, significant at $99 \%$ level). To derive a monetary value of time savings, they may either be related to the (local) wage labour market or calculated as the income forgone from collecting more of a (priced) resource (Köhlin and Amacher 2005). This is a very simplified assumption of farming in the research area, as we do know next to nothing about the potential utilisation of time savings $^{8}$. Average income from unskilled wage labour is about 10,000 IDR per day (10h). On average, people went to collect rattan 18 times per year. One km less can therefore be as-

\footnotetext{
${ }^{7}$ Mean value over four planting seasons $(2003$ - 2004) for households that paid irrigation fees in 6 of the sample villages. The authors like to thank Alwin Keil (University of Hohenheim, Germany) for the provision of this data.

${ }^{8}$ Our data suggests that income from rattan per day is invariant on the distance of the rattan harvesting locations. Rattan collectors always look for locations where there are still enough large diameter canes, as they are far better priced than smaller diameters (and where transport is still feasible). Hence, it is justified to use time savings rather than changes in income in order to derive an estimate of the marginal economic impact of the distance of rattan harvesting locations.
} 
sociated with $18 \times 0.4 \mathrm{~h}=7.2$ hours saved per year. Assuming perfect substitutability of time and labour, one $\mathrm{km}$ less would equal income forgone from wage labour of about 7,200 IDR/ yr for the average rattan collector. MWTP for $1 \mathrm{~km}$ less is about 1,600 IDR/yr, while rattan collectors respond much stronger to changes in the rattan attribute (Glenk et al. 2006). The fraction of the sample selling rattan is $12.8 \%$.

Comparisons like that are more difficult for cocoa and particularly anoa due to the complexity of the benefits associated with these attributes on one hand, and to a lack of background data available on these benefits on the other hand. For the water and rattan attributes, however, there is indication that the MWTP values are in a reasonable range. Furthermore, Pattanayak and Kramer (2001) report a WTP of 2-3 US\$ for drought mitigation services by watershed protection on Flores/ Indonesia derived by CVM. Although not directly comparable, their result for a similarly framed ecosystem service can provide some weak evidence that MWTP for water as calculated in this study seems to be neither completely over- or underestimated.

\subsection{Scenario analysis}

In 'State of the World' models (Bennett and Adamowicz 2001: 65) there are two general 'paths' to address change: first, attribute levels can be set to an equal value for the whole sample (e.g. the rattan attribute is set to $5 \mathrm{~km}$ ). Second, attribute levels can be changed for every individual of the sample by a predefined amount (e.g. the rattan attribute is changed for every individual by $5 \mathrm{~km}$ less). We follow the second path. As we have an individual specific status quo, we do not assign a WTP for changes in certain attributes when it cannot be improved or changed any further.

There has been some discussion whether the ASC has to be included for calculating welfare estimates or not (Mogas et al. 2002). One strong argument for inclusion is that the ASC captures systematic but unobserved information on why respondents choose particular alternatives (Morrison et al. 2002). On the other hand, as ASCs do not explain choice in terms of the observable attributes they "cannot easily be used in predicting the effect of changes due to attribute changes" (Adamowicz et al. 1997:73). If the ASC indicates that the probability of choosing the status quo was higher relative to that of choosing the management alternatives for reasons that are not explained by the attributes, neglecting the 
ASC for the calculation of CV measures would lead to an overestimation of WTP for a change that may be substantial (Adamowicz et al. 1998b, Colombo et al. 2005). In this study, however, we found a systematic deviation of the choice pattern in favour of the alternatives other than the status quo. Despite having a marked effect on the CV welfare measures, we omitted the ASC, therefore deriving a more conservative measure of WTP.

In order to extrapolate estimates from the sample to the population of the research region, sampling weights have to be applied due to the stratified sampling frame. For details about the calculation of sampling weights see Schwarze (2004). Mean values of WTP were calculated for each individual, averaged for each stratum, and finally aggregated to the total population using sampling weights (Morrison 2000). For the aggregation, the fraction of the population that has zero WTP has to be considered. Therefore, we assumed that those respondents who gave 'protest' answers have zero WTP (13 respondents). Protest respondents are assumed to be equally distributed over the population, as no clusters were found in certain strata.

We calculate estimates for three alternative scenarios. In different ways, a development program may target those ecosystem services mainly affected by changes at the forest margin (water availability, shading in cocoa cultivation), those mainly affected by changes of the forest interior (rattan stocks, anoa population) or both. Scenario 1 ('margin') describes a program focusing on production at the forest margin (intensification of cocoa) while neglecting the forest interior. This is assumed to lead to further depletion of forest resources. Scenario 2 ('integrated' management) takes all services into consideration. A strict enforcement of National Park borders is combined with conservation efforts at the forest margin (extensification of cocoa) in scenario 3 ('biodiversity'). We assume a decline of rattan availability in Scenario 3 because strict enforcement leads to restricted access. Although the actual rattan stocks in the National Park increase or stay the same, individuals from villages bordering the National Park would have to collect rattan in forests which are further away - additionally increasing pressure on rattan resources in unprotected forests outside of the Lore Lindu National Park. For all scenarios, we assumed the impact of changes on water availability to be half as large for villages with technical or semi-technical irrigation systems as compared to villages with simple - local - irrigation systems. We did so because rice fields irrigated by water from small streams and water- 
sheds might be affected first and more severely compared to those who receive water from larger watersheds.

Table 6. Scenarios and CV

\begin{tabular}{lcccc}
\hline \hline & $\begin{array}{c}\text { Status Quo } \\
\text { (average) }\end{array}$ & $\begin{array}{c}\text { Scenario 1 } \\
\text { 'margin' }\end{array}$ & $\begin{array}{c}\text { Scenario 2 } \\
\text { 'integrated } \\
\text { management' }\end{array}$ & $\begin{array}{c}\text { Scenario 3 } \\
\text { 'Biodiversity }\end{array}$ \\
\hline Rattan [km] & 10.61 & 15.03 & 7.55 & 15.59 \\
Water [months] & 1.32 & $0.42)$ & $(-0.29)^{\S}$ & $(0.47)$ \\
Cocoa [\%] & 45.31 & $(-0.44)^{\S}$ & $(-0.22)^{\S}$ & 1.03 \\
& & $(-0.77$ & 35.8 & 74.79 \\
Anoa [N] & 350 & 100 & $(-0.21)^{\S}$ & $(0.65)$ \\
\hline CV household [US\$] & - & $(-0.71)$ & 350 & 500 \\
CV aggregated [US\$] & - & $\mathbf{- 0 . 9 8}$ & $\mathbf{- 2 . 1 2}$ & $(0.43)^{\S}$ \\
\hline § utility gain associated with change in attribute; percent changes compared to status quo in parentheses
\end{tabular}

Mean changes of the single attributes within each alternative scenario relative to the mean status quo as well as the resulting CV measures are summarized in table 6. While benefits are largest for scenario 2, they are much lower, if management of the forest resources (anoa, rattan) is neglected (Scenario 1). Restricting access to the forest resources in combination with extensification of cocoa, i.e., more shading trees - leads to welfare losses (Scenario 3). It is important to note that these measures are net benefits of the investigated nonmarket goods alone. The financial costs of actually implementing the scenarios are not considered here.

\section{Concluding remarks}

With a carefully adjusted instrument, a choice experiment on the valuation of four mostly functional biodiversity services was successfully conducted on one of Indonesia's outer islands. The respondents understood the choice task sufficiently; statistical diagnostics indicate very reasonable model performance. The MNL model results provide some evidence that the choice experiment can be applied to the valuation of complex ecological functions if the functions are translated into ecosystem services attributes relevant to respondents' lives. 
The design strategy to adjust the status-quo to the perceptions of the individual respondents contributed essentially to this result. One of the major advantages of using individual-specific perceived levels for the status-quo is its ability to account for heterogeneous environmental conditions. This enhances credibility among respondents, and frames the attribute levels of the alternative options properly as gains and losses. The bio-physical heterogeneity of the research region is reflected in differing livelihood strategies, farming structure and perceptions of environmental risks. Such factors, in turn, explain preference heterogeneity among respondents (Barkmann et al. subm., Glenk et al. 2006).

Measures of MWTP for an improved provision of ecosystem services ('water', 'rattan', 'anoa') were documented. The magnitude of MWTP is quite substantial considering the living conditions of the inhabitants of the Lore Lindu region. The conflict between economic development and conservation is clearly reflected in people's preferences. They indicate a willingness to contribute actively to the maintenance of their natural resource base. Even for maintaining viable population sizes of the local endemic dwarf buffalo anoa, residents have small MWTP although direct or indirect use benefits are likely to be very low. In the fast growing sector of cocoa agroforestry systems, on the other hand, respondents indicated an unexpectedly clear preference for more intensively managed plantations with less shade trees. Thus, biodiversity conservation measures aiming at more sustainable ways of cocoa cultivation (measured here by a shade tree gradient) will be unlikely to be successful without creating economic incentives for the cocoa farmers. One such incentive could be a price premium for "biodiversity-friendly" cocoa production.

We calculated CV measures for alternative management scenarios. As the scenario analysis (i) includes only a limited number of non-market benefits, (ii) does not account for the implementation costs of the scenarios, (iii) does not consider impacts on market goods, it cannot be finally judged which scenario is relatively more beneficial to the society of the research region in welfare economic terms. This study was not designed to generate comprehensive cost-benefit data; still, the presented scenario analysis provides essential nonmarket data for such an endeavour.

Even if the WTP of respondents as, e.g., in the 'integrated' scenario would be realised on a village or regional scale, it is doubtful whether an effective resource management 
could be financed merely by the contribution of the locals. In fact, numerous issues hinder the success and resource management programs in the project area. Examples are unresolved property rights conflicts around and in Lore Lindu the National Park, weak law enforcement, and continuously increasing pressure from population growth and agricultural intensification. Hence, the influence of our findings on the resource management in the Lore Lindu region should not be exaggerated. However, the importance ascribed to the attributes should encourage decision makers to find solutions that sufficiently consider the local demand for the provision of the ecosystem services observed.

There is still much to be learned about economic benefits of non-market goods and particularly of functional ecosystem services in tropical rainforest areas (Balmford et al. 2002) as well as in so-called developing countries in general. Our results should be conceived as a point of reference for future research in this field. Among alternative approaches available, the choice experiment promises to be a useful tool for such an endeavor.

\section{References}

Abou-Ali, H. and F. Carlsson (2004), "Evaluating the welfare effects of improved water quality using the choice experiment method." Working Papers in Economics no. 131. Department of Economics, Gothenburg University.

Adamowicz, W., J. Louviere and M.Williams (1994), 'Combining Stated and Revealed Preference Methods for Valuing Environmental Amenities‘. Journal of Environmental Economics and Management 26, 271-292.

Adamowicz, W., J. Swait, P. Boxall, J. Louviere, and M. Williams (1997), 'Perceptions versus Objective Measures of Environmental Quality in Combined Revealed and Stated Preference Models of Environmental Valuation'. Journal of Environmental Economics and Management 32, 65-84

Adamowicz, W., J. Louviere and J. Swait (1998a) Introduction to Attribute-Based Stated Choice Methods. Prepared by Advanis Inc. for the National Oceanic and Atmospheric Administration, US Departement of Commerce.

Adamowicz, W., P. Boxall, M. Williams and J. Louviere (1998b), 'Stated preferences approaches to measuring passive use values‘. American Journal of Agricultural Economics 80, 64-75. 
Akiyama, T. and A. Nishio (1996) “Indonesia's Cocoa Boom. Hands-off Policy Encourages Smallholder Dynamism." Policy Research Working Paper 1580. Washington, D.C.: World Bank.

ANZDEC (1997) Central Sulawesi Integrated Area Development and Conservation Project. TA NO 2518 - INO. Draft Final Report - Annex (Working Papers). Indonesia.

Balmford, A., A. Bruner, P. Cooper, R. Constanza, S. Faber, R. Green, M. Jenkins, P. Jefferiss, V. Jessamy, J. Madden, K. Munro, N. Myers, S. Naeem, J. Paavola, M. Rayment, S. Rosendo, J. Roughgarden, K. Trumper, and R. Turner (2002), 'Economic reasons for conserving wild nature'. Science 297, 950-53.

Barkmann, J., N. Dietrich, K. de Vries, G. Gerold, K. Glenk, A. Keil, H. Faust, C. Leemhuis, and R. Marggraf (submitted), 'Confronting unfamiliarity with ecosystem functions: The case for an ecosystem service approach to environmental valuation with stated preference methods.' Submitted to Ecological Economics.

Bateman, I., R. Carson, B. Day, M. Hanemann, N. Hanley, T. Hett, M. Jones-Lee, G. Loomes, S. Monrato, E. Ozdemiroglu, D. Pearce, R. Sugden, and J. Swanson (2002) Economic Valuation with Stated Preference Techniques - A Manual. Cheltenham, UK: Edward Elgar.

Bawa, K., W. Kress, N. Nadkarni, S. Lele, P. Raven, D. Janzen, A. Lugo, P. Asthon, and T. Lovejoy (2004), 'Tropical Ecosystems into the $21^{\text {st }}$ Century'. Science 306, 227-228.

Belsky, J. and F. Siebert (2003), 'Cultivating Cocoa: Implications of sun-grown cocoa on local food security and environmental sustainability ${ }^{6}$. Agriculture and Human Values 20, 277-285.

Bennett, J. and W. Adamowicz (2001), 'Some Fundamentals of Environmental Choice Modelling', in J. Bennett and R. Blamey, eds., The Choice Modelling Approach to Environmental Valuation. Cheltenham, UK: Edward Elgar.

Bennett, J. and R. Blamey, eds. (2001) The Choice Modelling Approach to Environmental Valuation. Cheltenham, UK: Edward Elgar.

Blamey, R., J. Rolfe, J. Bennett, and M. Morrison (1997) Environmental Choice Modelling: Issues and Qualitative Insights. Research Report No. 4. Canberra, Australia: School of Economics and Management, The University of New South Wales.

Blamey, R., J. Louviere, and J. Bennett (2001), 'Choice Set Design', in J. Bennett and R. Blamey, eds., The Choice Modelling Approach to Environmental Valuation. Cheltenham, UK: Edward Elgar.

Bradley, M. (1988), 'Realism and Adaptation in Designing Hypothetical Travel Choice Concepts‘. Journal of Transport Economics and Policy 22, 121-137.

Bradley, M. and A. Daly (1994), 'Use of the logit scaling approach to test for rank-order and fatigue effects in stated preference data'. Transportation 21, 167-184.

Burkard, G. (2002) Natural Resource Management in Central Sulawesi: Past Experience and Future Prospects. STORMA Discussion Paper Series No 8. Bogor, Indonesia: Universities of 
Göttingen and Kassel, Germany and the Institut Pertanian Bogor and Universitas Tadulako, Indonesia.

Burton, J., S. Hedges and A. Mustari (2005), 'The taxonomic status, distribution and conservation of the lowland anoa Bubalus depressicornis and mountain anoa Bubalus quarlesi‘. Mammal Review 35 (1), 25-50.

Carson, R., N. Flores and R. Mitchell (1999), 'The Theory and Measurement of Passive Use Value', in I. Bateman and K. Willis, eds., Valuing Environmental Preferences. Oxford University Press, Oxford.

Colombo, S., J. Calatrava-Requena and N. Hanley (2005), 'Designing Policy for Reducing the Offfarm Effects of Soil Erosion Using Choice Experiments'. Journal of agricultural Economics 56(1), 81-95.

Freeman III, A. (1998), 'On Valuing the Services and Functions of Ecosystems', in A. Feeman III ed., The economic approach to environmental policy: the selected essays of A. Myrick Freeman III. Cheltenham, UK: Edward Elgar.

Gatto, M. and G. de Leo (2000), 'Pricing Biodiversity and Ecosystem Services: The Never-Ending Story'. Bioscience 50 (4), 347-355.

Glenk, K., Barkmann, J., Marggraf, R. (2006) Unveiling regional preferences for biological diversity in Central Sulawesi: a choice experiment approach. STORMA Discussion Paper Series No 16. Bogor, Indonesia: Universities of Göttingen and Kassel, Germany and the Institut Pertanian Bogor and Universitas Tadulako, Indonesia.

Green, C. and S. Tunstall (1992), 'The Recreational and Amenity Value of River corridors', in P. Boon, P. Calow and G. Petts, eds., River Conservation and Management. Chichester: John Wiley.

Greene, W. (2003) LIMDEP Version 8.0 NLogit Version 3.0. Plainview, N.Y.: Econometric Software, Inc.

Hanley, N., R. Wright and G. Koop (2000), 'Modelling Recreation Demand using Choice Experiments: Climbing in Scotland'. Environmental and Resources Economics 22, 449-466.

Hausman, J. and D. McFadden (1984), 'Specification Tests for the Multinomial Logit Model. Econometrica 52(5), 1219-1240.

Hensher, D., J. Rose and W. Greene (2005) Applied choice analysis: a primer. Cambridge, U.K: Cambridge University Press.

Jae, H. and D. Delvecchio (2004), 'Decision Making by Low-Literacy Consumers in the Presence of Point-of-Purchse Information“. The Journal of Consumer Affairs 38(2), 342-354.

Johnson, F. and K. Matthews (2001), 'Sources and effects of utility-theoretic inconsistencies in stated-preference surveys'. American Journal of Agricultural Economics 83(5), 1328-1333. 
Keil, A. (2004) The socio-economic impact of ENSO-related drought on farm households in Central Sulawesi, Indonesia. Ph.D. thesis, Institute of Rural Development, University of Goettingen.

Köhlin, G. and G. Amacher (2005), 'Welfare Implications of Community Forest Plantations in Developing Countries: The Orissa Social Forestry Project‘. American Journal of Agricultural Economics 87(4), 823-1096.

Kontoleon, A. and M. Yabe (2004), 'Assessing the Impacts of Alternative 'Opt-out' Formats in Choice Experiment Studies'. Journal of Agricultural Policy Research 5: 1-32.

Krinsky, I. and A. Robb (1986), 'On approximating the statistical properties of elasticities'. Review of Economics and Statistics 68, 715-719.

Lancaster, K. (1966), 'A New Approach to Consumer Theory'. Journal of Political Economy 74, 132-157.

Lancaster, K. (1991) Modern Consumer Theory. Brookfield VT: Edward Elgar.

Louviere, J., D. Hensher and J. Swait (2001) Stated Choice Methods - Analysis and Application. Cambridge, UK: Cambridge University Press.

Luce, M. (1998), 'Choosing to Avoid: Coping with Negatively Emotion-Laden Consumer Decisions'. Journal of Consumer Research 24(4), 409-433.

Luce, R. (1959) Individual choice behaviour. New York: Wiley.

Manski, C. (1977), 'The Structure of Random Utility Models'. Theory and Decision 8, 229-254.

Maertens, M. (2004) Economic Modelling of Agricultural Land-Use Patterns in Forest Frontier Areas. Ph.D. thesis, Institute of Rural Development, University of Goettingen.

McFadden, D. (1973), 'Conditional Logit Analysis of Qualitative Choice Behavior', in P. Zarembka, ed., Frontiers in Econometrics. New York: Academic Press.

McFadden, D. (2001), 'Economic Choices'. The American Economic Review 91(3): 351-378.

Mogas, J., P. Riera and J. Bennett (2002), “A comparison of contingent valuation and choice modeling: Estimating the environmental values of Catalonian forests". Occasional Paper no. 1, National Centre for Development Studies, Australian National University.

Morrison, M. (2000), 'Aggregation Biases in Stated Preference Studies'. Australian Economic Papers 39(2), 215-230.

Morrison, M., J. Bennett and R. Blamey (1998) Valuing improved wetland quality using choice modelling. Research Report No.6. Canberra, Australia: School of Economics and Management, The University of New South Wales.

Morrison, M., J. Bennett, R. Blamey, and J. Louviere (2002), 'Choice Modelling and Tests of Benefit Transfer'. American Journal of Agricultural Economics 84(1), 161-170.

Myers, N., A. Russel, R. Mittermeier, C. Mittermeier, G. da Fonseca, and J. Kent (2000), 'Biodiversity hotspots for conservation priorities'. Nature 403, 853-858. 
Nunes, P. and J. v.d. Bergh (2001), 'Economic valuation of biodiversity: sense or nonsense?‘ Ecological Economics 39(2), 203-222.

Olson, D.M. and E. Dinerstein (1998), 'The Global 200: a representation approach to conserving the Earth's most biologically valuable ecoregions'. Conservation Biology 12(3), 502-515.

Othman, J., J. Bennett and R. Blamey (2004), 'Environmental values and resource management options: a choice modelling experience‘. Environment and Development Economics 9(6), 803-824.

Pattanayak, K. and R. Kramer (2001), 'Pricing ecological services: Willingness to pay for drought mitigation from watershed protection in eastern Indonesia'. Water Resources Research 37(3), 771-778.

Pearce, D. and D. Moran (1994) The economic Value of Biodiversity. IUCN - The World Conservation Union. London: Earthscan Publications.

Pham, K. and V. Tran (2005) Household Demand for Improved Water Services in Ho Chi Minh City: A Comparison of Contingent Valuation and Choice Modeling Estimates. EEPSEA Research Report Series No.2005-RR3, Economy and Environment Program for Southeast Asia, Singapore.

Samuelson, W. and R. Zeckhauser (1988), 'Status Quo Bias in Decision Making'. Journal of Risk and Uncertainty 1, 7-59.

Seenprachawong, U. (2003) An Economic Valuation of Coastal Ecosystems in Phang Nga Bay, Thailand. EEPSEA Research Report Series No.2003-RR5, Economy and Environment Program for Southeast Asia, Singapore.

Schwarze, S. (2004) Determinants of Income Generating Activities of Rural Households, A quantitive Study in the Vicinity of the Lore-Lindu National Park in Central Sulawesi/Indonesia. $\mathrm{Ph}$.D. thesis, Institute of rural Development, University of Goettingen.

Siebert, S. (2001), 'Sustainable harvesting of wild rattan: viable concept or ecological oxymoron? Unasylva 52, 36-45.

Siebert, S. (2002), 'From shade to sun-grown perennial crops in Sulawesi, Indonesia: implications for biodiversity conservation and soil fertility'. Biodiversity and Conservation 11, 18891902.

Siebert, S. (2004), 'Demographic effects of rattan cane collecting and implications for sustainable harvesting'. Conservation Biology 18(2), 424-431.

Slovic, P. and S. Lichtenstein (1971), 'Comparison of Bayesian and Regression Approaches to the Study of Information Processing in Judgment‘. Organizational behavior and Human Performance 6, 649-744.

STORMA 2003 Ergebnisbericht 2003/1. Sonderforschungsbereich 552 der DFG: "Stability of Rainforest Margins”. Georg-August-University Goettingen and University of Kassel. 
Suryahadi, A. and S. Sumarto (2001), "The chronic poor, the transient poor, and the vulnerable in Indonesia before and after the crisis, " SMERU Working Paper. Jakarta: SMERU Research Institute.

Thurstone, L. (1927), 'A Law of Comparative Judgment'. Psychological Review. 34, 273-286.

Train, K. (1986) Qualitative Choice Analysis, Theory, Econometrics and an Application to Automobile Demand, MIT Press, London.

Train, K. (1998), 'Recreation demand models with taste differences over people‘. Land Economics 74(2), $230-40$.

Vantomme, P. (2003), 'Growing imbalance between supply and demand for rattan?' Journal of Bamboo and Rattan 2(4) 407-415

Vedeld, P, A. Angelsen, E. Sjaastad, and G. Berg (2004) Counting on the environment: Forest incomes and the rural poor. Environment Department Papers No. 98. The World Bank, Washington DC

Waltert, M., A. Mardiastuti and M. Mühlenberg (2004), 'Effects of land use on bird species richness in Sulawesi, Indonesia'. Conservation Biology 18(5), 1339-1346.

Weber, R. (2005) Kulturlandschaftswandel während des 20. Jh. in Zentralsulawesi - eine historisch-geographische Analyse der Lore-Lindu-Bergregenwaldregion. Ph.D. thesis, Institute of Geography, University of Goettingen.

Whitten, A., G. Henderson and M. Mustafa (1987) The Ecology of Sulawesi. Yogyakarta, Indonesia: Gadjah Mada University Press.

Whittington, D. (1998), 'Administering contingent valuation surveys in developing countries'. World Development 26(1), 21-30

Zeller, M., S. Schwarze and T. van Rheenen (2002) Statistical Sampling Frame and Methods Used for the Selection of Villages and Households in the Scope of the Research Programme on Stability of Rainforest Margins in Indonesia (STORMA). STORMA Discussion Paper Series No 1. Bogor, Indonesia: Universities of Göttingen and Kassel, Germany and the Institut Pertanian Bogor and Universitas Tadulako, Indonesia. 


\section{CHAPTER 4}

Differential Influence of Relative Poverty on

Preferences for Ecosystem Services:

Evidence from Rural Indonesia 


\section{Introduction}

Are environmental goods luxury goods? From a rural development perspective, a generally affirmative answer to this question appears highly unlikely. Most peasants in developing countries rely directly on environmental goods for subsistence agriculture or small-scale production of cash crops. The poorer they are, the more they are vulnerable to a degradation of the resource base - and hence, income elasticities below one are expected. On the other hand, local species diversity with only limited direct resource use may display luxury goods characteristics. In this paper, we present data from two surveys in twelve rural villages in the Lore Lindu National Park Area (Central Sulawesi, Indonesia). We document differential influences of poverty as measured by a relative poverty index on the demand of a range of ecosystem services expressed by the marginal willingness to pay (MWTP) for these services.

\section{Methods}

\subsection{Study area}

The research region is located within the humid tropics about 1 degree south of the equator. It comprises 7 administrative districts in the Indonesian province of Central Sulawesi. In more than 115 villages, it holds a population of about 130.000 - mainly smallholder farmers on $7.220 \mathrm{~km}^{2}$. Centred within the study region, the Lore Lindu National Park covers some $2.200 \mathrm{~km}^{2}$ of mainly mountainous rainforest. A large number of species endemic to Sulawesi, including, for example the mammal anoa (Bupalus sp.), can be found in the National Park area, which is one of few large forest areas left on Sulawesi.

\section{2 'Poverty' elasticity of willingness to pay (WTP)}

In order to assess differential influences of individuals with different welfare on the demand for goods, income is commonly used to derive elasticities of demand. Depending 
on the sign and magnitude of the elasticities, different types of goods are defined. We distinguish four (only partly exclusive!) types of goods. Normal goods have a positive elasticity of demand; inferior goods have a negative elasticity of demand; luxury goods have elasticity greater than one, whereas necessities are defined to have elasticity below one.

Measuring incomes of rural households in semi-subsistence economies poses many challenges concerning data collection and data analysis. Income surveys are in general time-consuming and costly because of the length of the interviews and the high demands with respect to human capital (enumerators, data analysis). Also, incomes of rural households tend to fluctuate highly between the years. Furthermore, income neither captures the multiple dimensions of welfare nor of poverty. Thus, we applied a simple, low-cost poverty assessment tool to estimate the medium term relative welfare of households (Zeller et al. 2006). Principal component analysis is employed to select and eventually aggregate various indicators of poverty into a $(0,1)$ normally distributed variable which increases with wealth. Details of this method are reported in Henry et al. (2003). The poverty index was estimated for each of the sample households using three asset related indicators, four dwelling indicators, and two consumption indicators in 2001 (Abu Shaban 2001). We recalculated the index in 2005 using the same indicators and weights as in 2001. The poverty groups are the terciles of the poverty index. Because the index contains negative values we transformed the index by using its cumulative density function (CDF) which yields values for the poverty index between zero (the poorest) and one (the less-poor).

Demand for ecosystem services is expressed by MWTP. For the range of services described above, MWTP values were obtained from Multinominal Logit (MNL) results of 
the choice experiment as described below. By using the positive cumulative density function values of the poverty index, the effect of a (percentage) change in the quantity demanded on a percentage change of relative poverty was assessed. Hence, rather than deriving estimates of income elasticity of WTP, we observed what can be called "poverty elasticity" of WTP.

MNL models were calculated for each of the poverty groups as well as for the total sample. Using the parameter estimates for the attributes, mean MWTP and 90\% confidence intervals around the mean were derived using a Krinsky and Robb (1986) procedure with 1000 random draws. Differences were calculated between three point estimates for demand expressed as the marginal willingness to pay of the three poverty groups. We stress again that we use a terminology that is usually applied to denote income effects on demand to describe poverty effects on demand.

The information about "poverty" elasticity of WTP can be useful for distributional reasons. If poverty elasticities of WTP are below zero, improving a service is relatively more beneficial to the poor in comparison to the less poor (Kriström and Riera 1996).

\subsection{The choice experiment}

In a choice experiment, respondents choose from alternatives or different 'goods' that alternative with the highest (expected) utility. In an environmental context, the alternatives usually consist of a number of "proposed changes" and a "status quo option". In our case the choice set presented to the respondent consists of two different management alternatives for the Lore Lindu area and the present situation. These 'goods' are characterized by a number of attributes. The attributes, in turn, are represented by quantitative or qualitative levels that the 'goods' take. Within and between the choice sets 
presented to the respondent the attribute levels and thus the goods or commodities vary according to an experimental design. Attributes and interactions of attributes with socioeconomic variables form the arguments of a linear and additive expression of the (indirect) utility function; the respective utility coefficients can be calculated by employing maximum likelihood estimation procedures, e.g. the MNL model. MWTP is calculated by dividing the environmental attribute's coefficient by the 'cost' attribute coefficient.

Selection of attributes and attribute levels were guided by an ecosystem service approach (Barkmann et al. subm), and facilitated by information gathered in individual and peergroup interviews in various villages of the Lore Lindu area. Additional information and data was obtained from scientists working in the region and from literature (e.g. Belsky and Siebert 2003; Keil 2004; Siebert 2003). We used 4 attributes: water for irrigation of wetland rice (number of months/yr with water scarcity); rattan availability in the forest (distance to rattan harvesting location); ways of cocoa cultivation (preponderance of cocoa plantations in the village along a shade tree gradient); population size of anoa (number of individuals). Bundles of these attributes were framed as a government development program. An additional 'cost' attribute was double split-sampled: (i) a rise in "house and land" tax versus a donation to a village fund affecting every household of the research region; (ii) a monthly versus a yearly payment scheme. For simplicity reasons, the attributes/ ecosystem services are denoted by 'water', 'rattan', 'cocoa', 'anoa' and 'cost'.

For the main-effects experimental design, an orthogonal fraction of 16 out of the $4^{5}$ possible combinations of attribute levels was selected (Louviere et al. 2001), and combined into choice scenarios that consisted of two (generic) alternatives A and B and a status-quo option presented on choice cards. The choice sets of the experimental design were blocked into 4 versions so that each respondent faced 4 choices. In order to account for the 
heterogeneous environmental conditions of the research region, the status quo was offered as a self-explicated alternative for all attributes except anoa (regional average).

\subsection{Expectations}

We expected rattan to be an inferior environmental good (MWTP increases with higher poverty), and (ii) anoa is a luxury good (MWTP falls sharply with poverty). Water and cocoa were expected to behave as necessity goods (no clear effects of poverty but no luxury goods).

\subsection{Data collection}

The choice experiment survey was administered in-person to 249 randomly selected households in 12 villages of the research region from December-March 2004/05. Data for the calculation of the poverty index was collected from March-June 2004 in the same households using standardised, formal questionnaires. Details on the sampling procedure are given in Zeller et al. (2002).

\section{Results}

For the total sample, the MNL model was highly significant at the $99 \%$ level $\left(\chi^{2}=597.4\right.$, d.f. $=7$ ). The overall model fit of this base model was assessed by the value of adjusted $\rho^{2}$ (Pseudo- $\mathrm{R}^{2}$ ) over a model with no coefficients, which was $0.293 . \rho^{2}$ values between 0.3 and 0.4 correspond to $\mathrm{R}^{2}$ values of 0.6 to 0.8 as in OLS regression models and indicate a good fit (Hensher et al. 2005).

Hausman-McFadden (1984) tests were performed to test for violations of the Independence of Irrelevant Alternatives (IIA) assumption that is implicit in MNL models. The results 
were somehow inconclusive as violations were found for dropping one alternative. However, the assumption could not be rejected when dropping the other two alternatives. Inclusive value parameters for branches of various nestings in nested logit (NL) models were not found to be significantly different from one, suggesting that the NL model can be collapsed to a MNL model (Louviere et al. 2001).

Table 1: MNL model results

\begin{tabular}{lc}
\hline Constant (ASC) & $0.2111^{* *}(1.401)$ \\
Rattan & $-0.0278^{* *}(-3.126)$ \\
Rattan*Collection & $-0.0973^{* * *}(-3.375)$ \\
Water for irrigation of wetland rice & $-0.5074^{* * *}(-7.228)$ \\
Water*Paddy Involvement & $-0.7130^{* * *}(-7.044)$ \\
Cocoa (Shade) & $-0.0101^{* * *}(-5.677)$ \\
Anoa & $0.0012^{* * *}(3.537)$ \\
Tax rise/ donation to a village fund & $-0.0259^{* * *}(-8.357)$ \\
\hline Log-likelihood & -710.1272 \\
Number of observations & 996 \\
Adjusted $\rho^{2}$ (Pseudo- $\left.{ }^{2}\right)$ & $29.3 \%$ \\
\hline \multicolumn{2}{c}{ t-statistics in parentheses; significancies: ${ }^{* * *} \mathrm{p}<0.001 ;^{* *} \mathrm{p}<0.01$}
\end{tabular}

All attribute coefficients are significant and have the expected sign. I.e., disutility was observed for more months with water scarcity, with a greater distance to rattan harvesting locations, and with paying tax or donating to a village fund. A utility gain was observed for bigger population sizes of the endemic dwarf buffalo anoa. The results concerning cocoa indicate higher preferences for less shade in cocoa (Tab. 1).

The sub-models of the three poverty groups are overall significantly different from zero at the $99 \%$ level. Model fit for the three models is quite good with values of pseudo- $\mathrm{R}^{2}$ between 0.252 and 0.332 . The MWTP for the three poverty groups and elasticities for 
moving from the poorest to the poor, as well as from the poor to the less poor, are listed in table 2 .

Table 2: MWTP and elasticities

\begin{tabular}{|c|c|c|c|c|}
\hline Attribute & $\begin{array}{l}\text { Poverty } \\
\text { group }^{\mathrm{a}}\end{array}$ & $\begin{array}{l}\text { Mean total } \\
\text { MWTP } \\
\left(\text { IDR }^{\mathrm{b}}\right)\end{array}$ & $\begin{array}{c}\text { attributed to } \\
\text { usage }\end{array}$ & $\begin{array}{l}\text { Poverty } \\
\text { elasticity }\end{array}$ \\
\hline \multirow{3}{*}{ Rattan } & Poorest (1) & $1,540(1,219)^{\$}$ & 1,540 & \multirow{3}{*}{$\begin{array}{c}0.244(1-2) \\
-0.812(2-3)\end{array}$} \\
\hline & Poor (2) & 2,069 & 0 & \\
\hline & Less poor (3) & 1,278 & 0 & \\
\hline \multirow{3}{*}{ Water } & Poorest (1) & 33,518 & 14,650 & \multirow{3}{*}{$\begin{array}{r}0.257(1-2) \\
-0.421(2-3)\end{array}$} \\
\hline & Poor (2) & 45,680 & 23,233 & \\
\hline & Less poor (3) & 36,634 & 15,467 & \\
\hline \multirow{3}{*}{ Cocoa } & Poorest (1) & 181 & 181 & \multirow{3}{*}{$\begin{array}{l}0.902(1-2) \\
1.030(2-3)\end{array}$} \\
\hline & Poor $(2)$ & 409 & 409 & \\
\hline & Less poor (3) & 607 & 607 & \\
\hline \multirow{3}{*}{ Anoa } & Poorest (1) & 70 & n.a. & \multirow{3}{*}{$\begin{array}{c}-0.497(1-2) \\
3.342(2-3)\end{array}$} \\
\hline & Poor (2) & $21^{\S}$ & n.a. & \\
\hline & Less poor (3) & 54 & n.a. & \\
\hline
\end{tabular}

${ }^{\mathrm{a}}$ mean CDF for poverty groups: (1): 0.218; (2): 0.525; (3): 0.772; ${ }^{\mathrm{b}} 1$ US $\$ \sim 9000$ IDR (October 2004); ${ }^{\$}$ non-usage component not significantly different from zero; ${ }^{\S}$ not significant from zero

$90 \%$ confidence intervals of the MWTP values overlapped for all attributes and poverty groups (Fig. 1). Thus, we were not able to find statistical differences among the poverty groups with respect to their MWTP. At the $90 \%$ confidence level, elasticities for all attributes are therefore below one in consequence - and all attributes necessities in formal terms. Nevertheless, Figure 1 suggests the existence of interesting patterns of influence of poverty on MWTP that shall be further analysed for heuristic reasons.

Comparing only the difference between the poor and the less poor first, rattan tends to behave like an inferior good as MWTP increases with increasing poverty. Water behaves similarly. MWTP for intensification of cocoa increases at a rate of about 1 with declining poverty, suggesting that it is a normal, if not a luxury good. Anoa clearly behaves as a luxury good. 
However, by including MWTP values for the poorest households, the picture gets more complex and - in the cases of rattan, water and anoa - cannot be interpreted in a straightforward manner in terms of the common definitions of the different types of goods. With regards to rattan and water, MWTP of the poorest households is lower compared to the poor households, and is - surprisingly - increasing for the anoa attribute. MWTP for cocoa intensification is lower for the poorest group in comparison to the poor. Thus, we observe a continuous and monotone trend for this attribute.

Figure 1: MWTP and $90 \%$ confidence intervals

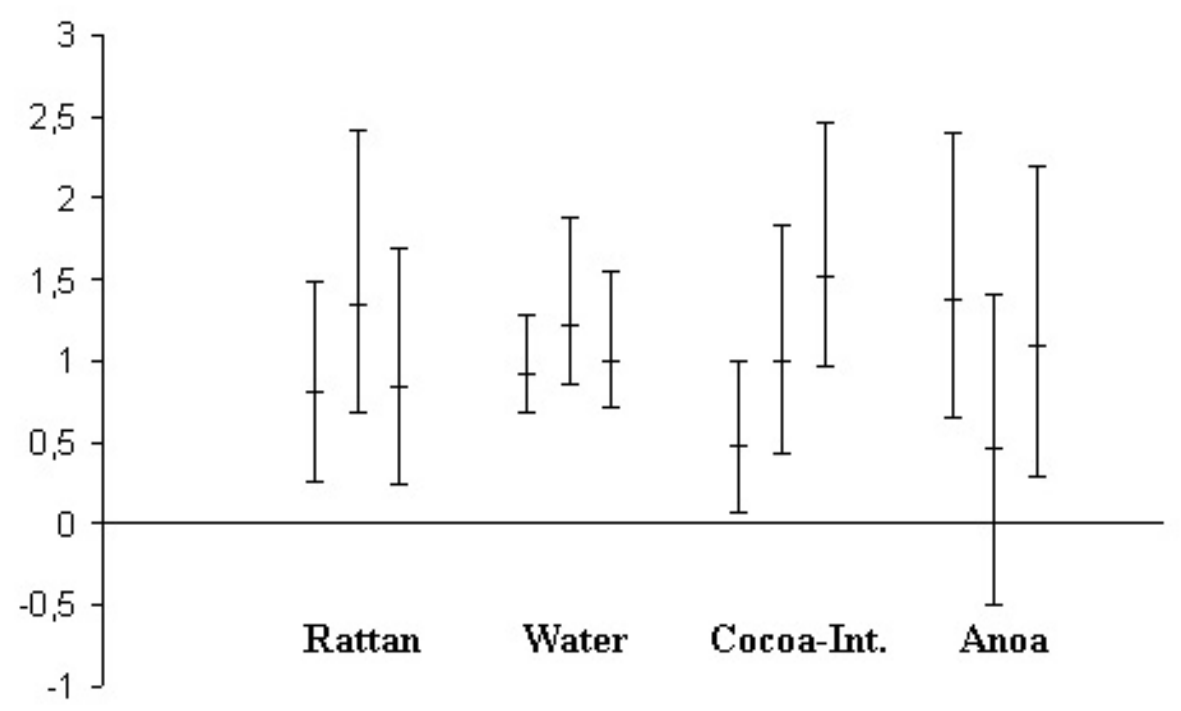

y-axis: mean MWTP; value for total sample = 1; poverty groups for each attribute (poorest, poor, less poor)

One may expect the MWTP values to be at least partly explained by whether the resource is directly used by respondents for production or not. As a first approximation, the attributes were interacted with a dummy for usage. The effect of usage on the total attribute effect is interpreted as the production value component; the remaining effect as the consumption value component. Table 3 lists shares of 'users' for the poverty groups as well as for the total sample. 
For rattan, we find that active rattan collection explains almost all of the MWTP in the case of poorest households ( $31 \%$ users). In the other two groups, less than $5 \%$ of respondent households collected rattan. An interaction therefore leads to insignificant values or even singularities. MWTP ascribed to production can thus be assumed to be zero.

Table 3: 'Users' and poverty groups

\begin{tabular}{clc}
\hline Attribute & \multicolumn{1}{c}{ Sample } & Users (\%) \\
\hline \multirow{4}{*}{ Rattan } & Total sample & 12,5 \\
& Poorest & 31,3 \\
& Poor & 4,8 \\
& less poor & 1,2 \\
\hline \multirow{4}{*}{ Water } & Total sample & 60,2 \\
& Poorest & 47,0 \\
& Poor & 67,5 \\
& less poor & 66,2 \\
\hline \multirow{4}{*}{ Cocoa } & Total sample & 75,5 \\
& Poorest & 73,5 \\
& Poor & 78,3 \\
& less poor & 74,7 \\
\hline
\end{tabular}

Regarding water, $47 \%$ of the poorest households, $68 \%$ of the poor and $66 \%$ of the less poor households were involved in paddy rice cultivation. The share of MWTP explained by involvement in production rises from the poorest to the poor, which is probably due to a higher share of involvement among the poor households. It declines again when moving from the poor to the less poor although the number of users is almost equal in these two groups (see table 2). The non-use components, on the other hand, remain rather constant across all groups.

There are only small differences in the share of households of the single poverty groups that are engaged in cocoa cultivation compared to the high mean of all households $(76 \%)$. It was not possible here to split cocoa preferences into production and consumption value component: An interaction of cocoa with the dummy for usage becomes significant but 
leaves the cocoa attribute itself insignificant. Consequently, MWTP for intensified cocoa cultivation has to be interpreted as mainly resulting from its production value. Data on usage is not available for wild anoas, as all forms of usage - above all hunting - are prohibited by law.

\section{Discussion}

Rattan collection is the most physically demanding regular work in the project region. It has a low social status, and it is carried out mainly by members of the poorest households. The share of households that has ever collected rattan is still high among the poor. This suggests that rattan availability may still have an option value to them, and serves as a potential income alternative for people. Additionally - as opposed to the poorest - the poor already have an income, which enables them to pay for keeping that option in the future. For less poor households this option of future rattan use is less important because these relatively better-off households are likely to be more resilient against negative income shocks. Less poor households possess more assets, and obtain a significant share of nonfarm income (Schwarze 2004).

The constant MWTP for the consumption value component suggests that rice cultivation is perceived as a necessity that is of similar absolute importance for all poverty groups (as reflected by similar MWTP). This is not very surprising as rice is the main staple food in the research region. The "burden" in the form of cultivation risk, however, is mainly carried by households from the poorest and the poor groups. Higher shares of users explain the increase from the poorest to the poor group. Households in the poorest poverty group derive, on average, a higher share of income from agricultural wage labour - mainly in paddy rice cultivation. In contrast, poor households depend largely on agricultural activities for income generation although non-agricultural wage labour becomes more 
important. The drop to the relatively better-off group may be - as in rattan - due to a lower dependency on rice yields for securing household livelihood. Less poor households obtain about one forth of their income from self-employed work outside of agriculture (Schwarze 2004).

MWTP for anoa is higher among the poorest households than among the poor. Two lines of explanation suggest themselves: (i) the poorest are often - by not only collecting rattan - more closely linked to and dependent on the forest and its resources. This may result in a willingness to protect the livelihood of creatures living in the forest apart from direct use, symbolically expressed by a MWTP for anoa; (ii) although it is an illegal activity, there is some evidence that households also gain benefits from hunting of anoa (Glenk et al. 2006). In this case, the direct use, in e.g. the form of hunting, is unlikely to be important for the less poor. To them, however, consumption value components such as consuming the mere knowledge on the continued existence of anoa may result in a willingness to contribute to the maintenance of viable population sizes of this endemic animal. Higher income certainly facilitates this behavior typical for environmental 'luxury goods'.

Finally, MWTP for intensified cocoa production indicated by a shade gradient increases linearly with decreasing poverty, and elasticities are around one. The share of households cultivating cocoa is almost equal among all three poverty groups. The linear increase may display an increasing budget with decreasing poverty. The linear pattern of the cocoa attribute differs from the more complex, non-linear ones found for the other attributes.

Based on our findings, we pose the hypothesis that non-linearity can be induced (i) when an ecosystem service affects human well-being for different reasons in different poverty groups, and/or (ii) when the share of people deriving well-being from an ecosystem service 
in a specific way (e.g. related to direct use) differs among poverty groups. As an aside, the cocoa attribute is the only attribute that does not represent a common-pool natural resource.

It is interesting to discuss our findings along with literature on the link between poverty and environment, particularly on the relationship between income of rural households and their dependence on natural resources. As we lack the space for a more detailed discussion, we exemplarily point out Narain et al. (2005), who also provide an extensive literature review on this issue. They analysed the relationship of actual natural common-pool resource use (wood and fodder collection) with household income rather than using stated preferences to assess the demand for ecosystem services. Regarding wood collection, they found evidence of a U-shaped relationship (dependence first declines with income and then increases), while fodder collection monotonically increased with income. Furthermore, the probability of collecting any common-pool resources at all follows an inverse U-shaped relationship. Using data on household characteristics, they provide a detailed explanation of these results. Their findings are of consequence for our study for two reasons.

First, it seems to be difficult to establish regularities of the relationship between actual resource use and demand with rural household incomes that follow monotonistic concepts. Rather, the relationship may largely depend on the natural resource observed as well as on the social and economic local conditions.

Second, MWTP is an expression of scarcity of the service demanded, and need not be related to actual resource use. However, there is potential for additional insights into the poverty-environment link by using stated preference methods - particularly the choice experiment method explored in this study. This potential is based on the possibility of (i) 
assessing demand for natural resources along a gradient of future changes rather than being restricted to revealed preferences of actual past or present use; and of (ii) considering value components such as option or existence value. In our study, the differentiation of such value components contributed to a better understanding of the suspected relationships. Prospectively, considering them allows for a more comprehensive assessment of the distributional impact of improvements or degradation of the natural resource base on the welfare of rural households.

\section{Conclusion}

From a heuristic point of view, our results suggest that anoa is a luxury good if illegal hunting is disregarded. Also, rattan appears as an inferior good while water is a necessity if elasticities between the poor and less poor households are compared. If the poorest households are included in the analysis, and accounting for production and consumption value components, this analysis holds only for water and (cautiously) for anoa. Using data on household characteristics of the poverty groups observed it is possible to provide plausible explanations for the apparent tendencies across all three poverty groups. However, these differences cannot be fully captured by a monotonistic concept of effects on wealth on the demand for the ecosystem services analysed. Quite to the contrary, the results suggest inverted U-shaped relations for the common pool resources water and rattan availability.

Concerning distributional aspects, the poorest and poor households would benefit relatively more from improvements of the rattan and water attributes. As compared to the poor for anoa, both, the poorest and the less poor, gain relatively higher benefits, however for probably very different reasons. 
Methodologically, the results of this study indicate that combining stated preference methods with a measurement of relative poverty can enrich the discussion on the povertyenvironment link, particularly with respect to the relationship of the dependence of rural households on the use of (common-pool) natural resources and income.

\section{References}

Abu Shaban, A., 2001. Rural Poverty and Poverty outreach of Social Safety Net programs in Central Sulawesi - Indonesia. MSc- thesis, Institute of Rural Development, University of Göttingen.

Barkmann, J., de Vries, K., Dietrich, N., Gerold, G., Glenk, K., Keil, A., Leemhuis, C., Marggraf, R. Confronting unfamiliarity with ecosystem functions: The case for an ecosystem service approach to environmental valuation with stated preference methods. (submitted to Ecological Economics)

Belsky, J. M., Siebert, F. S., 2002. Cultivating Cocoa: Implications of sun-grown cocoa on local food security and environmental sustainability, Agriculture and Human Values $20,277-285$.

Glenk, K., Barkmann, J., Marggraf, R., 2006. Unveiling regional preferences for biological diversity in Central Sulawesi: a choice experiment approach. STORMA Discussion Paper Series 16. Bogor, Indonesia: Universities of Göttingen and Kassel, Germany and the Institut Pertanian Bogor and Universitas Tadulako, Indonesia.

Hausman, J., McFadden, D., 1984. Specification Tests for the Multinomial Logit Model, Econometrica 52, 1219-1240.

Henry, C. J., Sharma, M., Lapenu, C., Zeller, M., 2003. Microfinance poverty assessment tool. Technical Tools Series 5, Consultative Group to Assist the Poor (CGAP) and TheWorld Bank, Washington, D.C. 
Hensher, D. A., Rose, J. M., Greene, W. H., 2005. Applied Choice Analysis: A Primer. Cambridge University Press, Cambridge, 337 pp.

Huber, J., Zwerina, K., 1996. The Importance of Utility Balance in Efficient Choice Designs, Journal of Marketing research 33, 307-317.

Keil, A., 2004. The socio-economic impact of ENSO-related drought on farm households in Central Sulawesi, Indonesia. Ph.D. thesis, Institute of Rural Development, University of Goettingen.

Kriström, B., Riera, P., 1996. Is the Income Elasticity of Environmental Improvements Less Than One? Environmental and Resource Economics 7(1), 45-55.

Krinsky, I., Robb, A. L., 1986. On approximating the statistical properties of elasticities, Review of Economics and Statistics 68, 715-719.

Louviere, J., D. Hensher, Swait, J., 2001. Stated Choice Methods - Analysis and Application. Cambridge University Press, Cambridge.

Nairan, U., Gupta, S., van 't Veld, K., 2005. Poverty and the Environment: Exploring the Relationship between Household Incomes, Private assets, and Natural Assets. Discussion paper 05-18. Washington, D.C.: Resources for the Future.

Schwarze, S., 2004. Determinants of Income Generating Activities of Rural Households, A quantitive Study in the Vicinity of the Lore-Lindu National Park in Central Sulawesi/Indonesia. Ph.D. thesis, Institute of rural Development, University of Goettingen.

Siebert, F. S., 2003. From shade- to sun-grown perennial crops in Sulawesi, Indonesia: implications for biodiversity conservation and soil fertility, Biodiversity and Conservation 11, 1889-1902. 
Zeller, M., Schwarze, S., van Rheenen, T., 2002. Statistical Sampling Frame and Methods Used for the Selection of Villages and Households in the Scope of the Research Programme on Stability of Rainforest Margins in Indonesia (STORMA). STORMA Discussion Paper Series 1, Universities of Göttingen and Kassel, Germany and the Institut Pertanian Bogor and Universitas Tadulako, Indonesia.

Zeller, M., Sharma, M., Henry, C. J., Lapenu, C., 2006. An Operational Method for Assessing the Poverty Outreach Performance of Development Policies and Projects: Results of Case Studies in Africa, Asia, and Latin America. World Development $34(3), 446-464$. 


\title{
CHAPTER 5
}

\author{
Unveiling Regional Preferences for \\ Biological Diversity in Central Sulawesi:
}

A Choice Experiment Approach 


\section{Introduction}

An important issue for the biodiversity debate is the loss of species, for which land use change is an important driving force (e.g. Pearce and Moran 1994). Land use change alters ecosystems and thus influences the provision of ecosystem goods and services. The Central Sulawesi rainforests are part of the global Wallacea biodiversity hotspot (Myers et al. 2000), and Sulawesi's moist forests were found to be among the world's most biologically valuable eco-regions (Olson and Dinerstein 1998). The Lore Lindu National Park in Central Sulawesi is one of few large forest areas left on the island of Sulawesi (Waltert et al. 2004). Therefore, ensuring its integrity is an important contribution to global biodiversity conservation efforts as demanded by the Convention on Biological Diversity. The CBD recognizes that any conservation effort needs to consider the livelihood of people that depend on the use of natural resources. Consequently, it is acknowledged that economic and social development targeting poverty eradication are priority issues in developing countries. Central Sulawesi is one of the poorest provinces in Indonesia (Suryahadi and Sumarto 2001). Thus, residents are situated between (global) conservation objectives and (local) development goals. By eliciting preferences for biodiversity held by inhabitants around the Lore Lindu National Park in Central Sulawesi, this study aims at (i) improving the knowledge base of decision makers for the development of economically informed conservation strategies, and at (ii) providing information regarding the economic behaviour of agents - mainly smallholder farmers (Schwarze 2004).

Methodologically, the purpose of this study is to improve the choice experiment approach for an estimation of locally perceived values of biodiversity. We make explicit use of an ecosystem service approach to assess functional biodiversity benefits. In particular, combining design attributes of ecosystem services with socio-demographic characteristics of individuals provides further insights into the choice behaviour of the respondents.

\section{The research area}

The research region is located in the humid tropics about 1 degree south of the equator. It comprises 7 administrative districts (kecamatan) in the province of Central Sulawesi/Indonesia. The districts of the research region mainly follow distinct valleys and their bordering mountain ranges. In more than 115 villages, it holds a population of about 
130.000 on $7.220 \mathrm{~km}^{2}$. The Lore Lindu National Park is centered within the study region and covers some $2.200 \mathrm{~km}^{2}$ of mountainous rainforest. Although already founded in 1982 , the National Park was not officially recognized until 1993, and its permanent border was not established until 1999 (Maertens 2004). A large number of species endemic to Sulawesi, including e.g. the mammals anoa (Bubalus sp.) or babirusa (Babyrousa babirussa) as well as many endemic bird species, can be found in the National Park area (Waltert et al. 2004).

The geophysical conditions of the research region vary to a large extend. The altitude ranges from just above sea level up to 2500 meters, and rainfall varies from 500 to 2500 mm per year (Maertens 2004). In combination with other heterogeneous physical features such as relief and soil conditions, the prerequisites for agricultural activity are diverse among the 7 districts.

Demographics and land use are characterized by strong dynamics, providing an interesting background in the potential area of conflict between development and conservation goals. In the period from $1980-2001$, the population increased by $60 \%$. Approximating this is an annual rate of $2.4 \%$ on average. The spatial distribution of the growth is unequal. In one of the districts (Palolo), population size doubled, and in Lore Utara it almost tripled (Maertens 2004). A large share of population growth results from migration - mainly from within the research region or other parts of Sulawesi ${ }^{1}$. There are also migrants from other islands of the Indonesian archipelago. A main driving force for this migration processes was the availability of land for agricultural use (Maertens 2004). The complex demographic history led to a high ethnical diversity (Faust et al 2003).

A large variation of land use patterns can be found (Schwarze 2004). In the course of the 'cocoa boom' in Indonesia (Akiyama and Nishio 1996), cocoa became the dominant 'cash' crop in the research region being often cultivated in the upland. Wetland rice remained the dominant 'food' crop being cultivated in the lowland, resulting in a lowland-upland dichotomy throughout the research region. Based on data from household surveys, cocoa and wetland rice together account for $57 \%$ of the net crop income (Schwarze 2004). Factors that facilitated the increasing cultivation of cocoa included, among others, the availability of suitable land, low production cost and the entrepreneurship of smallholders (Akiyama and Nishio 1996). Thus, the agricultural areas in the Lore Lindu region itself increased to a 
large extend over the past two decades (Maertens 2004). The related land use change (LUC) is closely related to the increasing production of (cash) crops (e.g. cocoa) (ibid 2004). LUC can be divided into conversion of (primary or secondary) forest into arable land, and conversion within land previously used for agriculture (e.g. wet rice fields to cocoa plantations, coffee to cocoa). Concerning forest products, collection of fuel wood is widespread for private consumption, while rattan is the most important marketed forest product (Schwarze 2004). A broad array of factors can be identified as driving forces for LUC, ranging from market forces over changes in the natural environment (e.g. lack of water for irrigation) to social processes within local communities related to in-migration (e.g. Burkard 2002b).

\section{Valuation of functional benefits of biological diversity - the ecosystem ser- vice approach}

The CBD regards ecosystems as functional units made up of a dynamic complex of plant, animal and micro-organism communities and their non-living environment. The ecosystem concept is an appropriate approach to compartmentalize nature into units that can be examined by researchers of both ecological and economic disciplines. Biodiversity is defined as the diversity within and between living organisms as well as between ecosystems. It provides flows of products and benefits to humans. Thus, biological diversity can be regarded as 'natural assets'. There are manifold links between biodiversity and ecosystems. "Diversity is a structural feature of ecosystems, and the variability among ecosystems is an element of biodiversity." (Millennium Ecosystem Assessment 2003: 9). Thus, changes in biodiversity and the related changes of ecosystems can affect the generation of ecosystem functions beneficial to humans.

In order to show in what way these benefits influence human activity, environmental economics makes use of the Total Economic Value (TEV, Randall and Stoll 1983, Pearce and Moran 1994). On a first level, use and non-use values are distinguished. Non-use values are those parts of the TEV that are most difficult to be assessed and have been subject to extensive discussion (e.g. Kahnemann 1992; Sagoff 1996), particularly concerning the socalled "existence value", (Krutilla 1967). Use values are further divided in direct (active) and indirect (passive) use values. It is mainly the indirect/ passive use values that capture functional benefits of ecosystems, such as flood control or the benefits from nutrient cy- 
cling. The TEV is based on an economic concept of value, and was introduced for improving economic valuation. The TEV does not pretend to be the only possible way of conceptualizing the values generated by nature. However, the TEV does not explain which components or 'effects' of ecosystems beneficial to humankind belong to which value category. Particular difficulties arise when functional attributes of ecosystems are concerned. In particular, it is difficult to assign an economic value directly to ecosystem functions, such as nutrient cycling. 'Ecosystem function' itself is an analytic scientific term that has no direct economic meaning: neither do ecosystem functions directly enter economic production functions, nor are consumers sufficiently aware of their economic implications. Therefore, a concept that mediates between ecological processes and their impact on humans is required. What may be called ecosystem service approach is a promising complement to the TEV to fill this conceptual gap (Barkmann et al. subm. a). As de Groot et al. (2002: 395) put it: “...observed ecosystem functions are reconceptualized as `ecosystem goods and services ${ }^{3}$ when human values are implied. The primary insight here is that the concept of ecosystem goods and services is inherently anthropocentric: it is the presence of human beings as valuing agents that enables the translation of basic ecological structures and processes into value-laden entities."

The 'translation' process clarifies that the effects of ecosystem structures, functions and processes on human activity are the objects of valuation, not the ecosystem structure, function or process themselves. For economic valuation of ecosystem services, a large variety of valuation techniques have been developed during the past decades. They are commonly divided into revealed and stated preference methods, the first using actual market data, the second being a survey-based technique and assessing values from hypothetical markets (Adamowicz 1998a). As the effects that are investigated by revealed preference (RP) methods are already captured in existing markets, an ecosystem service approach might be particularly beneficial for stated preference (SP) methods. A prerequisite to perceive a benefit in the first place is the awareness of the interrelation between humans and nature. Awareness in turn is initiated by recognition, which needs prior identification. A number of implications are known through experience and tradition, especially those concerning the production of (material) goods. However, although „the science of ecology has matured, mankind's knowledge about the interconnectedness of ecosystem processes and structures has grown" leading to "...increasing concern about the effects of human actions on ecosystems" (Bingham et al. 1995:76), much more remains unknown both for ecolo- 
gists and laymen or simply not understood for the latter. This lack of scientific data on ecological relationships and functioning due to the complexity of nature, which can be termed "ignorance" (Fromm 2000), and, similarly, the lack of people's awareness of existing knowledge affect environmental and ecosystem valuation by limiting the array of services that are potentially valuable. Furthermore, it limits people's ability to express their preferences for services of ecosystems already identified and recognized. Consequently, it can be doubted, whether people are able to express meaningful preferences if they had to make decisions concerning complex ecosystem functioning (Nunes and v.d. Bergh 2001). The major conceptual improvement of the ecosystem service approach is to 'translate' complex aspects of ecological functions into concepts that non-experts recognize as important for their lives. In this form, they are potentially valuable by people. By using the ecosystem service approach in this case study for an assessment of functional benefits of ecosystems, its applicability and limitations can be evaluated. A more detailed account of the ecosystem service approach can be found in Barkmann et al. (subm. a).

\section{The choice experiment}

\subsection{Introduction to the method}

A "Choice Experiment" (CE) is a stated preference (SP) method that was first developed in transport and marketing research (Louviere et al. 2001). In recent years, the CE became increasingly popular in environmental valuation (Bennet and Blamey 2001). Due to the advantage of CE to allow for simultaneous elicitation of multi-attribute benefits (use and non-use, e.g. in a policy scenario), CE was preferred over the other popular stated preference technique (contingent valuation) for the purpose of this study. Further advantages include the possibility to explicitly incorporate substitute goods and some evidence that $\mathrm{CE}$ is less susceptible to bias (Morrison et al. 1996). However, CVM “...may be better suited to situations where changes in the total economic value of a non-market good are at issue or where environmental resources are hard to describe using attributes" (Colombo et al 2005: 82). Recent applications of the CE in environmental valuation investigated, e.g., moose management in Finland (Horne and Petäjistö 2003) and off-farm effects of soil erosion in Spain (Colombo et al. 2005). Studies using CE or similar techniques for the valuation of functional benefits of biodiversity in rural areas of so-called developing countries are rare. An exception are, e.g., Pattanayak and Kramer (2001) using contingent valuation method for pricing drought mitigation benefits to local farmers in eastern Indonesia. 
In a $\mathrm{CE}$, consumers state their preference by (repeated) choice among different alternatives or goods following an experimental plan. Having foundations in Lancastarian consumer theory (Lancaster 1966, 1991), the goods are being transformed into objective characteristics (attributes) from which the consumer is assumed to derive utility ('well-being' or 'satisfaction'). In environmental choice modelling, the alternatives are often described as different development or policy scenarios (Bennett 1999). The decision context including the description and specification of the options or alternatives constitute the stimuli. The decision itself (which is a choice in choice experiments) is the elicited response (Adamowicz et al. 1998a). The decision-maker is assumed to be an individual (Louviere et al. 2001). The term 'individual' reflects that $\mathrm{CE}$ is based on disaggregate data collected in surveys. The 'individual' decision-making entity can be a single person, but can also be defined as a group, e.g. a household. In this case, it is important to note that the internal decision-making process within a group is not captured. Choice modelling is based on random utility theory (RUT) (e.g. Thurstone 1927, McFadden 1973, Manski 1977). Before characterising RUT and the random utility model, assumptions about the process used by the decision-maker to evaluate alternatives of a choice set and to make a choice, the decision rule, are briefly outlined. The common decision rule used in the random utility approach is utility maximisation. It is based on neoclassical economic theory, namely utility theory, which assumes that the decision-maker's preference for an alternative is captured by a value, called utility. The decision-maker selects the alternative in the choice set with the highest utility (Ben Akiva and Bierlaire 1999). This rule is widely adopted within (micro-) economics. There are some assumptions associated with the application of this concept: it is assumed that individuals "... have full information, use all information and are compensatory in their decisions (i.e. they are willing to trade-off any one attribute for others)" (Louviere et al. 2001: 254), or in short, that individuals have a perfect discrimination capability. However, the researcher has incomplete information and faces uncertainty ${ }^{4}$. Uncertainty may arise due to: (i) unobserved alternative attributes, (ii) unobserved individual characteristics (unobserved taste variations), (iii) measurement errors and finally (iv) proxy or instrumental variables rather than the actual variables that appear in the utility function (Manski 1977). Due to this uncertainty, it is appropriate from the analyst's point of view to incorporate a probabilistic dimension in the model of the decision-making process. Some models assume intrinsically probabilistic decision rules. The model applied here, however, assumes a deterministic utility and a probabilistic decision-making process, re- 
flecting the randomness arising from uncertainty. Based on the findings of Thurstone (1927), a consumer "... may not choose what seems to the analyst to be the preferred alternative [when choosing between pairs of offerings consumers like best]. Such variations in choice can be explained by proposing a random component of consumer's utility function" (Adamowicz et al. 1998a: 9).

Utility can therefore be partionated into a deterministic, systematic component or 'representative utility' and a random, stochastic part of utility “... reflecting [the] unobserved individual idiosyncrasies of taste" (Louviere et al. 2001: 38):

$$
\mathrm{U}_{\mathrm{ij}}=\mathrm{V}_{\mathrm{ij}}\left(\mathrm{X}_{\mathrm{ij}}, \mathrm{S}_{\mathrm{i}}\right)+\varepsilon_{\mathrm{ij}} \forall \mathrm{j} \in \mathrm{C}_{\mathrm{i}}
$$

where $U_{i j}$ is the utility an individual $i$ is assumed to obtain from of alternative $j$ in choice set $\mathrm{C}_{\mathrm{i}}$, all $\mathrm{j}, \mathrm{k} \in \mathrm{C}_{\mathrm{i}} . \mathrm{V}_{\mathrm{ij}}$ is the deterministic (systematic) part that is held to be a function of the attributes of alternatives $\left(\mathrm{X}_{\mathrm{ij}}\right.$, which is a vector of attributes as perceived by individual $\mathrm{i}$ for alternative $\mathrm{j}$ ) and characteristics of the individual $\left(\mathrm{S}_{\mathrm{i}}\right) . \varepsilon_{\mathrm{ij}}$ is the random term. As the analyst is unable to measure $\varepsilon_{\mathrm{ij}}{ }^{5}$, s/he cannot determine exactly why an individual chooses an alternative $\mathrm{j}$ out of a set of competing options $\mathrm{C}_{\mathrm{i}} \forall \mathrm{j}, \mathrm{k} \in \mathrm{C}_{\mathrm{i}}$ and $\mathrm{i}=1, \ldots \mathrm{I}$. However, the systematic component $\mathrm{V}_{\mathrm{ij}}$ still allows making probabilistic statements about the outcome of such a choice. This leads to equation (2) and is called a Random Utility Model. The probability that individual $\mathrm{i}$ prefers to choose alternative $\mathrm{j}$ over any alternative $\mathrm{k}$ out of a choice set $C_{n}$ with $n=1,2, \ldots N$ and all $\mathrm{j}, \mathrm{k} \in \mathrm{C}_{\mathrm{n}}$ can be expressed as:

$$
\begin{aligned}
\mathrm{P}\left(\mathrm{j} \mid \mathrm{C}_{\mathrm{i}}\right)=\mathrm{P}\left(\mathrm{U}_{\mathrm{ij}}>\mathrm{U}_{\mathrm{ik}}\right) & =\mathrm{P}\left[\left(\mathrm{V}_{\mathrm{ij}}+\varepsilon_{\mathrm{ij}}\right)>\left(\mathrm{V}_{\mathrm{ik}}+\varepsilon_{\mathrm{ik}}\right)\right] \forall \mathrm{j}, \mathrm{k} \in \mathrm{C}_{\mathrm{i}} \text { and } \mathrm{j} \neq \mathrm{k} \neq 0 \\
& =\mathrm{P}\left[\left(\mathrm{V}_{\mathrm{ij}}-\mathrm{V}_{\mathrm{ik}}\right)>\left(\varepsilon_{\mathrm{ij}}-\varepsilon_{\mathrm{ik}}\right)\right] \forall \mathrm{j}, \mathrm{k} \in \mathrm{C}_{\mathrm{i}} \text { and } \mathrm{j} \neq \mathrm{k} \neq 0
\end{aligned}
$$

The model differs from the traditional economic model of consumer demand in the way that it is a "... more complex but realistic assumption about individual behaviour to account for the analyst's inability to fully represent all variables that explain preferences in the utility function" (Louviere et al. 2001: 40).

In order to be able to estimate the probabilities of equation ( $2 a / b)$, assumptions have to be made about the nature of the random error term. The majority of discrete choice models assumes that the random term is independently and identically distributed (IID), and re- 
lated to the choice probability with a Type I extreme-value (Gumbel, Weibull, doubleexponential) distribution (with zero mean and a variance of $\mu^{2}$ ). As a consequence of the IID assumption, the alternatives have to be independent from irrelevant alternatives (IIA). I.e., the ratio of probabilities of choosing alternative $j$ over $k$ out of a choice set $C_{i}$ remains unaffected by the presence or absence of any other alternative. All assumptions are given now for the conditional or multinomial logit model (MNL, McFadden 1973):

$$
P\left(j \mid C_{i}\right)=\frac{\exp ^{\mu V_{j i}}}{\sum_{k \in C_{i}} \exp ^{\mu V_{k i}}}
$$

where $\mu$ is the scale parameter usually set to 1 (constant error variances) and inversely proportional to the standard deviation of the error terms (Louviere et al. 2001). $\mathrm{V}_{\mathrm{ij}}$ is assumed to be linear and additive in parameters:

$$
V_{i j}=\alpha A S C_{j}+\beta_{1} f\left(X_{1}\right)+\beta_{2} f\left(X_{2}\right)+\cdots+\beta_{N} f\left(X_{N}\right)
$$

where $X_{n}$ is the attribute level of attribute $n(n=1,2, \ldots N)$ of the $j^{\text {th }}$ alternative and $\beta_{n}$ is the parameter value associated with attribute $n . \mathrm{ASC}_{\mathrm{j}}$ is short for alternative specific constants that equal 1 for alternative $\mathrm{j}$ (otherwise: 0 ), and can be included for $\mathrm{j}-1$ alternatives. If the alternatives are generic (unspecific, i.e. unlabelled), the ASCs are equal. "It is the role of the ASCs to take up any variation in choices that cannot be explained by either the attributes or the socio-economic variables" (Bennett 1999: 16). By using a statistical estimation technique such as 'maximum likelihood estimation' (MLE) available in statistical software packages, e.g. LIMDEP (Green 2003), estimates for the coefficients associated with the attributes can be obtained.

Socio-economic, attitudinal or survey-related variables can be interacted either with the ASC and/or the attributes. This is a way to incorporate heterogeneity in tastes into the model. By doing so, the analyst is able to better understand (i) why respondents preferred certain alternatives relative to others and (ii) what factors may influence the importance of attributes on the probability of an alternative to be chosen (i.e. the main effects). Accounting for heterogeneity of tastes may also improve predictive model capabilities. 
If the variance of unobserved components of the utility function or scale is different among (subsets of) alternatives, e.g. due to heterogeneous preferences, the IID and IIA assumptions do not hold. One test frequently applied in literature is a Hausman type test (Hausman and McFadden 1984). If IIA is violated, the MNL should not be used and models such as the Nested Logit (NL) (Louviere et al. 2001) or Random Parameters Logit (RPL) (Train 1998) should be considered that relax these assumptions (Louviere et al. 2001). Accounting for preference heterogeneity by interacting socioeconomic and/or attitudinal attributes may help to mitigate IIA violations (Train 1986).

As the parameters $\beta_{\mathrm{n}}$ in $\mathrm{V}_{\mathrm{j}}$ are confounded with $\mu$ and thus are not separable, they cannot be interpreted in absolute terms. "In other words, the extent of the variance of the statistical error involved in the estimation process has an impact on the absolute magnitude of the $\beta$ coefficients" (Bennett 1999: 18). The estimated probabilities using equation (3) can, consequently, merely serve as an indication for the relative utility an individual obtains from choosing a particular alternative from a choice set. However, the scale parameters are cancelled out if marginal rates of substitution between any pair of attributes a and $b$ is estimated. If one of the attributes reflects 'cost', the trade-offs are 'part-worths' or 'implicit prices'. For any attribute $\mathrm{n}$, they can be calculated by:

$$
\operatorname{Part}-\operatorname{worth}(n)=-\left(\frac{\mu \beta_{n}}{\mu \beta_{\text {cost }}}\right)=-\left(\frac{\beta_{n}}{\beta_{\text {cost }}}\right)
$$

where $\beta_{\mathrm{n}}$ is the coefficient of attribute $\mathrm{n}$, and $\beta_{\text {cost }}$ is the coefficient of the 'cost' attribute (Bennett and Blamey 2001). A positive coefficient $\beta_{\mathrm{n}}$ indicates that more of an attribute is associated with positive utility, a negative coefficient that more of an attribute is associated with disutility. 'Cost' in this context is understood as 'the amount given up in a voluntary exchange'. The implicit prices reflect the marginal willingness to pay (MWTP) for a marginal change in a single attribute on a "ceteris paribus" basis (Bennett and Blamey 2001).

\subsection{Choice experiment - a short summary}

In a choice experiment, respondents choose between alternatives or 'goods' that alternative with the highest (expected) utility. In the environmental context, the choice offered usually consists of a number of "proposed changes" and a "status quo option", for example be- 
tween different management alternatives for a certain area and the present situation. These goods are characterized by a number of attributes that ideally comprise all relevant aspects a respondent ascribes to a certain 'good' at stake. The attributes - being quantitative or qualitative dimensions of characteristics - in turn, consist of a number of levels. Within and between the choice sets presented to the respondent, the attribute levels and thus the goods or commodities presented vary, usually according to an experimental design. Coefficients for the attributes in a linear and additive expression of the utility function can be calculated by maximum likelihood estimation (MLE) procedures. If one attribute reflects 'cost', these parameters allow for a calculation of implicit prices, or part-worth utilities, preference ratios and elasticities. It is worth noting that it is also possible to infer the amount people are willing to pay for a shift from a 'status quo' bundle of attribute levels to an alternative bundle. Thus, willingness to pay for a specific alternative outcome can be calculated. "These estimates of compensating surpluses are consistent with the principles of welfare economics and are therefore suited for inclusion as value estimates in benefit cost analyses of policy alternatives" (Bennett 1999: 3). Benefit cost analysis, however, is not the aim of this study. Interacting socio-demographic or attitudinal variables allows for better understanding the choice behaviour of respondents.

\section{The choice experiment design}

“... the characteristics model of consumer behaviour is designed to simplify reality. Fitting it into any given situation ultimately involves some art as well as some science” (Lancaster 1991: 67).

The design of choice experiments includes decisions about the nature of the stimuli of choice. These decisions are concerned with (i) the attributes of an alternative and their levels, (ii) the nature of the 'cost' attribute, (iii) the situation in which the alternatives are presented to the respondent ('framing'), (iv) the definition of a base (reference) option and (v) the experimental plan that allows for statistical estimation of the attributes' coefficients.

\subsection{Attribute selection}

Out of the universe of potential "characteristics" of biological diversity and ecosystem services, which are to be selected? As a way to guide the decisions, a (multidimensional) space can be created, which is demarcated by (i) the objectives of the analyst and the re- 
search question, (ii) constraints imposed by the respondents (relevance, cognitive burden/ task complexity), (iii) the social context (e.g. problems concerning strategic behaviour) as well as (iv) the 'natural' environment in which the survey is being conducted.

Generally, only relevant characteristics should be considered in a choice experiment. According to Lancaster (1991: 56), a characteristic is "relevant to the situation if ignoring its existence would change our conclusions about choice or ordering of the goods by the consumers". Blamey et al. (1997) distinguishes between demand-relevance and policy- or context-relevance. Demand relevance refers to the relative importance people assign to an attribute (demand-driven), whilst policy relevance refers to what the government or researchers perceive to be important (supply-driven). In order to be sure that people make sense out of an attribute offered, any “... supply-driven attribute should always be screened from a demand-perspective" (Blamey et al. 1997: 7). Task complexity rises with the number of attributes offered. Alpizar et al. (2001) note that more than 4 to 5 attributes may have an unwarranted effect on the quality of the data collected. Louviere (2001), however, reports that there is no evidence that the number of attributes or alternatives would have significant impact on the estimated parameter values but that there is some evidence that it can have impact on the random error term. For details concerning attributes in CE and the related task complexity see also e.g. Blamey et al. (1998), Swait and Adamowicz (1996).

Figure 1. Results of the pre-study. Benefits derived by the forest

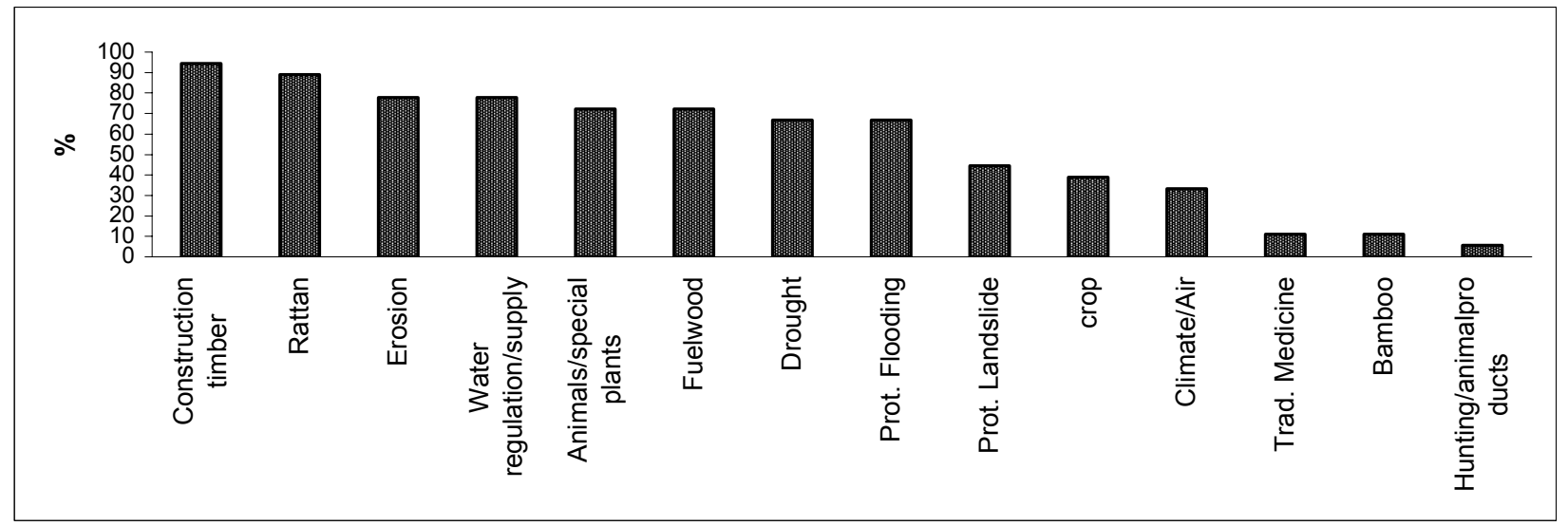

Source: own calculations; Percent mentioned by $n=18$ respondents.

For the attributes used in this study, selection followed aspects of relevance, and the maximum number of attributes was limited to 5. As well as the choice of appropriate levels, attribute selection was based on information gathered in individual and peer-group interviews ${ }^{6}$ in various villages of the research region. Furthermore, information and data 
obtained by experts as well as from literature (e.g. Belsky and Siebert 2003; Siebert 2002; Keil 2004) were incorporated. There was high awareness of functional (indirect) benefits, particularly concerning water-related issues such as water supply or flood protection/erosion (Figure 1). The attributes chosen and the respective levels are listed in Table 1 and are described in detail below.

Table 1. Attributes and levels

\begin{tabular}{|c|c|c|c|c|}
\hline & Attribute label & Levels & $\begin{array}{c}\text { Ecosystem } \\
\text { service cate- } \\
\text { gory }\end{array}$ & $\begin{array}{l}\text { Value type } \\
\text { (TEV) }\end{array}$ \\
\hline Rattan & $\begin{array}{l}\text { availability of rattan (Cala- } \\
\text { mus spp.) as expressed in } \\
\text { distance from village }\end{array}$ & $\begin{array}{c}{[\mathrm{km}]} \\
5,10,15,20\end{array}$ & $\begin{array}{l}\text { provisioning } \\
\text { service }\end{array}$ & $\begin{array}{l}\text { Direct use/ } \\
\text { Option value }\end{array}$ \\
\hline Water & $\begin{array}{l}\text { availability of irrigation } \\
\text { water for wet rice cultiva- } \\
\text { tion as expressed in number } \\
\text { of months with water scar- } \\
\text { city }\end{array}$ & $\begin{array}{c}{[\text { No of months }]} \\
0,1,2,3\end{array}$ & $\begin{array}{l}\text { regulating ser- } \\
\text { vice }\end{array}$ & $\begin{array}{l}\text { Indirect use } \\
\text { value }\end{array}$ \\
\hline Cocoa & $\begin{array}{l}\text { preponderance of cocoa } \\
\text { plantations differing along a } \\
\text { shade tree gradient }\end{array}$ & $\begin{array}{c}{[\% \text { under shade }]} \\
5,35,65,95\end{array}$ & $\begin{array}{l}\text { regulating ser- } \\
\text { vices }\end{array}$ & $\begin{array}{l}\text { Indirect use / } \\
\text { Option value }\end{array}$ \\
\hline Anoa & $\begin{array}{l}\text { populations of different } \\
\text { sizes of the endemic dwarf } \\
\text { buffalo anoa (Bubalus sp.) }\end{array}$ & $\begin{array}{c}{[\text { No of animals }]} \\
10,180,350^{\S}, 520\end{array}$ & $\begin{array}{l}\text { cultural/ } \\
\text { provisioning } \\
\text { service }\end{array}$ & $\begin{array}{c}\text { Existence/ } \\
\text { direct use value }\end{array}$ \\
\hline $\begin{array}{l}\text { 'Cost' } \\
\text { attribute }\end{array}$ & $\begin{array}{l}\text { extra taxes or donation to } \\
\text { village fund }\end{array}$ & $\begin{array}{c}{[1 \text { o00 IDR per year }]} \\
0,18,36,54,72\end{array}$ & - & - \\
\hline
\end{tabular}

Cocoa (Theobroma sp.) is the dominant cash crop in the research region. Increasingly, production is intensified, resulting in monocultures with no or merely low levels of (planted) shade trees (e.g. Gliricidia sepium). Despite the generation of higher yields on average, intensification to sun-grown cocoa leads to higher agronomic and socioeconomic risks, e.g. soil degradation and negative impacts on local food security (Belsky and Siebert 2003). Shade-grown cocoa farming can provide habitat for a wide range of native species, thus contributing to biodiversity conservation, while soil productivity may be retained to a certain degree (Siebert 2002). Thus, this attribute implies trade-offs between (short-term) economic goals and (long-term) biodiversity conservation objectives. The trade-offs are mapped by shade tree gradient (5-35-65-95\% under shade) for preponderance of cocoa plantations ranging from full-sun grown cocoa on one side, and cocoa cultivated beneath primary or secondary forest vegetation on the other side. 
Sufficient water for irrigation is essential for the production of wetland rice, the region's main food crop. There is indication that deforestation on the hillsides leads to water shortages in the dry months of the year, particularly when the water originates from small watersheds in combination with prevailing simple irrigation techniques (own data ${ }^{7}$, Burkard 2002b). Keil (2004) showed that perceptional data on irrigation water fits quite well to the related measured precipitation. Thus, an attribute was created relating effects of land conversion on slopes to the provision of irrigation water. The levels were described as the perceived months with water shortage for irrigation purposes ${ }^{8}$.

Rattan (Calamus spp.) is the most important marketed forest product and serves as a secondary income source for locals, particularly at the poorer margin of the population (Maertens 2004, Schwarze 2004). If harvests fail, e.g., as a cause of natural disasters (droughts, flooding), rattan can serve an additional income alternative, and thus has an 'option' or insurance value component. In accordance with results from our pre-study investigations, previous research of Zeller and Birner (2003) showed that the encounter distance from the forest edge to harvesting locations increased from $4.4 \mathrm{~km}$ on average in 1990 to $14.5 \mathrm{~km}$ in 2001, indicating an overuse of rattan resources. Rattan supplies are in decline, while market demand remains strong. This suggests that rattan resources will become increasingly scarce, particularly affecting large-diameter canes (Siebert 2001). The rattan attribute was operationalized by the encounter distance to the nearest extracting location $(5,10,15,20 \mathrm{~km})$.

An important issue for the biodiversity debate is the loss of species. The Sulawesi region is an important centre for species endemism, and the Lore Lindu National Park harbours many of Sulawesi's endemic mammals and birds (Waltert et al. 2004, Whitten et al. 1987). Thus, conservation of the park's species is in line with global conservation objectives. However, large forest clearings inside the National Park show that the forest frontier in the research region is by no means secured (Weber 2005). To find out how conservation objectives are supported by the local population around the National Park, different population sizes of the dwarf-buffalo anoa (Bupalus depressicornis, B. quarlesi) were included as an attribute exemplarily for an endemic species. Population sizes in the research region are in decline (Zeller and Birner 2003, Burton et al. 2005). Burton et al. (2005) identified the 
Lore Lindu National Park as one of the areas on which to focus conservation efforts of this animal.

Individual interviews showed that anoa was a widely known forest species. As a result of discussions with locals and experts, the present state was estimated as 350 individuals living in the forests of the Lore Lindu region. Anoa populations provide a mixture of different TEV value categories. One is 'existence' value, e.g. the “... concern to protect [...] although he or she has never seen one and is never likely to ..." (Pearce and Moran 1994: 12). However, interactions between the living environment and the population are common, implying that other value components such as direct use value (e.g. hunting) or existence value (e.g. intergenerational aspects) have to be considered as well. The latter ones might even be of greater importance (see Burton et al. 2005). It was found in pre-tests and numerous conversations with the locals that the relationship towards anoa is ambiguous: although most people value anoa for the different reasons listed above, many also perceive anoa as a ferocious and wild animal, and thus as a threat if encountered ${ }^{9}$. If the latter aspect dominates the attitude of individuals, it may also happen that those may prefer smaller over larger populations.

A negative sign of the utility coefficient was expected for 'water', 'rattan' and 'cocoa'. A positive one for 'anoa', assuming that value aspects are more important on average. ${ }^{10}$

The 'cost' attribute was split-sampled as (i) a rise in "house- and land" tax (Pajak Bumi Bangunan $(P B B)$ ) or a donation to a village fund (Iuran dana pembangunan desa) affecting every household of the research region as well as (ii) a monthly or yearly payment scheme $^{11}$. According to Whittington (1998), the highest price should be rejected by $90 \%$ $95 \%$ of the respondents in CVM studies. The levels were derived following this rule of thumb by using different 'prices' in pre-tests additional to information obtained by a payment-ladder approach for the subjectively 'best' option (e.g. Bateman et al. 2002). The income distribution in the study region is highly skewed: Some people live in concrete houses, have satellite television and sometimes even own a car. Others share a wooden hut without electricity. Some of the first group didn't hesitate to express a willingness to pay exceeding double the highest amount finally offered in the choice experiment (12.000 IDR per month, about 1,4 US\$), whereas some members of the second group were virtually struck by the same amount. Offering the highest price to the poor could embarrass them, 
and could make "... the interviewers look insensitive and/or uninformed" (Whittington 1998:8). Hence, the range of 'price' levels was cut at the high end, accepting an underestimation of WTP and other welfare-theoretic measures by ignoring the higher WTP of a low percentage of rather well-situated people. As no specific or unique time period could be defined to achieve a proposed improvement (and time-preferences respectively interest rates for continuous payment are unknown), WTP values are calculated on a one years' basis.

It is suggesting to use monetary 'cost' terms, as it is the 'universal' medium for exchange. However, it might be useful in so-called developing countries and semi-subsistence economies to employ other forms of payment. Shyamsundar and Kramer (1996), for example, use rice quantities in a case study on Madagascar, Mekonen (2000) offers payment in cash or kind for management of community woodland in rural Ethiopia, both using CV methods. Although rice is a staple food in the study region, it does not seem appropriate to use it for the 'cost' attribute. People may value a specific quantity of rice differently due to the following reasons: (i) varying breeds of rice are planted and sold with differing prices. (ii) There is a disparity between people owning rice fields and others, who do not own but work on rice fields as seasonal farm hands and finally those, who are not engaged in rice cultivation at all. This - in addition to fluctuating market prices - would result in a wide range of uncertainties for an ex post translation of rice quantities into monetary units. Another alternative payment method especially addressing the poorer parts of the population could be 'wage labour' (compare to Adamowicz et al. 1997a). However, it seems to be (i) morally questionable to 'let the poor work', and (ii) hard to find a specific and appropriate purpose for the work. Exploratory studies have shown that all people are familiar with monetary issues, though some were hardly able to pay some of the offered amounts. Therefore, following Whittington (1998), the use and interpretation of stated preference values will be bounded by respondents' ability to pay and by their willingness to pay. Before making their choices, respondents were reminded emphatically of their budget constraints in order to reduce bias resulting from strategic behaviour or interviewer compliance.

Bias may also arise from the order in which the attributes appear on the choice cards. In order to minimize such effects, a second version of choice sets has been created with an inverting order of the attributes. The two versions were randomly assigned to respondents in a way that approximately each half of the respondents received one of the versions. 
All attributes entered the analysis as continuous attributes 'anoa', 'water', 'cocoa' and 'rattan' using actual values. It is assumed that attribute levels reflect an individual's utility in a linear fashion. For the amount of shade in cocoa, a quadratic utility surface was included in the analysis because an (inverted) unimodal preference curve appeared likely (i.e. we assumed a threshold for intensification).

\subsection{Framing}

"The questionaire must strive to establish the frame in respondents' minds which is appropriate to the circumstances of the [...] decision being made" (Bennett 1999: 9). This step is called 'framing'. An appropriate context must be developed, in which the hypothetical scenarios are presented to the respondent. If the context is misleading or not credible, there is little incentive for respondents to take the choice task seriously. At the beginning of the questionaire, respondents were sensitized to potential changes in the future by letting them recall past changes in the fields of agriculture, infrastructure and living conditions. Thereafter, they were supposed to choose those 3 out of 6 competing development issues, which they thought should have priority for spending public money. Besides contributing to establish "a frame of reference for respondents", this question also served as a "warm-up" exercise" for the choice task (Bennett \& Adamowicz 2001: 52).

In the study, the 5 attributes were defined as results a government development program on a village scale. Multi-level development programs that address many different aspects are not unfamiliar to the locals. One example is the CSIADP (Central Sulawesi Integrated Area and Development Program, ANZDEC 1997). Intentions to link such a program to an actual policy process taking place in the Lore Lindu region in order to enhance credibility were abandoned. Rather than concentrating on impacts of attribute changes on their life, respondents tended to exhaustively discuss issues of e.g. property rights, or the management of the National Park area in pre-tests. Hence, it was not the question whether people took the informational context and therefore the choice task seriously. Instead, it was a problem that people took it too serious. Under such circumstances, choices could be increasingly biased by strategic behaviour (e.g. with respect to property rights) or be perceived as some kind of 'referendum' about policy measures described. A referendum-type frame can be desirable in a different context. In our case, however, we primarily focus on 
preferences for ecosystem services. In order to minimize strategic behaviour and accentuate neutrality, the program was not specified in detail. Respondents were repeatedly reminded that this research is not part of any NGO or governmental activity, and that there are no pre-defined interests regarding the future of the National Park and its surroundings. Further, people were sensitized to changes that occurred in the past and the desired direction of changes for the future by several questions addressing these issues prior to the choice experiment.

Presented orally only, the provision of the information regarding the attributes caused some fatigue and confusion among the respondents, indicating a high cognitive demand. The education of $53 \%$ of the respondents did not transcend elementary school, indicating a rather low level of literacy. Jae and Delvecchio (2004) found that the presence of a visual decision aid can improve choice by reducing task complexity and facilitating the mediation of information for low-literacy consumers. Thus, pictures containing the main information were painted in discussion with the local farmers in order to meet their perception. Painting was preferred to photographs as people's interest in the latter mainly consisted of the specific location shown on the picture, and in what differed from the conditions in their village. The paintings allowed for a more generalized visualization of the issues (attributes) in which village-specific details are less important. The pictures were collected in a picture book $^{12}$. The pictures and their respective informational background were simultaneously presented to the respondent during the explanation of the attributes. Visualizations were also included in the choice cards (see appendix 1).

Often, the first language of the respondents was not Indonesian (Bahasa Indonesia), but their local language. Every ethnicity again has its own language. Additionally, English is a secondary language for both the first author and his assistant. Furthermore, there are differences in the urban and rural use of Bahasa Indonesia. Understandably, special attention had to be paid on the wording during several pre-tests to avoid misunderstandings. For final refinement of the questionaire, a pilot study was conducted $(n=96)$.

\subsection{Experimental design and status quo}

Out of the $4^{5}$ possible combinations of attribute levels, an orthogonal fraction of 16 was selected by means of experimental design techniques (Louviere et al. 2001) and combined 
into choice scenarios that consisted of two (generic) alternatives A and B and a status-quo option presented on choice cards. The computed design was further improved following the design principles mentioned by Huber and Zwerina (1996), particularly with respect to level balance and minimal overlap. The sets of the main-effects experimental design were blocked into 4 versions, so that each respondent faced 4 choices.

Inclusion of a status quo option allows for economic welfare measures (e.g. Louviere et al. 2001). The status quo ('do-nothing') option is the reference point from which the scenarios the researcher offers to the respondents diverge (Bennett 1999). "Selection of a base may have an important influence on CM results by affecting the utility of the base option relative to others, and by influencing the framing of outcomes, for example, as gains or losses" (Blamey et al. 1997: 14). The status-quo was described as the present situation, because future attribute level changes could not easily be predicted and may differ in discrete villages. Particularly due to the heterogeneity concerning the environmental and socioeconomic conditions of the villages, it would have been plainly unrealistic to define one common base for all villages. Therefore, the respondents were directly asked which attribute level was most similar to their perception of the present situation (cocoa, water, rat$\tan )^{13}$. By this means, respondents created their 'individual' status-quo or “...'selfexplicated' alternative" (Bennet and Blamey 2001: 138). This approach is consistent with choice theory (Louviere et al. 2001). It is expected that such an approach improves the predictive properties of the model for the following reasons. (i) It addresses local heterogeneity better than a 'constant base reference'. (ii) Prior to the choice task, the respondents had to intensively engage themselves with the present state regarding the attributes. As a result, respondents are expected to be more certain about their choices. (iii) Involving respondents in the preparation for the choice experiment could suspend some 'disbelief' about the choice task and the survey. However, there might be some implications for welfare analysis if actual and perceived values diverge (Adamowicz et al. 1997b). A typical choice set is shown in appendix 1 .

\subsection{Data collection}

In order to maximise the benefits of data exchange with other projects in STORMA and to enable aggregation of the (perceived) values for ecosystem services by a sampled population on a regional level in congruency with the STORMA research region, the common 
sampling frame of STORMA was adopted (for details, see Zeller et al. 2002). The choice experiment survey was administered to 301 randomly selected households in 12 villages of the research region. In-person interviews were conducted by 6 well-trained and graduated (B.Sc. UNTAD/Palu) local enumerators. To minimize potential interviewer effects, enumerators were randomly assigned to the households.

Additional data was collected including data related to the choice task (e.g. difficulty, confusion), background data concerning the attributes (e.g. past experience, present use) as well as several socio-economic characteristics (e.g. age, education, wealth status). The socio-demographic variables listed in table 2 are used in the succeeding analysis. Additionally, attitude items on value, risk and coping issues were included (for analysis see Barkmann et al. subm. $a / b$ )

Table 2. Socio-demographic Variables

\begin{tabular}{|c|c|c|c|}
\hline Variable & Description & Mean & Interaction \\
\hline edu & Years in school (respondent) & 7.68 & ASC,Cost \\
\hline imppay & $\begin{array}{l}5 \text { point Likert score for importance ascribed to paying tax / village } \\
\text { fund on household well-being } \\
\text { [1: not important; } 5 \text { : very important }]\end{array}$ & 3.03 & ASC \\
\hline$K L$ & $\begin{array}{l}\text { Dummy variable showing whether respondent is from Lore or } \mathrm{Ku}- \\
\text { lawi districts }\end{array}$ & 0.52 & ASC \\
\hline colrat & Dummy variable showing if a respondent is collecting rattan & 0.13 & Rattan \\
\hline invwat & $\begin{array}{l}\text { Dummy variable showing if a household is involved in wet rice } \\
\text { cultivation }\end{array}$ & 0.60 & Water \\
\hline agecoc & Maximum age of cocoa plantations owned by respondent & 4.46 & Cocoa \\
\hline povind & Relative poverty index comprising a set of welfare indicators ${ }^{\S}$ & 0.02 & Cocoa \\
\hline anohappy & $\begin{array}{l}5 \text { point score (pictures) to express general attitude towards Anoa } \\
\text { [1 complies with "unhappy", } 5 \text { with "very happy"] }\end{array}$ & 3.05 & Anoa \\
\hline anosurv & $\begin{array}{l}5 \text { point Likert score to express impacts expected when Anoa popu- } \\
\text { lation is reduced to } 10 \text { individuals } \\
\text { [1: surely will survive; } 5 \text { : surely become extinct] }\end{array}$ & 2.99 & Anoa \\
\hline prisec & $\begin{array}{l}\text { Indicator for perceived discretionary income: share of total house- } \\
\text { hold income spend on primary needs (rather than secondary) }[1: 3 / 4 \\
\text { to everything; } 3: 1 / 4 \text { up to } 1 / 2]\end{array}$ & 2.05 & Cost \\
\hline depch & Dependency rate adults vs. children ${ }^{\S}$ & 0.54 & Cost \\
\hline
\end{tabular}

All 301 households completed the choice task, and 235 made choices which included either option A or B at least once. 66 respondents always chose the status quo. $80 \%$ of them reported that they (i) could not afford the payment (3 respondents) or (ii) they perceived the present situation to be "better" than the offered alternatives (36 respondents), or a combination of both (27 respondents). The first aspect underlines that WTP measures have to 
be interpreted as a combination of people's willingness and their ability to pay. The remaining 13 respondents $(20 \%)$ were classified as “...essentially not responding to the CE task." (Adamowicz et al. 1998b: 68) and were omitted ${ }^{14}$, leaving 288 responses for further analysis.

\section{Results and discussion}

\subsection{Overall model results}

We report the results from two multinomial logit models here: attributes only (model 1) and attributes and interactions with socioeconomic variables (model 2). Overall, models 1 and 2 were highly significant at the $99 \%$ level. As expected, we find a significant improvement of the interaction model 2 as compared to the base model 1 (LR test: $\chi^{2}=$ 211.10; 14 d.f.). The overall model fit increases from the base model 1 (Adjusted $\rho^{2}$ $\left(\right.$ Pseudo- $\left.\left.R^{2}\right)=0.258\right)$ to the interaction model $2\left(\rho^{2}=0.345\right)$. These pseudo- $R^{2}$ values can be compared with values of $\mathrm{R}^{2}$ as in OLS regression models. A $\rho^{2}$ between 0.2 and 0.4 corresponds to $\mathrm{R}^{2}$ values of 0.7 to 0.9 , indicating very good fit (Hensher et al. 2005).

In order to test whether the MNL model is the appropriate model, Hausman-McFadden tests (Hausman and McFadden 1974) were performed to test for violations of the Independence of Irrelevant Alternatives (IIA) assumption that is implicit in MNL models. The results for the basic model were somehow inconclusive, i.e. violations were found for dropping one alternative, and the assumption could not be rejected when dropping the other two alternatives. No violations were found in the interaction model, however. This result is in line with Morrison et al. (1998), where the inclusion of SDCs helped to minimise IIA violations.

All attribute coefficients are significant and have the expected sign. I.e., disutility was observed for more months with water scarcity, with a greater distance to rattan harvesting locations and with paying tax or donating to a village fund. A utility gain is observed for bigger population sizes of the endemic dwarf buffalo Anoa. Concerning cocoa, the results indicate on average higher preferences for less shade in cocoa, implicitly having lower species diversity. Model results are listed in table 3. 


\subsection{ASC and interactions}

The ASC is positive and significant in model 1. It is not significant; however, in model 2, indicating that much of the variation in choice is already explained by the attributes or interactions. This suggests that there is no particular propensity to choose the status quo option relative to the alternatives as more commonly reported in literature (e.g. Adamowicz 1998a). One exception are Mogas et al. (2002), who report a positive ASC in a study on afforestation in Catalonia. A preference for the status quo, all else equal, was often related to what is referred to as 'status-quo bias' (Samuelson and Zeckhauser 1988). One reason for status quo bias can be that the status quo is used as an 'easy way out', e.g., in case of decision difficulty and/or limited cognitive capability (e.g. Luce 1998, Kontoleon and Yabe 2003). The positive ASC gives some evidence that this strategy was not particularly important in our study. People receive on average - everything else held constant - more utility from departing from the present situation than from keeping it. This could be due to a number of reasons such as, inter alia, that respondents include unobserved attributes associated with a governmental programme or task compliance. According to the high rate of status quo choices among all choices (53.2\%) it is unlikely, however, that the respondents felt 'forced' to choose among the alternatives of change as a consequence of a falsely perceived compliance with the intentions of this research.

The interactions of the ASC with SDC can shed some light on potential reasons and their heterogeneous distribution among the sample population (model 2 in table 3). The tendency to choose the management alternatives rather than the status quo decreases with increasing years in school (ASC*edu), and if the respondent is from Kulawi or Lore districts $\left(\mathrm{ASC}^{*} K L\right)$. The education variable is positively correlated with the relative poverty index and with a dummy variable taking 1 if the respondent is involved in non-farm income activities (Pearsons $\mathrm{R}^{2}$ : 0.256 respectively 0.362 , both significant at the $99 \%$ level). Thus, respondents that are less poor and respondents that derive non-farm related income might be more satisfied with the current situation or may perceive to obtain less benefit from changes in mainly farming related attributes. On the other hand, better educated respondents may make less use of unobserved attributes when making their decision, which results in lower values for the ASC. 
Finding an interpretation for the negative coefficient for the interaction $\mathrm{ASC} * K L$ is far from straightforward. This dummy was created as Kulawi and Lore (comprising the districts Lore Utara and Lore Tengah) are - on the whole - still less intensively used agriculturally compared to Palolo and Sigi Biromaru districts, and farther from the urban capital Palu. Environmental degradation is more obvious here, resulting, e.g., in water shortages for irrigation as well as household usage. In Palolo district, deforestation of a large forest area named Dongi-Dongi was followed by a devastating flood event in December 2003. Hence, the threat imposed by environmental degradation could be felt more directly than in the Kulawi or Lore districts. This could increase the likelihood that respondents include unobserved attributes of environmental change for their choice. The positive and significant interaction ASC*imppay shows that respondents who give higher scores for the importance of paying tax on household well-being have higher preferences for a change away from the status quo. This could be due to the fact that these respondents expect higher utility from governmental programs.

Making sense intuitively, disutility for an impairment of rattan provision and water availability increases significantly if respondents are involved in either collecting rattan or cultivating wet rice. Large parts of a utility gain from an improved provision of rattan and water services can be explained by the involvement of respondents in these activities. However, involvement is not the only source that can explain people's preferences regarding the rattan and water attributes. This may lead to the assumption that these two activities are not easily substitutable for other income generating activities because they fulfil purposes other than related to the actual generation of income in cash or kind (i.e. for subsistence). In this context, rattan e.g. provides security as an alternative income source in the case of economic failure for vulnerable households. During our field work it became clear that in the perception of locals who were not involved in wet rice cultivation, the most important benefit from sustained wet rice cultivation in their region is to maintain a local market for the most important staple food which can be obtained at rather low prices. Due to improved access in most parts of the research region to the urban market of Palu, this aspect may actually be less important than perceived. Besides, there may be an array of social and cultural factors associated with wet rice cultivation that have influence on the life within local village communities. Some aspects are pointed out in Burkard (2002a), who also vividly shows the complexity and heterogeneity of such factors in the research region. 
Table 3. MNL model results

\begin{tabular}{|c|c|c|c|c|}
\hline \multirow{2}{*}{$\begin{array}{l}\text { Variable } \\
\text { Rattan availability }\end{array}$} & \multicolumn{2}{|c|}{ Base model 1} & \multicolumn{2}{|c|}{$\begin{array}{c}\text { Interaction } \\
\text { Model } 2 \\
\end{array}$} \\
\hline & $\begin{array}{l}-0.0404 \\
(-5.179)\end{array}$ & $* * *$ & $\begin{array}{l}-0.0307 \\
(-3.455)\end{array}$ & $* * *$ \\
\hline Water for irrigation of paddy rice & $\begin{array}{r}-0.8943 \\
(-18.772)\end{array}$ & $* * *$ & $\begin{array}{l}-0.5118 \\
(-7.268)\end{array}$ & $* * *$ \\
\hline Cocoa Shade & $\begin{array}{l}0.0126 \\
(2.067)\end{array}$ & $*$ & $\begin{array}{r}0.0260 \\
(3.712)\end{array}$ & *** \\
\hline Cocoa Shade ${ }^{2}$ (quadratic) & $\begin{array}{l}-0.0247 \\
(-3.913)\end{array}$ & $* * *$ & $\begin{array}{l}-0.0251 \\
(-3.545)\end{array}$ & $* * *$ \\
\hline Anoa Population Size & $\begin{array}{r}0.0009 \\
(2.688)\end{array}$ & $* *$ & $\begin{array}{l}-0.0030 \\
(-2.202)\end{array}$ & $*$ \\
\hline Cost (Tax rise/village fund donation) & $\begin{array}{r}-0.0254 \\
(-9.146) \\
\end{array}$ & $* * *$ & $\begin{array}{l}-0.0635 \\
(-6.845)\end{array}$ & $* * *$ \\
\hline ASC (non-status quo choice) & $\begin{array}{l}0.4892 \\
(3.486)\end{array}$ & $* * *$ & $\begin{array}{r}0.7189 \\
(1.677)\end{array}$ & \\
\hline $\mathrm{ASC} * K L$ & & & $\begin{array}{l}-0.3327 \\
(-2.183)\end{array}$ & $*$ \\
\hline ASC*edu (years in school) & & & $\begin{array}{l}-0.1716 \\
(-4.000)\end{array}$ & $* * *$ \\
\hline ASC*imppay (importance of payment) & & & $\begin{array}{r}0.4023 \\
(4.494)\end{array}$ & $* * *$ \\
\hline Rattan*colrat (dummy rattan collector) & & & $\begin{array}{l}-0.1172 \\
(4.034)\end{array}$ & $* * *$ \\
\hline Water*invwat (dummy wet rice activity) & & & $\begin{array}{r}-0.7548 \\
(7.520)\end{array}$ & $* * *$ \\
\hline Cocoa(linear)*povind (poverty index) & & & $\begin{array}{l}-0.0050 \\
(-2.138)\end{array}$ & $*$ \\
\hline Cocoa(linear)*KL (Kulawi/ Lore) & & & $\begin{array}{l}-0.0146 \\
(-3.980)\end{array}$ & $* * *$ \\
\hline Cocoa (quadr.)*agecoc (max. age of cocoa) & & & $\begin{array}{l}-0.0018 \\
(-3.642)\end{array}$ & $* * *$ \\
\hline Anoa*anohappy (gen. attitude anoa) & & & $\begin{array}{r}0.0007 \\
(1.939)\end{array}$ & * \\
\hline Anoa*anosurv (extinction probability) & & & $\begin{array}{r}0.0006 \\
(2.541)\end{array}$ & $*$ \\
\hline Cost*edu (years in school) & & & $\begin{array}{l}0.0036 \\
(4.000)\end{array}$ & $* * *$ \\
\hline Cost*prisec (discretionary income) & & & $\begin{array}{r}0.0064 \\
(2.761)\end{array}$ & $* *$ \\
\hline Cost*depch (child dependency rate) & & & $\begin{array}{l}-0.0093 \\
(-2.663)\end{array}$ & $* *$ \\
\hline Log-likelihood & -857.34 & & -759.55 & \\
\hline Number of observations & 1152 & & 1152 & \\
\hline Adjusted $\rho^{2}\left(\right.$ Pseudo-R $\left.{ }^{2}\right)$ & 0.2646 & & 0.3448 & \\
\hline
\end{tabular}

The quadratic term for cocoa is negative and significant, indicating that there is some threshold for intensification which would not have been detected in the basic linear model. 
At mean level for the socio-demographic characteristics and cocoa age interacted with cocoa, utility peaks at a level of shading of approximately $28 \%$. As the interactions with cocoa show, the likelihood is higher that the peak is reached at lower levels of shading if the maximum age of cocoa plantations increases and the respondent is less poor according to a relative poverty index measure.

Cocoa is usually planted under shade. The older it gets, the less shade is needed generally. Thus, people owning older plantations might be more confident in cultivation success under less shade as a result of longer experience. The less poor people are, the more agronomic risk they may be willing to take, and the more disposable capital they may have to invest in fertilizer or pesticides. Additionally, respondents living in Lore or Kulawi districts have higher preferences for more intensive cocoa cultivation compared to those living in Sigi-Biromaru and Palolo. This may at least partially be explained by a longer establishment of cocoa cultivation in these districts.

The results of the interactions show that it is likely that further intensification will take place in the future. Thus, biodiversity conservation measures aiming at more sustainable ways of cocoa cultivation (measured here by a shade tree gradient) will be unlikely to be successful without creating incentives for the cocoa farmers such as, e.g., price premiums. However, cocoa intensification can be very beneficial from a development economics standpoint: Keil (2004) has shown that there is still much potential for increasing the technical efficiency and therefore the benefits obtained from cocoa cultivation. Despite the risks, the spread of cocoa and its intensification has improved welfare not only for migrants from South Sulawesi, who have a longer tradition in cocoa cultivation, but also for many "locals". For an example that cocoa cultivation does not necessarily lead to an improvement of the living conditions for locals see Sitorus (2002). Weber (2005) has discussed the risks associated with the rising dependency on (world market) prices for cocoa. He concluded that a severe price crash would mean the end of cocoa as a driving force for improved welfare, but that it is likely that welfare would not drop below the state before the beginning of the cocoa boom. It is a matter of dispute whether intensification can help to mitigate encroachment in the forest or whether it may actually enhance it (see Keil 2004), while it can generally be assumed that the emergence of cocoa in the Lore Lindu region in the course of the cocoa boom has promoted forest encroachment (e.g. Maertens 2004). 
In general, not much is known about specific ecological and economic short and long term implications resulting from cocoa cultivation. Hence, it is in the realm of speculation to judge whether the (private) net benefits of cocoa cultivation and its intensification exceed the (social) cost, particularly in the long run. Still, the demand of people for further intensification should seriously be considered by decision makers. As an aside, we could not find any significant differences of preferences regarding the cocoa attribute between "locals" and migrants ${ }^{15}$ as well as between households with an indigenous or non-indigenous head of household (data not shown). This finding gives rise to the hypothesis that (i) there are no differences in the preferred way of cocoa cultivation between these groups and (ii) that the key factor influencing the cultivation decision is profit maximization. This does not mean that there are no actual differences between cocoa plots. However, these differences could be the result of e.g. different general cropping strategies, which are outlined in e.g. Burkard (2002a) and Weber (2005), different knowledge about cultivation practices or the access to the latter (Weber 2005).

Surprisingly, the sign of the coefficient (significant at the $5 \%$ level) for the anoa attribute changes in model 2 and is negative contrarily to prior expectation. The two interactions included are both positive and significant at $5 \%$ or lower. The more positive people felt about anoa, and the more likely they find it that a population of 10 remaining individuals will become extinct, the higher the utility they get from maintaining larger population sizes in the Lore Lindu area. If an individual's attitude is rather negative and/or it thinks that it is more likely that a population of 10 will survive, however, it will receive disutility from anoa conservation efforts. By calculating individual utilities based on model estimates and SDC, about one fifth of the respondents prefer smaller population sizes of anoa. When asked about negative and positive aspects associated with anoa, about one third (32\%) of the respondents could not mention any positive aspects, while more than half of the respondents $(53 \%)$ reported potential or actual problems. $51 \%$ stated to obtain benefits mostly related to the protection of a species which is 'special' (khas) to Sulawesi (including bequest motives). On the other hand, about $14 \%$ can name benefits from the direct use of anoa (meat, horns, skin etc.).

Results from population models reported by Manansang et al. (1996) indicate that anoa populations may only be able to survive a hunting rate of $2-3 \%$ of the total population 
number each year. Despite the fact that not every respondent of the $14 \%$ mentioning hunting-related benefits might actually hunt anoa ${ }^{16}$, it is not unlikely, on the other hand, that hunting rates may actually exceed $2-3 \%$ of the total anoa population. Burton et al. (2005: 42) suggest education and training of people as a measure for an anoa conservation programme: "It is necessary to explain to people living around protected areas why their activities need to be controlled and why wildlife, which they might otherwise utilize, should be conserved. The fact that anoas, along with many other species, do not occur outside Sulawesi should be stressed because many people on the island are unaware of their heritage ...".

The model results suggest that educational efforts can contribute to anoa conservation by altering people's attitude and their knowledge about anoa: further decline of the population would very likely lead to anoa becoming extinct in the National Park area. Thus, Burton et al. (2005: 40) conclude that "Law enforcement should be combined with an environmental education campaign that stresses that the anoas are unique to Sulawesi and in danger of being lost forever".

All included interactions of socioeconomic variables with the cost attribute were significant, and marginal WTP is a function of these variables. Individuals with higher education and a higher perceived discretionary (short-term) income are less responsive to increases of the cost attribute (thus having positive effect on WTP), whereas individuals with higher child dependency rates are more concerned about tax rise or village donation (thus having negative impact on WTP). As an aside, we did not find a significant influence of relative poverty on the cost attribute (data not shown). In addition to the documented linear influence on cocoa shading, relative poverty may have a systematically non-linear influence on preferences for anoa, rattan and water (Glenk et al. accepted). However, as relative poverty is a composite mid-term welfare measure, it does not directly reflect the current buying power or cash availability of respondents. These aspects are more likely to be determinants of sensitivity for changes in the cost attribute as indicated by the interaction with the perceived discretionary income mentioned above. 


\subsection{Part worths}

Implicit prices for the ecosystem services included in the choice experiment can be calculated using parameter estimates of model 2 by dividing the attribute coefficient with the coefficient of the cost attribute. For the interactions with SDC, mean values were used. Implicit prices “... can be used by policy makers to assign more resources to improving those attributes that have higher prices..." (Colombo et al. 2005:89). However, care must be taken when comparing the implicit prices as the attribute units differ. Results are listed in table 4. Most impressively, median MWTP to avoid 1 month of water scarcity for irrigation is about 35000 IDR (4.1 US\$) per year, 100 individuals more of anoa are still worth about 3300 IDR (0.39 US\$) per year. Confidence intervals were calculated by using a Krinsky and Robb (1986) procedure with 1000 random draws ${ }^{17}$.

Table 4. Part Worths in IDR/year/household (US\$)

\begin{tabular}{|c|c|c|c|c|c|}
\hline & & Rattan & Water & $\operatorname{Cocoa}^{\S}$ & Anoa \\
\hline Medi & n Part Worths & $\begin{array}{c}-1662 \\
(-0.2)\end{array}$ & $\begin{array}{c}-35106 \\
(-4.13)\end{array}$ & $\begin{array}{c}-530 \\
(-0.06)\end{array}$ & $\begin{array}{c}33 \\
(0.004)\end{array}$ \\
\hline \multirow{2}{*}{$95 \%$} & Lower bound & $\begin{array}{l}-2461 \\
(-0.29)\end{array}$ & $\begin{array}{c}-45806 \\
(-5.39)\end{array}$ & $\begin{array}{c}-733 \\
(-0.09)\end{array}$ & $\begin{array}{c}12 \\
(0.001)\end{array}$ \\
\hline & Upper bound & $\begin{array}{l}-1066 \\
(-0.13)\end{array}$ & $\begin{array}{c}-28715 \\
(-3.38)\end{array}$ & $\begin{array}{c}-386 \\
(-0.05)\end{array}$ & $\begin{array}{c}62 \\
(0.007)\end{array}$ \\
\hline
\end{tabular}

What can be said about the absolute magnitude of the MWTP values? Are they in a reasonable range or particularly low or high? We collected some background data related to attributes, allowing a vague assessment of the plausibility of the magnitude of MWTP values, particularly for rattan and water availability. The following comparisons should not be conceived as a formal proof of external validity. Still they are helpful in anchoring the MWTP values within a broader context. First, the average direct tax (PBB: pajak bumi bangunan) paid by households in the research region is about 15000 IDR per year. Thus, MWTP for one month less with water scarcity for irrigation equals up to $200 \%$ of the "house and land" tax people have to pay on average per year. A number of households in some villages have to pay irrigation fees of about 19200 IDR per ha and year on average ${ }^{18}$. Therefore, WTP for improved water availability expressed by the respondents can be considered to reflect a substantial amount for the inhabitants of the Lore Lindu region. Concerning rattan, we conducted a linear regression of the time needed to reach the rattan harvesting locations $(\mathrm{h})$ on the distance $(\mathrm{km})$ (see appendix 2). 
One $\mathrm{km}$ less is associated with a time saving of about 0.4 hours $(\mathrm{n}=37$, significant at the $99 \%$ level). To derive a monetary value of time savings, they may either be related to the (local) wage labour market or calculated as the income forgone from collecting more of a (priced) resource (Köhlin and Anmacher 2005). This is a very simplified assumption of economic activity in the project area, as we do know next to nothing about the potential utilisation of time savings ${ }^{19}$. Average income from wage labour is about 15000 IDR per day. On average, people collected rattan 18 times per year. One $\mathrm{km}$ less is therefore associated with $14.4 \mathrm{~h}((18 \times 2) \times 0,4 \mathrm{~h})$ saved per year. Assuming perfect substitutability of time and labour, one km less would equal income forgone from wage labour of about 22000 IDR per year, while the fraction of the sample selling rattan is $12.8 \%$. Median MWTP for $1 \mathrm{~km}$ less is about $1600 \mathrm{IDR} /$ year.

Comparisons like that are more difficult for cocoa and particularly anoa due to the complexity of the benefits associated with those attributes on one hand, and to a lack of data available on those benefits on the other hand. For the water and rattan attributes, however, there is indication that the MWTP values are in a reasonable range. Furthermore, Pattanayak and Kramer (2001) report a WTP of 2-3 US\$ for drought mitigation services by watershed protection on Flores/ Indonesia derived by contingent valuation method. Although not directly comparable, their result for a similarly framed ecosystem service can provide some weak evidence that MWTP for water as calculated in this study seems to be neither completely over- or underestimated.

\section{Conclusion}

With a carefully adjusted instrument, the choice experiment could be conducted successfully on one of Indonesia's outer islands. Model performance was quite good. The MNL model results provide some evidence that the choice experiment can be applied to complex ecological services in an ecologically and socially diverse rural area and in a developing country setting. The design strategies to adjust the status-quo scenario to the individual respondents and the translation of biodiversity values into ecosystem services contributed essentially to this result. Concerning the first, one of the major advantages of using individual-specific perceived levels for the status-quo is the availability to account for heterogeneous environmental conditions in an on-site study, therefore enhancing credibility among respondents as well as framing choices properly as gains and losses. 
Using the ecosystem service approach and translating ecosystem functions into concepts that correspond to and interact with peoples life may contribute to reduce potential problems arising from the divergence of perceived and actual values for welfare analysis. The ecosystem approach proved to be a successful instrument to be used for the valuation of ecosystem services in general and for ecosystem services provided by complex ecosystem functions in particular. However, the link between ecosystem services as described in this study and the underlying ecosystem structures, functions and processes is not well established (also see Barkmann et al. subm. a). It is for instance neither known, what management practices would be necessary to reduce the encounter distance to the harvesting locations for rattan by $5 \mathrm{~km}$, nor is it clear, what kind of quantitative and qualitative land use change would result in a water shortage for irrigation of one month more. Thus, one of the major challenges for future applications of the ecosystem service approach is to improve the 'tuning' with ecological sciences to achieve that data is produced in a form that is translatable into ecosystem services for the assessment of (welfare) implications of humaninduced changes. The task for economists, on the other hand, is to identify the values of ecosystem services for consideration in decision-making processes. By combining the impacts on human-wellbeing with ecological background data and other societal aspects, a useful policy/management tool could arise. Hence, further efforts are needed to improve the communication between the two disciplines.

Measures of MWTP for an improved provision of ecosystem services ('water', 'rattan', 'anoa') were documented. We outlined that the magnitude of MWTP is quite substantial considering the living conditions of the inhabitants of the Lore Lindu region. Furthermore, we provided some indication that MWTP values calculated in this study are neither completely over- nor underestimated. There is a willingness of local respondents to contribute actively to the maintenance of their resource base concerning water availability and rattan provision. This could also be beneficial from a biodiversity conservation standpoint. On average, residents even have small MWTP for maintaining viable population sizes of the local endemic dwarf buffalo anoa. By taking a closer look, we found a substantial amount of respondents who either don't care or even have preferences for smaller populations, which is of concern for the conservation of that species. This shows the importance of accounting for heterogeneity of tastes by interactions. In the fast growing sector of cocoa agroforestry systems, the respondents indicated an unexpectedly clear preference for more intensively managed plantations with fewer shade trees. Benefits due to increased welfare 
are opposed by negative impacts on biodiversity. However, the relationship between private net benefits and social costs is not clear for neither short nor longer terms.

Overall, the conflict between locally predominant objectives of economic development and more globally defined conservation objectives is clearly reflected in people's preferences for the range of ecosystem services observed. MWTP figures reflecting net benefits can serve as a benchmark for future research and may be utilized as measures of Hicksian compensating variation (e.g. Bennett and Blamey 2001) in a cost-benefit framework, which addresses all relevant costs and benefits, associated with a development program. It is the results from interactions with socio-demographic variables, however, which contribute to a more distinguished understanding of people's preferences.

\section{References}

Adamowicz, W., Luckert, M. and M. Veeman, 1997a. Issues in using valuation techniques cross-culturally: three cases in Zimbabwe using contingent valuation, observed behaviour and derived demand techniques. Commonwealth Forestry Review, 76(3): 194-97.

Adamowicz, W., Swait, J., Boxall, P., Louviere, J. and M. Williams, 1997b. Perceptions versus Objective Measures of Environmental Quality in Combined Revealed and Stated Preference Models of Environmental Valuation. Journal of Environmental Economics and Management, 32: 65-84.

Adamowicz, W., Louviere, J. and J. Swait, 1998a. Introduction to Attribute-Based Stated Choice Methods. Prepared by Advanis Inc. for the National Oceanic and Atmopheric Administration, US Departement of Commerce.

Adamowicz, W., Boxall, P., Williams, M. and J. Louviere, 1998b. Stated preference approaches to measuring passive use values. American Journal of Agricultural Economics, 80: 64-75.

Akiyama, T. and A. Nishio, 1996. Indonesia's Cocoa Boom. Hands-off Policy Encourages Smallholder Dynamism. Policy Research Working Paper 1580. Washington, D.C.: World Bank.

Alpizar, F., Carlsson, F. and P. Martinsson, 2001. Using Choice Experiments for Non-Market Valuation. Economic Issues, 8: 83-110.

ANZDEC, 1997. Report on the Central Sulawesi integrated area development and conservation project. Palu, Sulawesi.

Barkmann, J., Dietrich, N., de Vries, K., Gerold, G., Glenk, K., Keil, A., Faust, H., Leemhuis, C. and R. Marggraf, (submitted a). Confronting unfamiliarity with ecosystem functions: The case for an ecosystem service approach to environmental valuation with stated preference methods. Submitted to Ecological Economics. 
Barkmann, J., Glenk, K., Marggraf, R. (submitted b): Assessing economic preferences for biological diversity and ecosystem services at the Central Sulawesi Rainforest Margin - a choice experiment approach. Guhardja, Leuschner and Tscharntke (Eds): The stability of rainforest margins: linking ecological, economic and social constraints of land use and conservation.

Bateman, I.J., Carson, R.T., Day, B., Hanemann, M., Hanley, N., Hett, T., Jones-Lee, M., Loomes, G., Monrato, S., Ozdemiroglu, E., Pearce, D., Sugden, R. and J. Swanson, 2002. Economic Valuation with Stated Preference Techniques - A Manual. Cheltenham, UK: Edward Elgar.

Belsky, J.M. and F.S. Siebert, 2003. Cultivating Cocoa: Implications of sun-grown cocoa on local food security and environmental sustainability. Agriculture and Human Values, 20: 277-85.

Ben-Akiva, M. and M. Bierlaire, 1999. Discrete Choice Methods and Their Applications to Short Term Travel Decisions, in R.W. Hall (Ed.): Handbook of Transportation Science: 5-33. USA: Kluwer Academic Publishers.

Bennett, J., 1999. Some Fundamentals of Environmental Choice Modelling. Research Report No.11. Canberra, Australia: School of Economics and Management, The University of New South Wales.

Bennett, J. and W. Adamowicz (2001), 'Some Fundamentals of Environmental Choice Modelling', in J. Bennett and R. Blamey, (Eds), The Choice Modelling Approach to Environmental Valuation. Cheltenham, UK: Edward Elgar.

Bennett, J. and R. Blamey (Eds), 2001. The Choice Modelling Approach to Environmental Valuation. Edward Elgar, Cheltenham, UK.

Bingham, G., Bishop, R., Brody, M., Bromley, D., Clark, E., Cooper, W., Constanza, R., Hale, T., Hayden, G., Kellert, S., Norgaard, R., Norton, B., Payne, J., Russell, C. and G. Suter, 1995. Issues in ecosystem valuation: improving information for decision making. Ecological Economics, 14: 73-90.

Blamey, R., Rolfe, J., Bennett, J. and M. Morrison, 1997. Environmental Choice Modelling: Issues and Qualitative Insights. Research Report No. 4. Canberra, Australia: School of Economics and Management, The University of New South Wales.

Blamey, R., J. Bennett, M. Morrison, J. Louviere and J. Rolfe, 1998. Attribute Selection in Environmental Choice Modelling Studies: The Effect of Causally Prior Attributes. Research Report No. 7. Canberra, Australia: School of Economics and Management, The University of New South Wales.

Burkard, G., 2002a. Stability or Sustainability? Dimensions of Socio-economic Security in a Rainforest Margin. STORMA Discussion Paper Series No. 7, Universities of Göttingen and Kassel, Germany and the Institut Pertanian Bogor and Universitas Tadulako, Indonesia.

Burkard, G. 2002b. Natural Resource Management in Central Sulawesi: Past Experience and Future Prospects. STORMA Discussion Paper Series No. 8, Universities of Göttingen and Kassel, Germany and the Institut Pertanian Bogor and Universitas Tadulako, Indonesia. 
Burton, J.A., Hedges, S. and A.H. Mustari, 2005. The taxonomic status, distribution and conservation of the lowland anoa Bubalus depressicornis and mountain anoa Bubalus quarlesi. Mammal Review, 35(1): 25-50.

Colombo, S., Calatrava-Requena, J. and N. Hanley, 2005. Designing Policy for Reducing the Offfarm Effects of Soil Erosion Using Choice Experiments. Journal of Agricultural Economics, 56(1): 81-95.

De Groot, R., Wilson, M. and R. Boumans, 2002. A typology for the classification, description and valuation of ecosystem functions, goods and services. Ecological Economics, 41: 393-408.

Faust, H., Maertens, M., Weber, R., Nuryartono, N., van Rheenen, T. and R. Birner, 2003. Does Migration lead to Destabilization of Forest Margins? Evidence from an interdisciplinary field study in Central Sulawesi. STORMA Discussion Paper Series No. 11, Universities of Göttingen and Kassel, Germany and the Institut Pertanian Bogor and Universitas Tadulako, Indonesia.

Glenk, K., Barkmann, J., Schwarze, S., Zeller, M. and R. Marggraf, (accepted). Differential influence of relative poverty on preferences for ecosystem services: Evidence from rural Indonesia. Brisbane Conference on Environment and Development, 2006.

Greene, W.H., 2003. LIMDEP Version 8.0 NLogit Version 3.0. Plainview, N.Y.: Econometric Software, Inc.

Hausman, J. and D. McFadden, 1984. Specification Tests for the Multinomial Logit Model.Econometrica, 52(5): 1219-40.

Hensher, D.A., Rose, J.M., and W.H. Greene 2005. Applied choice analysis: a primer. Cambridge University Press, Cambridge, U.K.

Horne, P. and L. Petäjistö, 2003. Preferences for Alternative Moose Management Regimes among Finnish Landowners: A Choice Experiment Approach. Land Economics, 79(4): 472-82.

Huber, J. and K. Zwerina, 1996. The Importance of Utility Balance in Efficient Choice Designs. Journal of Marketing Research, 33: 307-17.

Jae, H. and D. del Vecchio, 2004. Decision Making by Low-Literacy Consumers in the Presence of Point-of-Purchase Information. The Journal of Consumer Affairs, 38(2): 342-54.

Kahneman, D. and J.L. Knetsch, 1992. Valuing Public Goods. The Purchase of Moral Satisfaction. Journal of Environmental Economics and Management, 22: 57-70.

Keil, A., 2004. The socio-economic impact of ENSO-related drought on farm households in Central Sulawesi, Indonesia. Ph.D. thesis, Institute of Rural Development, University of Goettingen.

Kemper, D. 2005. Die Bedeutung von „Wissen“ für Landnutzungsentscheidungen - eine kulturgeographische Untersuchung in zwei Dörfern am Rande des Lore Lindu Nationalpark, Indonesien. M.Sc. Thesis, Institute of Geography, University of Goettingen. 
Köhlin, G. and G.S. Amacher, 2005. Welfare Implications of Community Forest Plantations in Developing Countries: The Orissa Social Forestry Project. American Journal of Agricultural Economics, 87(4): 823-1096.

Kontoleon, A. and M. Yabe, 2004. Assessing the Impacts of Alternative 'Opt-out' Formats in Choice Experiment Studies. Journal of Agricultural Policy Research, 5: 1-32.

Krinsky, I., and A. L. Robb, 1986. On approximating the statistical properties of elasticities. Review of Economics and Statistics, 68: 715-719.

Krutilla, J. V., 1967. Conservation Reconsidered. American Economic Review, 57(4): 777-786.

Lancaster, K., 1966. A New Approach to Consumer Theory. Journal of Political Economy, 74: 132-157.

Lancaster, K., 1991. Modern Consumer Theory. Brookfield VT: Edward Elgar.

Louviere, J., Hensher, D. and J. Swait 2001. Stated Choice Methods - Analysis and Application. Cambridge, UK: Cambridge University Press.

Luce, R.D., 1959. Individual choice behaviour. New York: Wiley.

Luce, M.F., 1998. Choosing to Avoid: Coping with Negatively Emotion-Laden Consumer Decisions. Journal of Consumer Research, 24: 409-33.

Maertens, M., 2004. Economic Modelling of Agricultural Land-Use Patterns in Forest Frontier Areas. Ph.D. thesis, Institute of Rural Development, University of Goettingen.

Manski, C., 1977. The Structure of Random Utility Models. Theory and Decision, 8: 229-54.

Marggraf, R. and R. Birner, 1998. The Conservation of Biological Diversity from an Economic Point of View. Theory in Biosciences, 117: 238-55.

McFadden, D., 1973. Conditional Logit Analysis of Qualitative Choice Behavior. In P. Zarembka (Ed.): Frontiers in Econometrics. New York: Academic Press.105-42.

Mekonnen, A., 2000.Valuation of Community Forestry in Ethiopia: a Contingent valuation Study of Rural Households. Environment and Development Economics, 5: 289-308.

Millennium Ecosystem Assessment, 2003. Ecosystems and human well-being: A framework for assessment. Washington, District of Columbia: Island Press.

Mogas, J., Riera, P. and J. Bennett, 2002. A comparison of contingent valuation and choice modelling: Estimating the environmental values of Catalonian forests. Occasional paper no. 1, National Centre for Development Studies, Australian National University.

Morrison M., Blamey, R. Bennett, J. and J. Louviere, 1996. A Comparism of Stated Preference Techniques for Estimating Environmental Values. Research Report No.1. Canberra, Australia: School of Economics and Management. The University of New South Wales.

Morrison, M., Bennett, J., and R. Blamey, 1998. Valuing improved wetland quality using choice modelling. Research Report No.6. Canberra, Australia: School of Economics and Management, The University of New South Wales. 
Myers, N., Russel, A., Mittermeier, R., Mittermeier, C., da Fonseca, G. and J. Kent, 2000. Biodiversity hotspots for conservation priorities. Nature, 403: 853-58.

Nunes, P. and J. v.d. Bergh, 2001. Economic valuation of biodiversity: sense or nonsense? Ecological Economics, 39: 203-22.

Olson, D.M. and E. Dinerstein, 1998. The Global 200: a representation approach to conserving the Earth's most biologically valuable ecoregions. Conservation Biology, 12: 502.

Pattanayak, K. and R. Kramer, 2001. Pricing ecological services: Willingness to pay for drought mitigation from watershed protection in eastern Indonesia. Water Resources Research, 37(3): 771-78.

Pearce, D.W. and D. Moran, 1994. The economic Value of Biodiversity. IUCN - The World Conservation Union. London: Earthscan Publications.

Randall, A. and J. Stoll, 1983. Existence Values in a Total Valuation Framework. In: Row, R. D. and L.G. Chestnut: Managing Air Quality and Scenic Resources at National Parks and Wilderness Areas. Boulder, Colorado: Westview Press.

Sagoff, M., 1996. On the Value of Endangered and Other Species. Environmental Management, 20(6): 897-911.

Samuelson, W. and R. Zeckhauser, 1988. Status Quo Bias in Decision Making. Journal of Risk and Uncertainty, 1: 7-59.

Schwarze, S., 2004. Determinants of Income Generating Activities of Rural Households, A Quantitative Study in the Vicinity of the Lore-Lindu National Park in Central Sulawesi/Indonesia. Ph.D. thesis, Institute of rural Development, University of Goettingen.

Shyamsundar, P. and R. Kramer, 1996. Tropical Forest Protection: An empirical analysis of the costs borne by local people. Journal of Environmental Economics and Management, 31: 12944.

Siebert, F.S., 2001. Sustainable harvesting of wild rattan: viable concept or ecological oxymoron? Unasylva, 52: 36-45.

Siebert, F.S., 2002. From shade to sun-grown perennial crops in Sulawesi, Indonesia: implications for biodiversity conservation and soil fertility. Biodiversity and Conservation, 11: 18891902.

Sitorus, F. 2002. Land, ethnicity and the competing power. Agrarian dynamics in forestmargin communities in Central Celebes, Indonesia. STORMA Discussion Paper Series No. 6, Universities of Göttingen and Kassel, Germany and the Institut Pertanian Bogor and Universitas Tadulako, Indonesia.

Slovic, P. and S. Lichtenstein, 1971. Comparison of Bayesian and Regression Approaches to the Study of Information Processing in Judgment. Organizational behavior and HumanPerformance, 6: 649-744. 
Suryahadi, A. and S. Sumarto, 2001. The chronic poor, the transient poor, and the vulnerable in Indonesia before and after the crisis. SMERU working paper. Jakarta: SMERU Research Institute.

Swait, J. and W. Adamowicz, 1996. The Effect of Choice Experiments and Task Demands on Consumer Behavior: Discriminating Between Contribution and Confusion. Staff Paper 96-09. Edmonton, Canada: Departement of rural Economy, University of Alberta.

Thurstone, L.L., 1927. A Law of Comparative Judgment. Psychological Review, 4: 273-86.

Train, K., 1986. Qualitative Choice Analysis, Theory, Econometrics and an Application to Automobile Demand, MIT Press, London.

Train, K., 1998. Recreation demand models with taste differences over people. Land Economics, 74(2): $230-40$.

Turner, R., Paavola, J., Cooper, P., Faber, S., Jessamy, V. and S. Georgiou, 2002. Valuing Nature: Lessons Learned and Future Research Directions. CSERGE Working Paper EDM 02-05. Norwich, UK: University of East Anglia.

Waltert, M., Mardiastuti, A. and M. Mühlenberg, 2004. Effects of land use on bird species richness in Sulawesi, Indonesia. Conservation Biology, 18: 1339-46.

Weber, R., 2005. Kulturlandschaftswandel während des 20. Jh. in Zentralsulawesi - eine historisch-geographische Analyse der Lore-Lindu-Bergregenwaldregion. Ph.D. thesis, Institute of Geography, University of Goettingen.

Whitten, A.J., Henderson, G.S. and M. Mustafa, 1987. The Ecology of Sulawesi. Yogyakarta, Indonesia: Gadjah Mada University Press.

Whittington, D., 1998. Administering contingent valuation surveys in developing countries. Environmental Economics Program for Southern and Eastern Asia Working Paper.

Zeller, M., Schwarze, S. and T. van Rheenen, 2002. Statistical Sampling Frame and Methods Used for the Selection of Villages and Households in the Scope of the Research Programme on Stability of Rainforest Margins in Indonesia (STORMA). STORMA Discussion Paper Series No. 1, Universities of Göttingen and Kassel, Germany and the Institut Pertanian Bogor and Universitas Tadulako, Indonesia.

Zeller, M. and R. Birner, 2003. Teilprojekt A3. Der Einfluss von Märkten und Politikmaßnahmen auf die Ressourcennutzung. in: Sonderforschungsbereich 552 "Stability of Rainforest Margins in Indonesia“ der Deutschen Froschungsgemeinschaft. Ergebnisbericht über die 1. Förderungsphase 2000/2-2003/1. Georg-August-University Goettingen and University of Kassel. 


\section{Notes:}

${ }^{1}$ Particularly from South Sulawesi many ,cocoa migrants' were attracted by the availability of land (Faust et al 2003).

2 "Existence value" can be defined to be the value arising merely from the information that a resource exists regardless of whether this asset now or in the future generates a productive, recreational or aesthetic use for the person holding the preferences (e.g. Bingham et al. 1995, Fromm 2000). In this sense, there is a notion that the resource or asset has a value of its own, which is of anthropocentric intrinsic nature. Intrinsic values, however, are not consistent with conventional economic thought (Turner et al. 2002).

${ }^{3}$ There is no need to distinguish between ecosystem goods and services if the provision of goods within an ecosystem is being classified as an ecosystem service itself. The distinction between production and consumption values (Marggraf and Birner 1998) as well as direct and indirect values within the TEV concept suggests that it may be appropriate to separate goods (production value, often direct use) and services (consumption value, often indirect use) conceptually from an economic point of view.

${ }^{4}$ We do not subscribe to extreme interpretations of this way to model actual human decisionmaking. Namely, we do not assume that actual individuals have perfect information. Our analytic paradigm models individuals 'as if' they have perfect information, however.

${ }^{5}$ According to the standard model, $\varepsilon_{\mathrm{ij}}$ remains perfectly deterministic from an individuals' point of view.

${ }^{6}$ Many CE case studies use "focus groups" for that purpose. It was hardly possible to conduct focus groups without the attendance of the most influential inhabitants of a village. The opinion of those people (e.g. village head) often dominated the sessions. Understandably, they wanted to shed the village into a favourable light. Therefore, it seemed appropriate to focus on individual interviews and use the peer-groups to obtain further information mainly about prevailing policy issues.

${ }^{7}$ E.g. in one village, one of the streams providing water for irrigation dried up, in another the water declined to such an extend that irrigation is hardly possible any more.

${ }^{8}$ This description implicitly entails that perceived effects of irrigation technology on irrigation water supply cannot be separated from the effects of land use.

${ }^{9}$ According to Kemper (2005) one inhabitant stated: "If I encounter anoa in the forest, either I kill it, or it will kill me".

${ }^{10}$ I.e. more months with water scarcity and more $\mathrm{km}$ to the rattan harvesting locations are expected to be associated with disutility.

${ }^{11}$ The split-samples are not analysed in this paper.

${ }^{12}$ The Indonesian version of the picture book, the text book and the questionaire can be seen at www.storma.de/DPS/pdf/SDP15b.pdf

${ }^{13}$ Present population sizes of anoa cannot possibly be known. Hence, a common reference point was defined (see table 1).

${ }^{14}$ Reasons for choosing always the status quo were 'protest' answers, payment aversion, and exceeding the cognitive capability to complete the choice task (one respondent).

${ }^{15}$ In this case, migrants were defined as households where the head of household or his/her father has moved to the village.

${ }^{16}$ On the other hand, not all respondents might have reported benefits from hunting as it is an illegal activity.

${ }^{17}$ A large number of random draws from a multivariate normal distribution with mean and variance of parameter estimates and a variance-covariance matrix from the estimated model.

${ }^{18}$ Mean value over four planting seasons from 2003 - 2004 for households that paid irrigation fees in 6 of the sample villages. Data from Alwin Keil (IMPENSO/ University of Hohenheim).

${ }^{19}$ The income from rattan per day is invariant on the distance of the rattan harvesting locations. Rattan collectors always look for locations where there are still enough large diameter canes, as they are far better priced than smaller diameters. Hence, it is justified to use time savings rather than changes in income in order to derive an estimate of the marginal economic impact of the distance of rattan harvesting locations. 


\section{CHAPTER 6}

Framing Effects of the Payment Mechanism in Choice Experiments 


\section{Introduction}

Along with the contingent valuation method (CVM), choice experiments (CE) have become an increasingly popular non-market environmental valuation technique. The $\mathrm{CE}$ method allows for simultaneous elicitation of multi-attribute benefits (use and non-use). In his lucid paper on the performance of CVM studies in so-called developing countries, Whittington (2002) finds that CVM studies are often of poor quality. One reason he mentions for this is the absence of split sample tests for the robustness of results when small changes in the design are applied.

Including split samples in the survey study design can be useful for two main reasons:

- Survey research has long demonstrated that small changes of the survey instrument with respect to wording (Schuman and Presser 1981, Payne 1951), context (Tversky and Kahneman 1981) or order (Krosnick and Alwin 1987) can significantly influence the outcome. Split samples can therefore improve the validity and robustness of the results by observing the influence of small changes in the design on welfare estimates.

- Offering alternative options via hypothetical scenarios is an integral part of stated-preference methods. Thus, the researcher has to carefully decide upon the type of information presented to the respondent. The researcher may not be able to assess a priori, how different information impacts choices. For example, there may be more than one specification for a payment vehicle, which seem to be equally appropriate. Split samples can provide both the researcher and the decision makers with valuable information on the influence of different alternatives of survey implementation or willingness-to-pay (WTP) activation.

Split sample experiments in CE research have been used to test for framing effects (Rolfe et al. 2002, Windle/Rolfe 2004), attribute level range effects (Hanley et al. 2005, Windle and Rolfe 2004) or ordering effects (Scott and Vick 1999, Kjaer et al. 2004, Glenk accepted).

CVM has been criticised as its results are often found to be biased by the type of payment vehicle used (Mitchell and Carson 1989). In a CE, the 'cost' attribute or price vector is 
used to obtain welfare measures such as implicit prices (IP) and Hicksian compensating variation. Therefore, testing for the robustness of parameter and IP estimates towards changes of the nature of the 'cost' attribute used is of particular importance for a validity assessment of welfare estimates in choice experiments.

Hanley et al. (2005) investigated price vector effects using data from a CE on water quality improvements. They used a split sample of two different price vectors, one of which was three times larger than the other one. Their main objective was to test whether the CE data would show the same type of anchoring, starting-point or framing effects that have been found in CVM applications. Calculating distributions of implicit prices (IP) from random parameter logit (RPL) parameter estimates, they found that the different price vectors used had a significant effect neither on estimates of preferences nor on IP distributions.

Windle and Rolfe (2004) assessed community preferences for the protection of an estuary. They used a split sample design to test for effects of different price vectors with the same main objective as Hanley et al. (2005). Similarly, they did not find significant differences of parameter estimates and WTP distributions for this split sample test. In another split sample, they investigated the influence of different payment mechanisms (one-off payment against an annual payment scheme, both framed for a 20 year period). Here, the lump-sum payment scheme generated lower WTP values than the periodic payment unless very high discount rates were used.

These studies indicate that CE may be less susceptible to the kind of starting point or anchoring bias found in CVM. It is less clear, however, if different framing of the payment mechanism has an impact on parameter and welfare estimates. In this paper, we used data from a choice experiment applied for an assessment of non-market benefits of biodiversity associated with a rural development program (cf. Barkmann et al. subm, Glenk et al. 2006a). We investigate the influence of (i) changes in the institutional background of the payment mechanism and (ii) changes in the payment mode, in particular payment frequency.

This paper proceeds as follows: after a brief introduction about the choice experiment technique and the multinomial logit model (section 2), the study area and the study design are presented (section 3); in the following sections, we outline the hypotheses (section 4) 
and describe the statistical tests used; the results of the tests are reported in section 6 , followed by a disussion for both split samples (section 7); and the paper ends with some conclusions.

\section{Choice experiments and the multinomial logit model}

In a CE, respondents state their preference by (repeated) choice from/of different alternatives or goods following an experimental plan. Having foundations in Lancastarian consumer theory (Lancaster 1966, 1991), the goods are being transformed into objective characteristics (attributes) from which the consumer is assumed to derive utility. In environmental choice modelling, the alternatives are often described as different development or policy options (Bennett and Adamowicz 2001). Another main pillar of choice modelling is random utility theory (RUT) (e.g Thurstone 1927, McFadden 1973, Manski 1977). ${ }^{1}$ Utility is partitioned into a deterministic, systematic component or 'representative utility' and a random part of utility "reflecting [the] unobserved individual idiosyncrasies of taste" (Louviere et al. 2001:38):

$$
\mathrm{U}_{\mathrm{ij}}=\mathrm{V}_{\mathrm{ij}}\left(\mathrm{X}_{\mathrm{ij}}, \mathrm{S}_{\mathrm{i}}\right)+\varepsilon_{\mathrm{ij}} \forall \mathrm{j} \in \mathrm{C}_{\mathrm{i}}
$$

where $U_{i j}$ is the utility an individual $i$ is assumed to obtain from of alternative $j$ in choice set $\mathrm{C}_{\mathrm{i}} \cdot \mathrm{V}_{\mathrm{ij}}$ is the deterministic part that is held to be a function of the attributes of alternatives $X_{i j}$, which is a vector of attributes as perceived by individual $i$ for alternative $j$ and characteristics of the individual $\mathrm{S}_{\mathrm{i}} . \varepsilon_{\mathrm{ij}}$ is the random term. As the analyst is unable to measure $\varepsilon_{\mathrm{ij}}$, $\mathrm{s} /$ he cannot determine exactly why an individual chooses an alternative $\mathrm{j}$ out of a set of competing options $\mathrm{C}_{\mathrm{i}} \forall \mathrm{j}, \mathrm{k} \in \mathrm{C}_{\mathrm{i}}$ and $\mathrm{i}=1, \ldots \mathrm{I}$. However, the systematic component $\mathrm{V}_{\mathrm{ij}}$ still allows her/him to make probabilistic statements about the choice. This leads to equation (2) and is called a Random Utility Model (RUM). Assuming utility maximization, the probability that alternative $\mathrm{j}$ is chosen by individual $\mathrm{i}$ over any alternative $\mathrm{k}$ out of choice set $\mathrm{C}_{\mathrm{i}}$ can be expressed as:

$$
\begin{aligned}
\mathrm{P}\left(\mathrm{j} \mid \mathrm{C}_{\mathrm{i}}\right)=\mathrm{P}\left(\mathrm{U}_{\mathrm{ij}}>\mathrm{U}_{\mathrm{ik}}\right) & =\mathrm{P}\left[\left(\mathrm{V}_{\mathrm{ij}}+\varepsilon_{\mathrm{ij}}\right)>\left(\mathrm{V}_{\mathrm{ik}}+\varepsilon_{\mathrm{ik}}\right)\right] \forall \mathrm{j}, \mathrm{k} \in \mathrm{C}_{\mathrm{i}} \text { and } \mathrm{j} \neq \mathrm{k} \neq 0 \\
& =\mathrm{P}\left[\left(\mathrm{V}_{\mathrm{ij}}-\mathrm{V}_{\mathrm{ik}}\right)>\left(\varepsilon_{\mathrm{ij}}-\varepsilon_{\mathrm{ik}}\right)\right] \forall \mathrm{j}, \mathrm{k} \in \mathrm{C}_{\mathrm{i}} \text { and } \mathrm{j} \neq \mathrm{k} \neq 0
\end{aligned}
$$

\footnotetext{
${ }^{1}$ Further theoretical input was obtained from research of informational processing in judgement and decision-making in psychology (e.g. Luce 1959, Slovic and Liechtenstein 1971).
} 
In order to be able to estimate the probabilities of equation $(2 \mathrm{a} / \mathrm{b})$, assumptions have to be made about the nature of the random error term. The majority of discrete choice models assumes that the random term is independently and identically distributed (IID), and related to the choice probability with a Type I extreme-value (Gumbel, Weibull, doubleexponential) distribution (with zero mean and a variance of $\mu^{2}$ ). As a consequence of the IID assumption, the alternatives have to be independent from irrelevant alternatives (IIA). That is, the ratio of probabilities of choosing alternative $\mathrm{j}$ over $\mathrm{k}$ out of a choice set $\mathrm{C}_{\mathrm{i}}$ remains unaffected of the presence or absence of any other alternative. All assumptions are given now for the conditional or multinomial logit model (MNL, McFadden 1973):

$$
P\left(j \mid C_{i}\right)=\frac{\exp ^{\mu V_{j i}}}{\sum_{k \in C_{i}} \exp ^{\mu V_{k i}}}
$$

where $\mu$ is the scale parameter usually set to 1 (constant error variances) and inversely proportional to the standard deviation of the error terms (Louviere et al. 2001). $\mathrm{V}_{\mathrm{ij}}$ is assumed to be linear and additive in parameters:

$$
V_{i j}=\alpha A S C_{j}+\sum \beta_{n} f\left(X_{n}\right)
$$

where $X_{n}$ is the attribute level of attribute $n$ of the $j^{\text {th }}$ alternative and $\beta_{n}$ is the parameter value associated with attribute $n$. $\mathrm{ASC}_{\mathrm{j}}$ is short for alternative specific constants that equal 1 for alternative $\mathrm{j}$ (otherwise: 0 ), and can be included for $\mathrm{j}-1$ alternatives. If the alternatives are generic (unspecific, i.e. unlabelled), the ASCs are equal. Socio-economic variables can be interacted either with the ASC and/or the attributes. "It is the role of the ASCs to take up any variation in choices that cannot be explained by either the attributes or the socioeconomic variables" (Bennett and Adamowicz 2001:60). By using a statistical estimation technique such as maximum likelihood estimation as available in statistical software packages, e.g. LIMDEP (Greene 2003), estimates for the coefficients associated with the attributes can be obtained.

Utilities for attributes are expressed by mean parameter estimates in the MNL model (Louviere et al. 2001). Mean parameter estimates are usually the main concern of CE researchers. They are used to generate implicit prices (IP) and other policy-relevant welfare estimates. Thus, analysing the impact of different specifications of the 'cost' 
attribute on mean parameters and implicit prices is an important contribution to assess the validity of choice experiment data. Implicit prices (marginal WTP) for an attribute are calculated using equation (1).

$$
\operatorname{Implicit} \text { price }(n)=-\left(\frac{\lambda \beta_{n}}{\lambda \beta_{\cos t}}\right)=-\left(\frac{\beta_{n}}{\beta_{\cos t}}\right)
$$

where $\beta_{\mathrm{n}}$ is mean parameter of attribute $\mathrm{n}$ in a linear and additive utility function (cf. equation 2), $\beta_{\text {cost }}$ is the coefficient of the 'cost' attribute and $\lambda$ denotes scale. The scale parameter $\lambda$ is inversely proportional to the variance of the error term, and is cancelled out for the calculation of implicit prices. Implicit prices reflect the marginal willingness to pay (MWTP) for a marginal change in a single attribute on a ceteris paribus basis (Bennett and Adamowicz 2001).

If the variance of unobserved components of the utility function or scale is different among (subsets of) alternatives (e.g. due to heterogeneous preferences), the IID and IIA assumptions do not hold. If IIA is found to be violated, the MNL should not be used and models such as the Nested Logit (NL) (Louviere et al. 2001) or Random Parameters Logit (RPL) (Train 1998) should be considered which relax these assumptions (Louviere et al. 2001). As we could not reject the IIA assumption for the total sample (cf. Glenk et al. 2006a), we see no urgent need on formal grounds for the use of NL or RPL models. ${ }^{2}$ Furthermore, IP estimates from both NL and RPL models not shown here yielded very similar results to the IP estimates presented in this paper. Hence, no substantial gain of information is expected from the use of other models for the specific purpose of this paper.

\section{Present study}

\subsection{Research area}

The research region is located in the humid tropics about 1 degree south of the equator. It comprises of four main areas divided into seven administrative districts in the province of Central Sulawesi, Indonesia. In more than 115 villages, the project area holds a population of approximately 130,000 on $7,220 \mathrm{~km}^{2}$. Lore Lindu National Park is centred within the study region and covers some $2,200 \mathrm{~km}^{2}$, which is one of the few large forest areas

\footnotetext{
${ }^{2}$ The IIA assumption could only be partly rejected for one of the sub-samples analysed in this paper ('tax').
} 
remaining on Sulawesi. A large number of animal species endemic to Sulawesi can be found in the National Park area (Waltert et al. 2004), including, e.g., the mammals anoa (Bubalus sp.), babirussa (Babyrousa babirussa), and many bird species.

The geophysical conditions of the research region vary greatly. Accordingly, a large variation of land use patterns can be found (Schwarze 2004). In the course of the 'cocoa boom' in Indonesia (Akiyama and Nishio 1996), cocoa became the dominant cash crop in the research region. Based on household data surveys, cocoa and wetland rice together account for $57 \%$ of the net crop income (Schwarze 2004). Concerning forest products, collection of fuel wood is widespread for private consumption, whilst rattan is the most important marketed forest product (Schwarze 2004).

\subsection{Study design and sample characteristics}

The choice sets offered to respondents consisted of two different management alternatives for the Lore Lindu area: A and B, and the present situation, C. Selection of attributes and attribute levels were guided by an ecosystem service approach (Barkmann et al. subm), and facilitated by information gathered in individual and peer-group interviews in various villages of the Lore Lindu area. Additional information and data were obtained from scientists working in the region as well as from literature (e.g. Belsky and Siebert 2003; Keil 2004; Siebert 2002). Four attributes with four levels each were used (table 1): water for irrigation of wetland rice; rattan stock in the forest; ways of cocoa cultivation; population size of anoa. Changes in these attributes were framed as a government development program. The alternatives were presented as 'show cards' to respondents. In order to test for ordering effects of attributes on choice cards, half of the respondents received choice sets with the reversed order of attributes on choice cards (Glenk accepted).

The 'cost' attribute was double split sampled as (i) a rise in "house and land" tax versus a donation to a village fund affecting every household of the research region and (ii) a monthly versus a yearly payment scheme. The split samples are described in detail in section 3 . 
Table 1: Attributes/Levels in sub-samples with different framing of the 'cost' attribute

\begin{tabular}{|c|c|c|}
\hline Label & Attribute & Levels \\
\hline Anoa & $\begin{array}{l}\text { different population sizes of the } \\
\text { endemic dwarf buffalo anoa (Bubalus } \\
s p .)\end{array}$ & $\begin{array}{c}{[\text { No. of animals }]} \\
10,180,350,520\end{array}$ \\
\hline Water & $\begin{array}{l}\text { Availability of irrigation water for } \\
\text { wet rice cultivation as expressed in } \\
\text { number of months with water scarcity }\end{array}$ & $\begin{array}{l}{[\text { No of months }]} \\
0,1,2,3\end{array}$ \\
\hline Rattan & $\begin{array}{l}\text { Availability of rattan (Calamus spp.) } \\
\text { expressed in distance from village }\end{array}$ & $\begin{array}{c}{[\mathrm{km}]} \\
5,10,15,20\end{array}$ \\
\hline Cocoa & $\begin{array}{l}\text { preponderance of cocoa plantations } \\
\text { differing along a shade tree gradient }\end{array}$ & $\begin{array}{l}{[\% \text { under shade }]} \\
\quad 5,35,65,95\end{array}$ \\
\hline 'Cost' & $\begin{array}{ll}\text { 'TAX' } & \text { extra taxes } \\
\text { 'FUND' } & \text { donation to village fund }\end{array}$ & $\begin{array}{cc}\text { 'YEAR' } & {[1,000 \mathrm{IDR} / \text { year }]} \\
& 18,36,54,72 \\
\text { 'MONTH' } & {[1,000 \mathrm{IDR} / \text { month }]} \\
& 1.5,3,4.5,6\end{array}$ \\
\hline
\end{tabular}

Exploratory studies have shown that virtually all people are familiar with monetary issues even in remote areas, though some were barely able to pay some of the higher amounts offered. Therefore, following Whittington (1998), the use and interpretation of stated preference values will be bounded by respondents' ability to pay and by their willingness to pay. As the wealth status of the inhabitants differed to a large extend, it proved to be a challenging task to derive an appropriate price range for the cost attribute. While a few households live in concrete houses, have access to satellite television and sometimes even own a car, others share a wooden hut without electricity. According to Whittington (1998), the highest price should be rejected by $90 \%-95 \%$ of the respondents in closed-ended CVM studies. The levels were derived following this recommendation by using different 'prices' in pre-tests based on initial information obtained by a payment-ladder approach (cf. Bateman et al. 2002). Offering the highest price to the poor could embarrass them, and could make "the interviewers look insensitive and/or uninformed" (Whittington 1998: 8). Hence, the range of 'price' levels was cut at the high end, accepting an underestimation of WTP by ignoring the higher WTP of a low percentage of rather well-situated people. In the analysis, IP values were calculated on a one years' basis.

Socio-economic characteristics of the respondents or their respective households are given in table 2 for the sample used in the subsequent analysis. Differences between the subsamples are not statistically significant at the $99 \%$ level. 
A more detailed description of the attributes and underlying assumptions is given in Glenk et al. (2006b). To simplify the exposition, attributes are denoted as 'rattan', 'water'. 'cocoa', 'anoa' and 'cost'. The alternative specific constant (ASC) is 'one' if alternatives A or B are chosen in a choice set, and 'zero' for the status-quo option.

Table 2: Household characteristics in the sub-samples

\begin{tabular}{|c|c|c|c|c|c|}
\hline \multirow[t]{2}{*}{ Variable } & \multirow[t]{2}{*}{ Unit/Scale } & 'fund' & 'tax' & 'month' & 'year' \\
\hline & & $\mathrm{N}=143$ & $\mathrm{~N}=145$ & $\mathrm{~N}=143$ & $\mathrm{~N}=145$ \\
\hline $\begin{array}{l}\text { Age of } \\
\text { respondent }\end{array}$ & Years & $\begin{array}{c}45.01 \\
(14.53)\end{array}$ & $\begin{array}{c}45.34 \\
(13.56)\end{array}$ & $\begin{array}{c}45.36 \\
(13.72)\end{array}$ & $\begin{array}{c}45.00 \\
(14.36)\end{array}$ \\
\hline Education & $\begin{array}{l}\text { Years in school; } 6=\text { finished primary } \\
\text { school }\end{array}$ & $\begin{array}{c}7.85 \\
(3.21)\end{array}$ & $\begin{array}{c}7.52 \\
(3.37)\end{array}$ & $\begin{array}{c}7.94 \\
(3.36)\end{array}$ & $\begin{array}{c}7.43 \\
(3.21)\end{array}$ \\
\hline Non-farm & $\begin{array}{l}\text { Dummy taking } 1 \text { if respondent derives } \\
\text { income from non-agricultural activities }\end{array}$ & $\begin{array}{c}0.20 \\
(0.40)\end{array}$ & $\begin{array}{c}0.20 \\
(0.40)\end{array}$ & $\begin{array}{c}0.24 \\
(0.43)\end{array}$ & $\begin{array}{c}0.16 \\
(0.37)\end{array}$ \\
\hline Cocoa owner & $\begin{array}{l}\text { Dummy taking } 1 \text { if respondent is an } \\
\text { owner of a cocoa plantation }\end{array}$ & $\begin{array}{c}0.75 \\
(0.44)\end{array}$ & $\begin{array}{c}0.78 \\
(0.42)\end{array}$ & $\begin{array}{c}0.76 \\
(0.43)\end{array}$ & $\begin{array}{c}0.77 \\
(0.42)\end{array}$ \\
\hline $\begin{array}{l}\text { Paddy rice } \\
\text { farmer }\end{array}$ & $\begin{array}{l}\text { Dummy taking } 1 \text { if respondent is } \\
\text { involved in paddy rice cultivation }\end{array}$ & $\begin{array}{c}0.57 \\
(0.50)\end{array}$ & $\begin{array}{c}0.64 \\
(0.48)\end{array}$ & $\begin{array}{c}0.64 \\
(0.48)\end{array}$ & $\begin{array}{c}0.57 \\
(0.50)\end{array}$ \\
\hline Rattan collector & $\begin{array}{l}\text { Dummy taking } 1 \text { if respondent collects } \\
\text { rattan }\end{array}$ & $\begin{array}{c}0.13 \\
(0.34)\end{array}$ & $\begin{array}{c}0.12 \\
(0.33)\end{array}$ & $\begin{array}{c}0.13 \\
(0.33)\end{array}$ & $\begin{array}{c}0.13 \\
(0.34)\end{array}$ \\
\hline $\begin{array}{l}\text { Child } \\
\text { dependency rate }\end{array}$ & Dependency rate adults vs. children ${ }^{\S}$ & $\begin{array}{c}0.53 \\
(0.47)^{\mathrm{a}}\end{array}$ & $\begin{array}{c}0.54 \\
(0.50)^{\mathrm{a}}\end{array}$ & $\begin{array}{c}0.52 \\
(0.48)^{b}\end{array}$ & $\begin{array}{c}0.55 \\
(0.49)^{\mathrm{b}}\end{array}$ \\
\hline $\begin{array}{l}\text { Household } \\
\text { members }\end{array}$ & Total number of household members & $\begin{array}{c}5.31 \\
(2.12)^{\mathrm{a}}\end{array}$ & $\begin{array}{c}5.54 \\
(2.20)^{\mathrm{a}}\end{array}$ & $\begin{array}{l}5.47 \\
(2.26)^{\mathrm{b}}\end{array}$ & $\begin{array}{c}5.39 \\
(2.07)^{\mathrm{b}}\end{array}$ \\
\hline Gross income & $\begin{array}{l}\text { Gross income per household/year in } \\
1,000 \text { IDR }^{\S}\end{array}$ & $\begin{array}{c}6,053 \\
(7,988)^{\mathrm{c}}\end{array}$ & $\begin{array}{c}6,458 \\
(8,965)^{\mathrm{c}}\end{array}$ & $\begin{array}{c}6,971 \\
(9,560)^{\mathrm{d}}\end{array}$ & $\begin{array}{c}5,604 \\
(7,349)^{d}\end{array}$ \\
\hline $\begin{array}{l}\mathrm{LN} \text { of Gross } \\
\text { income }\end{array}$ & $\begin{array}{l}\text { Natural log of gross income per } \\
\text { household/year in } 1000 \text { IDR }^{\S}\end{array}$ & $\begin{array}{l}7.880 \\
(1.838)^{\mathrm{c}}\end{array}$ & $\begin{array}{c}8.083 \\
(1.480)^{\mathrm{c}}\end{array}$ & $\begin{array}{c}8.135 \\
(1.511)^{\mathrm{d}}\end{array}$ & $\begin{array}{c}7.849 \\
(1.781)^{\mathrm{d}}\end{array}$ \\
\hline
\end{tabular}

A main-effects experimental design was applied. An orthogonal fraction of 16 out of the $4^{5}$ possible combinations of attribute levels was selected (Louviere et al. 2001), and combined into choice scenarios that consisted of two (generic) alternatives; A and B, and a status-quo option presented on choice cards. The choice sets were blocked into four versions so that each respondent faced four choices. In order to account for the heterogeneous environmental conditions of the research region, the status quo was offered as a selfexplicated alternative for all attributes except anoa (regional average). 
For data collection, a stratified village sampling frame was adopted. The strata for the sample were ethnicity composition, vicinity to the Lore Lindu National Park and population density of a village. Households were then randomly selected within each village. Details of the sampling are described in Zeller et al. (2002). The choice experiment survey was administered to 301 households in 12 villages of the research region (December 2004 - March 2005). Face-to-face interviews were conducted by 6 well-trained local enumerators. To minimize potential interviewer effects, enumerators were randomly assigned to the households.

According to previous results presented elsewhere (e.g., Barkmann et al. subm, Glenk et al. 2006a, b), 'water' and 'rattan' had - as expected - negative and significant signs. That is, more months/yr with water scarcity and an increased distance to rattan harvesting locations were associated with disutility. The sign of the 'anoa' attribute was positive and significant, indicating that people, on average, do care for the maintenance of viable populations of this animal. For the 'cocoa' attribute, the coefficient was negative and significant, denoting a negative effect for more shade on cocoa plantations.

\section{Hypotheses}

The first split sample consisted of a differentiation between a rise in "house- and land" tax (Pajak Bumi Bangunan $(P B B)$ ) or a donation to a village fund (Iuran dana pembangunan desa) affecting every household of the research region. In preliminary investigations including focus-group discussions and individual interviews, both types familiar to respondents seemed to be equally suitable as a payment vehicle for that particular task.

PBB is collected on a village scale, organized at the district level of government and afterwards provided to the province budget. ${ }^{3}$ Hence, the channels involved are less transparent for the individual. Corruption is widespread in Indonesia (World Bank 2003), including the level of local government (Henderson and Kuncoro 2004). Hence, the possibility could not be excluded a priori that at least some respondents were concerned, that not all of their money is being spent for achieving the improvements proposed in the

\footnotetext{
${ }^{3}$ the average direct tax (PBB: pajak bumi bangunan) paid by households in the research region is about 15,000 IDR per year.
} 
choice experiment. If this was the case, we would expect a negative impact on IPs in the 'tax' split sample.

Village funds are a common practice to (co-)finance village projects ranging from sport activities to the improvement of the village infrastructure. Collected by the village government, transparency is rather high. ${ }^{4}$ Furthermore, the immediate results of the efforts taken by a village community are obvious. However, respondents may doubt whether the village communities themselves had the knowledge and capacity to effectively manage the environmental resources providing the services included in the choice experiment.

We test the following null hypotheses:

$$
\begin{aligned}
& \text { H01: } \beta_{\text {tax }}=\beta_{\text {fund }} \\
& \text { H02: } \mathrm{IP}_{\text {tax }}=\mathrm{IP}_{\text {fund }} .
\end{aligned}
$$

In the second split sample we varied the payment mode. One half of the respondents received choice cards asking for monthly payment scheme ('month'), the other half for a yearly payment scheme ('year'). The absolute magnitude of payments did not differ between the two groups. We neglected time preferences and thus assumed a discount rate of zero. We did so because we did not specify at what time of the year the yearly payment had to be made because people can, in practice, also pay their taxes whenever they have enough cash available, independent of the time.

We found that due to their cash availability, low-income respondents would find it easier to continuously pay a rather low amount than to spend a rather large sum at a time. If this would be the case, effects of income on the sensitivity towards the 'cost' attribute could be expected to be less pronounced in the 'month' sub-sample. On the other hand, people might find it easier to make the payment only once a year at that time. This could be due to the fact that there are times when they have a larger sum of cash available, for example directly after harvests.

\footnotetext{
${ }^{4}$ In our case, we understand 'local government' to consist of all governmental institutions above village level (district, regional and provincial levels). We emphasize that this is an artificial distinction only made for the ends of this paper.
} 
The null hypotheses are:

$$
\begin{aligned}
& \mathrm{H} 03: \beta_{\text {month }}=\beta_{\text {year }} \\
& \text { H04: } \mathrm{IP}_{\text {month }}=\mathrm{IP}_{\text {year }}
\end{aligned}
$$

The possibility cannot be excluded a priori that merely the large amounts of money showing on the cards in the 'year' sub-sample could be a reason for choice refusal, despite that the yearly sum of the payments are equal. If this would be the case, one would expect the acceptance of improvement alternatives relative to the status quo to be lower in the 'year' group. This would lead to a higher rate of respondents choosing the status-quo alternative (cf. Hanley et al. 2005), resulting in the null:

H05: $\mathrm{SQ}_{\text {year }} /$ total choices $>\mathrm{SQ}_{\text {month }} /$ total choices.

H01 and H03 are tested by using Likelihood Ratio tests (Swait and Louviere 1993), H02 and H04 by applying a Poe et al. $(1994,2005)$ test for differences in distributions. For H05, we tested for differences in the distributions of the number of status quo choices per respondent in the choice experiment.

For both hypotheses results from multinomial logit (MNL) models (Louviere et al. 2001) are used. The deterministic part of the indirect utility function for alternative $\mathrm{j}$ is assumed to be linear and additive in parameters and contains the following aspects:

$$
V_{\mathrm{j}}=\alpha \mathrm{ASC}_{\mathrm{j}}+\beta_{1} f\left(\operatorname{Rattan}_{\mathrm{j}}\right)+\beta_{2} f\left(\text { Water }_{\mathrm{j}}\right)+\beta_{3} f\left(\mathrm{Cocoa}_{\mathrm{j}}\right)+\beta_{4} f\left(\mathrm{Anoa}_{\mathrm{j}}\right)+\beta_{5} f\left({ }^{\prime} \text { Cost' }_{\mathrm{j}}\right)
$$

\section{Methods}

\subsection{Test statistics for parameter equality}

As parameters are confounded with scale (equation 1), one has to account for differences in scale for a comparison of parameters. The scale parameter of a single data set cannot be estimated. For two different data sets, one can only calculate the ratio of scale parameters of the two sets. We use the procedure suggested by Swait and Louviere (1993). They suggest a two stage approach to test whether two samples share the same parameters. The 
first stage is designed to test whether parameters are equal while allowing for scale to differ. In a second stage, a test for scale parameter equality is conducted.

A grid search technique is applied to find the value of the scale parameter $\mu$ of a subsample $\mathrm{X}$ relative to a sub-sample $\mathrm{Y}$ that optimises the log-likelihood value in a pooled and re-scaled data set $\mathrm{XY}_{\mu}$. Then, a likelihood ratio test is used to test for parameter equality (i.e., $H 1_{\beta}$ : $\beta_{X}=\beta_{Y}=\beta_{X Y}$ ) while allowing for scale differences:

$$
L R_{1}=-2\left(\log L_{X Y \mu}-\left(\log L_{X}+\log L_{Y}\right)\right)
$$

$\log \mathrm{L}_{\mathrm{XY} \mu}$ is the likelihood value of the pooled data set after re-scaling with $\mu$, and $\log \mathrm{L}_{\mathrm{X}}$ and $\log L_{Y}$ are the likelihood values of sub-samples $X$ and $Y$. The test statistic is asymptotically chi-squared distributed with $\mathrm{K}+1$ degrees of freedom, with $\mathrm{K}$ being the number of parameters in both sub-samples. If parameter equality cannot be rejected, it is tested, if scale factors are equal (i.e., $\mathrm{H} 1_{\mu}: \mu_{\mathrm{X}}=\mu_{\mathrm{Y}}=\mu_{\mathrm{XY}}$ ). The test statistic is:

$$
L R_{2}=-2\left(\log L_{X Y}-\log L_{X Y \mu}\right)
$$

where $\log \mathrm{L}_{\mathrm{XY}} \mu$ is as previously defined and $\log \mathrm{L}_{\mathrm{XY}}$ is the likelihood value for the pooled sample with equal scale parameters. $\mathrm{LR}_{2}$ is asymptotically chi-squared distributed with one degree of freedom. Sub-sample $\mathrm{X}$ and $\mathrm{Y}$ share equal parameters if both $\mathrm{H} 1_{\beta}$ and $\mathrm{H} 1_{\mu}$ cannot be rejected.

\subsection{Testing equality of implicit prices}

As the scale parameter cancels out for the calculation of implicit prices (equation 5), one need not account for differences in scale. The procedure follows an approach of Poe et al. (1994, 2005). Using a Krinsky and Robb (1986) bootstrapping procedure, a large number (e.g. 1000) of IP estimates for the attributes are drawn from parameter estimates and for the corresponding variance-covariance matrix for both sub-samples. Implicit prices are derived by drawing from population means and calculated using equation (1) for the MNL models.

The procedure results in two vectors $\mathrm{v}_{\mathrm{i}}\left[\mathrm{IP}_{\mathrm{X}}\right]$ and $\mathrm{v}_{\mathrm{i}}\left[\mathrm{IP}_{\mathrm{Y}}\right]$ for sub-samples $\mathrm{X}$ and $\mathrm{Y}$. The difference vector between each single element of $\mathrm{v}_{\mathrm{i}}\left[\mathrm{IP}_{\mathrm{X}}\right]$ and each single element of $\mathrm{v}_{\mathrm{i}}\left[\mathrm{IP}_{\mathrm{Y}}\right]$ 
is calculated for attribute $\mathrm{i}^{5}$ The one-sided significance level of difference can be derived by assessing the value of the cumulative distribution of the difference vector at zero.

\section{Results}

13 respondents were classified as essentially not responding to the choice task and were omitted from subsequent analysis. ${ }^{6}$ MNL model results are listed in table 3. All models are overall significant at the $99 \%$ level and show a decent model fit in terms of adjusted $\rho^{2}$ $(0.25-0.27)$. All signs are as expected, and all attribute parameters are significant at $p<$ 0.05 or lower except for the anoa attribute in the 'fund' and 'year' samples. ASCs are positive and only significantly different from zero for the 'tax' sample and the pooled models.

\subsection{Parameter equality}

The grid search led to a relative scale factor that optimises the log likelihood function in the pooled and rescaled samples of 0.91 for the 'fund' sub-sample and 0.95 for the 'month' sub-sample. For the 'tax/fund' split sample, the $p$ values ( $L R<\chi^{2} ; \alpha=0.05$ ) for the LR tests were 0.9163 for $\mathrm{LR}_{\beta}$ and 0.2622 for $\mathrm{LR}_{\mu}$. Thus, $\mathrm{H} 1_{\beta}$ and $\mathrm{H} 1_{\mu}$ could not be rejected. According to the Swait and Louviere test, the 'tax' and 'fund' sub-samples do not have significantly different parameter estimates, and the ratio of scale parameters is not significantly different from one. Thus, $\mathrm{H} 01$ could not be rejected.

For the 'month/year' split sample, the $\mathrm{p}$ values $\left(\mathrm{LR}<\chi^{2} ; \alpha=0.05\right)$ for the LR tests are 0.0895 for $\mathrm{LR}_{\beta}$ and 0.5057 for $\mathrm{LR}_{\mu}$. and $\mathrm{H}_{\mu}$ could not be rejected at that level of significance. However, $\mathrm{H}_{\beta}$ could be rejected at $\alpha=0.1$. At that level of significance, $\mathrm{H} 03$, that is parameter equality between the 'month' and 'year' sub-samples, could be rejected.

\footnotetext{
${ }^{5}$ The vector being minuend has the larger average value.

${ }^{6}$ The 16 respondents always chose the status quo because of 'protest' (no change wanted), general payment aversion and exceeding cognitive capability.
} 
Table 3: MNL Model results: 'Tax' and 'Fund'

\begin{tabular}{|c|c|c|c|c|c|c|c|}
\hline & 'Fund' & 'Tax' & $\begin{array}{c}\text { 'Fund' + } \\
\text { 'Tax' }\end{array}$ & 'Month' & 'Year' & $\begin{array}{l}\text { 'Month'+ } \\
\text { 'Year' }\end{array}$ & Pooled \\
\hline Rattan & $\begin{array}{c}-0.0276^{* *} \\
(-2.61)\end{array}$ & $\begin{array}{c}-0.0436^{* * *} \\
(-3.90)\end{array}$ & $\begin{array}{c}-0.0374^{* * *} \\
(-4.65)\end{array}$ & $\begin{array}{l}-0.0494^{* * *} \\
(-4.48)\end{array}$ & $\begin{array}{c}-0.0236^{*} \\
(-2.18)\end{array}$ & $\begin{array}{l}-0.0354^{* * *} \\
(-4.59)\end{array}$ & $\begin{array}{c}-0.0354^{* * *} \\
(-4.62)\end{array}$ \\
\hline Water & $\begin{array}{l}-0.8684^{* * *} \\
(-13.38)\end{array}$ & $\begin{array}{l}-0.8942^{* * *} \\
(-13.07)\end{array}$ & $\begin{array}{l}-0.9220^{* * *} \\
(-18.70)\end{array}$ & $\begin{array}{l}-0.9393^{* * *} \\
(-13.63)\end{array}$ & $\begin{array}{l}-0.8443^{* * *} \\
(-12.91)\end{array}$ & $\begin{array}{l}-0.9013^{* * *} \\
(-18.72)\end{array}$ & $\begin{array}{l}-0.88^{* * *} \\
(-18.73)\end{array}$ \\
\hline Cocoa & $\begin{array}{l}-0.0102^{* * *} \\
(-4.61)\end{array}$ & $\begin{array}{l}-0.0109^{* * *} \\
(-4.74)\end{array}$ & $\begin{array}{l}-0.011^{* * *} \\
(-6.60)\end{array}$ & $\begin{array}{c}-0.0069^{* *} \\
(-3.09)\end{array}$ & $\begin{array}{l}-0.0139^{* * *} \\
(-6.13)\end{array}$ & $\begin{array}{l}-0.0109^{* * *} \\
(-6.69)\end{array}$ & $\begin{array}{l}-0.0105^{* * *} \\
(-6.62)\end{array}$ \\
\hline Anoa & $\begin{array}{l}0.0006 \\
(1.39)\end{array}$ & $\begin{array}{c}0.0013^{* *} \\
(2.71)\end{array}$ & $\begin{array}{l}0.001^{* *} \\
(2.92)\end{array}$ & $\begin{array}{l}0.0011^{*} \\
(2.34)\end{array}$ & $\begin{array}{l}0.0008 \\
(1.69)\end{array}$ & $\begin{array}{l}0.001^{* *} \\
(2.85)\end{array}$ & $\begin{array}{l}0.0009^{* *} \\
(2.86)\end{array}$ \\
\hline Cost & $\begin{array}{c}-0.0237^{* * *} \\
(-6.19)\end{array}$ & $\begin{array}{l}-0.0292^{* * *} \\
(-7.16)\end{array}$ & $\begin{array}{l}-0.0277^{* * *} \\
(-9.50)\end{array}$ & $\begin{array}{l}-0.0239^{* * *} \\
(-6.16)\end{array}$ & $\begin{array}{l}-0.0287^{* * *} \\
(-7.13)\end{array}$ & $\begin{array}{l}-0.0271^{* * *} \\
(-9.48)\end{array}$ & $\begin{array}{c}-0.0262^{* * *} \\
(-9.42)\end{array}$ \\
\hline ASC & $\begin{array}{l}0.2801 \\
(1.47)\end{array}$ & $\begin{array}{l}0.4351^{*} \\
(2.22)\end{array}$ & $\begin{array}{l}0.3586^{* *} \\
(2.63)\end{array}$ & $\begin{array}{l}0.3766 \\
(1.94)\end{array}$ & $\begin{array}{l}0.3104 \\
(1.6)\end{array}$ & $\begin{array}{l}0.3542^{* *} \\
(2.6)\end{array}$ & $\begin{array}{l}0.3482^{*} \\
(2.55)\end{array}$ \\
\hline Scale & - & - & $0.91^{\S}$ & - & - & $0.95^{\$}$ & - \\
\hline $\log L$ & -439.8448 & -423.3064 & -864.4705 & -427.8227 & -430.8786 & -864.8777 & -865.0992 \\
\hline Obs. & 572 & 580 & 1152 & 572 & 580 & 1152 & 1152 \\
\hline Adj. $\rho^{2}$ & 0.2488 & 0.2664 & 0.2588 & 0.2645 & 0.2589 & 0.2585 & 0.2583 \\
\hline
\end{tabular}

$\$$ 'Fund' sub-sample rescaled; 'Month' sub-sample rescaled
t-statistics in parentheses; Significancies: $* * * \mathrm{p}<0.001 ; * * \mathrm{p}<0.01 ; * \mathrm{p}<0.05$

\subsection{Implicit prices}

Mean IPs, standard errors and results of the probability values for difference in IPs are shown in table 4 . In both split samples, the parameter estimate for the anoa attribute is not significant in one of the sub-samples. Hence, we will focus the observation of IP differences on the remaining attributes.

Interestingly, IPs are not uniformly higher or lower in one of the sub-samples for both split samples. In the 'tax/fund' split sample, the IP for rattan is higher in the 'tax' sub-sample, while IPs for cocoa and water are higher in the 'fund' sub-sample. All the differences, however, are not significant at $\alpha=0.05$. IPs for the rattan and water attributes are higher in the 'month' sub-sample. The IP for cocoa, however, is higher in the 'year' sub-sample. In the 'month/year' split sample, all differences have values of one-sided significance levels of difference below 0.1, for rattan even below 0.05. Thus, the results of the Poe et al. test suggest that $\mathrm{H} 02$ cannot be rejected, while $\mathrm{H} 04$ can be rejected at $\alpha=0.1$ for all attributes. 
As implicit prices are calculated using parameters from two attributes, of which one is 'cost', different weighting of both attributes can drive the differences in implicit prices. Formally, one cannot directly compare parameter estimates, as they are confounded with scale. However, one still may investigate parameter estimates in table 3 in order to assess whether IP differences are subject to changes in response to both or either one of the attributes. The cocoa and water attributes in the 'tax/fund' split sample have quite similar parameter values in both sub-samples. Thus, the modest but statistically insignificant differences of IP for these attributes seem to be subject largely to a different sensitivity towards 'cost'. The lower parameter value for the 'cost' attribute in the 'tax' sub-sample indicates that respondents were more responsive to increasing 'cost' as compared to the 'fund' sub-sample. Differences in the rattan attribute for 'tax/fund' and all attributes for 'month/year' are the result of different sensitivity towards changes in both of the attribute, thus complicating a comparison.

Table 4: Mean implicit prices and probability values of IP equality

\begin{tabular}{|c|c|c|c|c|c|c|c|}
\hline & 'Fund' & 'Tax' & 'Month' & 'Year' & $\begin{array}{c}\text { Pooled } \\
\text { sample }^{\S}\end{array}$ & $\begin{array}{c}\text { Prob. } \\
\text { IP }_{\text {tax }} \neq I \mathbf{I}_{\text {fund }}\end{array}$ & $\begin{array}{c}\text { Prob. } \\
\text { IP }_{\text {month }} \neq \mathbf{I P} \text { year }\end{array}$ \\
\hline Rattan & $\begin{array}{l}-1.1845 \\
(0.0158)\end{array}$ & $\begin{array}{l}-1.5283 \\
(0.0134)\end{array}$ & $\begin{array}{l}-2.1335 \\
(0.0192)\end{array}$ & $\begin{array}{l}-0.8242 \\
(0.0127)\end{array}$ & $\begin{array}{l}-1.3638 \\
(0.0105)\end{array}$ & 0.2957 & $0.0249 *$ \\
\hline Water & $\begin{array}{l}-37.6954 \\
(0.2084)\end{array}$ & $\begin{array}{l}-31.1276 \\
(0.1505)\end{array}$ & $\begin{array}{l}-40.3915 \\
(0.2365)\end{array}$ & $\begin{array}{l}-30.1043 \\
(0.1527)\end{array}$ & $\begin{array}{l}-33.8215 \\
(0.1202)\end{array}$ & 0.1962 & $0.0968 *$ \\
\hline Cocoa & $\begin{array}{l}-0.4418 \\
(0.0037)\end{array}$ & $\begin{array}{l}-0.3776 \\
(0.0029)\end{array}$ & $\begin{array}{l}-0.2946 \\
(0.0034)\end{array}$ & $\begin{array}{l}-0.4939 \\
(0.0033)\end{array}$ & $\begin{array}{l}-0.4019 \\
(0.0023)\end{array}$ & 0.3329 & $0.0851^{*}$ \\
\hline
\end{tabular}

\subsection{Status quo choices}

Respondents preferred to choose the status quo option to the program alternatives in $53 \%$ of all choices for the total sample. The figure is $52 \%$ for the 'month' sub-sample, and slightly higher (54\%) for the 'year' sub-sample (table 5). The distributions of the numbers of status quo choices per respondent do not resemble a normal distribution. The asymptotic two-sided significance value for the non-parametric Mann-Whitney-U test is 0.63 , indicating that the 'month' and 'year' sub-samples do not differ with respect to the choice behaviour regarding the status quo choices. Thus, we can reject $\mathrm{H} 05$. 
Table 5: SQ choices in the 'month' and 'year' sub-samples

\begin{tabular}{cccc}
\hline No. of SQ choices & 'month' & 'year' & $\begin{array}{c}\text { Full } \\
\text { sample }\end{array}$ \\
\hline 0 & 21 & 20 & 41 \\
1 & 29 & 30 & 59 \\
2 & 32 & 31 & 63 \\
3 & 38 & 34 & 72 \\
4 & 23 & 30 & 53 \\
SQ choices/total choices & $299 / 572$ & $314 / 580$ & $613 / 1152$ \\
$(\%)$ & $(52.3 \%)$ & $(54.1 \%)$ & $(53.2 \%)$ \\
\hline
\end{tabular}

\section{Discussion}

\section{1 'Fund/Tax' split sample}

Differences between parameter estimates and IPs calculated for the 'fund' and 'tax' subsamples are not statistically significant according to the tests performed. We initially assumed that differences may be due to (i) a lack of trust for government as a result of widespread corruption and (ii) a lack of confidence in the capabilities village institutions to handle the management of environmental resources by themselves.

Regarding the first aspect, there is an indication that respondents are more responsive towards changes in the 'cost' attribute if it is framed as a tax rise. Overall, however, our findings do not suggest that respondents showed explicit distrust towards paying tax. The significant and positive ASC in the 'tax' sub-sample indicates that the choices of respondent were less restricted to the benefits they expected to receive only from the offered program alternatives compared to the 'fund' sub-sample. We would have expected a negative sign of the ASC if respondents expected their money to be lost due to corruption; that is, the choice data shows a tendency to keep the status quo that is not explained by the attributes. The positive ASC parameter value may at least partly be interpreted as a value arising from expected benefits from paying tax irrespective of the levels of the other attributes offered.

This result should not be misinterpreted. It does not tell much about either size or magnitude of perceived corruption, and may also simply be an expression of obedience 
towards government institutions or acceptance of existing structures while alternatives are missing.

Concerning the second assumption, our findings suggest that respondents may doubt whether the knowledge and capacity of the village communities themselves would be sufficient to effectively manage some of the environmental resources providing the services included in the choice experiment. The tendency towards higher sensitivity towards changes in the 'cost' attribute does not lead to uniformly lower IP values for all attributes. In the 'tax' sub-sample, IPs for rattan are higher, and the anoa attribute parameter only becomes significant for that sub-sample. While cocoa plantations and paddy rice fields are strictly organized on the village scale, boundaries are less clear for rattan, and not existing for anoa populations - which are both forest resources. Thus, respondents may perceive that the village institutions themselves are less capable of the coordination of the management of these two resources in the region. This may apply particularly to the management of the anoa population, which requires a management transcending village boundaries.

\section{2 'Month/Year' split sample}

The 'month' and 'year' sub-samples did not differ with respect to the numbers of statusquo choices. IP values were not higher for all the attributes in the 'month' sub-sample. These two findings strongly suggest that the effects of large amounts of money did not lead to a greater refusal of program alternatives. Thus, those effects are unlikely to explain the differences between the sub-samples.

Parameter equality is not given at $\alpha=0.1$, and IP values differ for all observed attributes. The parameter estimate for anoa is only significant in the 'month' sub-sample. We cannot offer a sound explanation for this finding. IP values are higher for the rattan and water attributes in the 'month' sub-sample, but higher for the cocoa attribute in the 'year' subsample. Rattan collection is mainly carried out at the poorer margin of the population. Paddy rice is at least partly cultivated for home consumption, and owning irrigated land can back the production of perennial (cash) crops (cf. Schwarze 2004), which is dominated by the cultivation of cocoa. The production of cash crops may - among other factors therefore have a positive influence on the cash availability of respondent households. The 
logarithmically transformed gross income ${ }^{7}$ can serve as an indicator for cash availability. It was significantly higher for those respondents who cultivate the cash crop cocoa on an area of 100 ar or more $\left(33.3 \%^{8}\right)$. We therefore conjecture that differences in cash availability, approximated by gross income, may play an important role to explain the differences found.

It was therefore suggestive to observe the influence of gross income on the cost parameter in the two sub-samples. In order to do so, we created an interaction of the (logtransformed) variable for gross income and the 'cost' attribute. Model results for the 'month' and 'year' sub-samples are shown in table 6. The interaction parameter is positive and significant at the $95 \%$ level in the 'year' sub-sample, i.e. respondents with higher gross income are less responsive towards a rise of the 'cost' attribute. For the 'month' subsample, however, income virtually does not have an influence on the sensitivity towards changes in the 'cost' attribute.

Our findings indicate that cash availability of a household plays an important role for explaining the differences between the 'month' and 'year' sub-samples. In reality, the relationship between gross income and cash availability may be more complex. Cash availability may also be determined by factors such as access to credit, assets owned or income from non-agricultural self-employment and household expenses. Despite the fact that we found a positive influence of the production of cocoa above 100 ar on gross income, it is not given that it definitely has a positive influence on cash availability as well. Therefore, we do not claim that our explanation pattern is exclusive. However, it is a very suggestive one under the constraint of the data available for our analysis.

Windle and Rolfe (2004) found different IPs for samples with either a continuous or a lump-sum payment mode. They related their differences to time preferences of respondents. Our study was not designed to capture effects of time preferences, as we specified neither the duration of the project nor the time of the year when the yearly payments had to be made. We cannot generally exclude that time preferences influenced

\footnotetext{
${ }^{7}$ The transformation was necessary due to the high standard deviation and skewness of the gross income variable (table 2), which mainly result from a low proportion of households with very high gross income.

${ }^{8}$ This analysis refers only to 252 of the total 288 respondents, for which information about income was available. Log-tranformed gross-income and the total area of cocoa plantations owned are positively correlated (Pearsons $\mathrm{R}^{2}=0.257$; significant at the $99 \%$ level).
} 
the choices of the respondents. However, we do not assume that they played a dominant role in our case, as the higher IPs for cocoa in the 'year' sub-sample are difficult to be explained by different time preferences and would actually reflect a negative discount rate.

Table 6: MNL models with income/'cost' interaction of the 'month' and 'year' sub-samples

\begin{tabular}{|c|c|c|}
\hline & 'Month' & 'Year' \\
\hline Rattan & $\begin{array}{l}-0.0495^{* * *} \\
(-4.44)\end{array}$ & $\begin{array}{c}-0.0220^{*} \\
(-2.03)\end{array}$ \\
\hline Water & $\begin{array}{l}-0.9398^{* * *} \\
(-13.6)\end{array}$ & $\begin{array}{l}-0.8531^{* * *} \\
(-12.94)\end{array}$ \\
\hline Cocoa & $\begin{array}{c}-0.007^{* *} \\
(-3.09)\end{array}$ & $\begin{array}{c}-0.0139^{* * *} \\
(-6.14)\end{array}$ \\
\hline Anoa & $\begin{array}{l}0.0011^{*} \\
(2.34)\end{array}$ & $\begin{array}{l}0.0007 \\
(1.55)\end{array}$ \\
\hline Cost & $\begin{array}{c}-0.0249^{*} \\
(-2.02)\end{array}$ & $\begin{array}{l}-0.05125^{* * *} \\
(-4.77)\end{array}$ \\
\hline $\begin{array}{l}\text { Cost } x \\
\text { LN Gross income }\end{array}$ & $\begin{array}{l}0.0001 \\
(0.09)\end{array}$ & $\begin{array}{l}0.0029^{*} \\
(2.32)\end{array}$ \\
\hline ASC & $\begin{array}{l}0.377 \\
(1.94)\end{array}$ & $\begin{array}{l}0.3104 \\
(1.6)\end{array}$ \\
\hline $\log L$ & -427.8185 & -427.8164 \\
\hline Obs. & 572 & 580 \\
\hline Adj. $\rho^{2}$ & 0.2638 & 0.2635 \\
\hline
\end{tabular}

Instead, we argue that the significant differences between the sub-samples offering a monthly or a yearly payment scheme are largely due to varying cash availability of respondents, which is a function of their socio-economic background. This is an important insight for CEs conducted with low-income samples, and particularly for applications in so-called developing countries. 


\section{Conclusion}

With a reasonable amount of effort, designing split sample experiments can produce further insights on the robustness and validity of $\mathrm{CE}$ results. CE researchers should therefore regularly include split samples in their surveys. The split sample experiments reported in this paper were designed to test for framing effects of the 'cost' attribute on parameter estimates and implicit prices. In particular, we tested for the influence on choices of (i) changes in the institutional background of the payment, and (ii) changes in the frequency of payments.

Despite intensive preparatory investigations, we did not know a priori, whether framing the 'cost' attribute as a donation to a village fund or a tax rise or using a monthly or a yearly payment scheme would be more appropriate. Thus, split sample analysis is a suitable way to find out how different framing impacts on IP estimates. This can provide useful insights for decision makers who want to include local contributions in development programs.

Our results suggest that changes in the institutional background of the payment did not result in significant differences for either the parameter estimates or IP values. They indicate that respondents did not have an explicit distrust in the efficiency of government above village level. For resources requiring a management not bound to village boundaries, such as the anoa population, respondents acted reasonable in showing a lower responsiveness if the payment was framed as a donation to a village fund.

Parameter estimates and IP values were not robust to changes of the frequency of payments. Interestingly, estimates were not uniformly higher or lower if the 'cost' attribute was framed as a yearly or monthly payment scheme. The varying cash availability of respondents related to the cultivation of cocoa on a relatively large scale may provide a meaningful explanation for the differences found. Furthermore, we acknowledge that respondents acted rational as the acceptance of improvement alternatives over the status quo did not decrease simply because of the larger amounts showing up on the cards for the sub-sample receiving a yearly payment scheme. 
Our findings add to the body of evidence indicating that different framing of the payment mechanism with respect to payment frequency ('large amount/lump-sum' versus ' frequent small amounts/installments') yield statistically different parameter and welfare estimates. In our case, varying cash availability may be an important factor to explain these differences. Therefore, CE researchers working with low-income samples and/or in socalled developing country environments should include split sample tests for impacts of payment frequency in their study design.

\section{References}

Akiyama, T. and A. Nishio, 1996. Indonesia's Cocoa Boom. Hands-off Policy Encourages Smallholder Dynamism. Policy Research Working Paper 1580. Washington, D.C.: World Bank.

Barkmann, J., Dietrich, N., de Vries, K., Gerold, G., Glenk, K., Keil, A., Faust, H., Leemhuis, C. and R. Marggraf submitted. Confronting unfamiliarity with ecosystem functions: The case for an ecosystem service approach to environmental valuation with stated preference methods. Submitted to Ecological Economics.

Bateman, I.J., Carson, R.T., Day, B., Hanemann, M., Hanley, N., Hett, T., Jones-Lee, M., Loomes, G., Monrato, S., Ozdemiroglu, E., Pearce, D., Sugden, R. and J. Swanson, 2002. Economic Valuation with Stated Preference Techniques - A Manual. Cheltenham, UK: Edward Elgar.

Belsky, J.M. and F.S. Siebert, 2003. Cultivating Cocoa: Implications of sun-grown cocoa on local food security and environmental sustainability. Agriculture and Human Values, 20: 277-85.

Bennett, J. and W. Adamowicz 2001. Some Fundamentals of Environmental Choice Modelling. In Bennett, J. and R. Blamey (Eds): The Choice Modelling Approach to Environmental Valuation. Cheltenham, UK: Edward Elgar.

Glenk, K. accepted. A split sample experiment to test for effects of attribute order in choice experiments. Book chapter prepared for the documentation of the workshop 'The Choice Experiment in Environmental Valuation', 21. - 22. November 2005, Leipzig, Germany. To be published by Metropolis: Marburg. 
Glenk, K., Barkmann, J. and R. Marggraf 2006a. Unveiling regional preferences for biological diversity in Central Sulawesi: a choice experiment approach. STORMA Discussion Paper Series No 16. Bogor, Indonesia: Universities of Göttingen and Kassel, Germany and the Institut Pertanian Bogor and Universitas Tadulako, Indonesia.

Glenk, K., Barkmann, J. and R. Marggraf 2006b. Locally Perceived Values of Biological Diversity in Indonesia - a Choice Experiment Approach. Paper presented at the $8^{\text {th }}$ Annual BIOECON Conference on Economic Analysis of Ecology and Biodiversity, Cambridge, UK.

Greene, W.H., 2003. LIMDEP Version 8.0 NLogit Version 3.0. Plainview, N.Y.: Econometric Software, Inc.

Hanley, N., Adamowicz, A. and R.E. Wright 2005. Price vector effects in choice experiments: an empirical test. Resource and Energy Economics 27: 227-234.

Henderson, J.V. and A. Kuncoro 2004. Corruption in Indonesia. National Bureau of Economic Research, Inc. NBER Working Papers 10674. Cambridge, USA.

Kjaer, T., Bech, M., Gyrd-Hansen, D. and K. Hart-Hansen 2004. Testing for internal consistency, ordering effects and dominant preferences in a discrete choice experiment: a study of preferences for psoriasis treatment. Applied Health Economics and Health Policy 3:S38 (1 Suppl).

Keil, A. 2004. The socio-economic impact of ENSO-related drought on farm households in Central Sulawesi, Indonesia. Ph.D. thesis, Institute of Rural Development, University of Goettingen.

Krosnick, J.A. and D.F. Alwin 1987. An Evaluation of a Cognitive Theory of ResponseOrder Effects in Survey Measurement. The Public Opinion Quarterly 51(2): 201-219.

Lancaster, K., 1966. A New Approach to Consumer Theory. Journal of Political Economy, 74: $132-157$.

Lancaster, K., 1991. Modern Consumer Theory. Brookfield VT: Edward Elgar.

Louviere, J., Hensher, D. and J. Swait 2001. Stated Choice Methods - Analysis and Application. Cambridge, UK: Cambridge University Press.

Luce, R.D., 1959. Individual choice behaviour. New York: Wiley.

Manski, C., 1977. The Structure of Random Utility Models. Theory and Decision, 8: 22954.

McFadden, D., 1973. Conditional Logit Analysis of Qualitative Choice Behavior. In P. Zarembka (ed.): Frontiers in Econometrics. New York: Academic Press.105-42. 
Mitchell, R.C. and R.T. Carson 1989. Using Surveys to Value Public Goods: The Contingent Valuation Method. Baltimore: John Hopkins University Press.

Payne, S. 1951. The Art of Asking Questions. Princeton: Princeton University Press.

Poe, G., Severance-Lossin, E. and M. Welsh 1994. Measuring the Difference (X-Y) of Simulated Distribution: A Convolution Approach. American Journal of Agricultural Economics 76: 904-915.

Poe, G., Severance-Lossin, E. and M. Welsh 2005. Simple Computational Methods for Measuring the Difference of Empirical Distributions. American Journal of Agricultural Economics 87(2): 353-365.

Rolfe, J., Bennett, J. and J. Louviere 2002. Stated values and reminders of substitute goods: Testing for Framing effects with choice modelling. The Australian Journal of Agricultural and Resource Economics 46(1): 1-20.

Schuman, H., and S. Presser 1981. Questions and Answers in Attitude Surveys: Experiments on Question Form, Wording, and Content. New York: Academic Press.

Schwarze, S. 2004. Determinants of Income Generating Activities of Rural Households, A Quantitative Study in the Vicinity of the Lore-Lindu National Park in Central Sulawesi/Indonesia. Ph.D. thesis, Institute of rural Development, University of Goettingen.

Scott, A. and S. Vick 1999. Patients, Doctors and Contracts: An Application of PrincipalAgent Theory to the Doctor-Patient Relationship. Scottish Journal of Political Economy, 46(2): 111-134.

Siebert, F.S. 2002. From shade to sun-grown perennial crops in Sulawesi, Indonesia: implications for biodiversity conservation and soil fertility. Biodiversity and Conservation, 11: 1889-1902.

Slovic, P. and S. Lichtenstein, 1971. Comparison of Bayesian and Regression Approaches to the Study of Information Processing in Judgment. Organizational behavior and Human Performance, 6: 649-744.

Swait, J. and J. Louviere 1993. The role of the scale parameter in the estimation and comparison of multinominal logit models. Journal of Market Research 30: 305-314.

Thurstone, L.L., 1927. A Law of Comparative Judgment. Psychological Review, 4: 27386.

Tversky, A. and D. Kahneman 1981. The framing of decisions and the psychology of choice. Science 211: 453-458. 
Waltert, M., Mardiastuti, A. and M. Mühlenberg, 2004. Effects of land use on bird species richness in Sulawesi, Indonesia. Conservation Biology, 18: 1339-46.

Whittington, D. 1998. Administering contingent valuation surveys in developing countries. World Development 26(1): 21-30.

Whittington, D. 2002. Improving the performance of contingent valuation studies in develop-ing countries. Environmental and resource economics 22 (1-2): 323-367.

Windle, J. and J. Rolfe 2004. Assessing Values for Estuary Protection Using Different Payment Mechanisms in the Choice Modelling Technique. Paper presented at the Australian Agricultural and Resource Economics Society 48th Annual Conference, Melbourne, Australia, 11-13 February 2004.

World Bank 2003. Combating Corruption in Indonesia: Enhancing Accountability for Development. World Bank. East Asia Poverty Reduction and Economic Management Unit.

Zeller, M., Schwarze, S. and T. van Rheenen, 2002. Statistical Sampling Frame and Methods Used for the Selection of Villages and Households in the Scope of the Research Programme on Stability of Rainforest Margins in Indonesia (STORMA). STORMA Discussion Paper Series No. 1, Universities of Göttingen and Kassel, Germany and the Institut Pertanian Bogor and Universitas Tadulako, Indonesia. 


\title{
CHAPTER 7
}

\author{
A split-sample experiment to test for effects of \\ attribute order in choice experiments
}




\section{Introduction}

Along with the contingent valuation method (CVM), choice experiments (CE) have become an increasingly popular non-market environmental valuation technique. The $\mathrm{CE}$ method allows for simultaneous elicitation of multi-attribute benefits (use and non-use). In his lucid paper on the performance of CVM studies in so-called developing countries, Whittington (2002) finds that CVM studies are often of poor quality. This is due to three major reasons, all of which may also apply for the CE:

- poor survey administration and execution;

- poor adjustment of scenarios to the research objective and the research environment;

- absence of split-sample tests for the robustness of results when small changes in the design are applied.

Including split-samples in the study design can be useful for two main reasons:

- Survey research has long demonstrated that small changes of the survey instrument with respect to wording (Schuman/Presser 1981, Payne 1951), context (Tversky/Kahneman 1981) or order (Krosnick/Alwin 1987) can significantly influence the outcome. Split samples can therefore improve the validity and robustness of the results by observing the influence of small changes in the design on welfare estimates.

- Offering alternative options via hypothetical scenarios is an integral part of statedpreference methods. Thus, the researcher has to decide upon the kind of information presented to the respondent. The researcher may not be able to decide a priori, how different information impacts choices. For example, there may be more than one payment vehicle that appears to be appropriate. Split samples can provide both the researcher and the decision makers with valuable information on the influence of different alternatives of survey implementation.

Split sample experiments in CE research were used to test for framing effects (Rolfe et al. 2002), attribute level range effects (Hanley et al. 2005) or ordering effects (Scott/Vick 1999, Kjaer et al. 2004). In my contribution to this book, I concentrate on ordering effects.

There are three ordering effects possible in a CE: (i) Choice set order, (ii) order of alternatives within choice sets and (iii) attribute order within alternatives. Among them, I focus 
on the effect of attribute order. For the analysis, I use data from a CE aiming at the valuation of ecosystem services. The study was carried out in a rural area of Central Sulawesi/ Indonesia.

\section{Response-order effects: primacy and recency effects}

Much survey research has been dedicated to response-order effects (Schuman/Presser 1981, Krosnick/Alwin 1987, Bishop 1997). Response-order effects can be defined as "changes in answers to close-ended survey questions produced by varying the order in which response options are presented" (Krosnick/Alwin 1987, 202). Response-order effects are distinguished in primacy and recency effects. Primacy effects describe an increased likelihood for an item to be chosen if it is placed at the top of a list. When receny effects occur, the likelihood of an item to be chosen is higher if its position is at the bottom of a list. Alternative efforts to explain response-order effects include the cognitive elaboration model (Schwarz et al. 1992, 1994; Sudman et al. 1996) and, based on Simon's (1957) satisficing principle, the satisficing theory (Krosnick/Alwin 1987). Both primacy and recency effects tend be more pronounced among respondents who are less educated, less cognitively sophisticated, and less cognitively skilled (Krosnick 1992; Krosnick et al. 1996).

\section{Effects of attribute order in choice experiments}

In a $\mathrm{CE}$, respondents choose from a choice set comprising of a number of alternatives. Alternatives are often described as attribute 'lists' on choice cards. Choosing from one list of items, and choosing between alternatives characterized by 'lists' of attributes and their level expressions are different tasks. There are additional cognitive processes involved. The respondent may weight the attributes of an alternative and value them depending on the levels they take. Integrating the weights and values, and comparing different alternatives and a reference option, allows the respondent to build a preference structure (Matsatsinis/Samaras 2000). The rather complex evaluation processes involved may imply different and more complex strategies applied by respondents.

Utilities for attributes are expressed by mean parameter estimates of models such as the multinomial logit model (MNL) (Louviere et al. 2001). Mean parameter estimates are usu- 
ally the main concern of CE researchers. They are used to generate implicit prices (IP) and other policy-relevant welfare estimates. Thus, analysing the impact of attribute order on mean parameters and implicit prices is an important contribution to assess the validity of choice experiment data. Implicit prices (marginal WTP) for an attribute are calculated using equation (1).

$$
\operatorname{Implicit} \text { price }(n)=-\left(\frac{\lambda \beta_{n}}{\lambda \beta_{\cos t}}\right)=-\left(\frac{\beta_{n}}{\beta_{\cos t}}\right)
$$

where $\beta_{\mathrm{n}}$ is mean parameter of attribute $\mathrm{n}$ in a linear and additive utility function (cf. equation 2), $\beta_{\text {cost }}$ is the coefficient of the 'cost' attribute and $\lambda$ denotes scale. The scale parameter $\lambda$ is inversely proportional to the variance of the error term, and is cancelled out for the calculation of implicit prices. Implicit prices reflect the marginal willingness to pay (MWTP) for a marginal change in a single attribute on a ceteris paribus basis (Bennett/Adamowicz 2001).

Due to its exceptional role for deriving welfare estimates, the influence of the position of the 'cost' attribute on implicit prices is of particular interest. The levels of a 'cost' attribute have to be carefully chosen in a range where an individual trades the other attributes against 'cost'. ${ }^{1}$ In theory, the 'cost' attribute doesn't differ from the other usually nonmonetary attributes. In reality, however, the 'cost' attribute can be expected to play a distinguished role. Intuitively, the 'cost' attribute is placed at the bottom of vertical attribute lists in most studies. Put in this position, the choice card resembles the format of a bill, and hence comes close to a familiar way of making trade-offs between 'goods' and 'cost' in the real marketplace. Considering the reality, the 'cost' attribute would still fit better in the top position than it would if placed somewhere in between.

Effects of attribute order in choice experiments may be either primacy or recency effects. In the CE context, primacy and recency effects occur when an attribute's utility or disutility is higher if it takes the first position or last position respectively on an attribute 'list'.

1 'Cost' in this context is understood as an amount (usually of money) given up in a voluntary exchange. 
Attribute order effects occurred in choice-based conjoint analyses (Chrzan 1994). Scott/Vick (1998) reversed attribute order in a choice experiment to test for ordering effects. The attribute being either first or last was found to receive higher utility if it was last in order. Kjaer et al. (2004) placed the 'cost' attribute as either the first or the last attribute. Respondents were more sensitive to 'cost' when the attribute was placed at the end of the alternative. These results suggest that recency effects occurred, i.e. respondents pay more attention to attributes placed at the bottom relative to the top of attribute 'lists'.

In order to develop a sophisticated theory on attribute ordering effects ${ }^{2}$ in choice experiments, it is necessary to know which decision strategies were applied by individual respondents, and how respondents processed the information presented on the choice cards. It has been suggested that complex choices may promote the use of simplifying heuristics (e.g. Simonson and Tversky 1992). ${ }^{3}$ Blamey et al. (1997) provide an overview over a variety of decision strategies and heuristics that can play a role in choice experiments. Finding out which particular strategy was applied by individual respondents in a $\mathrm{CE}$ is a difficult task and is beyond the scope of this article. Knowing about decision strategies is usually not a primary issue for CE researchers, despite the notion that "Understanding such strategies may be useful to identify ways of designing CM questionnaires that facilitate respondent processing of information" (Blamey et al. (1997, 11).

\section{Present study}

In this article, I report the results of a split-sample experiment designed to test for the impact of ordering effects on parameter values and implicit prices of discrete choice models. I use data from a choice experiment carried out in Central Sulawesi/Indonesia (Glenk et al. subm, Glenk et al. 2006a, Barkmann et al. subm.). Preferences for biodiversity held by inhabitants around the Lore Lindu National Park, which is one of few large forest areas left on the island of Sulawesi (Waltert et al. 2004), were observed.

The choice sets offered to respondents consisted of two different management alternatives: A and B for the Lore Lindu area and the present situation, C. Selection of attributes

\footnotetext{
${ }^{2}$ Unless not stated explicitly, ordering effects in this chapter refer to effects of attribute order.

3 "A heuristic is a cognitive short-cut that people use to make judgements, often involving uncertain events, and hence probabilities“" (Blamey et al. 1997, 12).
} 
and attribute levels were guided by an ecosystem service approach (Barkmann et al. subm), and facilitated by information gathered in individual and peer-group interviews in various villages of the Lore Lindu area. Additional information and data were obtained from scientists working in the region as well as from literature (e.g. Belsky and Siebert 2003; Keil 2004; Siebert 2003). Four attributes with four levels each were used (Tab. 1): water for irrigation of wetland rice; rattan stock in the forest; ways of cocoa cultivation; population size of anoa. Changes in these attributes were framed as a government development program. The alternatives were presented as 'show cards' to respondents.

The 'cost' attribute was double split-sampled as (i) a rise in "house and land" tax versus a donation to a village fund affecting every household of the research region and (ii) a monthly versus a yearly payment scheme.

Half of the respondents received choice sets with the reversed order of attributes on choice cards (Tab.1). In sub-sample $X$, the cost attribute appeared at the top position of each card, in sub-sample $\mathrm{Y}$ at the bottom. Choice cards were laid next to each other in front of the respondent in a horizontal line as, from left to right, options A, B and C. Socioeconomic characteristics and selected other variables of the respondents respectively households are given in Tab. 2. Differences between sub-sample X and Y are not statistically significant at the $99 \%$ level.

A more detailed description of the attributes and underlying assumptions is given in Glenk et al. (2006a). To simplify the exposition, attributes are denoted as 'rattan', 'water'. 'cocoa', 'anoa' and 'cost'. The alternative specific constant (ASC) is 'one' if alternatives A or B are chosen in a choice set, and 'zero' for the status-quo option.

A main-effects experimental design was applied. An orthogonal fraction of 16 out of the $4^{5}$ possible combinations of attribute levels was selected (Louviere et al. 2001), and combined into choice scenarios that consisted of two (generic) alternatives, $\mathrm{A}$ and $\mathrm{B}$, and a status-quo option presented on choice cards. The choice sets were blocked into four versions so that each respondent faced four choices. In order to account for the heterogeneous environmental conditions of the research region, the status quo was offered as a selfexplicated alternative for all attributes except anoa (regional average). 
Table 1: Attributes/Levels in sub-samples with different attribute order

\begin{tabular}{|c|c|c|c|c|}
\hline Label & Attribute & Levels & $\begin{array}{c}\text { Sub- } \\
\text { sample } \\
\quad X\end{array}$ & $\begin{array}{c}\text { Sub- } \\
\text { sample } \\
\text { Y }\end{array}$ \\
\hline Anoa & $\begin{array}{l}\text { different population sizes } \\
\text { of the endemic dwarf } \\
\text { buffalo anoa (Bubalus } \\
\text { sp.) }\end{array}$ & $\begin{array}{c}{[\text { No. of animals }]} \\
10,180,350,520\end{array}$ & $\begin{array}{c}5 \\
\text { bottom }\end{array}$ & $\begin{array}{c}1 \\
\text { top }\end{array}$ \\
\hline Water & $\begin{array}{l}\text { Availability of irrigation } \\
\text { water for wet rice culti- } \\
\text { vation as expressed in } \\
\text { number of months with } \\
\text { water scarcity }\end{array}$ & $\begin{array}{c}\text { [No of months }] \\
0,1,2,3\end{array}$ & 4 & 2 \\
\hline Rattan & $\begin{array}{l}\text { Availability of rattan } \\
\text { (Calamus spp.) ex- } \\
\text { pressed in distance from } \\
\text { village }\end{array}$ & $\begin{array}{c}{[\mathrm{km}]} \\
5,10,15,20\end{array}$ & 3 & 3 \\
\hline Cocoa & $\begin{array}{l}\text { preponderance of cocoa } \\
\text { plantations differing } \\
\text { along a shade tree gradi- } \\
\text { ent }\end{array}$ & $\begin{array}{c}{[\% \text { under shade }]} \\
5,35,65,95\end{array}$ & 2 & 4 \\
\hline 'Cost' & $\begin{array}{l}\text { extra taxes or donation to } \\
\text { village fund }\end{array}$ & $\begin{array}{c}{[1,000 I D R / y r]} \\
18,36,54,72\end{array}$ & $\begin{array}{c}1 \\
\text { top }\end{array}$ & $\begin{array}{c}5 \\
\text { bottom }\end{array}$ \\
\hline
\end{tabular}

Status quo: individual except for anoa (350) and 'Cost' (0); 1 US\$ 8 500 IDR at the time of the survey

For data collection, a stratified village sampling frame was adopted. The strata for the sample were ethnicity composition, vicinity to the Lore Lindu National Park and population density of a village. Households were then randomly selected within each village. Details of the sampling are described in Zeller et al. (2002). The choice experiment survey was administered to 326 households in 13 villages of the research region (December 2004 March 2005). Face-to-face interviews were conducted by 6 well-trained local enumerators. To minimize potential interviewer effects, enumerators were randomly assigned to the households.

According to previous results presented elsewhere (e.g., Barkmann et al. subm, Glenk et al. 2006a, Glenk et al. subm.), 'water' and 'rattan' had - as expected - negative and significant signs. That is, more months/yr with water scarcity and an increased distance to rattan harvesting locations were associated with disutility. The sign of the 'anoa' attribute was positive and significant, indicating that people do care for the maintenance of viable populations of this animal. For the 'cocoa' attribute, the coefficient was negative and significant, denoting a negative effect for more shade on cocoa plantations. 
Table 2: Household characteristics in sub-samples $X$ and $Y$

\begin{tabular}{|c|c|c|c|}
\hline Variable & Unit/Scale & $\mathbf{X}$ & $\mathbf{Y}$ \\
\hline & & $\mathrm{N}=160$ & $\mathrm{~N}=166$ \\
\hline $\begin{array}{l}\text { Age of respon- } \\
\text { dent }\end{array}$ & Years & $\begin{array}{l}44.56 \\
(13.20)\end{array}$ & $\begin{array}{c}45.79 \\
(14.82)\end{array}$ \\
\hline Education & $\begin{array}{l}\text { Years in school; } 6=\text { finished primary } \\
\text { school }\end{array}$ & $\begin{array}{c}7.84 \\
(3.40)\end{array}$ & $\begin{array}{c}7.53 \\
(3.18)\end{array}$ \\
\hline Non-farm & $\begin{array}{l}\text { Dummy taking } 1 \text { if respondent derives } \\
\text { income from non-agricultural activities }\end{array}$ & $\begin{array}{c}0.22 \\
(0.41)\end{array}$ & $\begin{array}{c}0.19 \\
(0.39)\end{array}$ \\
\hline Cocoa owner & $\begin{array}{l}\text { Dummy taking } 1 \text { if respondent is an } \\
\text { owner of a cocoa plantation }\end{array}$ & $\begin{array}{c}0.78 \\
(0.42)\end{array}$ & $\begin{array}{c}0.75 \\
(0.43)\end{array}$ \\
\hline $\begin{array}{l}\text { Paddy rice } \\
\text { farmer }\end{array}$ & $\begin{array}{l}\text { Dummy taking } 1 \text { if respondent is involved } \\
\text { in paddy rice cultivation }\end{array}$ & $\begin{array}{c}0.63 \\
(0.48)\end{array}$ & $\begin{array}{c}0.58 \\
(0.50)\end{array}$ \\
\hline Rattan collector & $\begin{array}{l}\text { Dummy taking } 1 \text { if respondent collects } \\
\text { rattan }\end{array}$ & $\begin{array}{c}0.11 \\
(0.32)\end{array}$ & $\begin{array}{c}0.15 \\
(0.35)\end{array}$ \\
\hline Anoa attitude & $\begin{array}{l}5 \text { point Likert scale using pictures to ex- } \\
\text { press general attitude towards } \text { Anoa }^{\$}\end{array}$ & $\begin{array}{c}2.95 \\
(0.87)\end{array}$ & $\begin{array}{c}3.14 \\
(1.00)\end{array}$ \\
\hline Anoa extinction & $\begin{array}{l}5 \text { point Likert scale to express impacts } \\
\text { expected when Anoa population is re- } \\
\text { duced to } 10 \text { individuals } \$\end{array}$ & $\begin{array}{c}2.88 \\
(1.39)\end{array}$ & $\begin{array}{c}3.09 \\
(1.40)\end{array}$ \\
\hline $\begin{array}{l}\text { Child depend- } \\
\text { ency rate }^{\mathrm{a}}\end{array}$ & Dependency rate adults vs. children ${ }^{\S}$ & $\begin{array}{c}0.57 \\
(0.50)\end{array}$ & $\begin{array}{c}0.51 \\
(0.47)\end{array}$ \\
\hline $\begin{array}{l}\text { Household } \\
\text { members }^{\mathrm{a}}\end{array}$ & Total number of household members & $\begin{array}{c}5.58 \\
(2.21)\end{array}$ & $\begin{array}{c}5.29 \\
(2.11)\end{array}$ \\
\hline Gross income $^{b}$ & $\begin{array}{l}\text { Gross income per household/year in } 1000 \\
\text { IDR }^{\S}\end{array}$ & $\begin{array}{c}6,123 \\
(8,876)\end{array}$ & $\begin{array}{c}6,415 \\
(8,133)\end{array}$ \\
\hline Migration $^{\mathrm{a}}$ & $\begin{array}{l}\text { Dummy taking } 1 \text { if household head is } \\
\text { from another village }{ }^{\S}\end{array}$ & $\begin{array}{c}0.54 \\
(0.50)\end{array}$ & $\begin{array}{c}0.47 \\
(0.50)\end{array}$ \\
\hline
\end{tabular}

§Data from subproject A4; \$1 complies with "unhappy", 5 with "very happy"; $\$ 1$ : surely will survive; 5 : surely become extinct; ${ }^{\mathrm{a}} \mathrm{X}(\mathrm{N}=154), \mathrm{Y}(\mathrm{N}=165){ }^{\mathrm{b}} \mathrm{X}(\mathrm{N}=143), \mathrm{Y}(\mathrm{N}=148)$

\section{Method}

I analyse differences in mean parameters and implicit prices as a consequence of reversed attribute order between sub-samples $\mathrm{X}$ and $\mathrm{Y}$. Formally, the hypotheses for parameter equality are

$$
\begin{aligned}
& \mathrm{H} 0_{1}: \beta_{\mathrm{X}}=\beta_{\mathrm{Y}} \\
& \mathrm{H} 1_{1}: \beta_{\mathrm{X}} \neq \beta_{\mathrm{Y}} .
\end{aligned}
$$

For equality of implicit prices:

$$
\begin{aligned}
& \mathrm{H}_{2}: \mathrm{IP}_{\mathrm{X}}=\mathrm{IP}_{\mathrm{Y}} \\
& \mathrm{H}_{2}: \mathrm{IP}_{\mathrm{X}} \neq \mathrm{IP}_{\mathrm{Y}} .
\end{aligned}
$$


For both hypotheses, results from multinomial logit (MNL) models (Louviere et al. 2001) are used. The deterministic part of the indirect utility function for alternative $\mathrm{j}$ is assumed to be linear and additive in parameters and contains the following aspects:

$$
V_{\mathrm{j}}=\alpha \mathrm{ASC}_{\mathrm{j}}+\beta f\left(\text { Rattan }_{\mathrm{j}}\right)+\beta f\left(\text { Water }_{\mathrm{j}}\right)+\beta f\left(\mathrm{Cocoa}_{\mathrm{j}}\right)+\beta f\left(\mathrm{Anoa}_{\mathrm{j}}\right)+\beta f\left(\mathrm{Cost}_{\mathrm{j}}\right)
$$

\subsection{Test statistics for parameter equality}

As parameters are confounded with scale (equation 1), one has to account for differences in scale for a comparison of parameters. The scale parameter of a single data set cannot be estimated. For two different data sets, one can only calculate the ratio of scale parameters of the two sets. I use the procedure suggested by Swait/Louviere (1993). They suggest a two stage approach to test whether two samples share the same parameters. The first stage is designed to test whether parameters are equal while allowing for scale to differ. In a second stage, a test for scale parameter equality is conducted.

A grid search technique is applied to find the value of the scale parameter $\mu$ of subsample $\mathrm{X}$ relative to sub-sample $\mathrm{Y}$ that optimises the log-likelihood value in a pooled and re-scaled data set $\mathrm{XY}_{\mu}$. Then, a likelihood ratio test is used to test for parameter equality (i.e., $H 1_{\beta}$ : $\beta_{X}=\beta_{Y}=\beta_{X Y}$ ) while allowing for scale differences:

$$
L R_{1}=-2\left(\log L_{X Y \mu}-\left(\log L_{X}+\log L_{Y}\right)\right)
$$

$\log L_{X Y} \mu$ is the likelihood value of the pooled data set after re-scaling with $\mu$, and $\log L_{X}$ and $\log L_{Y}$ are the likelihood values of sub-samples $\mathrm{X}$ and $\mathrm{Y}$. The test statistic is asymptotically chi-squared distributed with $\mathrm{K}+1$ degrees of freedom, with $\mathrm{K}$ being the number of parameters in both sub-samples. If parameter equality cannot be rejected, it is tested, if scale factors are equal (i.e., $\mathrm{H} 1_{\mu}: \mu_{\mathrm{X}}=\mu_{\mathrm{Y}}=\mu_{\mathrm{XY}}$ ). The test statistic is:

$$
L R_{2}=-2\left(\log L_{X Y}-\log L_{X Y \mu}\right)
$$

where $\log \mathrm{L}_{\mathrm{XY}} \mu$ is as previously defined and $\log \mathrm{L}_{\mathrm{XY}}$ is the likelihood value for the pooled sample with equal scale parameters. $\mathrm{LR}_{2}$ is asymptotically chi-squared distributed with one degree of freedom. Sub-sample $\mathrm{X}$ and $\mathrm{Y}$ share equal parameters if both $\mathrm{H} 1_{\beta}$ and $\mathrm{H} 1_{\mu}$ cannot be rejected. 


\subsection{Testing equality of implicit prices}

As the scale parameter cancels out for the calculation of implicit prices (equation 1), one need not account for differences in scale. The procedure follows an approach of Poe et al. (1994, 2005). Using a Krinsky/Robb (1986) bootstrapping procedure, a large number (e.g. 1000) of IP estimates for the attributes are drawn from parameter estimates and the corresponding variance-covariance matrix for both sub-samples. Implicit prices are derived by drawing from population means and calculated using equation (1) for the MNL models.

The procedure results in two vectors $\mathrm{v}_{\mathrm{i}}\left[\mathrm{IP}_{\mathrm{X}}\right]$ and $\mathrm{v}_{\mathrm{i}}\left[\mathrm{IP}_{\mathrm{Y}}\right]$ for sub-samples $\mathrm{X}$ and $\mathrm{Y}$. The difference vector between each single element of $\mathrm{v}_{\mathrm{i}}\left[\mathrm{IP}_{\mathrm{X}}\right]$ and each single element of $\mathrm{v}_{\mathrm{i}}\left[\mathrm{IP}_{\mathrm{Y}}\right]$ is calculated for attribute i. ${ }^{4}$ The one-sided significance level of difference can be derived by assessing the value of the cumulative distribution of the difference vector at zero.

\section{Results}

16 respondents were classified as essentially not responding to the choice task and omitted from subsequent analysis. ${ }^{5}$ MNL model results are listed in table 3. All models are overall significant at the $99 \%$ level and show a decent model fit in terms of adjusted $\rho^{2}(0.22-$ 0.24). All signs are as expected, and all attribute parameters are significant at $p<0.05$ or lower. ASCs are positive but not significantly different from zero in all models.

\subsection{Parameter equality}

The grid search led to a relative scale factor of 0.91 for sub-sample $\mathrm{X}$ that optimises the $\log$ likelihood function in the pooled and rescaled sample $A B .^{6}$ The $p$ values (LR $<\chi^{2} ; \alpha=$ 0.05 ) for the $L R$ tests are 0.8231 for $L_{\beta}$ and 0.2275 for $L_{\mu}$. Thus, $H 1_{\beta}$ and $H 1_{\mu}$ could not be rejected. According to the Swait/Louviere test, sub-sample X and Y do not have significantly different parameter estimates, and the ratio of scale parameters is not significantly different from one. Thus, $\mathrm{H}_{1}$ cannot be rejected.

\footnotetext{
${ }^{4}$ The vector being minuend has the larger average value.

5 The 16 respondents always chose the status quo because of 'protest' (no change wanted), general payment aversion and exceeding cognitive capability.

${ }^{6}$ The approximate confidence region at $\alpha=0.05$ for the relative scale factor is [0.69 - 1.18].
} 
Table 3: MNL Model results

\begin{tabular}{|c|c|c|c|c|c|c|}
\hline & $\mathbf{X}$ & & $\mathbf{Y}$ & $\mathbf{X Y}$ & & XY rescaled \\
\hline Rattan & $\begin{array}{c}-0.0324 \\
(-3.16)\end{array}$ & ** & $\begin{array}{c}-0.0426 \\
(-4)\end{array}$ & $\begin{array}{r}-0.0373 \\
(-5.06)\end{array}$ & *** & $\begin{array}{c}-0.0392^{* * *} \\
(-5.07)\end{array}$ \\
\hline Water & $\begin{array}{l}-0.7771 \\
(-13.04)\end{array}$ & *** & $\begin{array}{l}-0.7974 \\
(-13.14)\end{array}$ & $\begin{array}{l}-0.7858 \\
(-18.52)\end{array}$ & *** & $\begin{array}{l}-0.8226^{* * *} \\
(-18.50)\end{array}$ \\
\hline Cocoa & $\begin{array}{r}-0.0113 \\
(-5.42)\end{array}$ & *** & $\begin{array}{c}-0.0131 \\
(-6.01)\end{array}$ & $\begin{array}{r}-0.0122 \\
(-8.06)\end{array}$ & *** & $\begin{array}{c}-0.0128 \\
(-8.09)\end{array}$ \\
\hline Anoa & $\begin{array}{r}0.0011 \\
(2.63)\end{array}$ & $* *$ & $\begin{array}{r}0.0006 \\
(1.30)\end{array}$ & $\begin{array}{r}0.0009 \\
(2.81)\end{array}$ & ** & $\begin{array}{c}0.0009^{* *} \\
(2.78)\end{array}$ \\
\hline Cost & $\begin{array}{r}-0.0209 \\
(-5.74)\end{array}$ & $* * *$ & $\begin{array}{c}-0.0297 \\
(-7.83)\end{array}$ & $\begin{array}{r}-0.0252 \\
(-9.62)\end{array}$ & $* * *$ & $\begin{array}{r}-0.0267 \\
(-9.72)\end{array}$ \\
\hline $\mathrm{ASC}$ & $\begin{array}{r}0.1582 \\
(0.87)\end{array}$ & & $\begin{array}{r}0.3564 \\
(1.95)\end{array}$ & $\begin{array}{r}0.2566 \\
(1.99)\end{array}$ & & $\begin{array}{r}0.2648 \\
(2.06)\end{array}$ \\
\hline Scale $(\mathrm{X} / \mathrm{Y})$ & - & & - & - & & 0.91 \\
\hline $\log \mathrm{L}$ & -486.254 & & -476.2341 & -965.039 & & -964.2958 \\
\hline Observations & 612 & & 628 & 1240 & & 1240 \\
\hline Adjusted $\rho^{2}$ & 0.2203 & & 0.2447 & 0.2325 & & 0.2331 \\
\hline
\end{tabular}

\subsection{Implicit prices}

Mean IPs, standard errors and results of the probability values for difference in IPs are shown in table 4. Mean IPs are higher in sub-sample $\mathrm{X}$ than in sub-sample $\mathrm{Y}$. According to results of the Poe et al. test, differences in IPs are significant for water and anoa at $\alpha=0.1$, but not at $\alpha=0.05$. $^{7}$

As implicit prices are calculated using parameters from two attributes of which one is 'cost', different weighting of both attributes can drive the differences in implicit prices. Thus, one may investigate parameter estimates in table 3 in order to judge, whether differences are subject to changes in response to both or either one of the attributes. Obviously, the tendency towards higher IPs in sub-sample $\mathrm{X}$ is driven by a lower sensitivity towards 'cost' in sub-sample X. Both the (insignificant) parameter estimate for the attribute in subsample Y and higher sensitivity towards 'cost' result in lower IP for anoa. Sensitivity towards changes in water is almost equal. Therefore, IP differences are due to a varying sen-

\footnotetext{
${ }^{7}$ The parameter value for anoa is not significantly different from zero in sub-sample B.
} 
sitivity towards 'cost' and anoa, which had either bottom or top position on the choice cards.

Table 4: Mean implicit prices and probablity values of IP equality

\begin{tabular}{lcccc}
\hline & Rattan & Water & Cocoa & Anoa \\
\hline $\mathbf{X}$ & -1.6234 & -38.7133 & -0.5643 & 0.0559 \\
& $(0.0185)$ & $(0.2554)$ & $(0.0045)$ & $(0.0007)$ \\
$\mathbf{Y}$ & -1.4752 & -27.2562 & -0.4481 & 0.0200 \\
& $(0.0127)$ & $(0.1221)$ & $(0.0028)$ & $(0.0005)$ \\
XY (resc) & -1.4854 & -31.2020 & -0.4832 & 0.0332 \\
Prob. & $(0.0102)$ & $(0.1104)$ & $(0.0023)$ & $(0.0004)$ \\
(IPX $\neq$ IPY) & 0.4229 & $0.0604 *$ & 0.2369 & $0.0879 *$ \\
\hline \multicolumn{2}{c}{$*$ marks significant difference $(\alpha=0.1) ;$ Standard errors in parentheses }
\end{tabular}

$\mathrm{HO}_{2}$ cannot be rejected for all attributes. Significantly higher IPs in sub-sample X for 'water' and 'anoa' appear to be the result of recency effects.

\subsection{Potential 'drivers' enhancing ordering effects}

I have two conjectures to explain why ordering effects may be more pronounced for subsamples of respondents differing in selected individual characteristics (education, income, anoa score). I do not aim at proving our conjectures using rigorous statistical tests. Sample sizes for these groups and sub-samples $\mathrm{X}$ and $\mathrm{Y}$ become critically low, leading to very high standard errors. Instead, I simply compare parameter estimates of MNL models reported in table 5 .

The line of argumentation is based on two aspects: (i) significance of parameters for the anoa attribute (in this case, t-values as low as 1.5 are accepted) and (ii) sensitivity towards 'cost'. In order to ensure that differences in 'cost' parameter estimates are not mainly due to differences in scale between the sub-samples, differences in 'cost' parameter estimates relative to the 'water' parameter estimates are compared. These prove to be quite stable over the different models. Results are shown in table 5. I only present the model output 
relevant to discuss the expectations. ${ }^{8}$ All sub-samples show the ordering (recency) effects found for the whole sample.

\section{A: Education}

Based on the findings from behavioral decision research about response-order effects summarized in section 2 , I expect that ordering effects tend to be stronger among less educated respondents. I use the level of education (number of years in school) to analyse differences using results from MNL models for higher and lower educated groups in subsamples $\mathrm{X}$ and $\mathrm{Y}$. The lower educated group comprises those respondents with a level of education that does not exceed primary school.

Respondents with higher education tend to be less sensitive towards changes in 'cost'. Higher educated respondents tend to have higher incomes (Pearson's $\mathrm{R}^{2}=0.229 ; \mathrm{p}<0.01$ ) and better access to sources of income from non-agricultural activities (e.g. officials, teacher), which are often also more stable (Pearson's $\mathrm{R}^{2}=0.354 ; \mathrm{p}<0.01$ ). The comparison of 'cost' parameters within the higher and lower educated samples suggests that sensitivity towards 'cost' between sub-samples $\mathrm{X}$ and $\mathrm{Y}$ is not much different from the differences found in the whole sample. Contrary to the expectations, however, differences are slightly higher for the higher educated sample. Anoa, however, is only significant for the lower educated sample and sub-sample X (bottom position), which is in line with the expectations. Hence, the findings for the education samples are mixed.

As an interesting aside, ASCs are positive and significant for lower educated respondents and insignificant for higher educated ones. This result suggests that the higher educated make less use of unobserved attributes for their choices. One reason may be that people with higher education are more able to focus on the attributes offered in the choice task (Glenk et al. subm.).

\section{B(1) and B(2): Income and Anoa score}

The relative weight ascribed to the attributes in the choice process differs between respondents as a function of their individual characteristics. The occurrence of ordering effects may be more pronounced if attributes at the top or bottom of the choice card are perceived

\footnotetext{
${ }^{8}$ Full model outputs are available from the author upon request.
} 
to be more or less 'important' relative to other attributes. To recall, the top and bottom attributes in sub-samples $\mathrm{X}$ and $\mathrm{Y}$ are 'cost' and anoa.

B(1): Based on findings in Glenk et al. (2006a), the relative importance ascribed to the 'cost' attribute is expected to differ with respect to income. Respondents with lower income are expected to pay relatively more attention on changes in the 'cost' attribute. This may result in less pronounced effects of ordering. The higher income group is defined as those respondents with above-median gross household income per year. ${ }^{9}$

Respondents with higher income are less responsive to a tax rise or a higher donation to a village fund. As expected, the ordering effect is clearly higher than for the whole sample for the higher income group. Interestingly, anoa is given less weight in the lower income group, where it is only significant if it is placed at the bottom position (sub-sample X). This weakly confirms the findings presented in Glenk et al. (2006). Disregarding illegal hunting of the endemic and protected animal anoa, there is indication that being concerned about declining population sizes of anoa is a luxury good.

$\mathrm{B}(2)$ : According to results reported in Glenk et al. (2006a), (i) general attitude towards anoa and (ii) perceived likelihood of extinction of anoa significantly influence marginal utilities for the anoa attribute. The more positive people feel about anoa, and the more likely they find it that a population of 10 remaining individuals will become extinct, the higher the utility respondents expect to obtain from maintaining larger population sizes in the Lore Lindu area. Both aspects were operationalised using 5-point Likert scales. High scores correspond to a general positive attitude and a higher perceived likelihood of extinction. The item scores for both variables is added. Individuals with above-median scores for the resulting variable are expected to be less prone to ordering effects between sub-samples $\mathrm{X}$ and $\mathrm{Y}$.

Respondents with high scores care more for changes in the population size of anoa. The parameter estimate for anoa is significant if the anoa attribute takes in the bottom position on the choice cards (sub-sample X), and not significant with even a reversed sign if it takes

\footnotetext{
${ }^{9}$ The median is used in order to obtain two groups of similar size. The median is 3.04 million Indonesian Rupees (approx. $270 €$ ). Cases where no income data was available were omitted. The author would like to thank Stefan Schwarze and STORMA sub-project A4 for providing the income data, and several variables in table 2 .
} 
the top position (sub-sample Y). As expected, respondents yielding higher scores are more responsive to changes in the anoa attribute relative to those with lower scores. In line with the expectations, the low score group exhibits a more pronounced ordering effect.

Table 5: Selected MNL parameters for education, income and anoa score

\begin{tabular}{|c|c|c|c|c|c|}
\hline & & & $\mathbf{X}$ & $\mathbf{Y}$ & $\mathbf{X Y}$ \\
\hline \multirow{13}{*}{$\begin{array}{l}\text { A Educa- } \\
\text { tion }\end{array}$} & \multirow{6}{*}{ High } & ASC & $\begin{array}{c}-0.3232 \\
(-1.2)\end{array}$ & $\begin{array}{c}-0.1422 \\
(-0.52)\end{array}$ & $\begin{array}{c}-0.2257 \\
(-1.18)\end{array}$ \\
\hline & & Anoa & $\begin{array}{c}0.0004 \\
(0.62)\end{array}$ & $\begin{array}{c}0.0006 \\
(0.87)\end{array}$ & $\begin{array}{c}0.0005 \\
(1.11)\end{array}$ \\
\hline & & & -0.7488 & -0.8889 & -0.8099 \\
\hline & & Water & $(-8.5)$ & $(-8.95)$ & $(-12.38)$ \\
\hline & & 'Cost' & $\begin{array}{c}-0.0107 \\
(-2.06)\end{array}$ & $\begin{array}{c}-0.0212 \\
(-3.77)\end{array}$ & $\begin{array}{c}-0.0156 \\
(-4.2)\end{array}$ \\
\hline & & Model\$ & $284 / 0.18$ & $276 / 0.24$ & $560 / 0.21$ \\
\hline & \multirow{7}{*}{ Low } & $\mathrm{ASC}$ & $\begin{array}{c}0.5824 \\
(2.29)\end{array}$ & $\begin{array}{c}0.7387 \\
(2.98)\end{array}$ & $\begin{array}{c}0.6583 \\
(3.71)\end{array}$ \\
\hline & & Anoa & $\begin{array}{c}0.0018 \\
(2.94)\end{array}$ & $\begin{array}{c}0.0006 \\
(0.97)\end{array}$ & $\begin{array}{c}0.0012 \\
(2.73)\end{array}$ \\
\hline & & & -0.8281 & -0.7445 & -0.7821 \\
\hline & & Water & $(-9.92)$ & $(-9.57)$ & $(-13.76)$ \\
\hline & & 'Cost' & -0.0304 & -0.0373 & -0.0338 \\
\hline & & $\operatorname{cost}$ & $(-5.78)$ & $(-7.07)$ & $(-9.1)$ \\
\hline & & Model & $328 / 0.26$ & $352 / 0.25$ & $680 / 0.26$ \\
\hline \multirow{10}{*}{$\begin{array}{l}\text { B(1) In- } \\
\text { come }\end{array}$} & \multirow{4}{*}{ High } & Anoa & $\begin{array}{c}0.0016 \\
(2.4)\end{array}$ & $\begin{array}{c}0.0011 \\
(1.76)\end{array}$ & $\begin{array}{c}0.0014 \\
(3.02)\end{array}$ \\
\hline & & Water & $\begin{array}{c}-0.9326 \\
(-9.68)\end{array}$ & $\begin{array}{c}-0.7424 \\
(-8.59)\end{array}$ & $\begin{array}{c}-0.8280 \\
(-13)\end{array}$ \\
\hline & & 'Cost' & $\begin{array}{c}-0.0113 \\
(-2.08)\end{array}$ & $\begin{array}{c}-0.0204 \\
(-3.83)\end{array}$ & $\begin{array}{c}-0.0162 \\
(-4.29)\end{array}$ \\
\hline & & Model & $280 / 0.25$ & $280 / 0.23$ & $580 / 0.24$ \\
\hline & \multirow{6}{*}{ Low } & Anoa & $\begin{array}{c}0.0012 \\
(1.67)\end{array}$ & $\begin{array}{c}0.0005 \\
(0.78)\end{array}$ & $\begin{array}{c}0.0008 \\
(1.74)\end{array}$ \\
\hline & & Water & -0.8767 & -0.8688 & -0.8650 \\
\hline & & water & $(-8.87)$ & $(-9.05)$ & $(-12.66)$ \\
\hline & & & -0.0303 & -0.0382 & -0.034 \\
\hline & & $\cos t$ & $(-4.98)$ & $(-6.10)$ & $(-7.86)$ \\
\hline & & Model & $264 / 0.26$ & $280 / 0.26$ & $544 / 0.26$ \\
\hline \multirow{11}{*}{ B(2) Anoa } & \multirow{5}{*}{ High } & Anoa & $\begin{array}{c}0.0021 \\
(2.48)\end{array}$ & $\begin{array}{c}0.0011 \\
(1.5)\end{array}$ & $\begin{array}{c}0.0014 \\
(2.70)\end{array}$ \\
\hline & & & -0.8520 & -0.7397 & -0.7622 \\
\hline & & Water & $(-7.20)$ & $(-7.82)$ & $(-10.56)$ \\
\hline & & 'Cost' & -0.0165 & -0.0323 & -0.0250 \\
\hline & & Model & $\begin{array}{c}(-2.42) \\
192 / 0.23\end{array}$ & $\begin{array}{c}(-5.15) \\
260 / 0.22\end{array}$ & $\begin{array}{c}(-5.5) \\
452 / 0.22\end{array}$ \\
\hline & \multirow{6}{*}{ Low } & Anoa & $\begin{array}{c}0.0015 \\
(2.27)\end{array}$ & $\begin{array}{c}-0.0003 \\
(-0.4)\end{array}$ & $\begin{array}{c}0.0007 \\
(1.51)\end{array}$ \\
\hline & & & -0.9061 & -0.8922 & -0.8773 \\
\hline & & Water & $(-9.2)$ & $(-7.92)$ & $(-12.19)$ \\
\hline & & & -0.0191 & -0.0248 & -0.0210 \\
\hline & & ${ }^{-} \cos t^{\prime}$ & $(-3.43)$ & $(-3.85)$ & $(-5.04)$ \\
\hline & & Model & $276 / 0.25$ & $204 / 0.28$ & $480 / 0.26$ \\
\hline
\end{tabular}

$\S$ Model: Number of observations $/ \rho^{2}$ 


\section{Discussion}

The results from testing for equality of implicit prices, however, show that 'recency effects' have occurred, i.e. the attribute at the bottom position (anoa in sub-sample X, 'cost' in sub-sample $\mathrm{Y}$ ) is given relatively greater weight. In this respect, the findings presented in my contribution add to the large body of research suggesting that respondents do not always behave as perfectly rational individuals assumed by neo-classical economic theory. ${ }^{10}$ They are in line with previous CE studies, which tested for attribute order effects (Scott/Vick 1998; Kjaer et al. 2004).

Since not much is know about the cognitive processes and strategies respondents applied during this choice experiment, I am not able to explain in detail why the ordering effects described above may have occurred. Respondents may use the longest processing time on the attributes placed at the bottom. I conjectured that the observed effect may be related to the cognitive capabilities of respondents. Higher education of respondents (indirectly reflecting cognitive capabilities) may alleviate the effects of ordering. For anoa, this assumption could not be supported. Regarding 'cost', however, recency effects were not less pronounced in the higher educated sample.

Along with the findings for the income and anoa score samples, this leads me to conjecture that the weight placed upon an attribute relative to others may enhance or alleviate the extent to which ordering effects occur in choice experiments. The internal weighting of attributes, in turn, can be expected to be strongly influenced by aspects such as socioeconomic characteristics, attitudes, beliefs, perceptions and experience of individuals.

The results suggest that alterations in the position of the 'cost' attribute significantly influence estimates of implicit prices, and may also influence other welfare measures such as the compensating variation. The important question to ask is if this is of practical relevance for CE research. The answer is rather 'no' if the 'cost' attribute is placed at the bottom of vertically arranged attributes on choice cards. Recency effects suggest that most attention is being paid to the 'cost' attribute in this position. ${ }^{11}$ In most choice experiments using vertical attribute 'lists', the 'cost' attribute indeed takes that position. Because of its excep-

\footnotetext{
${ }^{10}$ See McFadden (1999) for a review.

${ }^{11}$ This conclusion is drawn with reservation that we did not test for effects of 'cost' in a middle position.
} 
tional role in choice experiments that aim at the generation of welfare estimates, it is desirable that respondents think carefully about the 'cost' attribute, e.g. with respect to their budget constraints. Higher sensitivity towards 'cost' results in lower and therefore more conservative implicit prices and welfare estimates, ceteris paribus.

\section{Conclusion}

With a reasonable amount of effort, designing split-sample experiments can produce further insights on the robustness and validity of choice experiment results. Choice experiment researchers should therefore regularly include split-samples in their surveys. The split-sample experiment reported in this chapter was designed to test for effects of attribute order on choice cards on parameter estimates and implicit prices. I found significantly different implicit prices for two attributes. Differences were subject to varying sensitivity for the top and bottom attributes and suggested the occurrence of recency effects, i.e., respondents were more sensitive to attributes at the bottom of the attribute 'lists' on choice cards compared to the top position.

Being of practical importance, the results suggest that the 'cost' attribute should be positioned at the bottom of vertically arranged choice cards. This will result in the generation of more conservative welfare estimates. I investigated differences of the bottom relative to the top position. The results also suggest that the top position was being paid less attention. I do not know how the middle positions are perceived in the choice process relative to the top. However, it would be desirable to address future research on this issue.

Besides cognitive capabilities of respondents, there is weak evidence that recency effects are more pronounced for respondents who weight a top or bottom attribute less relative to the other attributes than other respondents do. Further research could specifically target this question. 


\section{References}

Barkmann, J., Dietrich, N., de Vries, K., Gerold, G., Glenk, K., Keil, A., Faust, H., Leemhuis, C., Marggraf, R. (submitted): Confronting unfamiliarity with ecosystem functions: The case for an ecosystem service approach to environmental valuation with stated preference methods, submitted to Ecological Economics

Belsky, J., Siebert, F. (2003): Cultivating Cocoa: Implications of sun-grown cocoa on local food security and environmental sustainability, in: Agriculture and Human Values, 20, pp. 277285

Bennett, J., Adamowicz, W., (2001): Some Fundamentals of Environmental Choice Modelling, in: Bennett, J., Blamey, R., (eds.): The Choice Modelling Approach to Environmental Valuation, Cheltenham, UK: Edward Elgar

Bishop, G.F., Smith, A.E. (1997): Response-order effects in public opinion surveys: The plausibility of rival hypotheses, ASA Proceedings of the Section on Survey Research Methods, American Statistical Association (Alexandria, VA), pp. 1041-1046

Blamey, R., Rolfe, J., Bennett, J., Morrison, M. (1997): Environmental Choice Modelling: Issues and Qualitative Insights, Canberra, Australia: School of Economics and Management, The University of New SouthWales, Research Report No. 4

Chrzan, K. (1994): Three Kinds of Order Effects in Choice-Based Conjoint Analysis, in: Marketing Letters 5(2): pp. 165-172

Glenk, K., Barkmann, J., Marggraf, R. (2006a): Unveiling regional preferences for biological diversity in Central Sulawesi: a choice experiment approach, Bogor, Indonesia: Universities of Göttingen and Kassel, Germany and the Institut Pertanian Bogor and Universitas Tadulako, Indonesia.STORMA Discussion Paper Series 15

Glenk, K., Barkmann, J., Schwarze, S., Zeller, M., Marggraf, R. (2006b): Differential Influence of Relative Poverty on Preferences for Ecosystem Services: Evidence from Rural Indonesia, International Association of Agricultural Economists Conference, Gold Coast, Australia, August 12-18, 2006, contributed paper

Glenk, K., Barkmann, J., Marggraf, R. (submitted): Locally Perceived Values of Biological Diversity - a Choice Experiment Approach, submitted to Environmental and Resource Economics

Hanley, N., Adamowicz, A., Wright, R.E. (2005): Price vector effects in choice experiments: an empirical test, in: Resource and Energy Economics 27, pp. 227-234

Keil, A. (2004): The socio-economic impact of ENSO-related drought on farm households in Central Sulawesi, Indonesia, Ph.D. thesis, Institute of Rural Development, University of Goettingen

Kjaer, T., Bech, M., Gyrd-Hansen, D., Hart-Hansen, K. (2004): Testing for internal consistency, ordering effects and dominant preferences in a discrete choice experiment: a study of preferences for psoriasis treatment, in: Applied Health Economics and Health Policy S38 2004:3 (1 Suppl)

Krinsky, I., Robb, A. L. (1986): On approximating the statistical properties of elasticities, in: Review of Economics and Statistics 68, pp. 715-719

Krosnick, J.A., Alwin, D.F. (1987): An Evaluation of a Cognitive Theory of Response-Order Effects in Survey Measurement, in: The Public Opinion Quarterly 51(2), pp. 201-219

Krosnick, J. (1992): The Impact of Cognitive Sophistication and Attitude Importance on ResponseOrder and Question-Order Effects, in: Schwarz, N., Sudman, S. (eds.): Context Effects in Social and Psychological Research. New York: Springer-Verlag 
Krosnick, J., Narayan, S., Smith, W. (1996): Satisficing in Surveys: Initial Evidence, in: Braverman, M., Slater, J. (eds.): Advances in Survey Research, San Francisco: Jossey-Bass, No. 70, Summer

Louviere, J., Hensher, D., Swait, J. (2001): Stated Choice Methods - Analysis and Application, Cambridge University Press, Cambridge

Matsatsinis, N.F., Samaras, A.P. (2000): Brand choice model selection based on consumers' multicriteria preferences and experts' knowledge, in: Computers \& Operations Research, 27, pp. 689-707

McFadden, D. (1999): Rationality for Economists?, Journal of Risk and Uncertainty, 19(1-3), pp. 73-105

Payne, S. (1951), The Art of Asking Questions, Princeton: Princeton University Press

Poe, G., Severance-Lossin, E., Welsh, M. (1994): Measuring the Difference (X-Y) of Simulated Distribution: A Convolution Approach, in: American Journal of Agricultural Economics 76, pp. $904-915$

Poe, G., Severance-Lossin, E., Welsh, M. (2005): Simple Computational Methods for Measuring the Difference of Empirical Distributions, in: American Journal of Agricultural Economics 87(2), pp. 353-365

Rolfe, J., Bennett, J., Louviere, J. (2002): Stated values and reminders of substitute goods: Testing for Framing effects with choice modelling, in: The Australian Journal of Agricultural and Resource Economics 46(1), pp. 1-20

Schuman, H., Presser, S. (1981): Questions and Answers in Attitude Surveys: Experiments on Question Form, Wording, and Content, New York: Academic Press

Schwarz, N., Hippler, H., Noelle-Neuman, E. (1992): A Cognitive Model of ResponseOrderEffects in Survey Measurement, in: Schwarz, N. Sudman, S. (eds.): Context Effects in Social and Psychological Measurement, New York: Springer-Verlag

Schwarz, N., Hippler, H., Noelle-Neuman, E. (1994): Retrospective Reports: The Impact of Response-Alternatives, in: Schwarz, N. Sudman, S. (eds.): AutobiographicalMemory and the Validity of Retrospective Reports, New York: Springer-Verlag

Scott, A., Vick, S. (1999): Patients, Doctors and Contracts: An Application of Principal-Agent Theory to the Doctor-Patient Relationship, in: Scottish Journal of Political Economy, 46(2), pp. 111-134

Siebert, F. (2003): From shade- to sun-grown perennial crops in Sulawesi, Indonesia: implications for biodiversity conservation and soil fertility, in: Biodiversity and Conservation 11, pp. 1889-1902

Simon, H.A. (1957): Models of Man, New York: Wiley

Simonson, I., Tversky, A. (1992): Choice in Context: Tradeoff Contrast and Extremeness Aversion, in: Journal of Marketing Research, 29(3), pp. 281-295

Sudman, S., Bradburn, N., Schwarz, N. (1996): Thinking About Answers: The Application of Cognitive Processes to Survey Methodology, San Francisco: Jossey-Bass

Swait, J., Louviere, J. (1993): The role of the scale parameter in the estimation and comparison of multinominal logit models, in: Journal of Market Research 30, pp. 305-314.

Tversky, A., Kahneman, D. (1981): The framing of decisions and the psychology of choice, in: Science 211, pp. 453-458

Waltert, M., Mardiastuti, A., Mühlenberg, M. (2004): Effects of land use on bird species richness in Sulawesi, Indonesia, in: Conservation Biology 18(5), pp. 1339-1346

Whittington, D. (2002): Improving the Performance of Contingent Valuation Studies in Developing Countries, in: Environmental and Resource Economics 22, pp. 323-367 
Zeller, M., Schwarze, S., van Rheenen, T. (2002): Statistical Sampling Frame and Methods Used for the Selection of Villages and Households in the Scope of the Research Programme on Stability of Rainforest Margins in Indonesia (STORMA), Bogor, Indonesia: Universities of Göttingen and Kassel, Germany and the Institut Pertanian Bogor and Universitas Tadulako, Indonesia.STORMA Discussion Paper Series 1 


\section{CHAPTER 8}

Summary of Research Outcomes 
In summary, the following specific research outcomes were achieved when addressing the research objectives (R1-R4, M1-M3):

(1) Local residents of the Lore Lindu area obtained a wide range of non-market benefits of ecosystem goods and services.

(2) Depending largely on the natural resource base for their livelihood, local residents showed sensitivity regarding the impacts of human interference on the provision of ecosystem goods and services.

(3) The conflict between economic development and conservation was clearly reflected in people's preferences.

(4) Resulting from (3), biodiversity conservation measures aiming at more sustainable ways of land use should address the urging need for economic development.

(5) The magnitude of willingness-to-pay for maintaining the resource base was quite substantial considering the living conditions of the inhabitants of the Lore Lindu region.

(6) Rather than being of immediate relevance to decision makers, the importance ascribed to the choice experiment attributes should be conceived as a signal that encourages them to find solutions that sufficiently consider the local demand for the provision of the ecosystem services observed.

(7) Scenario analysis showed that neglecting forest management can have a significant impact on the overall benefits of ecosystem services.

(8) The results of welfare estimates for ecosystem services should be conceived as a point of reference for future research addressing deficiencies of knowledge about economic benefits of non-market goods and particularly of functional ecosystem services in tropical rainforest areas.

(9) Preferences for ecosystem goods and services were found to be a function of a wide range of socio-demographic, socio-economic or attitudinal variables.

(10) Knowledge on the sources and of preference heterogeneity and their influence on the choice behaviour of respondents greatly contributed to an improved understanding of the behaviour and situation of local economic agents with respect to their demand for forest ecosystem goods and services. 
(11) The observed differential influence of relative poverty on preferences for ecosystem services provided important insights for an improved understanding of distributional effects of changes regarding the provision of ecosystem services on the welfare of local households.

(12) The relationship between actual resource use and demand with rural household incomes may largely depend on the natural resource observed as well as on the social and economic local conditions.

(13) Using the choice experiment method has a potential to obtain additional insights into the poverty-environment link by allowing for a more comprehensive assessment of the distributional impact of improvements or degradation of the natural resource base on the welfare of rural households.

(14) The choice experiment could be applied to the valuation of complex ecological functions.

(15) The methodological framework of the ecosystem service approach contributed largely to (14).

(16) A choice experiment could be successfully applied in a rural area of a so-called developing country.

(17) The design strategy to adjust the status-quo to the perceptions of the individual respondents contributed essentially to (16).

(18) The self-explicated status quo alternative is a methodological feature addressing the bio-physical heterogeneity of the research region. It therefore facilitates the application of choice experiments on a regional scale by ensuring that the program alternatives of the choice experiment are consistently framed as gains and losses.

(19) A carefully developed questionnaire with respect to wording, questionnaire setup and the use of visual decision aids contributed to (14) and (16).

(20) A validity assessment for (14) and (16) mainly grounds on

a) sufficient understanding of the choice task by respondents;

b) the wide range of socio-demographic, socio-economic or attitudinal variables providing sound explanation for the choice behaviour of respondents;

c) indication from literature and background data that implicit prices for water as calculated in this study seems to be neither completely over- or underestimated; 
d) very reasonable model performance.

(21) A test for effects of attribute order on choice cards suggested the occurrence of recency effects.

(22) There is indication that the magnitude of recency effects depended on the relative importance respondents ascribe to the attributes on the choice cards.

(23) Changes in the institutional background of the payment did not result in significant differences for either the model parameter estimates or implicit prices.

(24) Model parameters and implicit prices were not robust to changes of the frequency of payments.

(25) Varying cash availability could be an important factor to explain (24).

The results contained in this thesis may be used to facilitate the design of economically informed and socio-economically sensitive conservation strategies in the Lore Lindu area. The information on preferences for ecosystem services could contribute to the development of policies that take the sustainable use of biological resources into account. In this respect, future research may be aimed at integrating the information about nonmarket benefits of the rainforest margin into a valuation framework that considers all the relevant private and social costs and benefits comprehensively. In particular, the estimated non-market benefits may be incorporated into a cost-benefit analysis of the conversion of forests and agroforestry systems. Such an analysis could be helpful for deciding which land use patterns or conservation strategies would be most beneficial to society. 


\section{APPENDIX}

(on an enclosed $C D^{*}$ )

\section{Appendix I:}

Survey instrument (Indonesian version): survind.pdf

\section{Appendix II:}

Questionnaire (condensed English version): questeng.pdf 